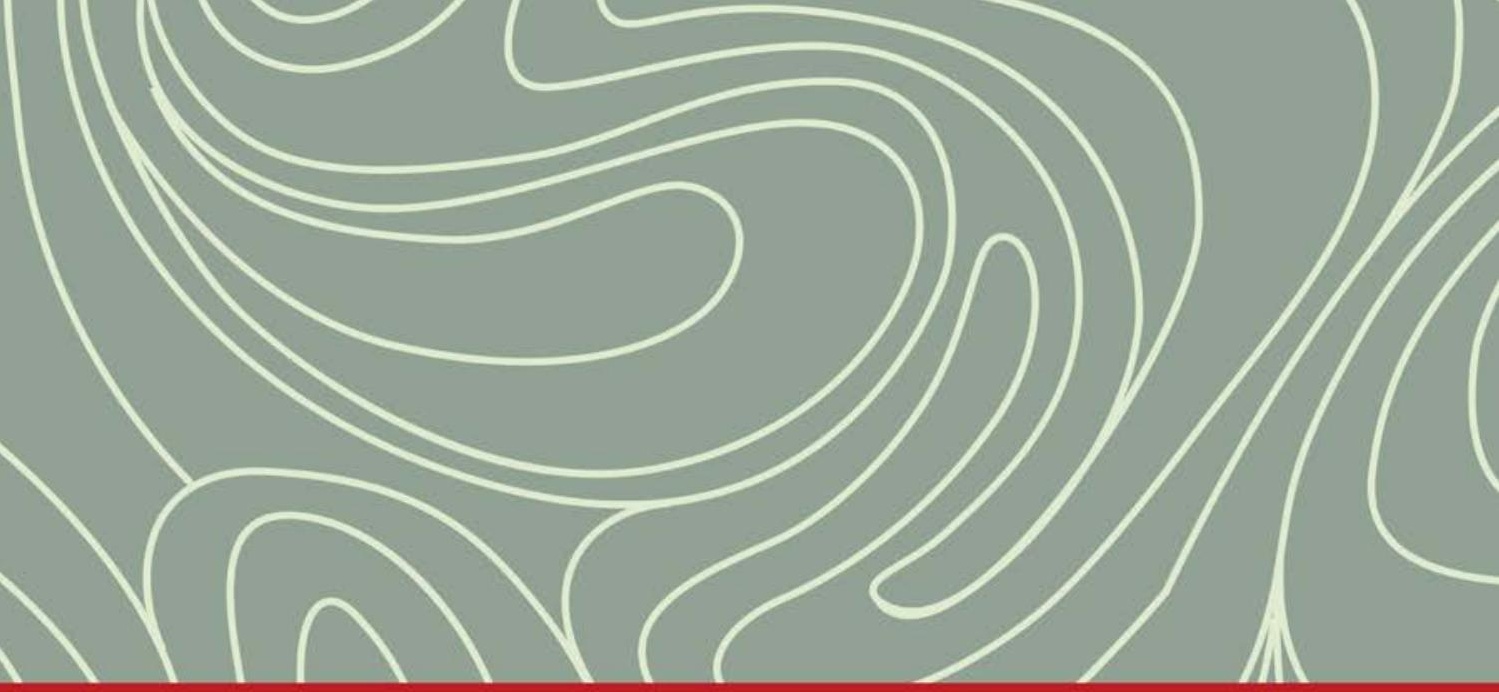

Routledge Studies on China in Transition

\title{
CHINA'S ARCHITECTURE IN A GLOBALIZING WORLD: BETWEEN SOCIALISM AND THE MARKET
}

Jiawen Han

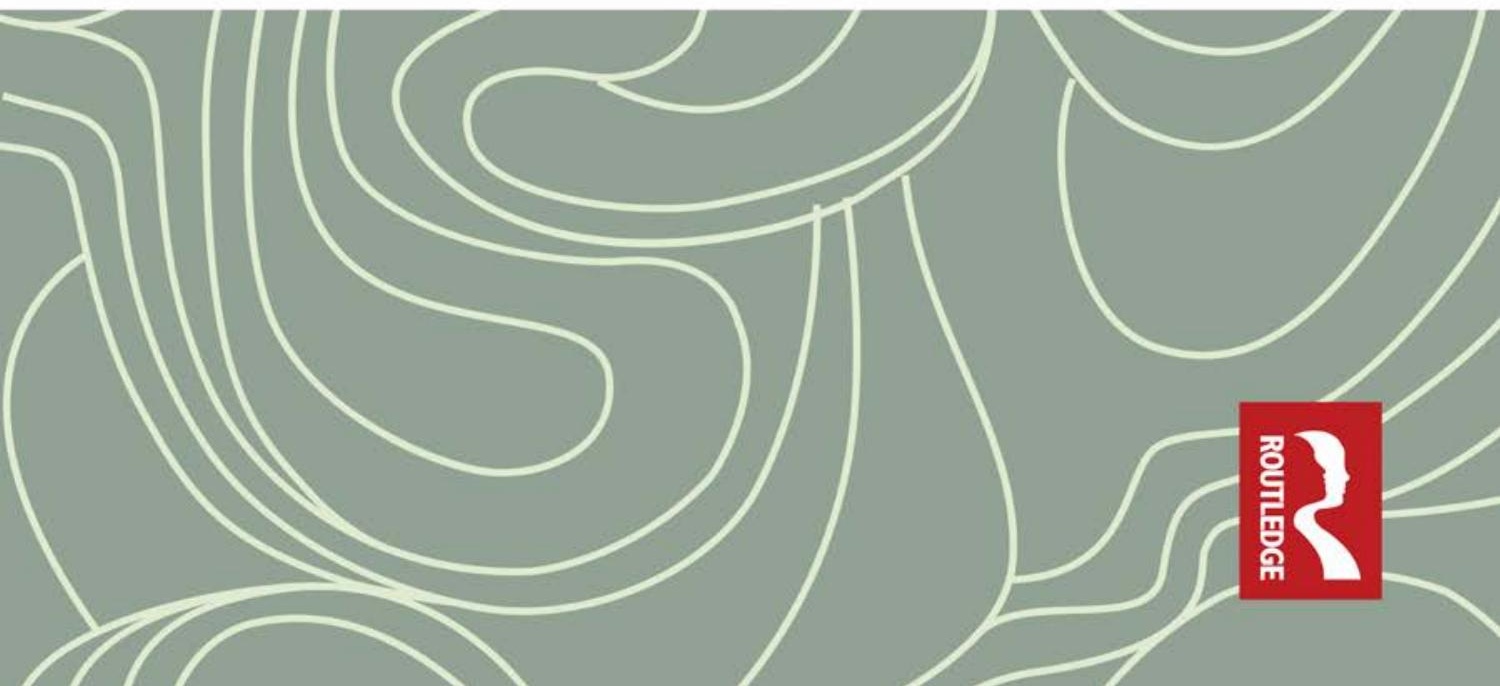




\section{China's Architecture in a Globalizing World: Between Socialism and the Market}

China is currently in the midst of an unprecedented building boom and, indeed, interest in Chinese contemporary architecture has been fuelled by this huge expansion. Through a cutting-edge theoretical discussion of Chinese architecture in relation to Chinese modernity, this book examines this phenomenon in detail. In particular, it highlights how changes in the socio-political system, the residual influence of Mao and the demands of the market have each shaped and determined style and form in recent years. Using the key case studies of Liu Jiakun, Cui Kai and URBANUS, it analyses the intricate details of historical pressures and practical strategies affecting Chinese architecture. In doing so, it demonstrates that Chinese architects contribute in specific ways to the international architectural discourse, since they are actively engaging with the complex societal transition of contemporary China and managing the dynamics and conflicts arising during the process.

China's Architecture in a Globalizing World: Between Socialism and the Market offers a lens into the innovation and uniqueness of architectural design in China. As such, this book will be useful for students and scholars of architecture, Chinese culture and society and urban studies.

Jiawen Han is Lecturer in the Department of Architecture at the Xi' an Jiaotong Liverpool University, China. 


\section{Routledge Studies on China in Transition}

Series Editor: David S. G. Goodman

For a full list of available titles: www.routledge.com/Routledge-Studies-on-Chinain-Transition/book-series/SE0082

47 Rural Policy Implementation in Contemporary China

New Socialist Countryside

Anna L. Ahlers

48 NGO Governance and Management in China

Edited by Reza Hasmath and Jennifer Y. J. Hsu

49 Dams, Migration and Authoritarianism in China

The Local State in Yunnan

Sabrina Habich

50 New Mentalities of Government in China

Edited by David Bray and Elaine Jeffreys

51 China's Cinema of Class

Audiences and Narratives

Nicole Talmacs

52 Economic Development in China's Northwest

Entrepreneurship and Identity along China's Multi-ethnic Borderlands

Joshua Bird

53 Governing HIV in China

Commercial Sex, Homosexuality and Rural-to-Urban Migration

Elaine Jeffreys and SU Gang

54 China's Housing Middle Class

Changing Urban Life in Gated Communities

Beibei Tang

55 China's Architecture in a Globalizing World:

Between Socialism and the Market

Jiawen Han 


\title{
China's Architecture in a Globalizing World: Between Socialism and the Market
}

\author{
Jiawen Han
}

\author{
Routledge \\ Daylor \& Francis Group \\ LONDON AND NEW YORK
}


First published 2018

by Routledge

2 Park Square, Milton Park, Abingdon, Oxon OX14 4RN

and by Routledge

711 Third Avenue, New York, NY 10017

Routledge is an imprint of the Taylor \& Francis Group, an informa business

(C) 2018 Jiawen Han

The right of Jiawen Han to be identified as author of this work has been asserted by her in accordance with sections 77 and 78 of the Copyright, Designs and Patents Act 1988.

All rights reserved. No part of this book may be reprinted or reproduced or utilised in any form or by any electronic, mechanical, or other means, now known or hereafter invented, including photocopying and recording, or in any information storage or retrieval system, without permission in writing from the publishers.

Trademark notice: Product or corporate names may be trademarks or registered trademarks, and are used only for identification and explanation without intent to infringe.

British Library Cataloguing-in-Publication Data

A catalogue record for this book is available from the British Library

Library of Congress Cataloging-in-Publication Data

Names: Han, Jiawen, author.

Title: China's architecture in a globalizing world : between socialism and the market/Jiawen Han.

Description: New York : Routledge, 2018. | Series: Routledge studies on China in transition ; 55 | Includes bibliographical references and index.

Identifiers: LCCN 2017039488 | ISBN 9781138559462 (hardback) | ISBN 9780203712672 (ebook)

Subjects: LCSH: Architecture and society-China-History-20th century. | Architecture and society-China-History-21st century. | Architecture and globalization-China-History - 20th century. | Architecture and globalization-China-History-21st century.

Classification: LCC NA2543.S6 H365 2018 | DDC 720.951/0904 -dc23

LC record available at https://lccn.loc.gov/2017039488

ISBN: 978-1-138-55946-2 (hbk)

ISBN: 978-0-203-71267-2 (ebk)

Typeset in Times New Roman

by Apex CoVantage, LLC 
献给我的父母韩彦铎和汪冰

For my parents, Han Yanduo and Wang Bing 


\section{Contents}

Acknowledgements viii

Abbreviations $\quad$ xi

Introduction: multiple modernities 1

1 History, ideology and Chinese architecture 4

2 Chinese architecture and China's architecture 23

3 Conceiving the modern past: Liu Jiakun 42

4 Renarrating the state: Cui Kai $\quad 80$

5 Casting a civic shadow in the city: URBANUS 123

6 A delicate balance 162

$\begin{array}{ll}\text { Glossary } & 168\end{array}$

Illustration credits and sources 169

$\begin{array}{ll}\text { Bibliography } & 170\end{array}$

Index 180 


\section{Acknowledgements}

This book grew out of my doctoral dissertation, which I finished in Australia. It is noteworthy to think of how much Sydney's beaches and the sun have nourished the content of this book. I would like to express my thanks to the place and people first: thanks to Australia, the natural and cultural environment of which made me naturally join in without feeling like an alien, and the spirit of which has seemingly encouraged me to never act like a tame bird.

I came across a song titled "Better Me," originally recorded by a young singer, Fiona Sit, which struck me while I reflected my time in Australia. I owe my deepest gratitude to my $\mathrm{PhD}$ supervisor, Dr. Harry Margalit, for his rigorous intellectual guidance and continual encouragement, both of which supported me in becoming a "better me." Though I am imperfect, I can always see a "better me" in his eyes and hear it in his words - so much so that it is difficult to count the changes he has gifted me. He has not only brought unique perspectives to see architecture, as well as ability in conducting research and skills with resolving problems, but he also taught me to bear a sunny heart on any intellectual journey. Our countless chats have always been enjoyable and, interestingly enough, turned out to be useful, for most of my ideas emerged from our chats and were later developed in my writing. His extensive comments on my drafts also helped my ideas to finally come out of their shells. When I was revising the dissertation, I recalled a hard time during my $\mathrm{PhD}$ journey: I was struggling with the academic standard of my dissertation and the readability and pleasure, the flow, the sense of reading I wanted to bring to it, yet Harry understood my intention and supported me in doing it in my own way. He is not a stereotypical scholar, yet he is open-minded and kind-hearted. We have been in contact since I came back to China. I have to say that it is not easy to have a person I am certain would always be with me, always be there to listen to me about research and teaching, and help me make my way. Yet Harry is always there. I am also quite fortunate to have had Professor Xing Ruan as my PhD co-supervisor, who significantly impacted the development of this thesis. I was impressed with his scholarship, his personality and his attitude towards research. I have always sought to learn the confidence and grace of traditional Chinese intellectuals from him, and I hope that I have somehow merited a little bit of that. 
A most special thanks is due to my dear husband, Lun Jiyun. He is a practicing architect, yet he has held a very respectful attitude towards my research. He has listened to me and pointed out my moments of error as well as my moments of excellence. It is a great man who can let my soul fly freely, something not every man can achieve, but you let me spread my wings. His decisiveness, rational thought, his sense of humour, and everlasting support have been the most robust supports of my life. His existence and thinking also influences my ways of teaching design in the studio and teaching theory in the classroom. His always intriguing way of thinking on the capital, design, construction and management as a practitioner repeatedly opens a new inquiry for me to reflect.

There has been a hidden observer of this book, my mother Wang Bing, who shared her experiences, thoughts and feelings of both Maoist and contemporary China with me, which were always different from my assumptions and have inspired me to think more. She has been a third voice in shaping my arguments. At the same time, my father, Han Yanduo, has been unconditionally supporting me in a fatherly way: you are not good at expressing your feelings, but I understood them all, Dad. I know that the trouble I caused when I rebelled seriously hurt and disappointed my parents, and I hope that at this moment they are proud of me. I also owe personal debts of gratitude to my parents-in-law, Lun Qiang and Jiang $\mathrm{Li}$, for their constant encouragement and emotional support.

I also would like to express my sincere gratitude to Professor David Goodman. It was an interesting coincidence to meet him in an IT training class after I arrived in Suzhou. Obviously, the IT class was either boring, or we were not good students, but we began to chat in English and Chinese, exchanging information about our trips in Shanxi province. At one certain moment he invited me to transfer my dissertation into a book, and his continuous whip on this book by reminding me, "Jiawen, the book!" dragged me out of my obsession with teaching in the early days of my life in Suzhou.

I would like to say thank you to my colleagues in Xi'an Jiaotong Liverpool University for their support. I also thank my students in the Department of Architecture. Every one of my students is part of my professional journey as their tutor, and in most of the cases, part of my personal journey as well. I am also very fortunate to have many friends in Australia. In particular, I would like to thank Mengyu Huang, Annie Yuxuan Xu, Steven Chang, Nicole MaNamara, Yolanda Tobing, Laura Goh, Sarah Judd, Anumitra Mirti, Jennifer Kent and Samira Alp.

I express gratitude to all architects who accepted my interview invitations, provided images, permissions and other materials to URBANUS and Liu Xiaodu, Land-based Rationalism D.R.C and Cui Kai, Jiakun Architects, and Liu Jiakun, Zhang Xiaogang Art Studio. Especially to Liu Jiakun, the extensive discussions and chats with him allowed me to find myself more.

I have matured while writing my dissertation and transferring it into this book. Happiness, illness and the love from my family and friends were all part of the ingredients. Yet I am not sure whether I am mature in appearance, since I still always get the friendly suggestion to get a perm in my hair, and so on and so forth, 
x Acknowledgements

so I can look older and more sophisticated. I have realised that being mature is not to give up anything sincere. What I am keen to find and what stirs my heart is something genuine and real. Yet being mature is being capable of being calm and smiling at that which is fake. I would like to keep it simple: to be a person, to be a tutor and to be a researcher.

Years may wrinkle my skin; I hope it will not wrinkle my soul, nor the souls of all the people I love. 


\section{Abbreviations}

CAG China Architecture Design \& Research Group

CCP Chinese Communist Party

CCTV China Central Television

PRC People's Republic of China

SEZ Special Economic Zone

SOE State-owned Enterprise

WTO World Trade Organisation 


\section{Introduction}

\section{Multiple modernities}

There is an idiosyncratic relationship between, on the one hand, architecture and architects, and on the other hand, the developing market of China. Broadly speaking there is a constructive tension between the centralised state and the developing market. This book examines, in detail, diverse elements of this phenomenon: how changes in the socio-political system, the residual influence of Mao and the demands of the market, have all affected Chinese architecture in recent times. This book argues that Chinese architects contribute in specific ways to the international architectural discourse, since they are actively engaging with the complex societal transition of contemporary China, and managing the dynamics and conflicts arising during the process. In particular, I wish to highlight that architectural modernity in the work of Chinese architects' works moves beyond the interpretation provided by existing scholarship, both in consideration of the revival of traditional features and in the domain of modern technology. In that sense, Chinese architecture acquired a hearing in theory in relation to Chinese modernity concerning the clarity of its means and ends.

The interest in Chinese contemporary architecture has been fuelled by an unprecedented building boom and the novelty of some specific projects. Introducing the notion of "modernity" into this discussion permits us to include complex elements of Chinese society and history. The process from Mao to market currently cannot be easily situated within any overarching theory, nor is it a linear and systematic transition, but it has far-reaching effects in every corner of China, every Chinese social group, and on bureaucratic agendas and personal motives. Looking at architecture from this perspective provides a strategy, a fresh way of reading architecture and architects, and a theoretical framework constructed around the uncertain nature of the socialist transition in China.

The concept of modernity raises many questions: What were the dynamics in the complex market transition? What impact did these forces have on architecture and on the opportunities available to architects? What were the interactive dynamics between personal goals, life experiences and the architectural designs of individual architects, most of whom were born into and educated by the philosophy of collectivism, but who now work in a market-oriented society? How did their architecture address the social problems in the transitional phases of recent history in China? What are the contributions of new Chinese architecture 


\section{Introduction}

and contemporary architects to the international architectural discourse? It is time to reflect upon the new roles that architects and architecture have assumed in this transition, and the new values and innovations in Chinese architectural design based on individual personal liberation and market-driven reforms.

China is in the midst of the biggest growth spurt in its modern history, but it is also struggling with many transitional problems. Parallel with the endeavour of bestowing an abstract vision of social transformation, advancement and modernity in China, that same ideal is also subject to a plethora of influences from the societal transformation that in turn affects the form, size, syntax, language and innovation of architects. There is a clear awareness of the radical transformation in architecture, and the astonishing amount of demolition occurring in China. During this wave of construction, the emergence of some innovative architecture designs by Chinese architects has given rise to hybrid identities in modern China. Popular terms like "experimental architecture" or "avant-garde architecture" are used to describe the new wave of architecture in China. But when one looks closely at these terms, it is difficult to assess whether they have any real merit in architecture.

It is crucial to position contemporary Chinese architecture accurately in its historical as well as its international context in order to clarify its relationship with the global system. Generally, descriptions of modern architecture in China are stripped of this historical and social complexity, encapsulated in the catchy phrase, "world construction site". This casual description of contemporary Chinese architecture reduces it to a palimpsest of modernity, which ignores the remarkable regional innovations and the multiplicity of solutions within unique architectural designs. The idea of "multiple modernities" was raised by Shmuel Eisenstadt, who argued, "The actual developments in modernizing societies have refuted the homogenizing and hegemonic assumptions of the Western program of modernity."2 Rather than responding to claims for or against influences of Western modernity, I will discuss the trajectories of different architectural groups and firms in China during the process of unfolding modernity. An accurate analysis of Chinese architecture in the modern and historical sense serves both to enrich our understanding of the achievements of the architects and to engage in the dialogue between the popular neo-liberal understanding of modernity in China and opposing concepts. It is imperative to position developing architecture within the unique challenges presented by contemporary China: the intersection of economic development, political ideology, demography and culture and the profound influence they each have had on architectural designs

Arif Dirlik argued that "globalisation represents not only a further unification of the world through the agency of capitalism, and its attendant political and cultural institutions, but also an effort to contain new forms of fragmentations." 33 This book presents an alternative perspective for seeing "new forms of fragmentations" in architecture. Therefore, this study begins with the interpretation of China's struggles with various kinds of transitional problems as a key to understanding the new wave of innovative Chinese architecture. Most existing studies focus on the material side of the construction boom, missing the crucial components in the 
development of urban landscape affected by subjective opinions from different quarters, implicit cultural pressures and the subjective experience and personality of each architect.

Necessarily, the examination presented here extends the research to an ideological level. The intricate details of historical pressures and practical strategies are clarified through three case studies: Liu Jiakun, Cui Kai and URBANUS. The study positions the designs of these architects in the historical vision of a broader cultural perspective. The global and domestic markets, the West, the East, the state, the architects themselves and the shifting perception of modernity - all these elements are decisive factors in shaping contemporary Chinese architecture, with different impacts in different cases. It should be noted that these elements affect architectural design at different points in time under different versions of socialism.

Tafuri wrote:

The interweaving of intellectual models, modes of production, and modes of consumption ought to lead to the "explosion" of the synthesis contained in the work. Wherever this synthesis is presented as a completed whole, it is necessary to introduce a disintegration, a fragmentation, a "dissemination" of its constitutive units. It will then be necessary to submit these dis-integrated components to a separate analysis. ${ }^{4}$

Neither praising nor criticising specific architectural design is the point of this exercise. Modernity is a device to interpret the seemingly "modern", the seemingly "normal" or the seemingly "absurd" Chinese architectural designs. Equal attention is paid to interconnecting elements drawn from literary resources, first-hand fieldwork observations, the history of political economics, the stylistic transformation and architectural innovations. The point of the exercise is to address how a hegemonic position was deconstructed during the transition from a planned economy to a market economy and how multiple forces, including the individual impulses from Chinese architects, have constructed new architectural identities.

All the events in this transformation are initially isolated for critical review because of their different plots, actors, strategies and resolutions. After being appropriately historically positioned, these fragments are then woven together in a systematic analysis, which situates architecture and architects against a sweeping historical and political backdrop.

\section{Notes}

1 Experimental architecture in China was first put forward by architectural activist, Mingxian Wang, in June 1999, at the time of the UIA Congress first to be held in Beijing.

2 Shmuel Eisenstadt, "Multiple Modernities," Daedalus 129, no. 1 (2000):1-29.

3 Arif Dirlik, "Modernity as History: Post-Revolutionary China, Globalization and the Question of Modernity," Social History 27, no. 1 (2002): 20.

4 Manfredo Tafuri, The Sphere and the Labyrinth (Cambridge, MA: MIT Press, 1987), 14. 


\section{History, ideology and Chinese architecture}

A great number of books have been published on China's transition ${ }^{1}$ with a specific focus on urban issues and the built environment. There is no doubt that for China, the journey from state to market socialism is a process towards a modernised and urbanised nation. This has led to a focus on its successes and scandals in urban development. The scholars who are examining spatial questions in China are mostly writing from the urban perspectives concerning urban image, spatial transformation, new physical and economic space and cultural spaces. Yet why does architecture continue to be absent in the research addressing China's transition era? Although architecture is the main subject of the built environment, the social impact of contemporary architecture in China, except for its aspect of novelty, remains largely unacknowledged. Urban researchers appear reluctant to canvass any specific architecture in their research, due to the fact that architecture is not perceived as an embodiment of the complex spatial and social phenomena represented by the Chinese city.

Chinese cities have been overrun by new traders, investors, brokers and clients, during the transitional era, and urban researchers are swiftly on the scent, since the transformation of urban space is part of capital investment, which in turn shapes the direction of Chinese reforms and opens the gateway to foreign investment. The occasional observations about architecture in urban studies tend to be vague and condescending. A certain degree of hostility veils the discipline of architecture. As a result, researchers' attention has shifted to the urban level, and every discussion focuses on urban issues, which positions architecture in a broad landscape, but at the same time obscures an in-depth, critical analysis of contemporary architecture.

Historically, discourses and theories on architecture concern themselves with formal questions, viewing the architect as a form giver. Common sense dictates that such a view is outdated, describing only forms in space, and relegating architectural concerns to filling empty spaces with lines, but researchers are still hesitant to give significance to the numerous issues that influence contemporary architects - including social and professional networks and conflicting pressures from socio-political circumstances. Contemporary architecture in China has been a huge market for the outside investor over the last ten years since the extraordinary growth surge, but this is just the surface. Chinese architecture has seen a 
series of booms and busts within its overall growth story; it deserves a far closer scrutiny into its newly emerging identity that embraces a broader social and cultural background. The process from Mao to market itself exerted considerable influence over architects and architecture.

In the first decade of the communist regime (1949-1959), the Chinese Communist Party sought full control over the architectural profession in a strategic way through its operational and ideological restructurings. ${ }^{2}$ The application of the Soviet model in the architectural profession was associated with nationalisation of private architectural firms into state-owned enterprises. China's economic reform from 1978 has been characterised by the unravelling of the traditional planned economic system, the shaping of the pattern of diversified sources of economic growth, and the increasing importance of the market mechanism. As a result, since the early 1980s a few private design enterprises were approved. Some independent architects, who used to work in the large-scale design institutes, or came back from overseas practices, gradually established their own design firms during the 1990s. In the 2000s, the private sector in the architectural industry flourished, including the privatisation of the state-owned design institutes and intensive emergence of the private design firms either small or medium scale. Moreover, markets have been useful for foreign visitors to China by providing new outlets and venues.

Consequently, the market transition and societal transformation brought opportunities to contemporary architecture in China. The reduced dependence on the state resourced collective working model moves towards large-scale privatised design institutes, and the diversified sources of growth in architectural market, all brought various changes to architecture in China. The pre-reform state-owned design institutes were characterised by a lack of enterprise autonomy because of the absence of market competition, or sufficient information on enterprise performance, problems directly resulting from information asymmetry and incentive incompatibility under the specific historical conditions of the era. In contrast, the reformed design institutes have already gained financial independence and been allowed to pursue profit in practice. Many private architectural firms gain many commissions and an enhanced reputation as the city also experiences tremendous building activities, but they cannot obtain any kind of open or hidden subsidies or other types of policy protection that the state-owned or pre-state-owned design institute enjoyed. Meanwhile, some of the reformed design institutes are still plagued by a series of cultural burdens left over from the previous development strategy.

For architects, associated with the erosion of collectivism and diminishing state control, the self-expression of architects in their designs have been depoliticised and become increasingly commercialised. The fact that the market-oriented reforms from the planned economy have eroded the state's ability to exercise its guiding rule seems appealing to architects, because they assume they will have increasing freedom for their individual choices with the emergence of the architecture market. But in practice, their attitudes towards market and individual identity are less straightforward. After decades of defending the autonomy of architectural 
design against the state's control, many architects found that vulgar designs in fact sometimes outsold the high-quality works in the real market. It also took time for architects to realise that it is the entrepreneurs who sustain them as professional architects, rather than the state supporting them as before, and the market has its own rules. Furthermore, if we attempt to categorise their pre-reform life experiences into one group, their life trajectories have been totally different since the 1980s: some of them went overseas, some of them stayed with state-owned design institutes, and some of them departed from collective-approved designs to a more independent creative way. Due to their different life experiences, their doubts in their pursuits of individual identity and their pursuit of private gains and private lives coexisted with the ideological limits in the private realm, and these tensions have caused diverse impacts on architectural designs from the 1990s onwards.

Xing Ruan noted that strangely, Chinese architecture in the twentieth century was almost given a complete miss by Western discourse. ${ }^{3}$ Since the late 1990 s, interest in China's modern architectural history has been partly revived. There has been some research gibing theoretical and historical interpretations of the architecture of modern China. ${ }^{4}$ Among such theoretical and historical studies, different from most of the information generating works, Jianfei Zhu and Tao Zhu's works are critical in nature, offering many critical reflections on the often-confusing landscape of Chinese architecture. Their unreservedly expressed socio-political views on Chinese architecture have given a penetrating insight into the domain of Chinese architectural analysis. There are also many books ${ }^{5}$ and journals ${ }^{6}$ that have introduced new architects and their designs during the rise of novelty and speed in construction, especially since the 1990s; however, their focus is limited to the introduction of particular projects, ranging from private residences to public museums, with beautiful architectural photographs and brief commentaries. What is missing in these collections of architectural images is discussion of the significance of buildings as cultural symbols, reflecting social and political changes. A misguided attitude on the part of professional researchers, combined with the lack of freedom of speech in China, circumvents discussion of the complex relationship between political, economic and cultural elements, evident in the domain of architecture as elsewhere.

Contemporary Chinese intellectuals have concealed their criticisms of controversial relations between political factions since 1989, which, if expressed, could have contributed to a healthy debate about the future. Jianfei Zhu and Tao Zhu's works indicated that the trend is turning from a focus on architecture as a specialised domain with actual works and the individual architect on one side, to its position in the socio-political landscape and its direct engagement with the cultural movements. This book employs a shifting focus, zooming in and zooming out to see some actual architectural works from the ideological perspective and the individual perspective, while positioning the works in a comprehensive big picture.

With regard to the historical periods under the communist regime, there have been two intensive works focusing on the architectural profession and architectural development respectively. Xiao Hu's investigation of the architectural profession, Reorienting the Profession: Chinese Architectural Transformation Between 1949 
and 1959, ${ }^{7}$ argued that a reconsideration of ideology in modern Chinese architecture is vital in order to understand a unique pattern of professional development under a communist regime. Guohua Ji's Building Under the Planned Economy: A History of China's Architecture and Construction 1949-1965 provides a valuable source for the historical study. However, the hidden link between post-Mao and pre-reform China associated with the ideological transition has not been sufficiently investigated in the realm of built environment. Duanfang Lu's work has greatly contributed to this field. She explores urban construction under Maoist socialism that contributed to the particularities of Chinese cities today. The reasons why it is hard to identify the legacy of the communist regime in architecture will be analysed in the following chapters. This study critically assesses the idiosyncratic relationships of post-Mao and pre-reform China in forming Chinese architecture.

Researchers have constructed various categories or used adjectives to categorise these architectures, such as regionalism, modernism and expressionism. This mode of analysis is useful, as it brings out the most salient features of a type of architecture existing at this particular period in time. However, it also has limitations, as it tends to emphasise the similarities of architecture belonging to a recognised architectural category, and glosses over their individual differences. Rather than being distracted by features that may characterise an architectural style, I will take note of unique stylistic transformations of modern architecture in China. There have been scholars who seek to characterise architectural styles into models, and there is no doubt that the varieties of architecture in post-Mao China sometimes can be categorised in terms of style, function, ownership or development right. However, their relations to history, society, ideology and architecture, the most complex and obscure elements, cannot be easily categorised, and they are always excluded in the existing scholarship. Except for the obvious influences of the West and the East, strict stylistic categorising is another limited way of viewing the complex transitions of Chinese architecture in relation to modernity.

\section{Mapping modernity in Chinese architecture}

During 2009 when I was working in a design institute, I discovered something frustrating but interesting. During that period, we were always asked to deliver a design proposal within a few days after we got the task from the client. Over several days' hard work we crafted the conceptual drawings, site plan, floor plans, and other drawings, and in many cases, when the client came in to our office and checked the design progress, they only wanted to see a bird's-eye view drawing. I was confused by the clients' request, because rendering a drawing from a bird'seye view is from an imagined perspective, rather than the representation of spatial interaction with a human being. Moreover, I found when I showed these architectural renderings to my foreign peers in the architectural industry, they would identify them as "architectural renderings with Chinese characteristics".

From the 2000s, due to the limited time given by the client, an architect would have multiple tasks to complete; therefore, the design institute would collaborate 
with another architectural visualisation company to obtain architectural renderings. It was standard practice in the architectural industry at that time, and many design institutes have continued this way until now. Although the design still begins with the architect's sketch, and then architects develop the sketch via computer into a site plan, floor plans, elevations and sections as per conventional practice, at the end of the process documents are sent to a professional architectural rendering company, where a professional modelling division will produce the $3 \mathrm{D}$ model according to the 2D drawings submitted to them. Depending on the company's scale, architectural rendering through 3DMax or rendering software, and post-processing through Photoshop, might be done by the same division or by other independent divisions. Due to the time demands from developers, architects sometimes do little by hand and search for precedent images for reference, and the architectural visualisation company will also produce their images from a simple site plan, often without any detail design. ${ }^{8}$

After I passed my 2D drawings and some precedent images to the professional rendering company, I sometimes had to go to their company to explain and supervise the details or the atmosphere requested. During communications with the rendering professionals and a gradual understanding of the preference of the clients, I saw particular aesthetics coming out by some specific treatments. For example, a variation of the transparency parameter of some opaque materials and the increase in reflectivity for certain materials: for example, glass, ceramic and aluminium all enhance the image of the un-built architecture in specific ways. In some commercial building renderings, entire glazed façades have been stamped with cosmopolitan-hued reflections, even though the actual architecture is located in remote countryside. In the rendering industry, strategies in the exaggeration in the presentation of materials and fake decorative components are carefully developed. These drawings' identities are dominated by the active and directed imagination of clients, public and private, and they have achieved effects that are not possible with traditional drawing instruments. The government, at all levels, subscribes to the temples of cosmopolitan cities intended to lure society into a collective imagination. Under these circumstances, a bird's-eye view rendering drawing can be a much more effective tool for satisfying the developer, as their imagination is firmly directed towards a specific vision. Architectural rendering drawings, which rest on the technological transition from print-based media to visual and electronic media to the computer, have accelerated the process of imagining forms of architectural modernity in China. It is evident that the homogenous dreams of the metropolis, regardless of their specific social conditions, puts the local culture and beauty of cultural diversity under threat. ${ }^{9}$ By investigating the rationale underlying the architectural rendering industry in China, we can see imagining modernity as incentives underlying outward appearance.

The important question is, is the contribution of this imagining of modernity in architecture, within the historically specific architectural culture of contemporary China, critical to the evolution of the distinctive formation of Chinese modernity? The answer is in the affirmative. Therefore, it is time to conduct a critical analysis of the new autonomous forms, widely overlooked in current research, that have played such a vital role in the distinctive formation of Chinese modernity. 


\section{- Modernity, Chinese modernity and Chinese architecture}

As a social concept, modernity is inseparably bound up with the process of modernisation of industry, urban city, science, civic society, nationalism and colonialism. Modernity involves the rationality, or more accurately, the purposive rationality discussed by Max Weber. As David Harvey demonstrates, modernity refers to a whole existential, social and cultural condition that distinguishes the modern period from the periods before or after. ${ }^{10}$ In this culturally and politically diverse world, it is argued that there are very few categories that can withstand critical viewing, ${ }^{11}$ and modernity of one of them. In the nineteenth century, Chinese activists imported ideas of modernity to China. The Chinese Communist Revolution of 1949 introduced a major historical disjunction in its politicaleconomic structure and in its social organisation. Wang Hui pointed out, "Mao's socialism is both an ideology of modernization and a critique of Euro-American capitalist modernization." 2 China's economic reform entitled "Socialism with Chinese Characteristics" began in 1978. In the 1980s, the term "modernity" was constantly raised among Chinese intellectuals in a confusing way.

For more than thirty years, China has been experiencing a major transition, as a consequence of the adoption of an economic paradigm commonly referred to in the West as "opening-up". The emergence of the market as a central legitimising institution brought the public/private distinction into the core of legal discourse during the late nineteenth century. China's trajectory, which started from the pre-reform socialist regime of production and accumulation dominated by, and designed solely for, the state's extensive socialist industrialisation programme, moved to a more market-based and uniquely hybridised system of production marked by "quasi-public" and "quasi-private" forms of ownership, production and accumulation. ${ }^{13}$ The additional steps of reform in the 1990s created a fundamental break with the "collective great union" that prevailed in China from 1949 to 1989. In the 1990s, the free flow of labour, goods and capital, as well as the boom in information and cultural signs and images, undoubtedly presented a vivid image of modernisation to the majority of Chinese people. ${ }^{14}$ There have been new and complex social relations and different versions of modernity associated with the rise of capitalism. After the 1990s, some Chinese scholars began to historicise or theorise modernity in a way that was unclear. They focused on how science and industrial technology had been engineered under the version of Mao's socialism, and it has taken quite a while for Chinese scholars to appreciate that science is not only concerned with the understanding/manipulation of nature, it must also engage with the social and cultural conditions of a species. The question of how China as a complex culture has received and engaged with the different aspects of modernity needs to be investigated.

Research on architecture and modernity has undergone a remarkable renaissance. There has been an expansion from a narrow focus in the attempt to understand modernity in architecture through scholars' explorations in diverse cultural domains. ${ }^{15}$ As the thriving corpus of literature ${ }^{16}$ on modernity and Chinese architecture has emerged in recent years, the new configuration of architecture depends on special social factors that cannot be divorced from ideas of modernity. Berman 
notes that modernity embraces both what he terms modernisation - the general process of socio-economic and technological development - and modernism: the various cultural and and/or "subjective" responses to this process of modernisation. ${ }^{17}$ The increasing preference for the word modernity in the architectural scholarship reveals a determination to set up a dialogue between "modernisation" and "modernism" in architecture. Modernism and modernist architecture as distinctive terms in modern Chinese contexts are plagued by ambiguity, and they require clarification if they are to be useful. I will be discussing these terms through chronological investigation and case studies in the following chapters.

"Modernity" refers to the state of being modern. In historical terms, we might date its precursor as the philosophical "age of enlightenment" in which clearly stated principles are tested against evidence, and the rational mind uses logic to arrive at conclusions, which allows principles to be amended in light of the evidence. Zygmunt Bauman saw modern society as being largely characterised by a need for order - a need to domesticate, categorise and rationalise the world so it would be controllable, predictable and understandable. On the other hand, modernity is always characterised by radical changes in traditional forms of economy and culture. ${ }^{18}$ However, views of contemporary Chinese architecture omit the ordering, rationalising tendency that is supposed to be the characteristic force driving modernisation. The theoretical and ideological motives that drive modernisation have been neglected from the 1990s onward, since socialism loses its momentum without an articulation of its agendas, as for example, the clarity of Marxist literature. The programmatic nature of modernity loses its weight. Therefore, when it fights with the other side of the modernity, it loses its sense of existence. The manifestation of modernity in architecture has moved towards the pursuit of progress for its own sake. Socialism can still play a vital role in the new China, but the lack of articulation of socialist goals has extended to all facets of the Chinese culture. The new wave of modernist Architecture appears to be motivated by purely selfish agendas.

First of all, there is a specific concern in this study that contemporary discussions of Chinese modernity do not become entangled in earlier assumptions based on the neo-liberal understanding of modernity, which has come to dominate studies of modernity in China. ${ }^{19}$ Second, there is no intention to demonstrate that Chinese new architecture is superior to other architectural forms in the world, or that it is fully differentiated from Western architecture. However, I confess that I am tired of seeing theoretical critiques based on Eurocentrism in architecture, and normally it leads to nothing in the end, as the viewpoint is without a solid basis. Since the 1980s the idea has emerged - well presented by Eisenstaed ${ }^{20}$ - that modernity can take on different forms responding to social change and individual modernisation, so my disapproval of the Eurocentric approach is not novel. When it extends to the materialised realm of architecture, I do not see a degeneration in architecture originating from the Eurocentric ideal, but the narrowness of this definition creates problems when discussing "marginalised" Chinese architectural projects that have long married a regional hybrid modernity with broader Eurocentric notions of modernity. 
It must be remembered that Chinese new wave innovative architecture is responding to a broader concept of modernity that reflects reconfigurations in global economic and political relationships. The Euro-American legacy has shaped our idea of what is "modern" for a long time, but what is "modern" in the West is open to question, and it sometimes makes Chinese architects feel unsafe. Contemporary Chinese are concerned with the problems of globalisation and modernity (if not postmodernity), and not surprisingly, with the issue of alternatives. ${ }^{21}$ According to the perspective of Hui Wang, if we are attempting to understand Chinese intellectual and cultural life in the last decade of the twentieth century, we must initially understand a key transformation: although socialism in China did not collapse in the same way as in the Soviet Union or Eastern Europe, this was no barrier to China's swift participation in the process of global economy in production and trade. ${ }^{22}$ Globalisation provides the common ground in the articulation of cultural conflicts within architecture, and it opens the way for a reflection on conflicting trajectories and autonomous forms of modernity. Besides trans-state networks, and exchange-cross-fertilisation on some specific conceptions of modernity, Chinese modernity can rest on China's complex ethnicities and the resulting social and political forms. However, placing the conceptualisation of Chinese modernity within globalisation is crucial in order to grasp the reconfiguration of social fragmentation within the big family and the autonomous forms of modernity in architecture.

\section{- Modernity and the individual}

Another by-product of modernity has been the arrival of the concept of individualism, which might be its most ambiguous achievement. It is unclear whether the emergence of "the individual" in religious and philosophical traditions indigenous to China has provided new intellectual and institutional resources. Although the discussion of the "self" occupies a specific place in popular media, the necessary debate about the implications of individualism in relation to modernity has not arisen. Wang Hui argued, "The abstract concept of human subjectivity and the concept of man's freedom and liberation, which were useful in the critique of Mao's socialist experiment, lack vigour in the face of the social crises encountered in the process of marketisation and modernization. ${ }^{23}$ In analysing the architecture of Maoist China, the incompatibility between the subjectivity of architects according to their life experiences, the architecture they designed and the general history of the structures with relation to production appears to be so blatant that any call for reconciliation under the Maoist socialism must sound utopian. Chinese architects at that time were still limited to a small portrait beside the collection of their works and an interview. How could a Chinese architect have garnered a strong profile?

As Peter Gay wrote,

Many historians have heard the music of the past but have transcribed for penny whistle. To be sure, as I have said before, the most accomplished and 
most sensitive historical craftsmen have appreciated, and tried to capture, the overwhelming diversity of human conduct, man's encounters with power, technology, nature - and himself. ${ }^{24}$

Is it possible to tap into Chinese new architects themselves as a possible guide to the mysteries of architecture in the discourse? While there may be parallel beliefs held by others in the field of Chinese architecture, this study does not in any way attempt to prove that that is, or is not, so. On the other hand, it is possible to infer that contemporaries of each architect would have some analogical interpretation of the era. This study is based on the idea that Herbert Marcus raised: formerly autonomous and identifiable psychical processes are being absorbed by the function of the individual in the state - by public existence. The individual architect is not a social isolate in this study. Chinese architects themselves are recipients of this social transition. Their experience and perception of modernity, and their understanding of Chinese people's perception of modernity, extend to the different realms of the architectural industry and manifest in diverse aspects of their works. We have yet to detangle the complexity. Encountering the Chinese context, Kipnis pointed out,

The individual psyche has never been and never will be a domain governed solely by socially isolated individuals. It is the site of conflicts between numerous contradictory discourses, emotions, and urges, a site where the social contradictions of Chinese modernity manifest themselves as a particular structures of feeling, and a target of the governing actions of a wider range of social actors. ${ }^{25}$

The integration of an individual architect's life experiences and their changing psychology with their architecture does not imply that my focus in the research is psychological.

\section{Misconceptions regarding the transition era}

Facing China's newly emerged metropolises and the influx of enormous capital, observers and critics are divided mainly into two groups. One group questions the veracity of reports, as the tales of corruption, nationalism, and totalitarianism easily mislead people who do not accept the fact that, increasingly, Chinese people are living in affluence, in contrast with previous decades of poverty. The other group celebrates the novelty, and outsiders are astonished with the exotica introduced by twenty years of prosperity, including extraordinary clothing that suggests Chinese people might have become intoxicated with self-satisfaction. In fact, all these frantic pursuits amid the continuing presence of the old cultural frameworks make it more difficult to analyse China, and mask the essential movements, obfuscating an understanding of its architecture. Therefore, only by challenging these established opinions and popular misconceptions regarding contemporary China in the transition era does it become possible to analyse contemporary architectural developments. 
There have been several publicised books ${ }^{26}$ about contemporary China with the theme of "changing" in their titles. The discussions in these books on change and other recent reports about contemporary China share some common themes dramatic economic growth in an unsynchronised political system; capitalism, the process of modernising production and the abuse of human rights - with three corresponding observations: "Money is the only language", "China does not remember Mao", and "People just want to be the individuated self". I would argue that these are three crucial fallacies in the current interpretation of the social transformation of China. It is necessary to disentangle them, although they are often connected, in order to provide a clear insight into socio-economic change, politico-ideological conflict, and China's cultural transformation. A clear articulation of the Chinese situation is possible only in a process of challenging and then reconstructing some of the premises and assumptions that govern our understanding of contemporary China.

\section{- Is Money the Only Language?}

The policy of reform and opening initiated in China in the past thirty years has proven to be both peaceful and economically successful. Since the living standards of both white-collar workers and farmers have been greatly enhanced by the opening-up of the market, Chinese people have begun to realise the value of money, how to benefit from money, and how to make money from money. Furthermore, China has been vigorously attracting foreign investment. Compared to the situation in the planned economy, the money flowing in China has brought actual prosperity. "In all of its behaviours, including economic, political, and cultural - even in government behaviour - China has completely conformed to the dictates of capital and the activities of the market." ${ }^{27}$ The transformation of China into the factory of the world and the ideological shift to the policy of "Socialism with Chinese Characteristics" have put money into the hands of more Chinese than ever before. ${ }^{28}$ These two developments have also seeded consumer aspirations and spurred spending habits that now mirror those of the capitalist West. Therefore, the observation "money is the only language" is usually assumed to be correct.

Looking into the majority of relevant literature, Ma summarised that much of the literature regarding economic restructuring after socialism automatically assumes that the socialist economy in the former Soviet Union, East and Central European counties and China are moving in a linear pattern away from central planning, production and redistribution towards market capitalism. He also pointed out that underlying this essentialist thinking is the assumption that capitalism is irresistible and that market forces are the most effective means of shaping national and regional economies - leaving little room for the possibility of alternative courses of change. ${ }^{29}$ Probably "daily becoming more intimately related to capital" 30 is at least visually real, or in other words, imaginably true. Therefore, it makes sense that people assume "money at least will be the language in China".

China's economic transformation away from state socialism should be viewed as a prolonged process of change with unpredictable consequences, instead of as 
a short transitory phase leading to a Western capitalist system of production. ${ }^{31}$ As Francis comments, the assumption of the dominant neo-liberal ideology is that post-communist market transitions will lead to and require a sharpening of the boundaries, both legal and practical, between the state and expanding private sectors. However, the post-communist economic transitions belie these assumptions. ${ }^{32}$ There is no doubt that by the end of the 1980 s, China saw the financial model embodied in the American Superhighway to capital as its road to riches. ${ }^{33}$ Therefore, China's domestic reforms in the 1990s followed a path of deregulation blazed by the United States. ${ }^{34}$

There have been several books and articles ${ }^{35}$ that utilised the term "red capitalism" or "red capitalist" in describing China's development. However, instead of the pure focus on the rising private economy, Red Capitalism: The Fragile Financial Foundation of China's Extraordinary Rise pointed out the real clue. In this book, Water and Howie argued that China is a family-run business: when ruling groups change, there will be an inevitable change in the balance of interests; but these families have one shared interest above all others: the stability of the system. Social stability allows their pursuit of special interests. ${ }^{36}$ Moreover, living and working in China for twenty-five years gave the authors a clear idea of "inside the system":

China's economic geography is not simply based on geography. There is a parallel economy that is geographic as well as politically strategic. This is commonly referred as the economy “inside the system" (tizhinei体制内) and, from the Communist Party's viewpoint, it is the real political economy. All of the state's financial, material and human resources, including the policies that have opened the country to foreign investment, have been and continue to be directed at the "system". ${ }^{37}$

No one can dispute that China's economic structure is much different from the West's. But even insiders cannot disagree with Water and Howie's observation that modern China's political economy is "inside the system". The vocabulary "inside the system" has actually become common coin in contemporary China, even among artists, taxi drivers or freelancers who would be shocked to find themselves in any way indebted "inside the system", or unable to untangle this debt. The command structure developed over the past eighty or more years of the party's existence, and especially over the half-century or more of the People's Republic, remains in place, although with modifications in the way in which they are used. ${ }^{38}$

The "Party" - that is, the winning interest group - can intervene for any convenient reason, changing CEOs, investing in new projects or ordering mergers. Due to these characteristics, the adoption of laws, accounting standards, markets, and other mechanisms of international capitalism are just examples of the formalism that characterized China today. The names are the same as in the West, but what things are and how they work is hidden beneath the surface. ${ }^{39}$ 
Outsiders may easily fail to understand this fragmented structure of the country's political system, how special interest groups co-exist within this political entity or how the whole system has some effect on every aspect of people's lives. Contemporary Chinese architects are part of this scenario. Contemporary architecture inevitably expresses the subtle balance between the free market and the system inside China.

\section{- Has China forgotten Mao?}

Can we believe that people still remember Mao when they are focused on the pursuit of money? Or should the question be posed thus: do people want to remember Mao when they are successful in making money? Among the most telling instances is Porter's 2011 book, From Mao to Market, an ambitious and wellconsidered study, which attempts to trace current trends back to the first three decades of the People's Republic, decades that have appeared to be ignored in most research. He bases his study on a deep understanding that "the issues faced by China all have a long pedigree; they did not simply appear when China began to open up in 1979." ${ }^{40}$

Many events - including the unequal treaty system of 1840 s, the foreign exploitation of Chinese resources and Chinese labour, the invasion by Japan in the 1930s and the policy of isolation assumed by much of the world after the founding of the People's Republic - all these factors have made their own historical stamp on the contemporary map. But to both an outsider and an insider, everything in China looks exhilaratingly new.

So how did it all happen? It is hard for anybody to consider or even remember that these brilliant achievements have any connection with the period of Mao. Porter's observation on Chinese people's relationship with the Maoist era is sharp and perceptive, and he writes:

Life under the People's Republic for the first thirty years brought its own hard lessons: that personal rivalries and struggles for power are just as likely under the Communist Party as among the transitional warlords or in the Imperial courts of the dynastic era; that despite offers of aid from apparently friendly states, taken up for a while, China ultimately stands alone and must never abandon its quest for self-sufficiency in all things essential to its way of life; that ideology and political commitment cannot ultimately solve China's problems, and indeed can rapidly become a blight on the discussion of policy alternatives, and even worse, an excuse for acts of violence and great inhumanity. All Chinese carried this psychological "baggage" with them into the latest phase of modernization. ${ }^{41}$

Socialism came into China as a trenchant ideological answer to the challenges of modern China. "Born of the underbelly of capitalism, socialism proposed a comprehensive futuristic vision of a fairer social order and offer a vastly powerful ideology to those who sought to change the world." ${ }^{\prime 2}$ The disillusionment with 
Maoism and the loss of the socialist-communist ideal after the mid-1980s has not changed socialism as the officially defined socio-political and economic system of China. Acceptance does not mean that an unpleasant thought or feeling will go away; it may stay awhile. Likewise, disillusionment with the reality does not mean forgetting the ideal; it is still present. Socialism is affecting the cultural formation of modernity in China, although it does not appear like seeking to change the world. Chinese commercialisation as a dilution of communist ideology raised up by Deng is healing. But healing does not mean forgetting. Yifu Lin, ${ }^{43}$ a former chief economist and senior vice president at the World Bank, argued that it was a gradual and long process for the Chinese to recognise the role of competition, to understand which organisations can put it to best use and, finally, to see the importance of global values and ideas. ${ }^{44}$ However this gradual and long process from Mao to market is full of blood and sacrifice, and architecture as well has been splashed with blood.

\section{- Do people just want to be the individuated self?}

It is true that Chinese people were collectively disciplined and controlled in the Mao era. Chinese citizens gradually realised that they do not have to remain residents under the collective unit. However, with the emergence of security, prosperity and stability, does individualism really matter to Chinese people? Does their consciousness about individual identity differ from the Western idea of individuation? Before China's transition to a market economy, the idealised public realm ultimately displaced private sectors. In pre-reform socialist China, the Communist party-state in its early years attempted to hijack the "social" identity and transform Chinese society into a massive bureaucratic structure under the rule of the Chinese Communist Party, where society was organised as a massive "super human family" under the gigantic nationwide administration of "collective housekeeping", and where "private interests assume public significance". ${ }^{45}$

Prior to economic reform and the opening-up of mainland China in the 1980 s, the rights of privacy of Chinese citizens were seldom invoked, and rarely debated. ${ }^{46}$ In the People's Commune, which was born in 1958, everything was shared. Private kitchens in the commune became redundant. Everything originally owned by the households - private animals, stored grains and household items were contributed to the commune. The collectivism stressing collectivised work activities began to pervade China, and promoted no distinction between private and public ownership. In the liberal-economic model dominant in public-policy analysis, public-private distinction is primarily marked in terms of the distinction between public state administration and the private market approach. Yet the state-dominated public sphere in the pre-reform socialist regime, denigrates any attempt to identify a distinction between the collective and the individual; to some extent it regarded maintaining a private life, and a private identity, as merely selfish activities. Therefore, it is logical to think that the return of the concept of a private life should suggest to Chinese people a greater autonomy and eagerness for individuality. 
The promotion of the market can be considered as much an economic reform as a social reform, considering that the removal of the iron rice bowl, the privatisation of housing and the retrenchment of subsidies, fundamentally changes the socialist contract. ${ }^{47}$ The individualistic capitalist notion "to get rich is glorious" has replaced the socialist idea of personal sacrifice for the good of the collective, and inequality becomes a consequence of the transition from a socialist to a more marketdriven economy. However, it should be noted that the context that Western theorists always refer to with regard to emerging individualism is different from the context of contemporary China. Western commentators always simply blame political freedom, but China's problem is much more complex because of recent Chinese history, and also because of the specific psychological circumstance: people are insecure about themselves as individuals and their new positions in the collective.

Western theorists who build their theories through an examination of European and North American societies since the 1970s pronounce the importance of framing contemporary individuation in a "high" or "liquid" modernity that comes after first-order modernity. In doing so, they imply a particular historical metanarrative that is in many aspects inappropriate for China. They suggest that first comes industrialization, urbanization, and nation-building; only afterwards comes globalization, the Internet, time-space compression, postindustrial societies, heightened reflexivity, the dismantling of the welfare state, neoliberalism, and so on. In contemporary China, to a greater extent than in Europe or North America, these social processes can be seen as developing simultaneously rather than sequentially, and it is not hard to argue that it is the social changes named by the classic social theorists that have been most consequential. ${ }^{48}$

Previous research found that people of all ages are still less individualistic than their counterparts in Western countries. ${ }^{49}$ And they always assume that the leaders in China have a vision of modernity that place leaders at the centre and ignore ordinary people. However, such claims are unsubstantiated and too broad to be credible, since the relationship between the state and ordinary people is still an unresolved question.

It should be noted that the vision of modernity is not merely viewed by the people as a command from the leaders, is a movement that ordinary Chinese people want to engage in as well, and while they are unhappy with the command structure, at the same time they sacrificed themselves to achieve this goal in the 1990s. For example, the research undertaken by Anne-Marie Broudehoux on the destruction of Yuanmingyuan ${ }^{50}$ tells the story that with the launch of the reconstruction of Yuanmingyuan, originally called the Imperial Gardens, the local residents were permitted to continue living in their houses only until replacement accommodation was provided outside Yuanmingyuan. However, Broudehoux found,

Anger is increasingly heard among Yuanmingyuan residents uncertain of their fate. Ironically, perhaps the greatest demonstration of patriotism at 
Yuanmingyuan today is found in these residents' willingness to serve the common good and to let their present lives be sacrificed at the expense of an idealized and fabricated past. ${ }^{51}$

What some scholars fail to understand is that in contemporary China major changes are all occurring simultaneously: industrialisation, urbanisation, nationbuilding, globalisation, the dismantling of the welfare state and neo-liberalism. Therefore, it is dangerous to draw a profile of the relationship between the state and individual person based on the experiences of European and North American societies, neglecting the specific dynamics and tensions peculiar to the emergence of modern China.

The underlying dynamics of the individual vs the collective, as a psychological problem stimulated by reform, need to be further explored. Chinese modernity and the individual psyche is a key theme for this study, and to clarify this third fallacy is to identify stereotypical thinking on the subject of individualism, which has a long and rich history in Western social theory. In this book, I will examine the effects of individualism on architects, and indicate that their pursuit of an individual identity is both a personal psychological issue and a general social factor. Clarifying the fallacy in this respect will be the foundation for understanding the psychology of individual architects and the role it plays in their architectural designs.

\section{- Clearing the path for the architectural research}

Eliminating the three crucial fallacies in general assumptions around Chinese societal transformation paves the way for a better understanding of contemporary Chinese architects and architecture in the transitional era. The fact that Chinese contemporary architecture looks disconnected from the past does not mean that China's architecture only reflects capitalist features, or follows the model of the West. If outsiders believe "Money is the only language" in China, and the primary goal of modern reform is to access the market, then they fail to understand that the goal of every reform effort undertaken by the party since 1978 is to achieve a balance between the free market and "inside the system".

It is easy for people to misinterpret the fake Western architectural façades all over China without fully understanding which part is the guise and which part is significant.

The character of China's style of capitalism is marked deeply by how the political elite has coalesced around certain institutions, corporations and economic sectors, how the government and various interest groups have used Western financial knowledge, and the crises the state has met along the way. ${ }^{52}$

For example, the heroic architectural capacity of absorbing the foreign form is virtually the only source of jobs, technology and foreign exchanges, and they are promoted as long as they are critical architectural components of constructing 
“' “entrepreneurial cities' that make land available for developmental projects, benefiting developer and officials, and enriching city coffers at the same time." ${ }^{53}$ This kind of architecture camouflages the true nature of some of the large-scale design institutes: these large-scale design institutes are not autonomous corporations. One example is China's Architecture \& Design Group located in Beijing, which has raised millions of dollars in capital with help from the state, growing to an economic scale never seen before in China. I will analyse this in detail in the works of one specific Chinese architect in the case studies. In addressing the fallacy, "money is the only language", it should be noted that the Chinese characteristics in architecture have assumed the guise of Western appearance and the mode of architectural corporations, listed companies on the stock exchange and made use of related professions such as architects, civil engineers and cost engineers.

Addressing the fallacy of Mao's role in contemporary China, we need to be aware of the latent role he still plays in the Chinese persona. The manifestation in architecture will be illustrated in the case studies. Most contemporary architects in China were born in Mao's era. Because of this influence, memories of socialist ideals and rhetoric continue to inform the manner in which people think architecture should be designed and constructed. The height of ambition under Mao is still visible in current architectural constructions.

Simultaneously, architects attempt to resolve this influence by expanding its conception to include the hidden or inner nature of selfhood in the concept of individualisation. The reforms implemented since 1978 have done more than just change the Chinese economy; they have also altered the architect's life and selfimage. Architects want to be recognised as individuals, and they are not collectively disciplined and controlled. But they are still seeking something through their architectural designs, which we will discuss in a later chapter. These are the architectural stories embedded in the new profiles of architects in contemporary China.

Looking at the dramatic economic growth, just how far could the socialpolitical system be reformed in China? Looking at capitalism and continuing innovations, how much longer can a socialist version of modernity persist in China? Confronting claims about lack of human rights, is it possible for individualism to flourish in China? Please keep these three questions in mind while reading the case studies, and we will find the answers in the detailed accounts of the architecture and architects. Most significantly: how have the answers to these questions shaped contemporary Chinese architecture?

\section{Notes}

1 For example, Anne Broudehoux, The Making and Selling of Post-Mao Beijing (New York; London: Routledge, 2004); Deborah Davis et al., eds., Urban Spaces in Contemporary China: The Potential for Autonomy and Community in Post-Mao China (Cambridge; New York; Melbourne: Cambridge University Press, 1995); Laurence J. C. Ma and Fulong Wu, eds., Restructuring the Chinese City: Changing Society, Economy and Space (New York: Routledge, 2005).

$2 \mathrm{Xiao} \mathrm{Hu}$, "Reorienting the Profession: Chinese Architectural Transformation Between 1949 and 1959" (Ph.D. Dissertation, University of Nebraska - Lincoln, 2009). 
3 Xing Ruan and Patrick Bingham-Hall, New China Architecture (Singapore: Periplus; Enfield: Publishers Group Worldwide distributor, 2006), 14.

4 See, for example, Denong Zou, Zhongguo Xiandai Jianzhushi 中国现代建筑史 [a History of Modern Chinese Architecture] (Tianjin: Tianjin kexue jishu chubanshe, 2003); Jianfei Zhu, Architecture of Modern China: A Historical Critique (London: Routedge, 2009); Peter Rowe and Seng Kuan, Architectural Encounters With Essence and Form in Modern China (Cambridge, MA: The MIT Press, 2004).

5 See, for example, the book Heart-Made: The Cutting Edge of Chinese Contemporary Architecture, which explores avant-garde Chinese architecture, design and urban planning via five separate themes: living architecture, digital architecture, video architecture, installation art and sound art. New Architecture China, by Xing Ruan, documents both designs of famed architects and the emergence of a whole new generation of Chinese architects. These books portray the spectacular landscape of new architecture in China and focus mainly on the introduction of individual architects and their works, for example, Yung Ho Chang, Liu Jiakun, Wang Shu, Zhang Lei and Qingyun Ma. Fang Zhenning, Christophe Pourtois, and Marcelle Rabinowicz, Heart-Made: The Cutting Edge of Chinese Contemporary Architecture (Brussels: MercatorFonds, 2010); Ruan and Bingham-Hall, New China Architecture.

6 There are various special issues of architectural journals focusing on new architecture. Stanislaus Fung provides an examination of four special issues on contemporary Chinese architecture published in Western journals. The December 2003 issue, The Flowering of Chinese Architecture, of the Japanese A+U reported various projects and provides the diverse viewpoints from architectural experts, government officer, developer and architects in the West and China. The special issue titled China Builds With Superhuman Speed, Reinventing Its Cities From the Ground Up in the American Architectural Record in 2004 is mainly focused on the institutional changes and market conditions, with particular emphasis on commercial principles when entering the Chinese market. China Boom, the special issued published by Spanish AV Monografias, stresses the balance between the traditional and the modern. Stanislaus Fung and Kai Wang, "Zhongguo Jianzhuxuezhong Kuawenhua Duihuade Qianjing Zouyi 中国建筑 学中跨文化对话的前景刍议[Notes on the Prospects of Cross-Cultural Dialogue in Chinese Architecture]," Shidai jianzhu no. 5 (2006): 24-29.

$7 \mathrm{Hu}$, "Reorienting the Profession: Chinese Architectural Transformation Between 1949 and 1959,"

8 For a detailed discussion of the design process, please refer to the paper that I published with Dr. Harry Margalit: Jiawen Han and Harry Margalit, "Imagining Modernity Through Architecture in Contemporary China," The International Journal of Design in Society 7, no. 1 (2013): 29-39.

9 For a detailed discussion of the rendering drawings, please refer to the paper that I published with Dr. Harry Margalit: ibid.

10 David Harvey, The Condition of Postmodernity: An Enquiry into the Origins of Cultural Change (Oxford; Cambridge MA: Blackwell, 1990).

11 This idea is greatly indebted to discussions with my doctoral supervisor, Dr. Harry Margalit.

12 Hui Wang, "Contemporary Chinese Thought and the Question of Modernity," Social Text 16, no. 2, Summer (1998): 14.

13 C. B. Francis, "Quasi-Public, Quasi-Private Trends in Emerging Market Economies: The Case of China," Comparative Politics 33, no. 3 (2001): 275.

14 Xudong Zhang, Postsocialism and Cultural Politics: China in the Last Decade of the Twentieth Century (Durham, NC: Duke University Press, 2008), 106.

15 See, for example, Peter Scriver, "Placing in-Between: Thinking Through Architecture in the Construction of Colonial-Modern Identities," National Identities 8, no. 3 (2006); Harry Margalit, "The State of Contemporary Architecture in Australia," Architectural Theory Review 11, no. 1 (2006). 
16 See, for example, Duanfang Lu, Remaking Chinese Urban Form: Modernity, Scarcity and Space, 1949-2005 (London; New York: Routledge, 2006); Samuel Y. Liang, Mapping Modernity in Shanghai: Space, Gender, and Visual Culture in the Sojourners, City, 1853-98, Asia's Transformations (Oxon England; New York: Routledge, 2010).

17 Marshall Berman, All That Is Solid Melts into Air: The Experience of Modernity (New York: Simon and Schuster, 1982).

18 Zygmunt Bauman, Liquid Modernity (Cambridge: Polity Press, 2000).

19 Arif Dirlik, "Modernity as History: Post-Revolutionary China, Globalization and the Question of Modernity," Social History 27, no. 1 (2002): 31.

20 Shmuel Eisenstadt, "Multiple Modernities," Daedalus 129, no. 1 (2000): 1-29.

21 Kang Liu, "Is There an Alternative to (Capitalist) Globalization? The Debate About Modernity in China," Boundary 2: An International Journal of Literature and Culture, 23, no. 3 (1996): 197.

22 Wang, "Contemporary Chinese Thought and the Question of Modernity,"

23 Ibid., 26.

24 Peter Gay, Freud for Historians (New York: Oxford University Press, 1985), 77.

25 Andrew Kipnis, Chinese Modernity and the Individual Psyche (New York: Palgrave Macmillan, 2012), 8.

26 See, for example, Duncan Hewitt, Getting Rich First: Life in a Changing China (London: Chatto \& Windus, 2007); John Gittings, The Changing Face of China: From Mao to Market (New York: Oxford University Press, 2005).

27 Wang, "Contemporary Chinese Thought and the Question of Modernity," 9.

28 Bianca Bosker, Original Copies: Architectural Mimicry in Contemporary China (Honolulu: University of Hawaii Press, 2013), 67.

29 Laurence J. C. Ma, "From China's Urban Social Space to Social and Environmental Justice," Eurasian Geography and Economics 48, no. 5 (2007): 1545.

30 Wang, "Contemporary Chinese Thought and the Question of Modernity," 9.

$31 \mathrm{Ma}$, "From China's Urban Social Space to Social and Environmental Justice," 1546.

32 Francis, "Quasi-Public, Quasi-Private Trends in Emerging Market Economies: The Case of China," 276.

33 Carl Walter and Fraser Howie, Red Capitalism: The Fragile Financial Foundation of China's Extraordinary Rise (Singapore: John Wiley \& Sons (Asia) Pte. Ltd., 2011), 3.

34 Ibid.

35 See, for example: Eliana Cardoso and Shahid Yusuf, "Red Capitalism: Growth and Inflation in China," Challenge 37, no. 3 (1994); George C. S. Lin, Red Capitalism in South China: Growth and Development of the Pearl River Delta (Vancouver: UBC press, 1997); Jing Yang, "Red Capitalist: The Rising Chinese Private Entrepreneurs," in China in an Era of Transition: Understanding Contemporary State and Society Actors, ed. Reza Hasmath and Jennifer Hsu (New York: Palgrave Macmillan, 2009).

36 Walter and Howie, Red Capitalism: The Fragile Financial Foundation of China's Extraordinary Rise, 21.

37 Ibid., 8-10.

38 Robin Porter, From Mao to Market: China Reconfigure (New York: Columbia University Press, 2011), 167.

39 Walter and Howie, Red Capitalism: The Fragile Financial Foundation of China's Extraordinary Rise, 23.

40 Porter, From Mao to Market: China Reconfigure, xi.

41 Ibid., 234.

42 Augusta Dimou, Entangled Paths Towards Modernity: Contextualizing Socialism and Nationalism in the Balkans (New York: Central European University Press, 2009), 1.

43 Justin Yifu Lin is a former Taiwanese military officer who moved to the PRC in 1979 to pursue his ambitions. He is Professor and Honorary Dean of the National School of Development, Peking University now, and the founding director of the China Centre for Economic Research. 


\section{History and ideology}

44 Justin Yifu Lin, Demystifying the Chinese Economy (New York: Cambridge University Press, 2012), 62.

45 Hannah Arendt, The Human Condition (Chicago: University of Chicago Press, 1998).

46 Choon-Piew Pow, "Constructing a New Private Order: Gated Communities and the Privatization of Urban Life in Post-Reform Shanghai," Social \& Cultural Geography 8, no. 6 (2007): 814.

47 Carrie Liu Currier, "The Gendered Effects of Market Reforms," in China in an Era of Transition : Understanding Contemporary State and Society Actors, ed. Reza Hasmath and Jennifer Hsu (New York: Palgrave Macmillan, 2009), 25.

48 Kipnis, Chinese Modernity and the Individual Psyche, 5.

49 For example, Gerard Lemos, The End of the Chinese Dream (New Haven: Yale University Press, 2012), 102.

50 Yuanmingyuan is located northwest of Beijing and to the east of the Summer Palace. The Garden was first constructed in the year of 1709 during the reign of the Emperor Kangxi of the Qing Dynasty (1644-1911). Over the next 150 years of the Qing Dynasty, this Garden was expanded to be a large-scale Chinese emperors' private pleasure garden, covering a total area of 350 hectares.

51 Broudehoux, The Making and Selling of Post-Mao Beijing, 88.

52 Walter and Howie, Red Capitalism: The Fragile Financial Foundation of China's Extraordinary Rise, 23-24.

53 In the article "From China's Urban Social Space to Social Environmental Justice", Ma pointed out that, at the subnational level, cities have become "entrepreneurial cities" in China that intensively pursue capital investment for urban construction. 


\section{Chinese architecture and China's architecture}

In the Chinese to English translation, "modern times" (jindai) in Chinese does not have an equivalent in the Western context. According to the Chinese academic convention, "modern times" (jindai) often refers to the period from the first Opium War (1839-1842) to 1949, when the People's Republic of China was founded. Subsequently, the period after 1949 until the present is usually regarded as the contemporary history of China (dangdai). In architectural discourse, Zhu argued that "contemporary China" may be best defined as post-Maoist starting from 1976, a turning point in the gradual transformation of China from a MarxistLeninist-Stalinist vanguard to a secular market economy. ${ }^{1}$ In this study, I define 1839-1949 as modern times, concurrent with the mainstream division; 1949-1976 is the period defined as pre-reform China or Maoist China; and the post-Mao era is from 1976 onwards, defined as the contemporary period for Chinese architecture in agreement with Zhu's definition. This book is focused on architecture from the 1990s onwards, since most architects active in the contemporary scene began to have intensive practices from 1990 in the post-Mao era.

In this chapter, the aim of the historical review is not to present a full and detailed picture of modern architecture in China. Nor is it focused on one consistent theme. Although my focus is the new waves of architecture in post-Mao China, I wish to clarify the unclear perception of the relationship with the past, by which it advances into contemporary forms. The main objective of the historical review is to trace forgotten elements in the compiled history. More significantly, the following three case studies will open with emphasis on historical events and cultural trends in different periods, aiming to elucidate the extent of the influence of specific historical factors in the architect's designs. Through a chronological historical analysis of events, it is possible to locate the context of the case studies and the associated ideology, clarifying the view of the architecture before and after the events. I will attempt to take a broader view of each historical period by seeking to understand the similarities and differences between Chinese architecture and architectural movements in Europe, Japan and elsewhere.

Based on existing research, the historical review takes a close look at society and architecture in three periods (1840-1949, 1949-1976, and 1976 onwards), with a different focus, and a special storyteller section of the new waves of architecture since the 1990s. This chapter first explores the trajectory of modern architecture 
in China and the influence of Chinese architects educated overseas from 1840 to 1949. The relationship between architecture and politics between 1949 and 1978 is examined in order to discover the effects of Maoism on architects and architecture. Here, Mao refers to the person who took power at gunpoint in 1949 and also extends to the communist or socialist regime and its philosophy. After 1978, the emphasis shifts from a unified political influence to the more fluid relationship in the post-Mao era, in which the multiple influences of politics, economics and cultural aspects of the market have been the driving forces. A number of architects positively responded to Chinese contemporary conditions after the 1990s. Since 2000, Chinese cities have been intensively driven by the market, and therefore, the intention here is to test to what extent the market has influenced architecture, and to what extent it could challenge the spiritual independence of emerging architects. However, the state still retains its crucial influence, and Zhu has made some general observations regarding the architecture of modern China as having four aspects: continuity, evolution, foreign influence and the presence of the state. ${ }^{2}$ Although "the presence of the state" has different expressions in different historical periods, it always persists. Since the theme of this study revolves around the transition from Mao to market, discussion of post-Mao Chinese architecture is not limited to the condensed historical narrative in the later part of this chapter.

\section{0-1949 unforgotten history}

The nineteenth century was a period of rapid decline in China. It saw the ruling Manchu Qing dynasty weaken and the bureaucracy grow more corrupt. China's modern times began with the first Opium War (1839-1842). The first of the unequal treaties ${ }^{3}$ was the Treaty of Nanjing, signed on August 29, 1842. The Opium War and these treaties were beginning of an era in which Western powers attempted to gain unfettered access to Chinese products and markets for European and US trade. China's defeat by Japan in the First Sino-Japanese War in 1895 gave further impetus to the need for reform and modernisation. In 1898, Kang Youwei and Liang Qichao instigated the Hundred Days' Reform. However, after 102 days the reform failed. It was a short-lived attempt to propel China into modernity.

In October of 1911, a group of revolutionaries in Southern China led by Sun Yat-sen conducted a successful revolt against the Qing Dynasty, establishing in its place the Republic of China and ending the imperial system. Sun Yat-sen, often called "the father of the nation", succeeded in overthrowing the monarchy in China and developing the ideology of a Nationalist Party. ${ }^{4}$ But state power soon fell into the hands of the counter-revolutionary Yuan Shikai, largely because the Nationalist Party failed to effectively mobilise the peasantry, the strongest mass force in China, and involve it in the struggle. ${ }^{5}$ The failure of Sun Yat-sen's revolution led to a period of intense instability, perhaps the most pronounced feature of which was the rise of warlords. Partly as a result of the ideological vacuum arising after the collapse of the imperial system, China experienced a new cultural movement. The patriotic May 4 Movement of 1919 marked the outbreak of a new revolutionary storm and the advance of the Chinese development to a 
new stage. ${ }^{6}$ The trigger for the demonstration was the Paris Peace Conference, which was negotiating the terms of a treaty to put a final end to the horrors of the First World War. The Conference had decided on 30 April 1919 to accept Japan's demands that all previously held German interests in Shandong Province should be handed over to Japan. ${ }^{7}$ This May 4 Movement is also called the New Culture Movement; the leaders of the movement believed that traditional Confucian values were responsible for the political weakness of the nation. This saw the rise of a generation of young people keen to overthrow the old traditions, who were also nationalistic and hostile to imperialism.

The beginning of modern Chinese architecture can be traced to developments in the late nineteenth century. ${ }^{8}$ In the early 1900 s, the practice of studying architecture abroad became common. When architects returned from overseas studies, they brought back to China progressive architectural ideas. ${ }^{9}$ Although the study of traditional architecture still prevailed, the significance of learning modern architecture was recognised. Chinese students, after studying architecture in Japan, the United States and Europe, returned and established design practice from the early 1920 s. $^{10}$ Zhang Jun (1888-1970) is a typical architect who graduated overseas in 1914, and soon after returning, he opened his own firm in China and established the Society of Chinese Architects in 1926. ${ }^{11}$ Liang Sicheng studied architecture at the University of Pennsylvania and Harvard Graduate School of Arts and Sciences between 1924 and 1927. Most of these architects were the last generation following traditional Chinese values, but they were also among the first generation who embraced Western knowledge in architecture.

The Nanjing decade is the term applied to the period beginning when Nanjing became the capital of China and ending with the outbreak of the War of Resistance against Japan in 1927. During this time, China was reunified, at least in name: Chiang Kai-shek and the Nationalist Party brought in a centralised bureaucratic system and functionaries after more than fifteen years of political chaos. At the same time, Chiang Kai-shek's National Government faced stiff opposition from several domestic and foreign quarters. According to Lloyd Eastman, "The regime that took shape in Chiang Kai-shek's hands after 1927 was neither totalitarian nor democratic, but lay uncertainly between those points on the political spectrum." 12

Born in the shadow of the May 4 Movement, the Chinese Communist Party played an important role in the nationalist movement of the 1920s. On July 1, 1921, with the assistance of the Communist International, the First National Congress of the Communist Party of China was held in Shanghai. It was established on the pattern of the Russian Bolshevik Party, a new type of revolutionary party. Such a party sees itself at the vanguard of the class-conscious task of liberating the working class, which it undertakes armed with the science of MarxismLeninism. ${ }^{13}$ After its suppression in 1927, the Chinese Communist Party went underground, founding its own Chinese Socialist Republic in Jiangxi Province in 1931.

China's condition in the 1920s was instrumental in forging the nation's subsequent architectural mindset. Young architects' interests lay in serving the needs of their country as it faced rapid development and modernisation, but it was increasingly apparent that China's needs were inextricably linked to resolving the 
question of foreign interference. ${ }^{14}$ Zhu Qiqian, as a scholar and collector, passed the city of Nanjing and discovered a manuscript of the Yingzao fashi (Treatise on Architectural Methods or State Building Standards) at the Jiangnan Library, the book of which is written by the Chinese author Li Jie, the directorate of Buildings and Construction during the mid-Song Dynasty (1097-1010). ${ }^{15}$ Almost at the same time, Adolf Loos delivered his influential lecture, Ornament and Crime, in Vienna in 1910, giving immortality to decorations by advocating clear surfaces in architecture. The ornament in the traditional Chinese architecture was regaining the morality associated with its reprinting, pushed forwards by Zhu, within "a much larger meaning: the development of a sense of the importance of a Chinese architecture to a Chinese nation-state." ${ }^{16}$ The competition to design Sun Yat-sen's mausoleum in 1925 was a prologue to the upsurge of this kind of Chinese renaissance in architecture. The competition document prescribed that traditional Chinese design must be applied, but the conventional timber-brick structure should be abandoned. ${ }^{17}$ Promoted by the Nationalist Government, such Chinese renaissance architecture prevailed during the 1920s and 1930s, especially in the national capital Nanjing and the most important economic centre, Shanghai. ${ }^{18}$ In 1928, a professional architectural infrastructure began to take shape with the creation of a department of architecture at the Northeastern University in Mukden, headed by Liang Sicheng. Liang's investigation into traditional Chinese architecture accompanied the rise of nationalism in China during the 1930s, when Japan launched its invasion into Manchuria.

By 1931, twenty-eight of the fifty-one architects in the Society of Chinese Architects were American-educated; that number rose to thirty-five of fifty-five members by 1935 , and eight more were trained in foreign countries other than the United States. ${ }^{19}$ From the 1930s, Shanghai witnessed the emergence of modern architecture. Associated with the imagination of the Chinese tradition, the influence of international style was transmitted into China and applied to some projects, for example, Picardie Apartments, designed by Minutti \& Co. Civil Engineers and Architects; and Ecole Remi, I.S.S. Gasgoigne Apartments and Le Dauphiné Apartments, by Leonard, Veysseyre and Kruze. ${ }^{20}$ The circles of Chinese architects began to introduce works and theories of modern architecture to China in the same decade. In 1933, the international exposition, "a century of progress", was held in Chicago. Several Chinese architectural publications carefully reported the exposition. ${ }^{21}$ The most common characteristics of this international style that was gaining acceptance included rectilinear forms and surfaces completely stripped of applied ornamentation and decoration.

In addition, in the 1920s, Art Deco was introduced into the United States, and shortly emerged in China as well. It soon became one of the most fashionable styles, especially in Shanghai. ${ }^{22}$ It is argued that the golden age of 1930s Shanghai was characterised by imagined modernity and its manifestation in architecture, like the chaotic present. In 1944, the writer Eileen Chang first used the term, "Chuanqi", which literally means legend, to represent the experience in the legendary urban life of Shanghai. Shanghai, known then as "The Paris of the East", its architectural style a collage of British and American Art Deco, conveyed a new 
urban vision. "There is no city in the world today with such a variety of architectural offerings, buildings which stand out in welcome contrast to their modern counterparts," wrote an experienced Shanghai visitor in the golden era. ${ }^{23}$ In the writing of Tess Johnston, "Shanghai has the largest array of Art Deco edifices of any city in the world." 24

With regards to modern architecture in this historical period, Ji summarised that,

The exploration of modern architecture by Chinese architects was in parallel with their pursuit of Chinese renaissance, and their views on modern architecture were lopsided. Only a few of them comprehensively recognized modern architecture, while most regarded it as a new optional architectural style for their design. Most Chinese architects synchronously designed international style buildings, western classical style buildings and Chinese renaissance style ones, and many of them only cared for the exterior forms of modern style..$^{25}$

The Second Sino-Japanese War (1937-1945) was the result of a decades-long Japanese imperialist policy aimed at dominating China politically and militarily and to secure its vast raw material reserves and other economic resources, particularly food and labour. At the end of 1936, Chiang Kai-shek was forced to give top priority to fighting the Japanese. Lasting until 1945, the war became enmeshed with the Second World War. Therefore, due to unstable social condition in China, modern architecture in that specific context was more connected to "being modern", in contrast with the overarching modernist movements in architecture at the turn of the twentieth century in the West, which were a strong response to rapid technological advancement and the modernisation of society. The various and entangled architectural styles providing different options for modern China were not be able to reflect their relations to the social and political revolution. "Being modern" revealed their intention to be "something new and different, something exciting and unorthodox, something Chinese and something characterised by a sense of independence". As a result, they displayed some peculiar aesthetic exuberance that was associated with Chinese modernity at that specific historical moment.

At the end of the war against Japan in 1945, Chiang Kai-shek was greatly weakened, while the Chinese Communist Party was much stronger than at the beginning of the war. Hardly had victory against Japan restored peace in 1945 than China faced yet another war, the Civil War between Chiang Kai-shek and the Chinese Communist Party. Lasting from 1946 till 1949, this resulted in a victory for the Chinese Communist Party, which established the People's Republic of China on October 1, 1949. In general, after the fall of the imperial government and the establishment of the Republic of China in 1912, the time from the 1910s until the 1940s gradually led to the emergence of new architecture styles associated with cosmopolitanism and nationalism. Some principles of modern architecture and modern city planning imported from the Western world, although not genuinely digested, were gradually accepted. The main trend still departed from 
traditional Chinese architecture. By the 1940s, the architectural profession was well established by the first generation architects' efforts. Some of the prominent figures, such as Yang Tingbao, Liang Sicheng, Tong Jun and Chen Zhi, were all trained at the University of Pennsylvania, and they were deeply influenced by the Beaux-Arts traditions prevalent in America in the 1920s. They returned to China and brought back this tradition, which had a long-term impact in Chinese architectural practice and education.

\section{9-1976: Mao's influence on architecture}

After the Second World War and the Civil War, the People's Republic of China was established in Beijing in 1949 under Mao and the Chinese Communist Party. The founding of the People's Republic of China marked the beginning of its socialist stage. The task in this stage was to build a socialist society in China. The People's Republic of China was founded upon the historical condition of a very low stage of economic development and an extremely backward economic structure. In response to this international economic pattern and its own situation, the first priority for the new Chinese Communist government was to bring about a quick improvement in the backward economic structure and upgrade the level of industrialisation. As Yifu Lin wrote,

The prioritizing of the development of heavy industry was commensurate with the international political and economic environment that China was facing at that time, as the Western countries, led by the United States, imposed political isolationist measures and an economic embargo on China. As a result, China was faced with the denial of sound international economic relations and the threat of war at any time. ${ }^{26}$

This made the Chinese leadership realise that the rapid development of an industrial system, especially a heavy industry system that included defence industries, was a matter of life and death for the new state and the new sovereignty. Moreover, the Soviet Union's successful implementation of rapid industrialisation by using state plans also exerted considerable influence over the choices of development strategy of the Chinese leadership. ${ }^{27}$ If a market mechanism had been adopted to allocate resources, it would have been impossible to channel investment towards heavy industries; instead, it would have induced industrialisation dominated by light industries. Therefore, the number of state-owned enterprises (SOEs) directly under the administration of the central government increased considerably, from over 2,800 in 1953 to over 9,300 in $1957 .{ }^{28}$

Architecture constructed after the establishment of People's Republic of China until 1978 was responding mainly to changing political agendas. The main objective of this section is to elucidate how politics governed Chinese architecture over this period, assessing the sensitiveness between architecture and Maoism since 1949 rather than tracing the stylist development in step with the political events. Specific architectural characteristics will be further discussed in the case study 
of Liu Jiakun. It should be noted that the sensitiveness in the initial stage is not purely passive. During the early 1950s, the communist victory was widely and eagerly welcomed. There was a strong and universal antipathy to the former corrupt nationalist regime. Although Chinese professional practitioners were inactive in politics and unfamiliar with the communist or socialist ideology, they welcomed the reunification of China and the restored peace and order brought by the new rulers. ${ }^{29}$ Within one year of the founding of the People's Republic, most foreign enterprises were immediately confiscated or nationalised. The party gradually reduced the opportunity for private architectural practices in the professional market. ${ }^{30}$ Most Chinese architectural practitioners ceased their individual firms because they believed that joining a state-initiated design institute would provide a stable income, secure their careers and offer more chances in architectural design. At the same time, they had great expectations of the new social order and wished to work under the communist regime, serving the nation and its people.

The first round of political influence in architecture was associated with the arrival of the Soviet experts. On February 17, 1950, Mao said in his farewell speech at the Moscow railway station, "It will be clear to everybody that the solidarity between the Soviet and the Chinese people, consolidated by a treaty, will be everlasting, indestructible and inalienable."31 In Beijing, as early as September 1949, the first team of Russian town planners and construction experts were invited to assist in planning the goals of urban development, proposing an optimum size and a general layout for the city. ${ }^{32}$ Social realism, prevalent in the art and architecture of the Soviet Union, was seen in China as an appropriate way of celebrating the Socialist Revolution and a newfound sense of nationalism. It is customarily stated that social realism was adopted as the official style of Soviet art and literature at the First Congress of Soviet Writers in 1934. Social realism governed the production and criticism of Soviet art and literature until the mid1980 s. $^{33}$ It is usually characterised as the aesthetic principle of Stalinism, and its specific formulation, like its first works, did indeed emerge as weapons of Soviet cultural policy at the height of his rule. Cooke pointed out that the basic conflict between social realism and avant-garde modernism lies in the contribution to the national culture: the modernists' work was international, seeking global aesthetic principles and languages that made no appeal to the particularities of a given national culture. ${ }^{34}$ This explains why the Soviet architects also emphasised that building design plan should include national traditions, integrating them with new technologies and standards. This model became a central part of communist city construction with an elaborate propaganda apparatus in China. "Socialist Content and National Form" was a slogan sponsored by the Soviet experts. Liang Sicheng, a Chinese architect, was one of the key figures in this movement. In Liang's summary of traditional vocabulary, most of the characteristics related to the traditional Chinese roof. Therefore, between 1952 and 1954, traditional Chinese roofs became the rule in decorating most civil buildings.

The second round of political waves was initiated with the Three-antiCampaign (1951) and Five-anti-Campaign (1952). Though originally not aimed at the architecture, they eventually developed into a wider movement embracing 
architecture. These campaigns aimed to consolidate Mao's power base by targeting political opponents and capitalists, especially wealthy capitalists. These movements were originally instigated by Mao in an effort to rid Chinese cities of corruption and enemies of the state. Construction easily became a pivotal target for accusations of fraud and theft of state property. During the First Session of the First National People's Congress in September 1954, the Premier Zhou Enlai indicated in his Report on the Work of the Government that there was too much unnecessary resource waste in the construction industry. He stressed that "this waste of resources phenomenon is not in single isolated cases in our construction industry; due to the lack of defined building criteria, many cities, schools, institutions, and enterprises have built many unnecessary and overly lavish projects, exhausting the limited resources of our country." ${ }^{35}$ Facing this problem, from December 27, 1954 to January 8, 1955, the Ministry of Construction conducted the First National Conference of the Directors of the Provincial Departments of Construction. ${ }^{36}$ In order to address the party leaders' concern of scarce resources, this meeting formulated a new guideline slogan - "function, economy, and aesthetic appearance when circumstances allow". ${ }^{37}$ Liang's national expression of "big roofs" were targeted as an "unnecessary resource waste in the construction industry", hence they soon ceased to be built. ${ }^{38}$ The Central Propaganda Department of the Chinese Communist Party also organised a group of articles targeting Liang in a nationwide criticism; luckily, the deputy director of the Central Propaganda Department, Yang Zhou, rejected those articles by claiming a lack of evidence. ${ }^{39}$ From then on, architectural emphasis was placed on a modern construction industry and on the development of new construction types. This led to the standardisation of building with a focus on mass production and systematic construction.

The next ideological whirlwind to strike architects was the Hundred Flowers Campaign (1956-1957) and the Anti-Rightist Movement (1957-1959), the impact of which was mainly in the suppression of their professional thoughts. During the Hundred Flowers Campaign, intellectuals and others were encouraged to offer diverse views and criticisms on matters of national policy under the slogan "letting a hundred flowers blossom and a hundred schools of thought contend." It did not last long as it was suppressed after critical thought began to target Mao and communist rule. The Anti-Rightist Movement emerged in response to the Hundred Flowers Campaign; people who had been critical of his regime and ideology were labelled "rightists" and persecuted. Architects who were educated in the modernist conventions were in fact suspicious of the architectural interpretation of Soviet realism. The Hundred Flowers Campaign encouraged them to speak out. Therefore, some architects, for example, Zhu Yanong and Li Xijun, argued that the Soviet experience was not a good example to emulate and began to advocate that Chinese architecture could also learn from the capitalist countries. ${ }^{40}$ Chen Zhanxiang even boldly attacked the design of the institute system. ${ }^{41}$ Unfortunately, the party struck back using the Anti-Rightist Movement. For example, Chen Zhanxiang was one of the prominent architects who was labelled "rightist" and lost their position. The 
individual architects' voices were ruthlessly suppressed and replaced by a rigid uniformity that paved the way for the radical social programme of the Great Leap Forward.

The Great Leap Forward (1958-1960) pushed architecture's loyalty to politics to the extreme. It was a campaign initiated by Mao Zedong, whose aim was to rapidly transform China into a modern communist society through the process of agriculturalisation, industrialisation and collectivisation of land. The Great Leap Forward commenced in 1958. Mao concluded that the Chinese people were capable of anything and the two primary tasks that he felt they should target was industry and agriculture. In March 1958, at a Working Conference of the Central Committee in Chengdu, the principles for the general line of socialist construction were first put forward using the formulation, "Go all out, aim high and achieve greater, faster, better and more economical results in building socialism". ${ }^{42}$ The most important driving force in Mao's thinking was his ambitious pursuit of a unique route to transform Chinese society from an economically backward state to a prosperous and ideal communist utopia in a relatively short period so as to equal and even outdo the achievements of its Soviet neighbour. ${ }^{43}$ In February 1958, the Journal of Building published an editorial calling for a "great leap forward" in architecture. The bold architecture experiment with Chinese characteristics in this period was the establishment of a series of Peoples' Communes. "Concurrent with sweeping institutional changes, the state mobilized planners, architects and students in spatial disciplines to make planning proposals for the newly established communes." 44 The Ministry of Construction's meeting in April 1958 also created a new slogan for architectural and construction practice - "fast design and fast construction". The other manifestation was the Ten Great Buildings in Beijing that were part of an architecture and urbanism initiative of the Great Leap Forward; most of the buildings were largely completed in a time span of ten months. In August 1958, the Chinese Communist Party decided to construct ten largescale building projects in Beijing as monuments displaying the first ten years of great socialist achievement of the People's Republic and celebrating the tenth anniversary of the People's Republic. The Ten Great Buildings include the Great Hall of People, the National Museum of China, the Beijing Railway Station, the Cultural Palace of Nationalities, the Worker's Stadium, the National Agricultural Exhibition Hall, the Chinese People's Revolutionary Military Museum, the Minzu Hotel, the Diaoyutai State Guesthouse and the Overseas Chinese Hotel. There was no unified style that was officially enforced: large and heavy roofs laden with ceramic tiles inspired by traditional Chinese architecture, rational and modernist architectural language and eclectic approaches were applied in different projects. There were complicated and mixed influences tied closely together, including modernism, historicism and social realism. The "socialist style" in China at that time was under debate. These monumental new buildings, constructed on a grand scale and providing modern facilities and services, helped establish and celebrate an image of Mao's New China.

The final interplay between architecture and ideology sinks into absurdity during the Cultural Revolution. National efforts had achieved a degree 
of industrialisation and a measure of self-sufficiency. However, the Cultural Revolution (1966-1976) ruined everything. China's Great Proletarian Cultural Revolution shook the politics of China and the world's perception of China between 1966 and 1976. It dominated every aspect of Chinese life: families were separated, careers upended, education interrupted and striking political initiatives attempted amid a backdrop of chaos, new beginnings and the settling of old scores. ${ }^{45}$ In March 1965, the Ministry of Construction Engineering officially published its "Suggestions on the integration of political work into design professional work" as a prelude for the next step in the revolution. In 1966, the Architectural Journal - one of the most important professional journals - ceased publication. In its stead, Architectural Revolution began publication in 1967. During the Cultural Revolution, many architecture professionals who worked in public institutes and universities were sent off to various rural sites. Bing Wang writes,

The overall architectural profession was paralysed sadly by the endless witch-hunt for political dissidents. Toward the end of the Design Revolution, political purges turned most of the design institutes into little more than empty shells, and only a few politically special projects designated by the central government managed to stay in operation. ${ }^{46}$

The "revolutionary soul" was absorbed in the guiding principle of design work, mostly led by lay people rather than design professionals, as design professionals were not considered revolutionary enough and did not maintain deep solidarity with the masses. As a result, anything related to Mao was worshipped and utilised as elements in architecture. Zhu summarised that there was a short period when a political expressionism emerged in the early 1970s after the Cultural Revolution, in which large sculptural forms, such as stars and red flags, were applied to many public buildings. ${ }^{47}$

Therefore, it could be argued that architecture was an integral manifestation of Mao's socialist aspiration between 1949 and 1976. In 1956, Architectural Journal declared, "We need modern architecture." Others immediately objected, arguing that modernist architecture was not socialist but functional, a mode of building in which technology had supplanted art. ${ }^{48}$ The continuous and unpredictable political campaigns forced architects to abandon their private work and join the "great tide of socialist construction". Generally speaking, the arrival of communism fundamentally altered China's architectural community, and from 1949, a new chapter in China's architectural history under Maoist ideology began to unfold. It can be seen from the unfolding of these historical events, that during each campaign, the great tide of socialist construction led architects to share the party's different aspirations and work alongside them, regardless of whether or not their aspirations were realist.

However, socialist construction did not manifest as traditional wooden structures. Socialist content was primarily focused on steel, concrete and glass and the 
abstract forms promoted by the modernists during this period. The shortage of housing and industrialisation did not even give way to inspiration from the BeauxArts. Instead, it boosted the experiments on minimum space standards and mass production techniques in order to be more functional, efficient and inexpensive, and then to be more socialist. But what does it mean "to be more socialist"? What is the legacy of the post-Mao Chinese architecture and architect? Duanfang Lu's erudite and insightful study Remaking Chinese Urban Form: Modernity, Scarcity and Space, 1949-2005 revitalised the role of the work unit in the study of modernity in China. Specifically, it demonstrates that work-unit-based urbanism was an alternative both to capitalist and Soviet urbanism. Drawing on Edward Said's travelling theory, Lu explored the modern planning ideas that occurred at intersecting regional, national and transnational levels. ${ }^{49}$ Her work has already proved something unique in the realm of the built environment, as Chinese modernity unfolded within a specific national and social context, which did not necessarily match the creeds of socialism. The idea of socialism originated from the West, and it was applied to China so overzealously that Chinese socialism and its architecture lost its sensitivity and became politically correct. However, there was no clear definition or agreement on what constituted a capitalist design ideology and a socialist design ideology.

At that time, the release of the modern from the Eurocentric notions of modernity had already extracted its price in the increasing incoherence of what it means to be modern. It is imperative to consider Chinese modernity both from an inside point of view and an outside point of view. For example, Japan started to reflect the project of modernity, identifying something characteristically Japanese that they could contribute to a "world" civilisation. In 1960s Japan, there were metabolist groups who wanted to address the problem that land was not only too expensive but also in critically short supply. Architecturally, they deliberately maintained an awareness of "tradition" with a sense of the local culture and history of Japan. The determination of the modern in China did not reach the negotiation of values in the global marketplace of modernity, but it was more or less like recourse to some abstract standard of value for the sake of ideology. In contrast to China's negotiation on modernity before Mao, in which the discussion on the modern and the traditional composed a continuum of historical development, there were no place to retreat. Architecturally, sometimes it was given a "big roof", and sometimes it was taken off. No doubt there were some important individuals who wanted to put Chinese architecture on the map through a re-investigation of the inherited ideas, paired with some modernist practices. But these proponents were too few in number, and their consideration was overzealously combined with ideology. There is no doubt that, although ideology dramatically influenced architecture between 1949 and 1976 and architecture mainly manifested as being busily sensitive in the flood of perpetual revolution and critique of capitalism, and the national form constantly entangled Chinese architecture under the specific ideology, the trend of modern architecture and modern construction could not be turned back. 


\section{After 1976: influences of the market on architecture}

All the interplays between Mao and architecture came to an end in the late 1970s. Following the death of Mao in 1976, his wife, Jiang Qing, and three of her supporters, Zhang Chunqiao, Wang Hongwen and Yao Wenyuan ("the Gang of Four") were arrested and put on trial, charged with being responsible for the Cultural Revolution. In December 1978, at the Third Plenum of the Eleventh Party Central Committee, Deng outlined a new political programme that was to have far-reaching consequences for Chinese society. It was the meeting that consolidated Deng Xiaoping's position as China's leader and laid the groundwork for a generation of economic reform. His primary aim was to initiate a series of economic reforms to make China prosperous and to guarantee his reputation on the international stage. In 1978, Deng was the great survivor when China's economy was on the brink of collapse.

Modern China, in terms of architecture and urban planning, in 1978 was not charming: most of the buildings, towns and cities were desperately ugly and shoddily built. Zou used the short heading "Back to Humanism, from the Shortage of Residential Architecture" in his book to describe the situation after $1978 .{ }^{50} \mathrm{On}$ October 1978, the State Council approved the National Committee's "Report on the acceleration of urban residential buildings' construction", requesting quick solutions for the severe problems in workers' housing shortage.$^{51}$ The tragic violence at Tiananmen Square in 1989 had a negative effect on the construction investment. Soon after this, Deng's southern tour gave Chinese people a boost of motivation again. In the spring of 1992, Deng made a historical tour of south China. To Deng, socialism was first and foremost about "liberating and developing the forces of production".$^{52}$ In his political vision, the kind of socialist system under the leadership of the Communist Party would be flexible enough to allow market forces, private enterprises, foreign capital and almost all kinds of institutions of a modern capitalist market economy. ${ }^{53}$ Deng foresaw in 1992 that it would take another thirty or so years for a comprehensive new system of governance to take shape and mature. ${ }^{54}$

The "great tide of socialist construction" gradually pulled on a capitalist jacket. The party gradually increased space for private architectural enterprises' practices in the professional market. In the paper entitled "Development and Evolution of Contemporary Chinese Private Architectural Offices", Huang divided the transition after 1978 into three periods, "1978-1992 economic enlightenment period; 1993-1998 development period; 1990-2009 mature and stable period". ${ }^{55}$ In the initial stage of the reform, the state-owned design institute was still dominant. In June 1979, there were eighteen pilot units nationwide, nine of which were practicing units: Beijing Institute of Architectural Design, Tianjing Architectural Design and Research Institute, Shanghai Civil Construction Design Institute, Shanghai Industrial Building Design Institute, Jiangsu Provincial Architectural Design Institute, Fujian Provincial Civil Construction Design Institute, Guangzhou Design Institute, Guangxi Design Institute and Yunnan Provincial Design Institute. ${ }^{56}$ The charging system reform stopped the allocated funding from the 
state to some extent, but it allowed the pilot units to take a self-supporting, selffinancing, self-restriction and self-development mode of operation. ${ }^{57}$

In 1984, the government formulated three specific regulations for opening a private architectural design firm: the first regulation required independent production and management, thus creating an independent economic entity; the second regulation asked for a fixed group of architectural designers, whose qualifications and number had to comply with the stated requirements, in accordance with the design task; and the third regulation required a fixed place of business and the necessary conditions for production and operation. ${ }^{58}$ In November 1984, the Ministry of Construction for the first time approved the small-scale private architectural design firm run by architect Wang Tianci. The real movement of private firms into the market began with Yung Ho Chang and his firm, Atelier FCJZ in the 1990s. Yung Ho Chang received his master of architecture degree from the University of California, Berkeley, and taught in the United States for 15 years before returning to Beijing to establish his private architecture firm, Atelier FCJZ. His return encouraged a wave of architects to establish private architectural firms and subsequently changed the practicing environment of the architectural market. At the same time, architectural design was gradually computerised in the 1990s, enabling architects to design and change their designs quickly and conveniently. In 1994-1995, a registration system was re-established after four decades of absence, allowing architects to obtain licences and establish private practice.

Zhu argued that the 1980 s witnessed a neo-national style, a new vernacular, a formalistic late modernism, and a commercial modernism, similar to the international style. ${ }^{59}$ They were quite unstable expressions that were fashionable for a very limited time before the nationwide modernist revival. The reason for these unstable expressions partially came from literary, philosophically and politically diversity ambiguity and confusion that was so pronounced in the 1980s, which in fact damaged the legitimacy of the Communist Party. Except the legal imagination of the West after opening-up, 1989 was a significant factor for China's turn into the largest building site in the world.

Unable to reconcile its Marxist ideology with the increasingly active role of the market and unwilling to whole heartedly embrace institutional and other political reforms, the party looked more and more to the economy as a means of shoring up its popular appeal. ${ }^{60}$

Therefore, the party was also keen to accelerate the transformation from a predominately socialist planned economy to a diverse and largely capitalist market economy and consumer society. Therefore, referring to modernism in the context of China 1990s onwards, Dubrau summarised that "Western architecture becomes Chinese modernism". ${ }^{61}$ He further asserts,

They are working less on specific concepts than falling back upon standardized patterns from Western countries which are considered modern in China. ... They are decorating themselves with completely oversized high-rises, 
congress centers, concert halls and exhibition halls, in order to at least be able to communicate a touch of grandeur with a newly designed landmark. ${ }^{62}$

This suggests that specific concepts in "modern" architecture have been endowed with the power of cultural supremacy. Chinese architects are using certain materials in certain ways in combination with some Western forms in some designated ways. Variety and individuality are not the primary concern for the investor; the buildings are often constructed as steel-glass structures possessing an allembracing dynamic and a shed-roof. Most often, it has been only when Western modernists "validated" Chinese aesthetics by appropriating them that Chinese architecture has been seen as having the capacity to be modern.

It is not always necessary to follow the tenets of modernism in architecture; the classic Euro-style forms are another important reference for being modern. Xue has observed that "the new apartments are constructed according to taste in appropriate styles such as Imperial Eclectic Style, European Modern Style, or Beyond Vision Style." ${ }^{63}$ Bosker looked deeply into these residential settlements that resemble theme parks in his book. She argued, "The simulacra movement was also a readily visible means by which the Chinese could demonstrate - to themselves and to other nations - that they had attained a certain level of sophistication, wealth, and modernity." ${ }^{\prime 64}$ Consequently, modern Chinese cities look like either modern Western cities or historical Western cities, as the party tried to show its prosperity compared to the other countries in this global condition, while also forgetting the trauma of 1989.

July 13, 2001, was a significant day for China, when the 112th plenum of the International Olympic Committee held in Moscow, voted for Beijing to host the 2008 Olympic Games. It was the first time China, the world's most populous country, would host the games. The year also held another milestone. Having quit the World Trade Organization (WTO) shortly after the Communist Revolution of 1949 and reapplying in 1986, China had to wait fifteen long years to gain reentry. The doors finally opened for China in December 2001. After that China's economy evolved faster than anyone expected. With the globalisation of the world economy and China's joining the WTO, the industrial structure and economic system of China are experiencing significant reforms. China under the WTO must continue to open its market to the outside world. The "Regulations on Management of Design Enterprises of Foreign-Funded Construction Projects" has also been enforced since December 1, 2002. The market economy system requires that the design institutes must be turned into enterprises that are market guided, service-oriented and knowledge-technique intensive, in order to provide project construction with a full range of services. ${ }^{65}$

However, the collective large-scale design institutes have not stepped down from their preeminent positions. By the end of 2001, there were 4,327 architectural design institutes in China, including twenty-one large institutes staffed by $300-500$ people, operating primarily at the provincial level (with eight especially large institutes employing more than 600 people). These large institutes are mainly established by municipalities under the state council, or by large districts. ${ }^{66}$ After the reform of the property rights system, diversified ownership forms emerged (stock-holding, joint 
venture, and small partnerships), but state-owned and collective-owned forms prevail. According to the annual report of survey design statistics 2001, state-owned, collective, solely state-funded or state-holding design institutes occupied 84.6 percent of the total market, especially large institutes that are entirely state-owned. ${ }^{67}$

The decades of the 1980s and 1990s saw a dynamic transformation driven by market reform and modernisation, resulting in urbanisation on a grand scale and intensive building construction throughout the country, turning China into the largest building site in the world today. ${ }^{68}$ Lin summarised the achievements of China's economic reform,

China's reform took a gradual approach, aptly described by Deng Xiaoping as "Crossing the river by groping the stones." At the beginning of the reform, there was no blueprint or clear orientation. The initial goal was more planned-economy-based than market-based. But the gradual reform brought China closer and closer to the market economy - in some ways closer even than some market economy countries. ${ }^{69}$

In architecture, Li sums up the collective ambitions, desires and inventions of the last two decades as "Five Points for New Chinese Architecture", and these could be the context for all relevant discussions in its urbanisation on a grand scale and intensive building construction throughout the country: "Novelty, Monumentality, Bigness, Swiftness and Cheapness". ${ }^{70}$ Regardless of the scale, new projects can be designed and constructed within a very short span of time in China. As a result, the majority of architecture in Chinese cities is losing its Chinese character. Many architects in China are increasingly losing their distinctive flavour. In the middle of this phenomenon of homogeneity, a rising generation of Chinese architects has begun to thrive on something different.

\section{The new wave architecture}

An important component of the current architectural scene, especially after the mid-1990s, is the emergence of a young generation of Chinese architects. They are the new wave of architects who resist the simulacra practice. They not only aim to sell their works to the public and entertain the public, but their work has an ethical and aesthetic value.

Several major events marked the emergence of this group; for example, the 5/18 "Symposium of Young Architects and Artists" in Guangzhou in 1998, and the "Chinese House" exhibition of the work of five experimental architects in Shanghai in 2001. At the Twentieth UIA Congress in Beijing, art critic Wang Mingxian organized an exhibition of experimental architecture that provided a platform for a group of ambitious young designers. ${ }^{71}$

Some of these designers studied architecture in China, for example, Liu Jiakun, Cui Kai and Wang Shu; some studied architecture in both China and the West, for 
example, architects in URBANUS, Qingyun Ma, Zhang Lei and Yung Ho Chang. Most of them began their independent architectural activities in China in the late 1990s: some of them had experience in the large design institutes. An exception is Cui Kai, who still holds fast to the state-owned design institute. Whether working in private architectural firms or in the large-scale design institute, it has been legitimate for them to accept commissions from individual people, public enterprise and the government.

As discussed in this chapter, the majority of contemporary Chinese architecture has been driven by the image of modernity in the massive inconsiderate wave of construction. For Yung Ho Chang, Liu Jiakun or Cui Kai, the desire for a new, recognisable Chinese identity, and an identity for themselves as Chinese architects, is growing. Yet there is no denying that the influences of current Western architecture are unmistakable in almost all the projects of the new generation.

Architects in China have always been burdened with cultural mission. This sense of mission is driven by a wide range of theoretical discourses and is often fueled by single-minded and extremist viewpoints, such as anti-Westernization, Westernization, doctrines of "contemporary architecture with Chinese characteristics," or those that stridently oppose the restoration of ancient form. ${ }^{72}$

However, Xue also argued that "such rigidly held positions can only lead to a dead end, as shown by some of the inferior and awkward buildings that have resulted from the adherence to such dogmatic ideologies." Do the new innovative architects swamp themselves in these dogmatic ideologies?

Three case studies, to be expanded in the following three chapters, are critical analyses of the architects Liu Jiakun, Cui Kai and URBANUS, and their designs. There is no intention of citing these three cases to stand for the sum of Chinese architects, neither should their works stand for all strands of architectural thought in contemporary China. These cases are selected because they are three different manifestations of intricate details of the societal transformation from a command economy to a market economy, and they offer various practical approaches by Chinese architects. The aim of this book is to explore the various interactions between architecture and the socio-political situation in contemporary China, rather than broad generalisations, as previously stated. In contrast, there are some prominent Chinese architects demonstrating their belief in "architecture for architecture's sake" no matter what societal transformation is taking place in China. In other words, their works show little connection with the socio-political situation, and they are not relevant to this study.

Liu Jiakun and Cui Kai were born in the 1950s; the three architects in URBANUS were born in the 1960s. The post-1970s architects and subsequent cohorts are also excluded from this discussion. First, Chinese architects born in the 1950s and 1960s are playing key roles in the profession. The specific reason will emerge in Cui Kai's case. Much was due to the abrupt pause of advanced education for ten years during the Cultural Revolution. Therefore, the post-1950s and 1960s architects are the driving force in both architecture and architectural 
discourse in China. Second, different from the architects born from the 1970s onwards, Chinese architects born in the 1950s and 1960s are real witnesses of the transition. They experienced all the ups and downs from pre-reform China to early market China: they are the last generations that grew up in a system largely connected with the ideology of Mao. Yet they became socialised and worked in an environment that increasingly signalled that consumerist materialism should be seen as the path to national advancement and personal well-being. Therefore, I selected them as target cases since the architects do not belong to the Maooriented generation or to the market-oriented generation. They disliked political references in their works, and their preferences are not global clothing labels or computer brands. Sometimes the way they differentiate themselves from others is, surprisingly, on the basis of their lives in Maoist China.

In each case, there will be a part seeing how both architects and the designs resonate with the political, social and cultural circumstances of the period from pre-Maoist China to the market in germination in the 1980s and early 1990s. Chronologically, there is another part focusing on the early 1990s market until the recent time. Although the historical review will be integrated with the architect's life experiences and thoughts, one part will focus on the individual architect as a disintegrated component, re-positioned in the architecture and its history: this will be a close look at the subjectivity of Liu Jiakun, Cui Kai and URBANUS and their respective architecture. In the other part, I will trace the profiles through the case studies by illustrating some main transformations in different levels, including: the reforms of state-owned enterprises, something out of Mao's shadow, something still in Mao's shadow, the floating population, new private goals and public policies. Infusing the different levels of analysis, this part indicates genuine social crisis and the architectural dynamics encountered in the process of marketisation and globalisation. In other words, this part will revisit the architects in each case whose architectural practice was advanced through their architecture, but whose concern in their work was society at large. Each case study concludes with a summary addressing the research questions previously proposed.

\section{Notes}

1 Jianfei Zhu, Architecture of Modern China: A Historical Critique (London: Routedge, 2009), 106.

2 Ibid., 241.

3 The "Unequal Treaties" were a series of treaties signed by the Qing Empire in China and foreign powers during the nineteenth and early twentieth centuries. It was denoted "unequal" because in most cases China was forced to pay astronomical amounts of reparation following military defeats, open up ports, cede lands and make various concessions to foreign "spheres of influence".

4 Colin Mackerras, China in Transformation, 1900-1949 (Harlow, England; New York: Pearson/Longman, 2008), 28.

5 Bing Wang, The Architectural Profession of Modern China - Emerging From the Past, First Edition (Beijing: China Foreign Language Press, 2011), 9.

6 In the May 4 Movement, 3,000 students from Peking University, the most prestigious in China, and some dozen other educational institutions in the capital, marched from beneath the Tiananmen at the entrance to the Imperial Palaces. 
7 Mackerras, China in Transformation, 1900-1949, 41.

8 Min-Ying Wang, "The Historicization of Chinese Architecture: The Making of Architectural Historiography in China, From the Late Nineteenth Century to 1953" (Ph.D. Dissertation, Columbia University, 2010), 5.

9 Ibid.

10 Zhu, Architecture of Modern China: A Historical Critique, 105.

11 Peter Rowe and Seng Kuan, Architectural Encounters With Essence and Form in Modern China (Cambridge, MA: The MIT Press, 2004), 49.

12 Lloyd E. Eastman, The Nationalist Era in China, 1927-1949 (Cambridge; New York: Cambridge University Press, 1991), 19.

13 Wang, The Architectural Profession of Modern China - Emerging From the Past, 41.

14 Denison Edward and Guang Yu Ren, Modernism in China: Architectural Visions and Revolutions (Chichester, England; Hoboken, NJ: John Wiley, 2008), 111.

15 Shiqiao Li, "Reconstituting Chinese Building Tradition: The Yingzao Fashi in the Early Twentieth Century," The Journal of the Society of Architectural Historians 62, no. 4 (2003): 472.

16 Ibid., 473.

17 Guohua Ji, "Building under the Planned Economy - A History of China's Architecture and Construction 1949-1965" (Ph.D. Dissertation, ETH, 2007), 40.

18 Ibid., 42.

19 Rowe and Kuan, Architectural Encounters with Essence and Form in Modern China, 49.

$20 \mathrm{Ji}$, "Building Under the Planned Economy - A History of China's Architecture and Construction 1949-1965," 48.

21 Ibid., 51.

22 Ibid., 47.

23 Leo Ou-fan Lee, Shanghai Modern: The Flowering of a New Urban Culture in China, 1930-1945 (Cambridge, MA: Harvard University Press, 1999), 70.

24 Ibid.

$25 \mathrm{Ji}$, "Building Under the Planned Economy - A History of China's Architecture and Construction 1949-1965," 54.

26 Justin Yifu Lin, Fang Cai, and Zhou Li, State-Owned Enterprise Reform in China (Hong Kong: Chinese University Press, 2001), 21.

27 Ibid.

28 Ibid., 41.

29 Xiao Hu, "Reorienting the Profession: Chinese Architectural Transformation Between 1949 and 1959" (Ph.D. Dissertation, University of Nebraska - Lincoln, 2009), 76.

30 Ibid., 70.

31 Wang, The Architectural Profession of Modern China - Emerging From the Past, 542.

32 Duanfang Lu, "Building the Chinese Work Unit: Modernity, Scarcity, and Space, 1949-2000" (PhD Dissertation, University of California, 2003), 75.

33 Alla Efimova, "To Touch on the Raw: The Aesthetic Affections of Socialist Realism," Art Journal 56, no. 1 (1997): 76.

34 Catherine Cooke, "Socialist Realist Architecture: Theory and Practice," in Art of the Soviets: Painting, Sculpture, and Architecture in a One-Party State, 1917-1992, ed. Matthew Cullerne Bown (Manchester; New York: Manchester University Press, 1993), 88.

35 Enlai Zhou, "Zhengfu Gongzuo Baogao (Report on the Work of the Government)," People's Daily, September 24, 1954.

$36 \mathrm{Hu}$, "Reorienting the Profession: Chinese Architectural Transformation Between 1949 and 1959," 169.

37 Ibid.

38 Ibid.

39 Ibid., 175. 
40 Ibid., 216.

41 Ibid., 221.

42 Maria Galikowski, Art and Politics in China, 1949-1984 (Hong Kong: The Chinese University Press, 1998), 79.

43 Ibid.

44 Duanfang Lu, Remaking Chinese Urban Form: Modernity, Scarcity and Space, 19492005 (London; New York: Routledge, 2006), 101.

45 Harriet Evans and Stephanie Donald, Picturing Power in the People's Republic of China: Posters of the Cultural Revolution (Lanham, MD: Rowman \& Littlefield Pub Inc, 1999).

46 Wang, The Architectural Profession of Modern China - Emerging From the Past.

47 Zhu, Architecture of Modern China: A Historical Critique, 106.

48 Rowe and Kuan, Architectural Encounters With Essence and Form in Modern China, 109.

49 Lu, Remaking Chinese Urban Form: Modernity, Scarcity and Space, 1949-2005.

50 Denong Zou, Mingxian Wang, and Xiangwei Zhang, Zhongguo Jianzhu 60nian 1949-2009 中国建筑60年(1949-2009)历史纵览 [Sixty Years of Chinese Architecture 1949-2006] (Beijing: Zhongguo jianzhu gongye chubanshe, 2009), 25.

51 Ibid., 10.

52 John Wong and Yongnian Zheng, eds., The Nanxun Legacy and China's Development in the Post-Deng Era (Singapore: Singapore University Press and World Scientific Publishing Co. Pte. Ltd., 2001), 204.

53 Ibid.

54 Ibid., 205.

55 Yuan-Shao Huang, “Zhongguo Dangdai Siyouhua Jianzhu Zhiye De Xingqi Yu Yanbian 中国当代私有化建筑执业的兴起与演变 [Development and Evolution of Contemporary Chinese Private Architectural Offices]," Chengshi huanjing sheji no. 2 (2010): 19.

56 Ibid.

57 Ibid.

58 Ibid.

59 Zhu, Architecture of Modern China: A Historical Critique, 6.

60 Robert Weatherley, Politics in China Since 1949: Legitimizing Authoritarian Rule (New York: Routledge, 2007), 133.

61 Christian Dubrau, Sinotecture : New Architecture in China $=$ Neue Architektur in China (Berlin: DOM Publishers, 2008), 17.

62 Ibid., 13.

63 Ibid., 18.

64 Bianca Bosker, Original Copies: Architectural Mimicry in Contemporary China (Honolulu: University of Hawaii Press, 2013), 70.

65 Wuying Li, “Guoyou Daxing Jianzhu Sheji Qiye De Liuanhuaming 国有大型建筑设 计企业的柳暗花明 [State-Owned Large-Scale Architectural Design Enterprises Facing a Bright Future Despite Difficulties],” Shidai jianzhu no. 1 (2004): 39.

66 Ibid.

67 Ibid.

68 Zhu, Architecture of Modern China: A Historical Critique, 106.

69 Justin Yifu Lin, Demystifying the Chinese Economy (New York: Cambridge University Press, 2012), 186.

70 Xiangning Li, “"Make-the-Most-of-It' Architecture," City: Analysis of Urban Trends, Culture, Theory, Policy, Action 12, no. 2 (2008): 232.

71 Charlie Q. L. Xue, Building a Revolution: Chinese Architecture Since 1980 (Hong Kong: Hong Kong University Press, 2006), 132.

72 Ibid., 131. 


\section{Conceiving the modern past Liu Jiakun}

Liu Jiakun is based in Chengdu, which is located in the Western region of China, and as an individual architect, he represents one specific stream in the increasingly diversified architectural discourse in China. An understanding of his architecture must start with attempting to understand some of key contradictions within contemporary China: the confusing relationship of contemporary architectural designs with Chinese life lived on a daily basis, and China's current connection with the pre-reform China of Mao's rule, are in conflict with the contemporary market. Liu Jiakun's architectural features are formulated in terms of the collective sense (in the socialist history of China), a memory that still permeates the social fabric in China. Architects like Liu Jiakun decode Maoist or socialist architectural-aesthetic programmes in the new social context, and they construct new architectural identities on the basis of a subconscious familiarity with architectural traditions and routines from the China of Mao.

\section{The necessity of being real}

In Building a Revolution: Chinese Architecture Since 1980, Charlie Q. L. Xue analysed the development record and prospects of Beijing, Shanghai and Guangzhou, based on their history, development process and spatial structure in order to present an overview of China's cities after 1980. He summarised the three distinctly different and instructive trajectories of Beijing, Shanghai, Guangzhou as "from walled kingdom to megacity", "from foreign concessions to metropolis", and "always a southern wind". ${ }^{1}$ Although Beijing, Shanghai and Guangzhou undoubtedly occupy preeminent positions in any ranking of Chinese cities, it is worth examining the general urban morphology, in which most of the second-tier cities, third-tier cities or country towns have not been part of the transitions taking place in Beijing, Shanghai and Guangzhou. Most of the existing literature is inclined to focus on the integration of globalisation and localisation in the major cities; however, this view has serious limitations for a broader understanding of the socialist contribution in the formation of the localisation of Chinese cities as a whole. Liu Jiakun's works architecturally contribute to the understanding of the socialist contribution in the formation of the localisation of Chinese cities. 


\section{- Decoding implicit historical references}

Scholars often describe the aesthetic inclination or style in art and architecture in the pre-reform period of modern China as social realism. ${ }^{2}$ However, the style of pre-reform architecture did not only originate in Mao's tastes or social realism. Cooke criticises younger academic writers in the Soviet Union who dismiss social realism as a phenomenon entirely confined to the Stalinist period and equally inaccurately, as a "style" originating in the dictator's own untutored and megalomaniac tastes. ${ }^{3}$ Pre-reform architecture in China has rich roots and Chinese expressions embedded in different political events, various political propagandas and the accompanying aesthetics and ideology. Liu Jiakun does not have a clear idea of what specific reference has been used in his work and from exactly where the reference is. To him, they are all from his collective memory. I will examine how Liu decodes these references in his designs and argue that Liu has made the connection in his designs by developing the industrial identity introduced by the Soviet Union that further took hold in the Great Leap Forward and critically integrating these with the unique aesthetics brought by the Cultural Revolution.

The examination of the reference in Liu Jiakun's designs to modern Chinese history will begin with the architectural aesthetics introduced by the Soviet experts and later promoted by the Great Leap Forward. The construction of a planned economy in a Soviet model necessitated Soviet forms of architectural and construction practice. For the Chinese communists, the Soviet model was the only historical example of completing the socialist transformation by industrialising an economically backward country into a powerful modern nation within a short period. Thus, Chinese communists believed that the Soviet means of development were extremely valuable for China and would lead China's socialist advancement to the desired outcomes. One significant contribution of this Soviet influence was the establishment of a complete set of industrialised building systems. The mass development of industrialisation generated an urgent need for housing. The Soviet experience of industrialisation provided relief. During 1954-1956, translations of Soviet industrialisation building systems were widely published. ${ }^{4}$

Except for the industrial architecture that naturally inherited the industrialised building systems, in the post-war housing shortage, the core of the industrialised in building system in China was mainly manifested in the standard dwelling unit, which was first built in 1952, under the guidance of Soviet experts in northeast China. ${ }^{5}$ Two types of residences were developed in the socialist period, with different degrees of access restrictions. In general, these housing units took the form of two to six storey apartments constructed in concrete and masonry, with access along the length of the block to each group of apartments offered via stairways or internal corridors. Dozens of Soviet advisers also worked with Chinese architects to compose the standardised design patterns for mass production and systematic construction. Based on the Soviet experience, major design institutes in different provinces were responsible for providing a few patterns of standardised housing units and spatial modules made up of standard building components. These housing units and building components were manufactured in factories and transported 
to the construction site to form buildings. ${ }^{6}$ A pattern of housing units could be used on multiple sites and repeatedly constructed as long as the site conditions suited the design. The industrialised building system held obvious benefits in fast construction: low costs and labour savings. This was critical for China in the 1950s, when construction resources and skilled designers were acutely scarce. ${ }^{7}$ Until the 1960s and 1970s, five to six storeys of apartments dominated the residential districts. Cities were constructed according to the standardised design, which in turn meant a standard dwelling unit or module made up of standard building components; various combinations of these units formed buildings, which were then placed together to create residential areas. The production of housing influenced by the Soviet legacy prevailed in Chinese cities in the Mao era, and the city had two main morphologies: industrial architecture and worker villages built for several work-units or the whole industrial sector, causally interrupted by monuments. The Great Leap Forward from 1958 to 1961 was led by Mao and aimed to rapidly transform the country from an agrarian economy into a communist society through rapid industrialisation and collectivisation, as previously introduced. It urgently called for a rapid development in both industry and agriculture. As a result, the standardised industrial model was further promoted in this campaign.

In Liu's designs, the pre-reform industrial identity in the planned economy can be detected in the educational building of the Sculpture Department of the Sichuan Fine Arts Institute and Sichuan Fine Arts Institute New Campus (Chongqing, 2003). It is one of Liu's operations in the industrial architectural language of Mao's era in post-Mao designs. The educational building of the Sculpture Department (Chongqing, 2003) is dignified and strong, and it was designed to suit the surrounding industrialised scenery that was left by the great industry era in Chongqing (Figure 3.1). The Sichuan Fine Arts Institute New Campus (Chongqing, 2003) in a suburb of Chongqing is a more sophisticated project echoing this reference (Figure 3.2). The site of the New Campus rests prominently on the top a hill. Lying along the slope, the whole complex is broken into parts and divided into different volumes. The architectural complex is composed of seven multistory buildings. The west, south and northeast ends are respectively topped by a vault roof, a pitched roof and a V-roof, which imply a prototype of industrial architecture. This is different from the general industrial zones, where buildings are arranged in lines, usually with a strong axial arrangement; the whole site was featured with a relatively loose and free site plan. In other words, it is considerate of its connection to the site and was designed to settle along the slope effortlessly, without boldness and straightness, without promoting the unease between the building and the place that can be seen in the old industrial zones. A close examination reveals the slab for the air conditioning equipment, usually hung outside the window, is reversely inserted into the building. As a result, the outside has a certain propensity towards the volumetric, as opposed to the planimetric industrial prototype. But unlike the extreme fluidity and freedom in the plan followed by many contemporary architects, following its prototype, a corridor with bilateral classrooms appears in each building - a well-disciplined and wellfunctional arrangement that gives rise to the volumetric expression in the Maoist standardised design. 


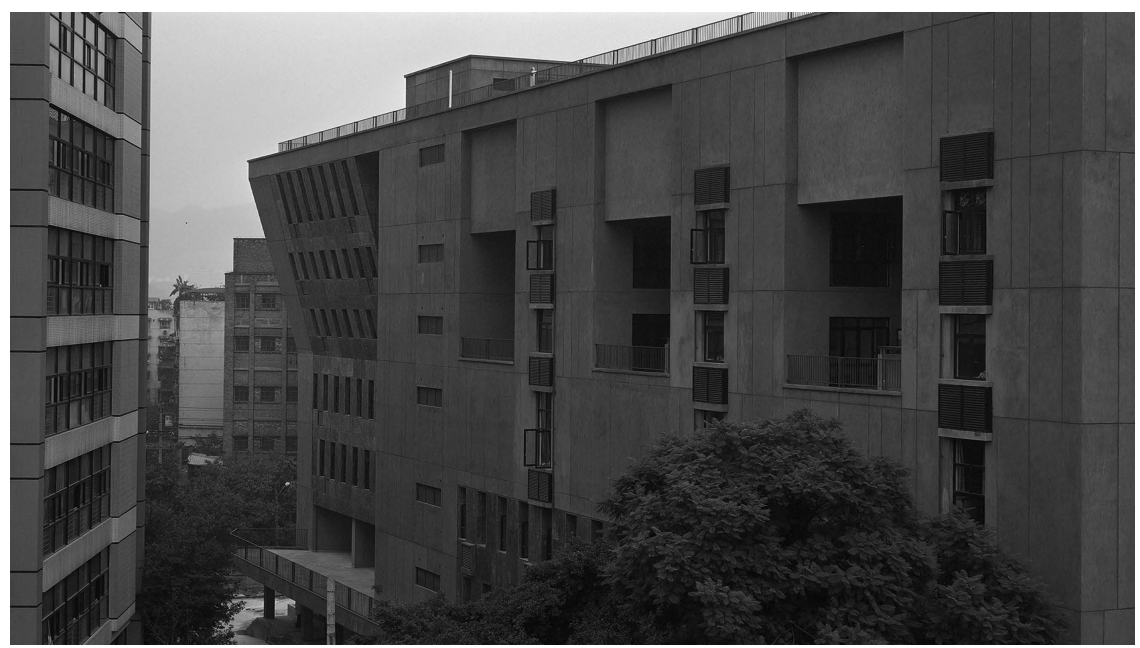

Figure 3.1 Liu Jiakun, educational building of the Sculpture Department, Sichuan Fine Arts Institute, Chongqing, 2003

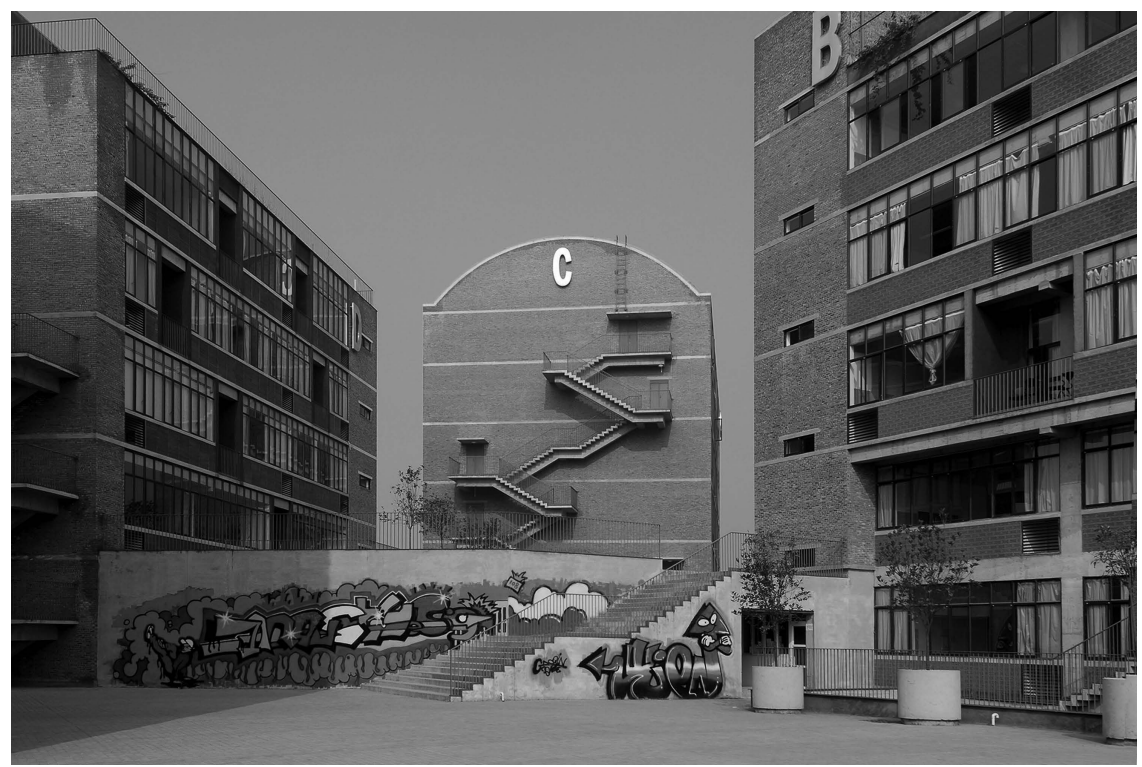

Figure 3.2 Liu Jiakun, Sichuan Fine Arts Institute New Campus, Chongqing, 2003

Another interesting reference looks more direct. The 512 Wenchuan Earthquake Memorial (Anren, 2011) in the museum cluster located in Anren, in the Sichuan province (Figure 3.3), designed by Liu Jiakun, employs the model of the Great Hall of the People, in "Ten Great Buildings". ${ }^{8}$ The Great Hall of the People, 


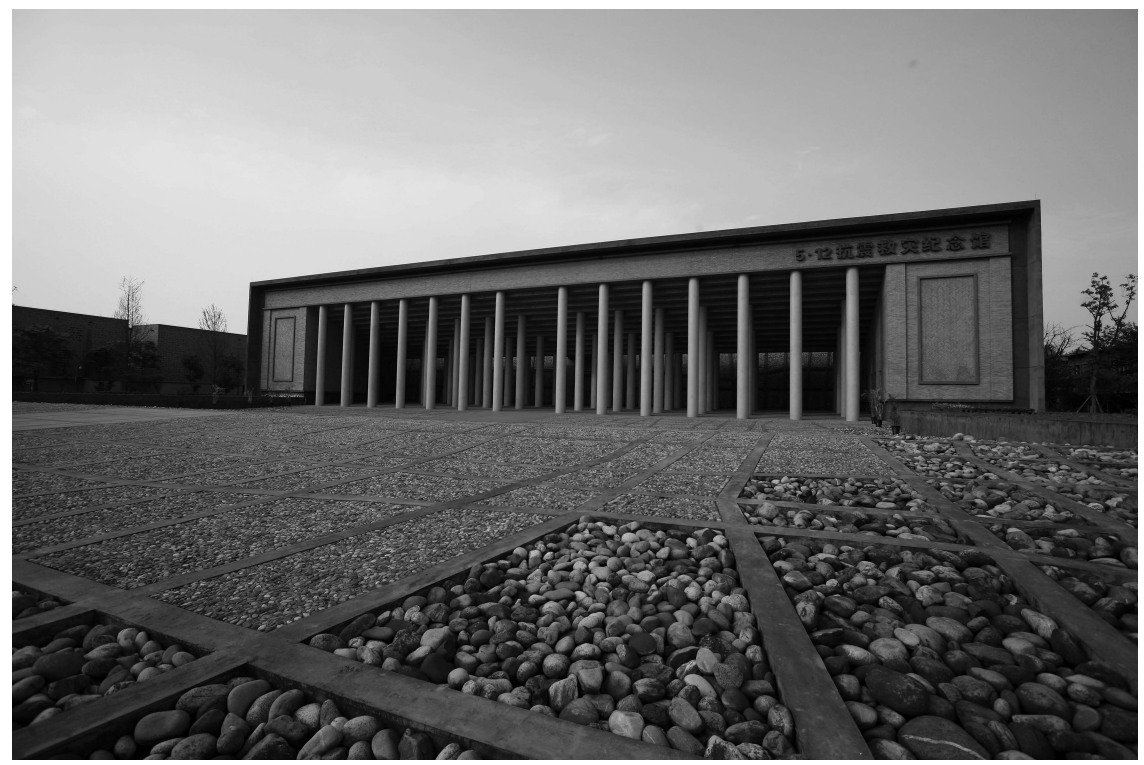

Figure 3.3 Liu Jiakun, 512 Wenchuan Earthquake Memorial, Anren, 2011

designed by Zhang Bo, is located on the Western side of Tiananmen Square. The complex is very large, at 336 by 174 metres; the central building component is 40 metres high. ${ }^{9}$ The central part of the Earthquake Memorial was composed of a portico leading first to a grand entrance hall and then to a large, assembly hall with various exhibition space. The tall and exaggerated columns in the memorial achieve a striking effect in replicating the "Ten Great Buildings". However, it goes beyond direct reference; instead, architectural features are allowed to be self-reflective. For one, the plaza in front of the Earthquake Memorial is not flat. It is slightly wavy, which, although difficult to detect, gives an alternative sense of experience to the grand portico. The sense of the ceremony regarding the nation-state is subtly reconsidered and transformed through the experience of the plaza. It also allows architecture to be an enlightening subject for the public. In the museum cluster in Anren, there are several earthquake memorials of different scales and derived from different ideologies. For example, the Hu Huishan Memorial, which is discussed in greater depth later, more or less represents Liu's individual's voice to an ordinary Chinese individual, Hu Huishan, who died in the earthquake. There is also an earthquake memorial integrated into an exhibition building originally for mirrors in the Cultural Revolution that was reloaded with a first-hand collection of relics from the site by the developer after the earthquake. Liu Jiakun was commissioned by local government to design the 512 Wenchuan Earthquake Memorial (Anren, 2011). It is an attempt to find the abstract stance of the nation-state or government among the diverse ideological positions. 
Another reference can be traced to the Cultural Revolution (1966-1976), yet it is a critical reflection as well. The stated goal of the Cultural Revolution was to enforce communism in the country by removing capitalist, traditional and cultural elements from Chinese society and to impose Maoist orthodoxy within the party. Architecture in the Cultural Revolution stagnated, except in the "Long Live Pavilion (wansuiguan)", where dozens of Mao statues were erected throughout the ten years of Cultural Revolution. The building of a Mao monument was considered a matter of patriotic pride and political necessity. In 1966, Mao possessed enormous moral authority with the Chinese public. People believed that his acts in the Revolution, and the establishment of socialism, were motivated for the good of China. The Mao cult grew from this spontaneous respect, which radicals then manipulated for political advantage. ${ }^{10}$ Mao's words were quoted in newspaper editorials, by the nation's intellectuals, and they were even used as decoration in architecture. Instead of making a sharp contrast between a good China and a bad China, as most of the Western media attempted to do, Kraus drew out the connections between the isolated and beleaguered China of the 1960s and the newly risen global power of today. ${ }^{11}$ He argued that these two Chinas are not opposites. Rather than fence off the Cultural Revolution as a historical swamp, Liu Jiakun architecturally and critically reflects "bad China" in the evolving "good China".

Liu's Clock Museum of Culture Revolution (Anren, 2004) in the Jianchuan Museum Cluster is probably the sole piece of architecture in contemporary China to convey the individual architect's critical reflection on the Cultural Revolution by exhibiting explicit symbols and implicit atmosphere. Mao's statues and Mao's words are applied in the project, like the title, "Long Live Pavilion". The museum uses bright brick and employs several typical classical geometries such as the circle, square and transept to construct a holy space; thus a special atmosphere of singleness, extremeness, purity and fanaticism is cultivated (Figure 3.4). In the banner section, space itself is a closed square front yard. On the top, under a grid, hangs a Red Soldier banner that casts a red shadow into the entire the room. In the middle of the floor stands a black granite inscription. Through architecture, Liu ushered in the most controversial historical period in modern China.

By analysing these selected works of Liu, it can be revealed how the architect decodes the architectural-aesthetic programme of socialism in the new social context. The fluctuation of architectural aesthetics during the pre-reform period was associated with a brand of architectural characteristics introduced by Soviet experts in 1949 that subsequently justified the Ten Great Buildings project, begun in Beijing in 1958 and the Cultural Revolution (1966-1976), among other ideological slogans and campaigns. Arguably, Liu Jiakun's designs architecturally formulate a context necessary to reflect socialism under the planned economy, which was a significant, though too often unilaterally forgotten, part of Chinese history. But China is one of the world's oldest civilisations. It has a long and complex history - with records dating to around $1600 \mathrm{BC}$ at the founding of the Shang dynasty. The question that arises is what makes Liu Jiakun have this personal and unusual choice, different from his peer architects, in confronting the long and complex history of his country. 


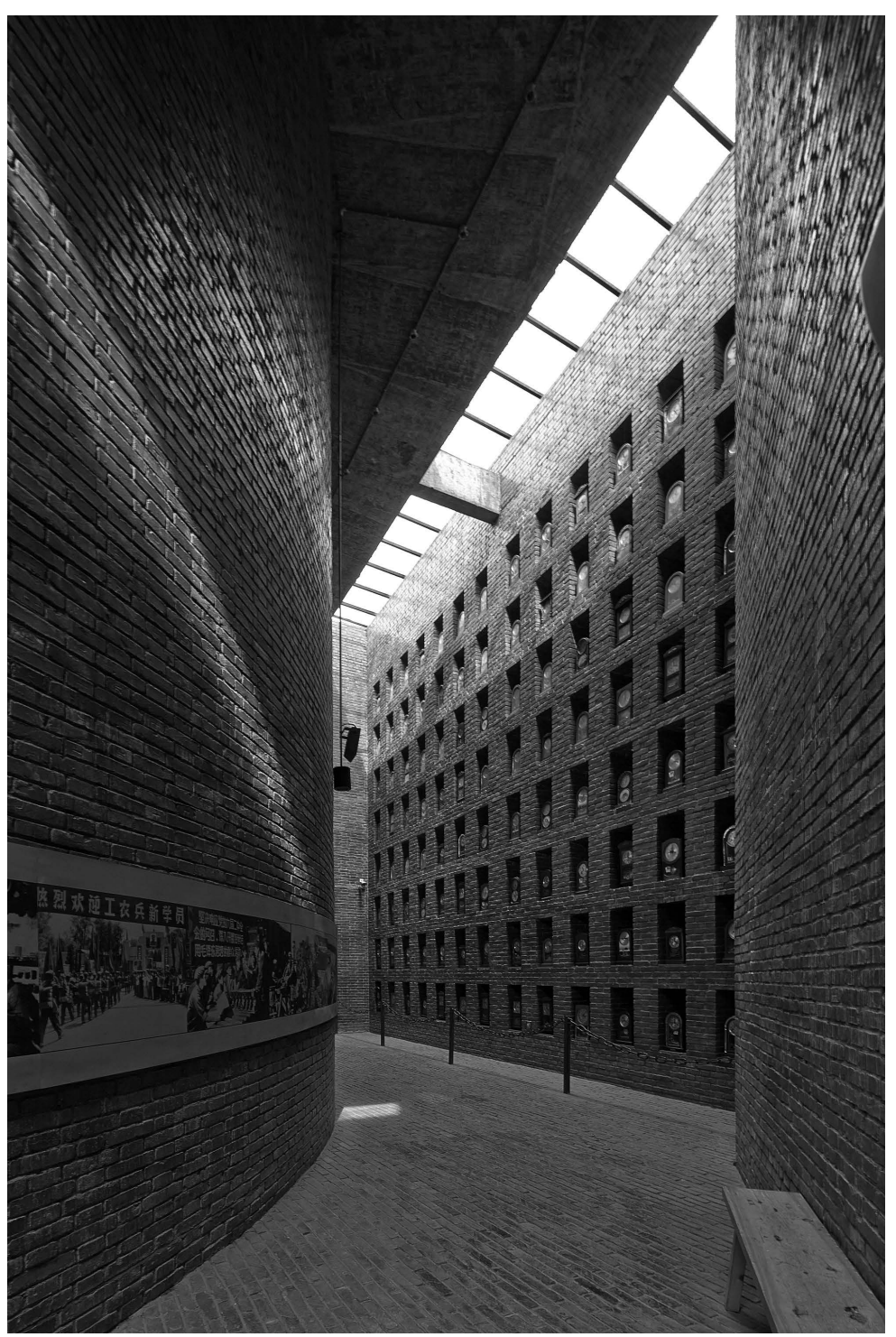

Figure 3.4 Liu Jiakun, Clock Museum of Culture Revolution, Anren, 2004. Clock exhibition space

\section{- The everyday urban landscape of China: Mao remains potent}

Chongqing, which houses many designs of Liu Jiakun, has a 3,000 year history. The Ba people, ancestors of today's Chongqingese, established Jiangzhou as the capital of the Ba Kingdom in about $1000 \mathrm{BC}$. The Ba people were traditionally good at shipping, textile production and agriculture, and by the time of the Qin 
Dynasty (221-206 BC), Jiangzhou was becoming a centre of transportation, business and agriculture in southwest China. ${ }^{12}$ As the wartime capital of China during the Second World War, Chongqing developed into a modern industrial city in the 1940s. ${ }^{13}$ After the founding of the People's Republic of China, the development of Chongqing was accelerated in the 1960s when the policy of the "Third Front (San Xian)"14 construction was carried out by the central government. Under the policy, a number of defence-related enterprises were established in and around Chongqing. For instance, from 1964 to 1965 , more than sixty state-owned enterprises under fifteen sectoral departments of the central government moved their factories from more than twelve cities and provinces, such as Beijing, Shanghai, Nanjing and Liaoning provinces, to Chongqing, with 46,000 workers migrating to the city and 200 key projects established. ${ }^{15}$

The architectural style of the Sichuan Fine Arts Institute New Campus (Chongqing, 2003) is closely related to the industrialised city image in the Soviet model under the planned economy. Whereas the new buildings being constructed in Chongqing are dominated by a novel and modern language that address the era's aspiration, the building in the Sichuan Fine Arts Institute New Campus incorporated a whole series of elements that clearly had their origin in Maoist Chongqing and standardised industrial design. However, contemporary architects often refer to ancient China in their designs through either nostalgia or novelty. What makes Liu Jiakun choose the pre-reform modern history of China as an element in his architecture? What is the contribution of this choice to the identity of his architecture?

Liu Jiakun himself does not have an accurate definition of socialist architecture, because he was on the outskirts of architectural design for ten years after he graduated, and he did not have an overseas education, as did most of the active practicing architects in China. His works are fully integrated in real observations of everyday life in China and have a more accurate definition of the real local identity of Chinese cities, which governs his choices. Liu has said,

I am not against the preservation of historical districts or historical architecture, but if you take a real look at this city that covers such an extensive area, you take a bus from Zhuge Liang Memorial Hall ${ }^{16}$ to Kuangzhai Alleys, ${ }^{17}$ but ignore the area between two visiting spots. ${ }^{18}$

This remark suggests the question proposed in the beginning of this chapter: what is the role of the socialist period in the formation of localisation of Chinese cities? What does the city look like between the Zhuge Liang Memorial Hall and Kuangzhai Alleys, both of which are preserved and renovated tourist hotspots?

After 1990, China experienced a major transition as a consequence of the adoption of a market-oriented paradigm. It is true that Beijing, Shanghai and Guangzhou have activated a process of altering their urban images to a new, economically refined vision invested primarily in skyscrapers, which particularly conjures up Western ideals. However, "all that is solid melts into air"19 should be "all that is solid seems melting into air". But the effect of these images is usually limited to the cities' central business districts and tourist hotspots, while 
the aesthetic programme of socialist China still holds sway over the other parts of modern Chinese cities. If the world sees that Paul Andreu's National Centre for the Performing Arts, Zaha Hadid's Guangzhou Opera House and Herzog \& de Meuron's Bird's Nest, as well as the myriad gargantuan, newly erected highrises, have reformed the skyline of major Chinese cities - and thus their municipal images - the distinct architectural characteristics wrought by socialist thinking after the Communist Revolution in fact remains potent in the architectures and urban landscapes of real Chinese cities where most Chinese people live. Even in the late 1980s and early 1990s, China's modern city remained a city with the primary features of Chinese design standardisation, mass production and systematic construction, which were characterised by grey exterior walls, concrete and masonry, red brick, pitched gable roofs and other simple motifs. It is imperative to clarify that the majority of the urban population are living in second-tier or thirdtier cities, and until now it is difficult to think about China and its cities without a certain residential type in the work unit and industrial sector images immediately coming to mind. The destruction of many large historic urban districts for new urban development is actually erasing the once-elegant urban patterns of the imperial era of China.

The reasons why Maoist architecture, urban landscape and construction models remain potent even in contemporary China's urban identity may be summarised into these points. First, the belief "fast design and fast construction" was deeply entangled with the architect's attitude and approach. It no longer means: the faster the design task is completed, the more loyal to the party the architect is considered, but it could be argued that the model in the Great Leap Forward and violence in the Cultural Revolution have been inevitably inherited in the haste of current construction.

Second, the influences of Soviet architectural theory and an advocacy of "socialist content and national form" or "cultural form and socialist content" delivered by official design institutes in China have been developed into systematic design principles. For example, in order to make better use of land and decrease construction costs, the increase of depth and reduction in width are naturally adopted as design principles. In addition, a concrete framework with a brick wall structure that reduces the consumption of steel and cement has been broadly accepted. According to the advice from the Soviet advisers, building five stories was the most economic strategy. This resulted in many apartment-style housing units with five or six stories built in concrete and brick, even in the 1990s. Inside the building, some architects were advised to abolish the living room and replace it with a hallway of smaller area.

Third, in 1979, thirty years after the founding of the People's Republic, China was taking stock of itself. Up until the communist takeover, 100 years of contact with the West, conditioned by the unequal treaties, had brought little in the way of modernity to China or economic benefit to the great bulk of its population. ${ }^{20}$ Xiaoping Deng memorably summed up the spirit of the times and the urgent demands of the times with his comments that "it does not matter if the cat is black or white, as long as it catches mice!" 21 supposedly uttered in justification 
of adopting some of the approaches of capitalism in pursuit of what was still said to be the goal of socialism after 1978 . Hence the fastest way to "catch mice" in accommodating the rising population is to produce a set of standardised designs which could be used on different sites with minor adjustment. At the same time, standardised design can reduce building costs and the consumption of construction materials and control spatial efficiency. Therefore, Maoist architecture, urban landscape and construction models remain potent even in contemporary China's urban identity. It could be argued that Liu's choice in this period of history created an architectural conjuncture, an architectural integration into the everyday urban landscape.

\section{- Confronting the psychological burden of Mao}

Yet his designs' engagement with the everyday urban landscape, and the local identity of Chinese cities in China, creates a contested identity with the glorious, ancient part of Chinese history that both the government and the people are interested in. In other words, the real everyday urban landscape is something both the government and people feel reluctant to face. As Porter wrote,

Life under the People's Republic for the first thirty years brought its own hard lessons: that personal rivalries and struggles for power are just as likely under the Communist Party as among the transitional warlords or in the Imperial courts of the dynastic era; that despite offers of aid from apparently friendly states, taken up for a while, China ultimately stands alone and must never abandon its quest for self-sufficiency in all things essential to its way of life; that ideology and political commitment cannot ultimately solve China's problems, and indeed can rapidly become a blight on the discussion of policy alternatives, and even worse, an excuse for acts of violence and great inhumanity. All Chinese carry this psychological "baggage" with them into the latest phase of modernization. ${ }^{22}$

Facing the materialised and concrete subject existing in most Chinese cities, Chinese people are inclined to ignore it, and no sophisticated words can adequately account for the psychological complexity of Chinese citizens. Chinese people, as they find it, have little interest in examining the link between Maoist China and the country today. They avoid awkward discussions about their own youth, and they adhere to an unspoken understanding to discard recriminations from that period. ${ }^{23}$

In regard to architecture and urban landscape, when standardisation became a powerful tool in socialist urban planning and architecture of equality to create a classless and moneyless social order structure, in urban planning and architecture, and the result was an undifferentiated urban landscape. The simplified design actually ignored the unique feature of architecture by removing the processes of the preliminary design and design development, which are the most creative and essential components of architecture. People became bored with the standardised design, which is fixed in form and sometimes monotonous in content. 
Psychologically, decades of civil unrest, poverty and ideological revolution had left China's cities ill-equipped to serve the needs of their residents. "If there was one thing on which almost all of China's people agreed at the end of the 1970s it was the cost in emotional, psychological and even physical distress of the methods used during the Cultural Revolution was too great to be sustained or repeated." 24 Hence the value of the modern metropolis has become especially meaningful for Chinese people. Furthermore, in the global political domain, socialism in China has been intensely scrutinised by the capitalist world, since the socialist spirit in the former Soviet Union, East and Central European countries collapsed. The value of socialism is hard to express in a world dominated by capitalism. Chinese people are still at a loss in understanding the socialist political system. Last but not least, with such a high speed of growth, it is also difficulty to assess and identify the underlying forces in the political, cultural and economic changes in the contemporary context.

Therefore, the psychological reactions of Chinese people to pre-reform China, and even to the characteristics of their architectural heritage, is far from straightforward; it is erroneous to think that they merely feel urged to have the lifestyle with the same logic of individual human rights that infuses some of the critiques of Chinese socialism. As summarised in Chapter One, the majority of architectures in contemporary China enthusiastically adopt modernisation in novel architectural forms and use technology as the language of development, thereby striving to create new images for modern Chinese cities in order to satisfy both the government and the citizenry's imagination of entering a new world. In Liu Jiakun's works, it could be further argued that they have a contested identity with psychological complexity and imagination. Here, architecture unconsciously becomes a psychological medium to urge Chinese people to confront themselves. While addressing the architecture of Liu Jiakun in detail, it should be noted that the familiar sense of architecture created by the architect parallels the perspective of people, rather than that of the state, yet it does not evoke the people's sense of feeling awkward about their own youth.

Architecturally, comparing the systematic design principles and outdated aesthetics in the architecture that survives from the pre-reform period with the novel forms being constructed in today's China seems to elicit memory loss. Liu Jiakun's awareness of a new way of manipulating the folk language evinced in his architecture, as well as his awareness of the dynamic use for sustaining the collective memory of contemporary Chinese people, makes these designs substantially different from their prototypes. For example, in the design of the new campus of the Sichuan Fine Arts Institute (Chongqing, 2003), the strong socialist and industrial presence in the buildings appears not only in certain architectural elements - red brick, sand plaster, a vaulted roof - but also in its systematic linguistic improvement. Both the particularities and the total design language show innovations in assemblage by recasting architectural elements from the Maoist period to achieve a contemporary presence. The tension between the industrial atmosphere and dynamic space, manifested in this exhibition space, finds an echo in the wooden case wrapping the obsolete industrial column, in the manner of 
decoration and a vehicle for exhibits, and allows it to be a visual centre with an advanced industrial sense. In addition, the construction is of a deliberately coarse quality, with cracks on the walls and staircases, and disorderly cement plaster. This is evidence of the architect's manipulation of the coarseness and ordinariness of the construction, and it is even more industrially provocative than the drawings and models had expressed.

It is impossible to determine whether Liu had considered the influence of the past in his design for the project, but the effect of lapsed time emanating from the accumulated drawings by students on the buildings' surfaces, as well as the easels and canvases haphazardly placed on balconies, are naturally synthesised in the front to showcase the verisimilitude of such chaos. Instead of being easily punctuated by everyday life as some other architecture, the seven multi-story buildings of the Sichuan Fine Arts Institute (Chongqing, 2003) incorporate everyday life experience and further demonstrate the special stamp of the architect's language. All the contradictions that the buildings incorporate are finally transferred to the sphere of everyday life.

\section{Architect and artist in the market: Liu Jiakun and Zhang Xiaogang}

Zhang Xiaogang is a contemporary Chinese symbolist and surrealist painter, and he is also an intimate friend of Liu Jiakun. In 1993, one of Zhang Xiaogang's works sold for a record high \$2.3 million in Hong Kong. However, in the same year, Liu was considering abandoning his architectural career. ${ }^{25}$ Liu came to the foreground of public attention after 1999. Zhang's artistic life runs parallel with the development of modern art in China, and he experienced many historical turns and transitions including the Cultural Revolution, market socialism, global forces, and economic boom with the opening-up of China to the West. In general, Zhang has experienced the ups and downs era from the pre-reform China to the early market China, which gives the Chinese contemporary art an opportunity to break restrictions and push boundaries. Liu also, in the discipline of architecture, achieves this same quality, but in different shape of waves from the pre-reform China to the early market, which will be explored by comparison with Zhang in this part.

The research concerning Chinese contemporary artists in this transition era has been explored extensively. ${ }^{26}$ In discussions about the individual and the state, the market and the planned economy, Salmenkari has explored how unofficial artists have worked to create a space for innovative elite culture outside both statepromoted official culture and market-driven popular culture. ${ }^{27}$ The author has argued that the non-official artists' strategies require non-state resources available through the market economy. Kraus investigated the artists operating between the state plan and global market in the development of modern art and artists in China. ${ }^{28}$ Andrews and Gao traced the way that the avant-garde movement, which seeks to attack and destroy the traditional order in China with the ultimate goal of attaining artistic freedom, challenges official art. ${ }^{29}$ Yet the research that crosses various disciplines 
is still missing, requiring interdisciplinary perspective and comparative study to see the trajectory of artists and architects and milestones of the disciplines within the tension from Mao to market under a socialist conceptual framework in China. A brief look at Liu and Zhang's life trajectories in the changing society allows a comparison that will answer the questions: What were the social and historical factors constituting the turning point in their careers from Mao to early market? What led Liu to a more individual creation? How did their attitudes towards the market change in the progression to a society dominated by the market? To what extent does the government still control art and architecture in China?

\section{- Life trajectories, 1950s-1990s}

Liu Jiakun was born in Chengdu in 1956. His parents were doctors in the local hospital. In 1982, he earned his degree in architecture from the Chongqing Institute of Architecture and Engineering. He was then assigned to the Chengdu Architectural Design Academy, while also working as a freelance author. He represented his work unit, Chengdu Architectural Design Academy, to help and support architectural design in the provinces of Tibet from 1984-1985 and Xinjiang from 1990-1992. While he designed a few art studios for his old artist friends that later added to his reputation, he also went through practices in some large-scale public architecture, such as Chengdu Sheraton Hotel $\left(1996-1997,78,000 \mathrm{~m}^{2}\right)$ and Chengdu City Art Centre (1996-1998, 29,000 m²). When Liu Jiakun was considering abandoning his architectural career, he was invited to the Shanghai Art Gallery to attend his schoolmate Tang Hua's architectural exhibition and a 21st Century Culture Symposium at the same time. He was impressed by the schoolmate's achievement in architecture, and this marked Liu Jiakun's real start in the architectural area. In 1997, he resigned from the Chengdu Architectural Design Academy and collaborated with the Beijing Sanlei Architectural Design Ltd. The year 1999 marked a significant change in his life, when he earned the Registered Architect Certificate and established Jiakun Architects.

Zhang Xiaogang was born in Kunming in 1958, the third of four boys. His mother Qiu Ailan and father Zhang Jing were employed as government officials. In 1963, his family moved to Chengdu in China's Sichuan Province. Lin Ling, a Chinese watercolour painter, trained Zhang in 1975, teaching him formal watercolour and sketching techniques. In 1976, Mao's death and the imminent arrest of the infamous Gang of Four heralded the end of the Cultural Revolution. Entrance exams were reinstated for the newly opened colleges and, in 1977, Zhang gained admission to the prestigious Sichuan Fine Arts Institute in Chongqing. ${ }^{30}$ After a ten-year hiatus from education, he entered the college as one of a group of extremely talented young artists. In 1978, he began his studies in the oil painting department. ${ }^{31}$ In 1982, Zhang graduated with a bachelor's degree from the Sichuan Fine Arts Institute. Although his work had received support from the independent art critic Li Xianting, Zhang was not offered a teaching post at the university, as he hoped. The next three years (1982-1985) - which he later referred to as the dark era in his life - represented a period of great uncertainty 
for Zhang in which he struggled with depression, although he continued to grow and develop as an artist. ${ }^{32}$ In 1992, Zhang travelled to Germany for three months, where he encountered firsthand many of the Western art works he had admired through art books and journals. Although when he returned filled with enthusiasm for the paintings of German artist Gerhard Richter, Zhang was disappointed with what he thought was the stale air of wealth and opportunity of the West's avantgarde. The art show hosted by the Hanart Gallery in 1993 declared that the new art from China was not just going to remain underground - it was also going to break new ground..$^{33}$ In 1994, Zhang Xiaogang showed his "Bloodline: The Big Family" series in the 22nd International Sao Paulo Biennial and in the 1995 Venice Biennale. Zhang as an individual artist became a best-selling contemporary Chinese artist and a favourite of foreign collectors from the early 1990s.

\section{- Establishing themselves in the new commercialised power}

In these two stories, the emerging market was the new site for the latent commercialisation that gradually provided alternative resources for the unofficial architect and artist. A Chinese art market based on the Western and Japanese models was created in the early twentieth century, but it was abolished in 1949 when the People's Republic of China. ${ }^{34}$ In the People's Republic, since the end of the Cultural Revolution and the death of Chairman Mao in 1978, the art world has been embroiled in a mesh of alternating political relaxations and tensions in the name of modernisation and party control. ${ }^{35}$ The architecture market followed a similar path as the art market. In the 1990s, in respect of the private sphere, there were no restrictions on private artistic creation or the launch of the private architectural firm. The authorities had little interest in paintings kept privately in homes or studios run by the private architect. Therefore, markets have been useful to unofficial architects working in the private architectural firm and artists, by providing a new medium for obtaining contracts or auctions, and new aesthetics associated with positive acceptance in the domestic market have been gradually established which show a departure from the official aesthetic standards of the past.

Exhibitions are still the most important platform for both artist and architect to let the market see them and make connections, transforming the artist and architect into celebrity status. In the early 1990s the series "Big Family" was shown in a range of international exhibitions including Chinese New Art from post-1989 in the Hong Kong Art Centre (1993), the 22nd International Biennial of Sao Paulo (1994), the 46th Venice Biennial in Venice (1995), China New Arts in Vancouver (1995), Chinese Contemporary Art in Hamburg (1995) and Des del Pais del Centre: avantguardes artistiques xineses in Barcelona (1995), and these facilitated Zhang Xiaogang's striking mark on the international scene. Around the late 1990s, Liu Jiakun began to make an impact through exhibitions inside and outside, including Chinese Architects Experimental works exhibition in Beijing initiated by Wang Mingxian (1999), Construction Document Exhibition of Five Persons in Shanghai's Dingceng Gallery (2000) and Chinese Young Architects' Work Exhibition in Berlin (2001). 
From the early 1990s, it could be argued that Chinese contemporary art was at least five years ahead of Chinese contemporary architecture in the creation and dissemination of the new reputation and values in both the internal and external market. Zhang Xiaogang's transition occurred quickly from hostility towards regional politics and cultural institutions to a self-reflective and more individual condition; from an instructor in the Education Department of the Sichuan Fine Arts Institute to an independent figure in many international exhibitions in the 1990s, until he gave up teaching and left the Sichuan Fine Arts Institute in 1997. In the architectural scene, Liu Jiakun received attention in the late 1990s through exhibitions as it became clearer to detect the market-oriented direction of economic privatisation in the field of architecture. He submitted his resignation to the Chengdu Architectural Design Academy and then established his own architectural firm in 1999. Unlike Zhang, his participation in the exhibitions was probably not driven by the desire and possibility to garner instant celebrity status overseas, because China was not a politicalised icon on the international scene in the late $1990 \mathrm{~s}$, but the West was still far from a two way communication with China. Liu Jiakun quoted a sentence from the movie Isabella in describing this situation, "It is not that I look down upon you, it is that I cannot see you." ${ }^{36}$ Hence it could be argued that the abrupt changes of artists were partially due to the country's political history and outside world's curiosity for this "other"; however, the mild changes in attitudes towards architects were more related to the localised development of the discipline within China, which finally flourished in the global geography in the 2000s.

Zhang Xiaogang is included in most of the selections featuring contemporary Chinese artists' works in colour photographs. China! New Art \& Artists by Dian Tong and The Revolution Continues: New Art From China documented a collection of new Chinese art which was presented on the eve of the opening of the new Saatchi Gallery in London's Chelsea; both used Zhang's paintings in his "Big Family" series as their covers. It indicates that he is an international celebrity in the contemporary art scene. In the early 1990s, when exhibition venues and art collectors were located almost exclusively abroad, the contents of the artworks were often planned for Western audiences. At that time, the Chineseness in the artworks was usually shallow. Installations with Chinese calligraphy or silkworms, or pop paintings of Mao, used symbols of Chineseness obvious to even those who knew little about China, and combined them with Western art forms. ${ }^{37}$ In the 1990s, much of Zhang's recognition came from abroad. Generally speaking, Zhang Xiaogang's works were displayed in various Western countries at a time when China was partially concealed.

As demonstrated by Salmenkari, unofficial artists have worked to create a space for an innovative elite culture, and sometimes a counterculture, outside both state-promoted official culture and market-driven popular culture. ${ }^{38}$ Although both Zhang and Liu have experienced problems in mapping themselves into the context of new commercialised power, Liu did not consciously align himself with elite culture or counterculture in operating within the commercialisation during the early 2000s, partly due to the limitations of the discipline of architecture. In the twenty-first century, their works have moved away from appropriation of and deviation from Maoist ideology and entered a new stage of self-discovery, rather 
than reacting to the country's political history. In spite of the immature domestic market and long-time political upheavals in the past that made them occasionally uncertain about their individual existence in the long-term collective umbrella, neither Zhang nor Liu are conscious of aligning themselves with or against the large-scale political, ideological campaigns from this period. However, even some politically sensitive projects, for example, the Hu Huishan Memorial, Liu Jiakun's connection with international peers - the influential architects participating in the international exhibitions held in China - give him greater opportunities to be invited to deliver lectures overseas, gain more online support, and thus mitigate the risk of being attacked by the Chinese government.

\section{- Similarities in their works}

As an intimate friend of Zhang Xiaogang, Liu Jiakun was regarded as capable of materialising the distinctive spirit of stupor, nervousness and surrealism in Zhang's paintings in the design of the Art Gallery of Zhang Xiaogang (Chengdu, 2008). The whole art gallery is the result of gathering several geometric spaces that gravitate towards a dynamic shape. Each volume intrudes into other spaces and concedes some of its lively spirit to the shadows cast by the shape outline. Inside, as the dimensions of the space voids are extended into a number of angles, accompanied by multi-angle light, space itself has an unsettling effect on visitors to the gallery (Figure 3.5). This art gallery can be considered to be a collaboration between Zhang and Liu from the perspective of both art and architecture - in

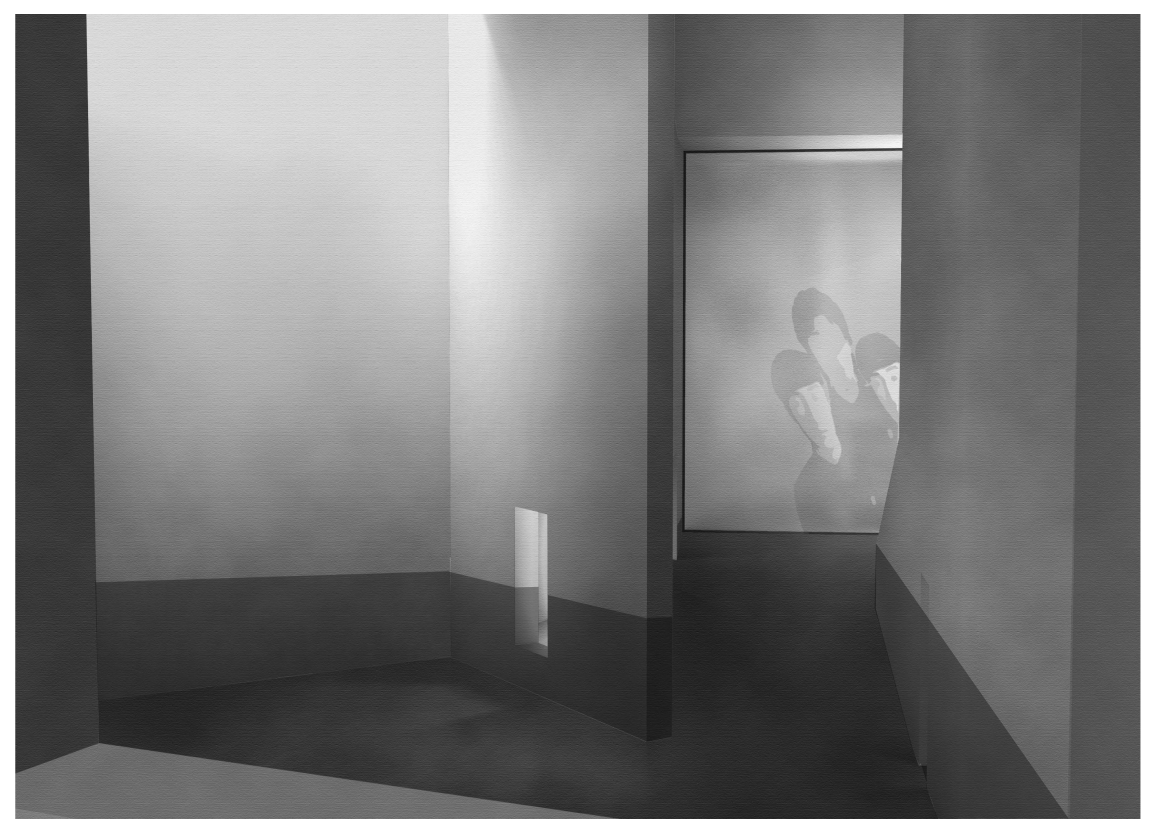

Figure 3.5 Liu Jiakun, Zhang Xiaogang Art Gallery, Chengdu, 2008 
achieving a surrealist space, and in achieving dream-like distortions architecturally that reflects a complex psychological dimension of Zhang's work.

Zhang Xiaogang's paintings themselves were embedded in the thinking about the anxiety between public veneer and private vulnerability, official doctrine and personal conscience. His trademark paintings, the "Big Family" series, make viewers sense the strong uniformity of the figures depicted, but at the same time, they also have some unique characteristics that challenge the utopian idea of an organic collective. Paintings in this series are often monochromatic, stylised portraits of Chinese people, usually with large, dark eyes, posed in a stiff manner deliberately reminiscent of family portraits in the Maoist period. Zhang's paintings were inspired by family photos from the Cultural Revolution, as well as the European tradition of surrealism. Zhang said,

For me, the Cultural Revolution is a psychological state, not a historical fact. It has a very strict connection with my childhood, and I think there are many things linking the psychology of the Chinese people today with the psychology of the Chinese people back then. ${ }^{39}$

His paintings convey a standard Chinese family, but actually question the notion of identity within the collectivism attached to the "Big Family", especially in the Maoist period. Each individual was destined to live in Chairman Mao's great revolutionary family in that period, where all individuals were brothers and sisters, irrespective of traditional family ties. Similarly, as I have discussed previously, Liu Jiakun's architecture legitimises a new dynamic based on the architect's reinterpretation of the collective memory in the Mao era, even if that means recalling a collectively traumatic past. Are there any similarities in their work, even if one is an artist and the other an architect?

The popular strategies of developing the collective theme in China are often very close to those traditional and federal styles, for example, the red lantern and Chinese traditional furniture. Meanwhile, the influence of surrealism, expressionism, minimalism and phenomenology imported from the West in Chinese architecture are especially noticeable. Zhang Xiaogang was not using obvious symbols of Chineseness, but his ambiguity in the object of resistance seems even more attractive to the West than the straight narrative of the communist past, pop Mao or the excesses of unregulated capitalism. Zhang Xiaogang's main reputation comes from the "Big Family" series, in which he superimposes the concept of family over the ideology of collectivism in China. In this series, one can easily sense the strong uniformity, yet it is also challenged by some subtle differences between these figures in the paintings (Figure 3.6). The expressionless eyes of the figures in Zhang's paintings can be seen as a motif that mocks the exaggerated tendency that Chinese culture attaches to the importance of the collective; however, the otherness of political collectivism and individualism emphasised by the West were somehow translated as an expression of political opposition, which all attracted the Western buyers of Chinese contemporary art who have been consistently fascinated by work that expresses political opposition. The motif 


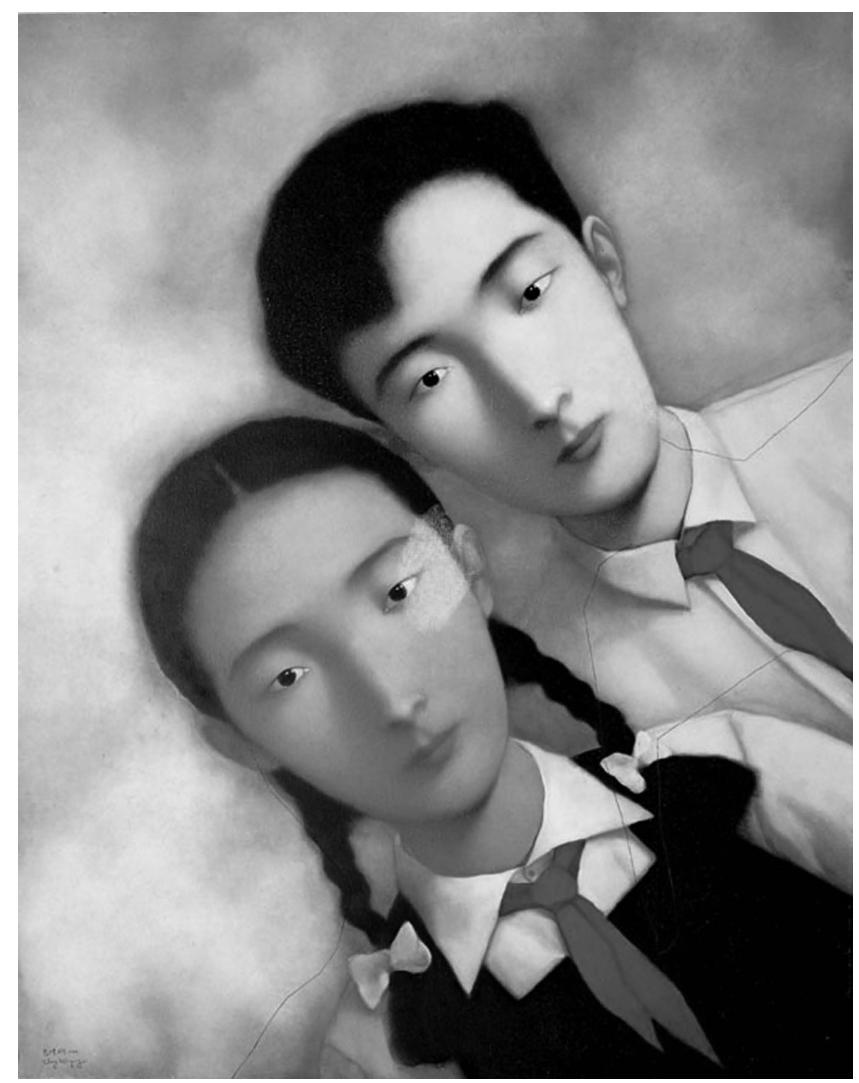

Figure 3.6 Zhang Xiaogang, Bloodline-Big Family No.3, 1996

representing Chineseness, chosen by Liu Jiakun, mocks the exaggerated tendency that the everyday urban landscape of China is attached to Mao, which neither the state centre nor the Chinese citizens are willing to face in the twenty-first century.

Chang tried to explain the concept of family in the context of communist China in tune with Zhang Xiaogang's paintings:

We all live "in a big family". The first lesson we have to learn is how to protect ourselves and keep our experiences locked up in an inner chamber away from the prying eyes of others, while at the same time living in harmony as a member of this big family. In this sense, the "family" is a unit for the continuity of life and an idealised mechanism for procreation. It embodies power, hope, life, envy, lies, duty and love. The "family" becomes the standard model and the focus for the contradictions of life experiences. We interact and depend on each other for support and assurance. ${ }^{40}$ 
Therefore, the memories of collectivism encapsulate many youthful memories, although many of them were traumatic memories, central to their practice, and continue to inform their careers. In their work, there are symbolic aspects not perceived by the senses, which distinguish the works from superficial aspects of painting or buildings such as novel colour, form and texture. Liu Jiakun and Zhang Xiaogang's works produce a different discourse and visual effect, partly because of a more precise awareness of Chinese modern history when collectivism was central to everyday life. In their works, one can see a willingness to explore the socialist cultural realm. In the era of collectivism, individual architects and artists adapted to and interpreted this mysterious code set by the party.

Furthermore, Zhang Xiaogang and Liu Jiakun's works show their capacity in polishing and consolidating the collective memory in architectural or painting details. For example, in the Zhang Xiaogang Art Gallery (Chengdu, 2008), in the treatment of the landscape, environmental elements constituting the everyday landscape from pre-reform China until the 1990s, such as, telegraph poles, round pools, fragments of brick wall and lines of cypresses, blend with typical signs of the era; roof yards as the relic of grim days, and gazeboes with trees are re-used. In this way, a contemporary sense and a historical depth of collective memory to get a surrealistic environment loom upon a rough and determined sensational environment. In Zhang Xiaogang's paintings, the comrades hide their individual personalities and histories behind the façade of a standardised portrait. Lacking a specific gender, they appear so similar that we are forced to search for subtle characteristics. Zhang's extended family conveys individual identity through their unalterable physical features: too big heads, tiny hands, long noses and subtle alterations in hairstyle give clues to intimate characteristics and stifled emotions. Incorporating the collective memory of their youth, their art styles finally waver between the exaggeration of animation and stoic flatness, neither provocative nor feeble.

\section{Untamed architecture}

Liu Jiakun is one of many influential contemporary architects in China. His schoolmate, Tang Hua, recalled that "Even though many years have passed; they still remember when Liu Jiakun recited the poems in the dark dormitory at night. The most memorable one is A Psalm of Life written by the American writer Henry Wadsworth Longfellow." ${ }^{41}$

The Department of Architecture in Chongqing Institute of Architecture and Engineering where Liu studied is located in Chongqing, an inland city of China, and it is one of the most prestigious architectural schools in modern China. It differs from the schools of architecture in Tongji University, Tsinghua University and Dongnan University, in that there is no dominating tradition or agenda in the architectural discourse. Liu's seemingly indifferent and casual attitude towards architecture was partially due to the fact that he was educated in a less strict tradition with a less systematic architectural curriculum. Liu Jiakun describes his own undergraduate period in these terms: "Everything could be tried from the 
very beginning, but everybody felt at a loss with what they tried in the end." ${ }^{42}$ Therefore, to him, architecture was not limited to any one school. Such an attitude led him to think that learning architecture could lead to its own epiphany in selfexploration in the new cultural, political and ideological context of China.

When Liu Jiakun was an undergraduate student in the university, young students' long-suppressed desire for a new life was a reaction to ten years of Cultural Revolution. In 1979 and 1980, a total of sixteen exhibitions of work in the avantgarde styles were held in Beijing, Shanghai and Xi'an..$^{43}$ During the mid-1980s, as government attitudes encouraged intellectuals to contribute to society, the social and cultural influence of Chinese intellectuals increased. This was reflected in an increase in activity in all cultural areas, ranging from university to newspapers to television networks. Moreover, at this time, many intellectuals felt a particularly strong responsibility to the public and believed that official and popular culture could be enlightened through their efforts.

The expression of the humanistic feeling by depicting ordinary individuals came to the foreground in the late 1970s and early 1980s, and Liu was part of that trend. In 1982, Liu entered Chengdu Architectural Academy. Yet he was not so much interested in the architectural design; in contrast, his career as a writer of fiction reached its first peak. In an analysis of Liu Jiakun's novel Hero (1983), Peng argued that the novel is a reflection of his long-term speculation on the relationship between hero and anti-hero. Furthermore, his novel Highland (1984) excited heated discussion in the literary journal Young Writer, in its reflection upon the value of the individual and the individual's relationship to nature, the era, society and the rest of the world. ${ }^{44} \mathrm{He}$ was able to memorise $A$ Psalm of Life, but in my interview when asked whether he clearly realised that life belongs to the individual in his university time, he said,

I did not have much theoretical fundamentals. I was just a young rebel. The period of my rebellion was prolonged by literature and writing. I did not have a clear consciousness at that time. . . I just felt moved by that poem, at that time. $^{45}$

Parallel to the Scar literature in the same period, Liu Jiakun's expression of humanism was more or less following the feeling produced by mental or physical scars. In literature, a specific type of socially critical work that used realist technique appeared: Scar literature, which describes ordinary people's calamities and spiritual wounds caused by the Cultural Revolution. Most of the representative authors of Scar literature were in their thirties and forties at the time; they worked as salaried writers and editors and published their works in state-sponsored literary journals. ${ }^{46}$ They aimed to turn the social realist style back onto itself, highlighting the detrimental effects left behind by the previous decades. But most of them just took over the writing technical legacy of realism and introduced other themes: self-reflection and humanism. From 1975-1978, Liu was sent to the countryside and forced to be re-educated by the uneducated poor peasants in the "Down to the Countryside Movement". During the creation of Hero (1983) and 


\section{2}

Conceiving the modern past

Highland (1984), Liu had been restricted by the doctrines of social realism and isolated from world literature for years; hence, his works were filled with enthusiasm and emotions but weak in profundity at that time.

After thirty years of contemplation and practice, Liu Jiakun's reflection was finally translated into the Hu Huishan Memorial (Anren, 2009) in mature profundity and artistry in 2009 (Figures 3.7 and 3.8). However, in the Hu Huishan

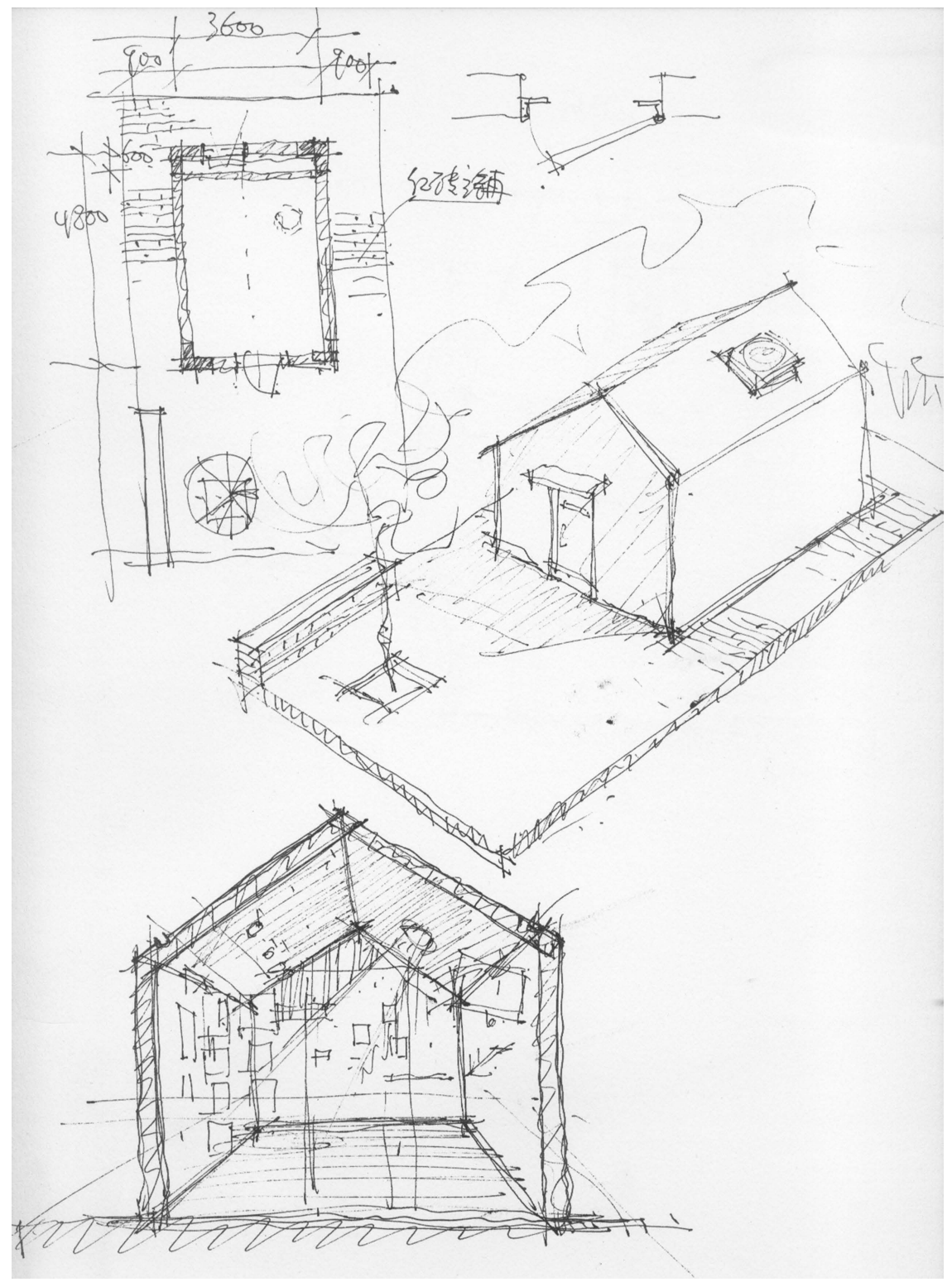

Figure 3.7 Liu Jiakun, Hu Huishan Memorial, Anren, 2009. Sketch 


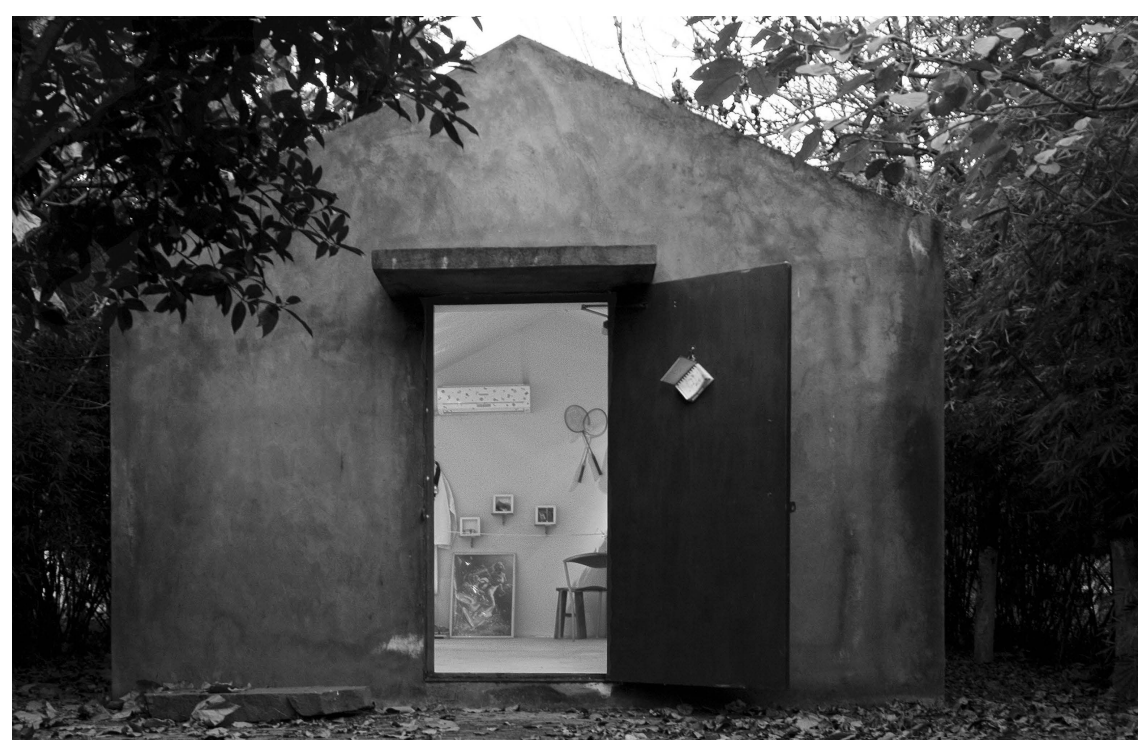

Figure 3.8 Liu Jiakun, Hu Huishan Memorial, Anren, 2009

Memorial (Anren, 2009), Liu takes advantage of the abstract architectural language, in less detailed decoration, and devoid of a direct inscription of the emotion to awaken Chinese people to the relationship between the individual and the nation by memorialising the collective traumatic earthquake of May 12, 2008, Wenchuan. This was one of the most destructive earthquakes in recent decades and occurred in the northern Sichuan province of China. It registered 8.0 on the Richter scale with an eleven-degree quake intensity. Based on the official government announcement of August 7, 2008, the earthquake killed 69,222 people and injured 37,4638, and 18,196 people were missing. In addition, it also destroyed a large number of buildings, house, bridges, and 43,125 km of roadways. ${ }^{47}$

After the earthquake, some memorials, memorial parks and a memorial museum were unveiled under national support to commemorate the lives lost and damage wrought by the Wenchuan earthquake. Cultural centres were also included in the later reconstruction of the cities. The first memorial park that opened in May 2008 included the entire destroyed city of Beichuan, its crumbled and crumbling remains propped up and preserved to serve as a reminder of the tragedy. Bechuan Culture Centre (Beichuan, 2009), which is adjacent to the Earthquake Memorial Park, originated from the Qiang minority nationality's settlement around Beichuan. It could be argued that the shared features of these memorials are their large scale and the same supporters: different levels of government. Hu Huishan Memorial (Anren, 2009) is perhaps the smallest memorial hall among them, which was not only designed but also financially supported by Liu Jiakun. Hu Huishan is neither a hero nor a great figure; she was a 15-year-old girl who was buried in the Wenchuan earthquake on May 12, 2008. The erection of the simple memorial for this third 
year student at Juyuan Middle School touches on ordinary people's values and an ordinary person's dignity. Liu Jiakun wrote for the Hu Huishan Memorial: "This memorial is built for a normal girl, and is also built for all the ordinary lives - and treasuring ordinary lives is a foundation for reviving the nation." This building instantly stirs distinct feelings when contrasted with the other buildings in the metropolis of China: it carries an independent person's spirit and an individual human being's concern about other ordinary people. The natural energy of this building links his thinking on the position of the individual. It is self-expression about the humanist position. It looks untamed.

\section{- The concept of tamed}

Yet most architecture in contemporary China looks tamed. It is imperative to identify the term "tamed" in the contemporary Chinese context. The nation's burgeoning real estate market, which serves up almost every conceivable fantasy and competes relentlessly for new consumers, has thrown into relief the altered relationship between the government and the individual. ${ }^{48}$ Apart from self-expression and a humanistic revival, there is another side in the societal transformation: it also includes private accumulation, self-promotion and self-interest in profitmaking. Especially after the 1990s, some fundamental changes began, as economic reforms in areas such as the privatisation of economic ventures, real estate development and foreign investments led to the transformation of architecture, architectural design and architectural function at every level.

Architecture has become a channel for investment. Building construction has become such a profit-making tool that a building's primary function is no longer to serve human needs. The traditional concepts associated with architecture such as aesthetics, comfortable environment, advanced building technology, and human occupancy have been suppressed to emphasize quantitative measures like construction volume, capital investment, construction time, cost and profit return. ${ }^{49}$

Consequently, the majority of the new architecture looks were somewhat tamed by the modernist authority in architecture, which is the fastest way to enjoy the economic relief offered by the market and accept the new cultures that the market exposes to the architecture. "In general, the average time to construct a fifteenstory and thirty-story concrete building was ten months and eighteen months respectively. The fastest high-rise project has been done in just seven days." ${ }^{\text {50 }}$ Hence, what an architect can do in seven days is usually to mimic any shape or façade of the architecture of Chicago. In other words, they look tamed by the international stylised style which has been promoted by globalisation. They look tamed by the immense amount of investment in the real estate. They look tamed by the excessive demands of the bureaucrats as well, in which many bureaucrats have assumed ambiguous roles as "entrepreneurial" officials-cum-businessmen ${ }^{51}$ in these construction projects, making the architect more lost than ever. They 
looked tamed by reaching their maturity in architecture by introducing a coarseness of architecture into high-speed urbanisation.

To characterise Liu Jiakun's Hu Huishan Memorial (Anren, 2009) as any “-ism” as modernism, brutalism, postmodernism, futurism, is to ignore this conjunction, since the architecture is untamed by any of the "-isms". When architecture has become the most overwhelming activity in contemporary Chinese cities, "to be tamed or not to be tamed" actually provokes continual dialogue in architecture itself between promoting self-expression in architecture and promoting self-interest by exploiting architectural design in contemporary China, especially when most clients are indicating their willingness to pay more money for faster service. In Great Leap Forward, Lin observed that,

Every architecture should have a recipe. Architectural recipes have become indispensable references to every professional architect and student. Existing project or previous designs are recycled with minimum alterations. Designs are processed simply by replacing new labels and "hats," a method that has become the most common for architectural design. "We collect a lot of brochures, pattern books, and projects from Taiwan and Hong Kong, so it is very easy to find a project where I have an entire set of construction drawings," says architect Sun Yimin. ${ }^{52}$

In contrast, Liu Jiakun walked away from the pattern books from which customers are constantly ordering their building designs. Rejecting the architectural elements, languages, styles, forms and standard details in this transitional era to convey an architect's own philosophy, his architecture is trapped between the relaxed self-expression and its unattainable and immature aspects; however, it is also an opportunity offered to architecture itself. Liu never expressly talks about these, but the nature of "untamed" has been reflected in the elements he utilises in his designs, for example, water and light, the materials he chooses purposely for different buildings, the wall as a special architectural component and the experience of space in his design.

\section{- The untamed thread in Liu Jiakun's works}

The untamed thread can be discerned in various elements in his built work, in which water is one of the best examples. The importance of water is well recognised by contemporary landscape planners and designers, but the water features have been further elevated to the human perceptual evaluation of the designed landscapes scenic quality, and the nature of the water has been diminished. In some of the architecture, water has been overexposed and over-intervened. For example, in the Gallery of Horyuji Treasures (Tokyo, 1999) designed by architect Yoshio Taniguchi, the building is poised beside a pond, tucked along a path on the water for visitors. The elegant shape of the water surface and water body gives the pond a monumental sculptured feature, making visitors feel the detailed texture of the water surface, when they walk alongside it. Endowed with social 


\section{6}

attributes as well, water is not deliberately tamed by Liu Jiakun in the Luyeyuan Museum (Chengdu, 2001), which is located on a plain site between a riverbed and a bamboo grove (Figure 3.9). The solution is quite different from the minimalism of allowing water no form of its own, but occasionally polishing the shape of its container. Yet overall, the reliance and independence between the architecture of Luyeyuan Museum (Chengdu, 2001) and water are a manifestation of the tender and vigorous design intervention of Liu. That is to say, the elegant play between water and architecture in the Gallery of Horyuji Treasures (Tokyo, 1999) makes the water odourless, colourless and tasteless. However, in the Luyeyuan Museum (Chengdu, 2001), water is not perfectly noticeable for the visitors but has been naturally embedded in the landscape and added into a three-dimensional architectural experience. Therefore, water here presents itself as a meditation of nature, events, sculptures and happenings. Water is not odourless, colourless and tasteless in Liu Jiakun's intervention anymore, but water still seems quiet.

The attitude in the element of light is similar and of particular importance for measuring the "untamed" essence of Liu Jiakun's architecture. Liu considered that "Light always does not send the surface a clear shadow in Sichuan province. If the light is searching the corner of one building, it does not mean it will determine the visual boundary of the building's corner on the land". ${ }^{53}$ The climate in Sichuan is vastly different between its eastern and eastern parts. The eastern part of Sichuan Basin has a humid sub-tropical monsoonal climate with China's lowest sunshine totals. Chongqing is one of the cities with the shortest sunshine time in China, and is called the "foggy city". Hence, in Liu Jiakun's works, it is difficult

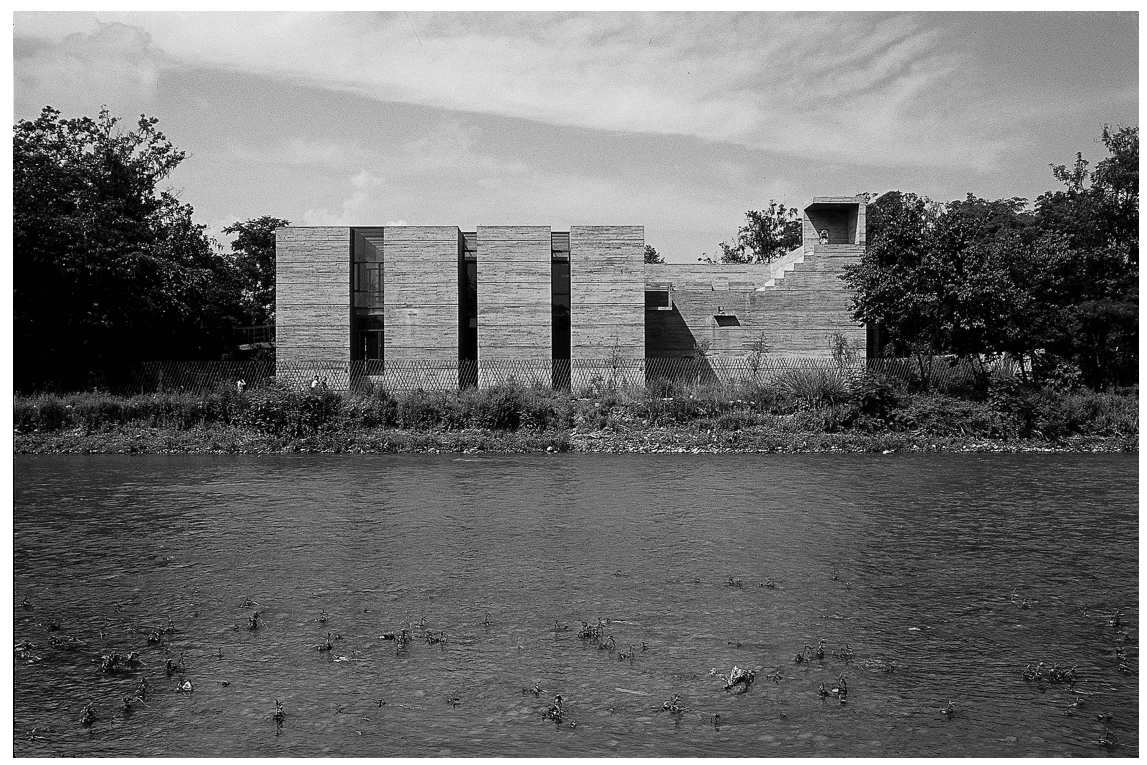

Figure 3.9 Liu Jiakun, Luyeyuan Stone Sculpture Museum, Chengdu, 2001. Presence of water in architecture 
to find highlights existing in the space. There is an awareness of a new way of manipulating light, of it being fogged. In Luyeyuan Stone Sculpture Museum (Chengdu, 2001), the sculpture of Buddha is exhibited in the natural light, which comes from the gap in-between the building blocks from three directions, creating an atmosphere of serenity among the silent statues (Figure 3.10). The sun, moon, fire and electricity all light our world, but Liu is inclined to choose fuzzy in-between light among the sources. In Zhang Xiaogang's Art Gallery (Chengdu, 2008), light is a very significant factor in the space arrangements. In order to maximise the effect of light in different functional areas, Liu employs light from the south in the rest area such as bedrooms, reading rooms and entrance hall in the affiliated building, and light from the north in the atelier. In order to achieve a mysterious atmosphere and a better environment for appreciating works, the exhibition space sets the windows on the sidewalls and roofs to import various light qualities through diffusion and reflected and controllable light. There can be no visual form without light, but Liu does not care about the visual form when he deliberately uses the in-between light. In his architecture, light is not necessarily integral to architecture, its mission is not to reveal beauty, function or form; its mission is to maintain innocence in the secular world. It is untamed. Here, it is strangely rationally controlled yet irrationally emotionalised.

With regard to the materials Liu Jiakun used, the exaggerated presence of industrial material in itself has a striking effect. These materials strike a contest with the glass, steel and other popularly used materials. The new campus design of Sichuan Fine Arts Institute (Chongqing, 2003) is an example of this effect. In this

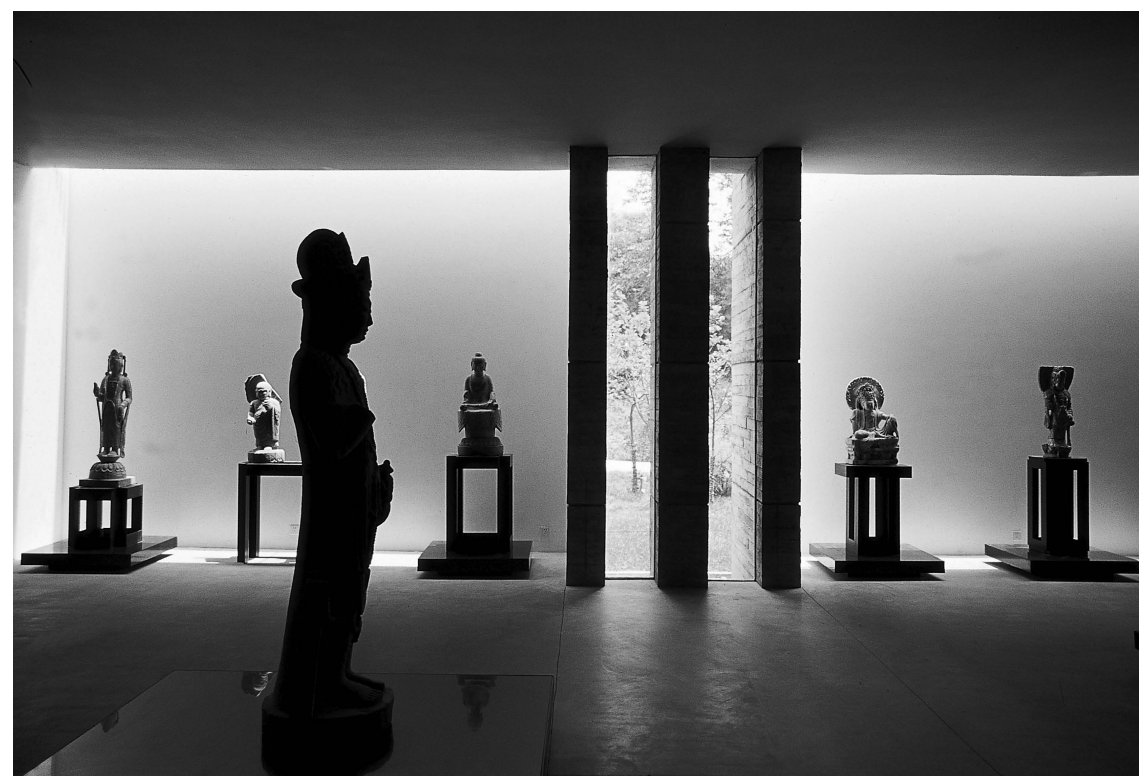

Figure 3.10 Liu Jiakun, Luyeyuan Stone Sculpture Museum, Chengdu, 2001. Presence of light in architecture 
project, he tackled the materials freely, unburdened by assumptions. The result is a complex combination of unselfconscious materials, including as-cast-finish shale brick, as-cast-finish concrete, perforated cellular brick, galvanised iron sheet, corrugated concrete slab, clay-pottery brick and concrete sun-shading board. A large part of its façade is made of bared shale bricks, which may create an illusion of piled-up red glaze tiles or surface painting for a visitor taking a glimpse from a distance. In China, bared shale brick is often used to build the façade of the shanties at construction sites or low-quality housing in rural areas. At the brick surface we can see black stains with white spots surrounding occasionally due to incomplete firing. Shale is a common building material; however, through the specific design, this façade creates a specific feeling: the red shale brick stands there, but it is not tamed into the surrounding, the fake Westernised buildings. In the building of the Sculpture Department of the Sichuan Fine Arts Institute (Chongqing, 2003), the surface has also adopted red shale bricks to blend with the environmental tone. And the special usage of the caesious cement is to resume the sand plaster tradition in the Chongqing zone. The rusty aluminium board partly used is made by the students of the Print Department. Besides the red brick, the black, white and grey concrete blocks are used as the main materials for the Lodging Centre of "China International Practice Exhibition of Architecture" (Nanjing, 2004). The design reflects local rural context by borrowing elements such as common cement products, which are often used in rural areas. Liu does not depend excessively on these low-quality materials but deploys their independent spirit (Figure 3.11).

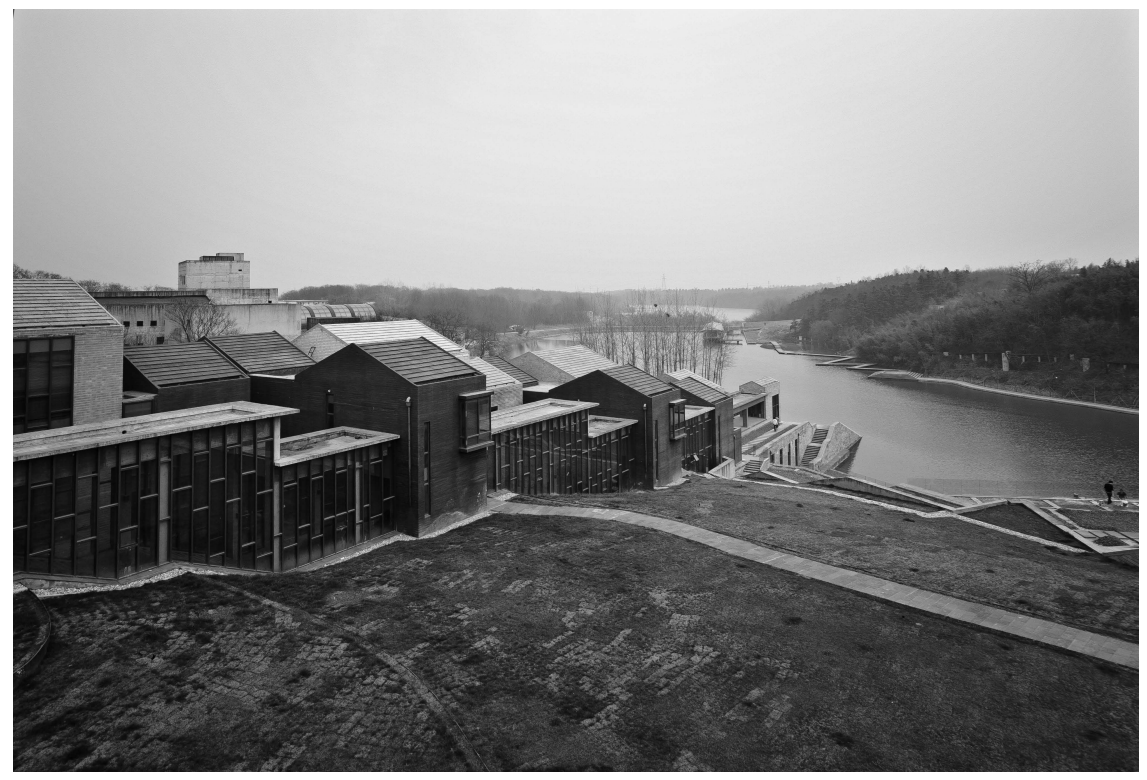

Figure 3.11 Liu Jiakun, Lodging Centre of China International Practice Exhibition of Architecture, Nanjing, 2004 
Yet untamed material is not the same as crude treatment. The material in the design of Shanghai Qingpu District Exhibition Centre (Shanghai, 2006) of New Town Construction by Liu Jiakun is one such case. Shanghai Qingpu district is dotted with group designs by star architects and popular in the architectural scene. The attempt of Qingpu district council to create a contemporary water city environment is a combination of architectural aesthetics and political and cultural intention. In the selection and treatment of material by Liu, stone window shading is a special design consideration, piling up black stone pieces (450-mm width and $35-\mathrm{mm}$ thickness) at intervals of $600 \mathrm{~mm}$. These pieces are ordered, according to their heights, as $1,350,1,200$ and $850 .{ }^{54}$ In order to prevent tumbling, there is a $15-\mathrm{mm}$-thick steel plate extending from the inner window frame, which has an engraved slot to fasten the stone pieces. The stone pieces are well processed, with deliberately chopped coarse and protruding short edges. The surface of the long side edge is especially polished, and some slots $(5 \mathrm{~mm} \times 5 \mathrm{~mm})$ are engraved at every $20-\mathrm{mm}$ spacing. This is an example of the delicate treatments of one material in the whole design (Figure 3.12). Being untamed is not the same as being disrespectful, although the building may be described as minimalistic.

The experience of space in this design is also good illustration of "untamed". Before visitors arrive at the Luyeyuan Museum (Chengdu, 2001), they need to walk up a slope in a bamboo grove and pass a pond decorated with lotus flowers. Liu explains it was intended to create an everyday life experience and let visitors walk downward from the gate of the museum. Visitors spiral down, generating a sense of coming into an underground palace. Like an archaeological dig, the Luyeyuan Stone Sculpture Museum (Chengdu, 2001) reveals itself from the top down, offering a sense of discovery as visitors move through it. ${ }^{55}$ From riverside open platform at the second floor, the stairs lead visitors to the roof space. The view from the roof is a pastoral scene of West Sichuan Plain and a river with cobblestones flows nearby. These experiences that the architect has deliberately created are fundamentally anti-everyday life experiences.

In the brick and reinforced concrete mixed structure Liu Jiakun initiated, the wall becomes a central element. What this wall carries is not only the untamed architectural element itself, but it shows the untamed attitude towards architectural theory. Luyeyuan Stone Sculpture Museum (Chengdu, 2001) is a collection of stone sculptures; thus, the architecture wants to tell people a story of an artificial stone. Owing to the limitations of the local building trades in this part of Sichuan, the architect used the inner brick wall as a template, ensuring a vertical pour for the wall. Shale bricks also provide a formwork to create a grid pattern on the concrete, which gives the walls texture and hides imperfections in the exposed material. As local construction technique is primitive and flexible modification afterwards is always possible, a combined technique of frame structure with fairfaced concrete and shale bricks is created. Indention templates with stripes are used to pour the fair-faced concrete walls of the main building in order that a clear pattern is formed, a strong impression of walls is made and the fault caused by lack of experience in the pouring technique is camouflaged behind the dense and wild lattice that covers it. 


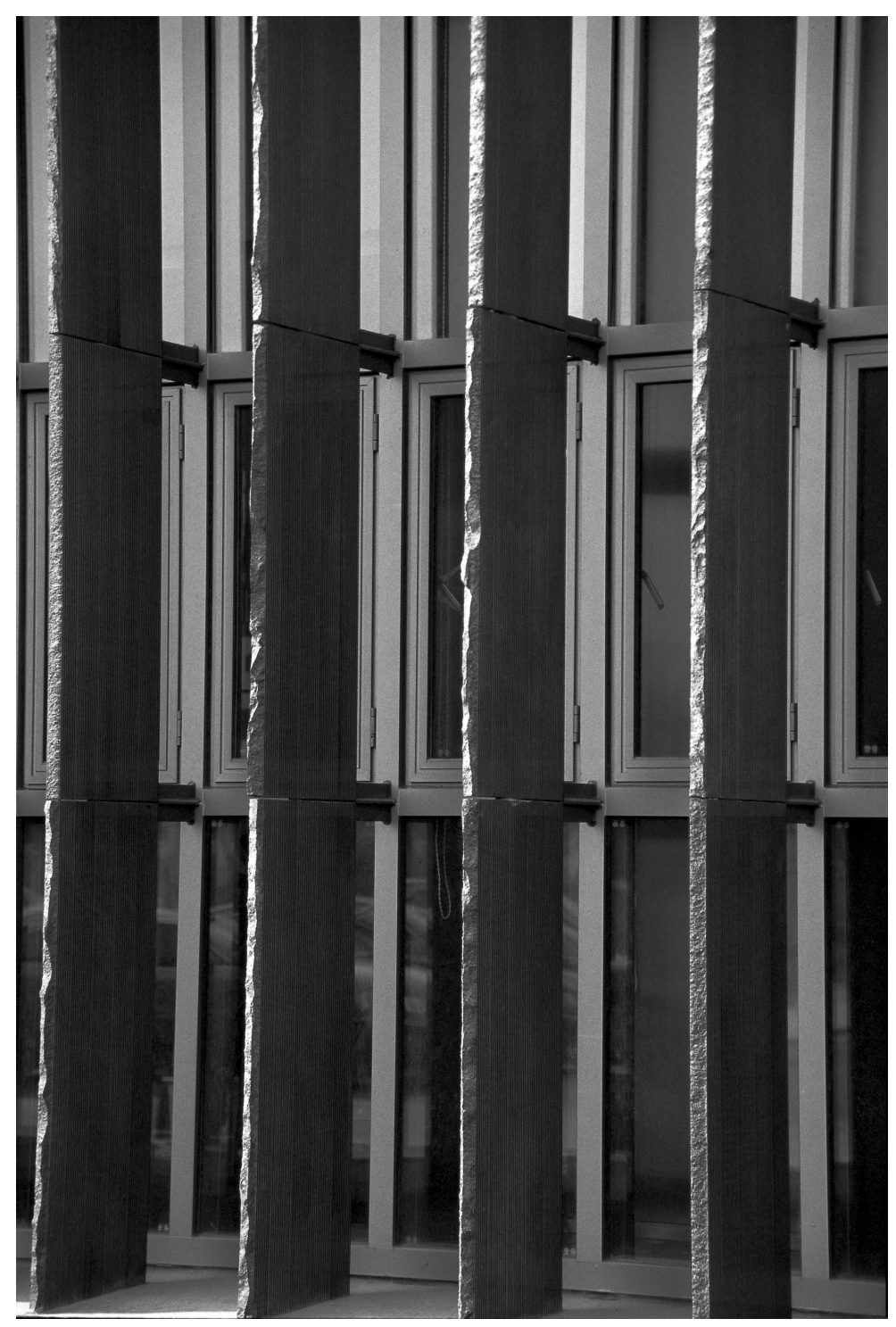

Figure 3.12 Liu Jiakun, Shanghai Qingpu District Exhibition Centre, Shanghai, 2006. Stone window shading

However, this wall caused many debates. The content of the debates are not my focus in this study, but I will list them out and then discuss Liu Jiakun's response to questions, which reflect his personal quality and its connection with the untamed architecture. In Tao Zhu's article published in 2002, Promises and Assumptions of Tectonics, ${ }^{56}$ he used the Luyeyuan Museum (Chengdu, 2007) as 
an example to illustrate the inclination of reduction in regards to tectonics. He argued that the expressiveness of the concrete tectonics was the priority for Liu Jiakun in Luyeyuan Stone Sculpture Museum (Chengdu, 2000), in order to represent a "monolithic structure": "if Liu Jiakun had at his disposal the same recourses as Tadao Ando, in terms of economic and technological conditions, he would not have had any hesitation in using a cast-in-place concrete wall to achieve a monolithic structure." ${ }^{57}$ In the same year, along with the book Here and Now by Liu, he subtly answered Tao Zhu's doubt. He rationally rectified the unusual combination of poured concrete and shale brick's structural concerns first; furthermore he peacefully made a stand regarding the notion of the tectonic: "Writing an architecture has writing's own aim, and it does not necessarily leave a space for the narration", ${ }^{58}$ which seemingly replied the doubts around tectonics in an indirect way. Peng Nu further discusses the essential difference between tectonic expression of material, when facing the question of the validity of tectonics. ${ }^{59}$ Therefore, that the combined technique of frame structure with fair-faced concrete and shale brick is inauthentic from the perspective of tectonics, has already been discussed abundantly, and it is not my focus in this study.

My focus here is the ways Liu Jiakun confronts doubts and the attitude he holds, showing his nimble mind, which is an important personal resource for the untamed attribute of architecture. When the visitor arrives at the site of Luyeyuan Stone Sculpture Museum (Chengdu, 2001), the real local condition is discovered, which helps people to understand that when Liu was requested to use the local farmers, unskilled, as the construction team in building the Luyeyuan Stone Sculpture Museum (Chengdu, 2001), it is hard to imagine that the perpendicularity of the walls could stir so much debate regarding tectonics. The fact is that due to the limited time and budget, the architect promptly dealt with the reality he faced, but with a long-term plan. For example, the interior face of the composite wall, which adopts brick-laying and plastering techniques, leaves a space for coping with different kinds of change afterwards, when the exhibits on display gradually moved in. Talking of architectural theories, like tectonics, Liu shows his respect in a few interviews, and he said he is not particularly familiar with architectural history or theory. However, he does not show the slightest fear when being involved in vague and theoretical discussions. He did not dispel the doubts directly but logically let them unfold in the article. Nu Peng later intellectually summarised what he replied into three points. But for Liu Jiakun, he responds to outside discussions that are full of jargon in simple words, analogous to his designs.

All these elements give his architecture a special stamp of being untamed. They do not look tamed by the authority of modernism; they do not look tamed by the international stylised stroke; and they do not look tamed by the immense amount of investment in the real estate. They do not look tamed by the excessive demand by the bureaucrats; they do not look tamed by quickly reaching their maturity in architecture by introducing a mature-coarseness of architecture into the highspeed urbanisation. They do not look tamed, but this adjective only refers to his designs, not to the person. 


\section{A tamed architect}

Apart from Liu Jiakun's consciousness of individualism and humanism that has been discussed above, what else makes his architecture look and feel untamed? Media and commentators have summarised Liu's design philosophy as,

Set foot on China's status quo, positively deal with all the social conflicts coming up in the process of development, make the best use of all the advantages and change the unfavourable factors into consignments and resources for the design. A good design equals the limited resources in a creative way. ${ }^{60}$

But nobody has pointed out what the main social conflicts are or why he is willing to deal with these social conflicts.

For Liu Jiakun, there were obscure years of dedication to self-reflection in Tibet, which all came to the fore between 1994 and 1997 with the artists' private studio projects, commissioned by Luo Zhongli, ${ }^{61} \mathrm{He}$ Duoling ${ }^{62}$ and other intimate friends of his youth. By the mid-1990s, China's once centrally planned arts world gave way to a partial disengagement of art from politics. ${ }^{63}$ With the post-socialist relaxation of control over personal pursuit, and the orientation towards the market since 1990, Luo Zhongli artists' studio (Chengdu, 1996) was the first batch of individual artist studios in China being legitimised. With the freedom outside the public cultural organisations, it allowed artists to have greater independence in art, but greater dependence on money as well. However, with the distance of time, we can say that this action itself was operating with massive uncertainties in the new wave of uncertain reform and an uncertain cultural sphere. Cultural markets operated with uncertainties and speculation, which introduced new jealousies and insecurities in commerce, alongside the more obvious problems of political pressure. ${ }^{64}$ Facing inflation and declining public subsidies, the huge uncertainty of self-investment possibly made the artists Luo Zhongli and He Duoling themselves insecure.

The He Duoling studio (Chengdu, 1997) was the first time Liu Jiakun experimented with the aesthetics and spatial possibilities of brick and a reinforced concrete mixed structure, which saves costs when compared to only a reinforced concrete structure (Figure 3.13). Meanwhile, the brick and reinforced concrete mixed structure is widely utilised in the local rural area. Moreover, the exterior and interior walls are both treated by local methods, adopting plaster and paint. In China, the brick and reinforced concrete mixed structure is always assumed to be backwards, with less potentiality in windowing, and less freedom in design. But it is still widely applied in the rural areas of China with a long-term history, and the local people have also accumulated a wealth of experience. However, the latent capacity of it has been explored and magnified by Liu's design: a rising path surrounds the podium of the patio, and makes a sharp turn when the perspective is about to close, the blind façade and the protective thick wall in contrast with the slight crevices, and the four blind walls formulating the inner patio are raised up deliberately, reinforcing the empty inward space. Even the poor quality 


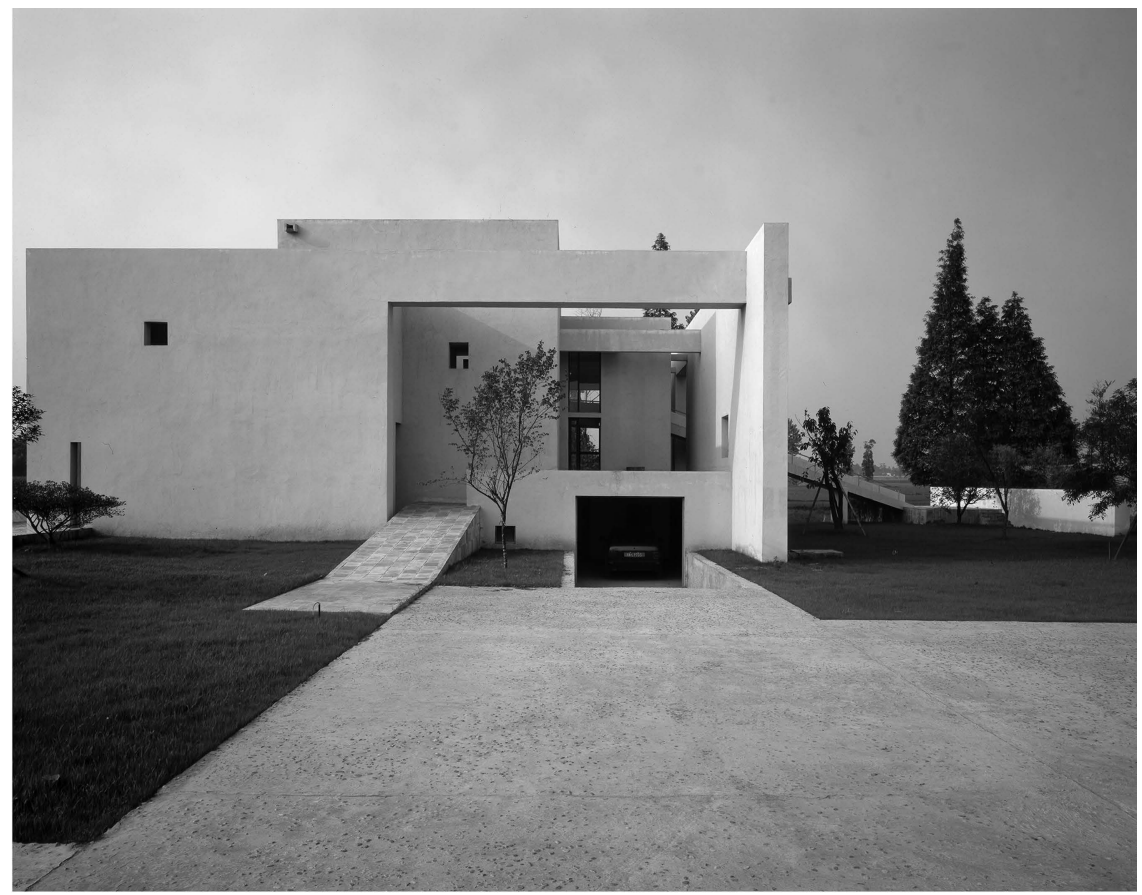

Figure 3.13 Liu Jiakun, Duoling He studio, Chengdu, 1997

of the locally produced bricks does not obstruct the expressive spatial ability of brick and reinforced concrete mixed structure. It is an experiment, but it is not an experiment ignoring the signs of the time and the place.

Luyeyuan Stone Sculpture Museum (Chengdu, 2001), which confirms Liu Jiakun as a leading figure in the China's architectural scene was also initiated by an individual artist, Zhong Ming, the curator of this small museum. As China moved boldly into a market economy in the 1980s and 1990s, Denton argues that museums of modern history edged slowly away from standard narratives of class oppression and revolutionary struggle towards representations of the past that legitimise the contemporary ideology of commerce, entrepreneurship and market reform. ${ }^{65}$ In the early $1990 \mathrm{~s}$, despite a lot of rhetoric about globalisation and pluralism from museum curators and musicologists, museums in China continued to be used by the state for legitimising purposes or are at least closely aligned with state interests. ${ }^{66}$ In June 1994, a new set of "Guidelines for Patriotic Education": was adopted at a National Conference on Education. This document gave the official stamp to the displacement of Marxist ideology by "pragmatic nationalism" ${ }^{67}$ The different types of patrons of museums were also encouraged as the new ideology was legitimised. A private museum like Luyeyuan Stone Sculpture Museum (Chengdu, 2001) was erected along with the rising self-fulfilment and 
self-expression of the successful individual entrepreneurs, artists who grasped the opportunities and made a lot of money in that period. Although the official propaganda was still in the transient period from socialism to patriotism, the content of Luyeyuan was not aligned with this. Although confronted by uncertainty, Liu Jiakun was commissioned and finally let the design have its own characteristics.

When considering how Liu Jiakun smoothly held the attitude to be naturally tamed in the social conflicts, we notice that the projects mentioned above are all built between the old-line and new-line: the rapidly rising personal income has meant that individuals can enjoy more choices with individual economic power, while it also pushed them to maintain their investments carefully. Unlike the architects who work in the National and Municipal Architectural Institutes who are usually commissioned by some national or municipal projects, Liu was commissioned by personal friends, and he gave importance to that reality: aware that the extremely limited funds of the artists themselves could only be solved by saving more money in the construction budget, and at the same time, the artists were extremely careful of their individual identities associated with the architecture. Different from most intellectuals at that time who considered private patronage to be the carrier of crudeness into intellectual life, Liu Jiakun embraced this embarrassment. Considering the studios of Luo Zhongli (Chengdu, 1996) and He Duoling (Chengdu, 1997) and Luyeyuan Stone Sculpture Museum (Chengdu, 2001), on one hand, the architecture had to be transgressive, while on the other hand, it was controlled by the investors' anxiety about the instability of the market, inflation of incomes and political unrest.

Liu's architecture embodies his own psychological acceptance of the declining sponsorship from the government, and his understanding of artists' anxiety regarding money and their will for "art for art's sake". According to Adorno's theory of aesthetic autonomy, cultural products embody social values and have the potential to push the limit of existing forms only when they can be protected against the effects of schematisation that result from the system of commodity exchange. ${ }^{68}$ Adorno's belief fails to find resonance in Liu's world. Liu salvages the limited resources provided by the artists who worked under personal pressures of living and working for material benefits and creates interesting designs that not merely aligned with state interests. Liu's psychological change occurred earlier than most of the architects who worked in the collective National and Municipal Architectural Institutes. That is to say, in opposition to most intellectuals at that time who considered private patronage to be the transmitter of crudeness into intellectual life, Liu Jiakun embraced this embarrassment. His psychological adjustment gave him new impetus in design and pushed the limit of existing forms in architecture in embracing this embarrassment.

"To make the best use of all the advantages and change the unfavourable factors into consignments and resources for the design", which has been repeated by many commentators, is his creative contribution to the new forms of architecture of contemporary China in the tension between centrally planning to the market economy. Therefore, we could say that Liu's own experiences have given him a better understanding of the relationship between design and market expectations. What makes his architecture unique is the elegant architectural play between the design and market expectations. 
Jianchuan Museum Cluster is a more recent case representing this interplay, as China's economy has continued to deliver double-digit growth, underpinned by a rapid expansion of individualism, which legitimised the launch of the museum cluster. Jianchuan Museum Cluster is located in Anren, a national-class historical and cultural town in Chengdu, Sichuan, planned together by Liu Jiakun and Yong Ho Chang. The groundbreaking fact of this cluster is that it is owned and very much directed by an individual person, the entrepreneur Fan Jianchuan. These museums have a rich repository of over eight million artefacts, with 121 of them classified as Class-One National Treasures, mainly collected by Fan Jianchuan. Liu Jiakun proposed that here a museum does not necessarily serve as political propaganda. With a total area of 500 acres $\left(2.0 \mathrm{~km}^{2}\right)$, the museum cluster is made up of fifteen museums, but Anren is still a rural and undeveloped town, one hour's drive from Chengdu. Liu summarised his vision before: "The core problem is to learn how to control the utilitarian; it drives the construction, and it is also the driver of destructive power." ${ }^{69}$ But how to make the utilitarian drive a building dedicated to sacred space in this project was the core problem for Liu. At that point, Liu was an architect aligned with the entrepreneur Fan Jianchuan. Therefore, how to sustain the largest private museum cluster in Anren was taken into serious consideration in Liu's designs.

In the design of the Clock Museum of Culture Revolution, Liu Jiakun regards the success of commercial business as a surviving foundation for the museum. The logic of realising the importance of money serves to promote achieving the satisfaction of the commercial facilities. Liu implements a museum inside the core of an abandoned commercial site, bisecting two different conditions into two extreme sectors by superimposing the cacophony of the surrounding commercial zone with the quietness of museum core space, and making an apparent contrast between "secular space" and "sacred space". By doing these things from above, Liu further strengthens and deepens the power of influence coming from commercial reality and historical heritage and eventually creates a unique sense of place.

Therefore, when the architect is tamed by the social conflicts in the transition era, it does not mean the architecture has to be tamed as well. Being tamed alternatively gives the architect a new understanding of architecture and evokes the new way of manipulation in design. In The Little Prince, there are some other words concerning "tame": "But if you tame me, then we shall need each other. To me, you will be unique in all the world. To you, I shall be unique in all the world." To Liu Jiakun, the market does not imply to meticulously reconstruct versions of the most iconic cities of the West. But as an architect, if the market and social transformation tame him, then they shall need each other. It could be argued that one of the main reasons for his good design with limited resources in a creative way is, to some extent, because he is psychologically tamed in the social conflicts.

\section{The individual architect and the emerging market}

Clearly the emerging market provided a new opportunity for latent commercialisation, gradually providing alternative resources for an individual architect like Liu Jiakun. In addition, exhibitions flourishing along with the development of 
the market helped unofficial and individual architects transform themselves into architect celebrities. Although contemporary architecture is lagging five years behind art in the dissemination of new reputation and values in both the internal and external markets, the personal changes in architects are more related to the development of the discipline itself, rather than purely serving foreign collectors, or aligning themselves for or against large-scale political/ideological campaigns during this massive transition.

Through the comparison between Liu Jiakun and Zhang Xiaogang, we can see a personal reaction to this huge social transformation becoming a significant factor in determining his career choice and designs. Even though Zhang and Liu practice in different disciplines, they consciously or unconsciously convey the same "collective memory", albeit through different techniques of expression. Liu's architecture legitimises a new dynamic based on the architect's own reinterpretation of the collective memory embedded in his life experiences, even if that means recalling a collectively traumatic past, for his designs confirm that socialism under the planned economy was a significant part of Chinese history, and the memory of the collective is an intrinsic part of the psyche of people born in the 1950s and 1960s. Incorporating the memory of the collective in architecture demonstrates Liu Jiakun's humanistic understandings of memory. His life experiences as a writer before embarking on a career in architecture gave him a heightened sensitivity to humanism, withstanding even the recent chaos of massive construction in China. Even with the immense amount of investment in real estate, Liu's subjectivity does not lead him to promote self-interest by exploiting architectural design. This is the reason that his works look untamed.

Liu Jiakun in his architectural practice significantly exceeds the limits of Chinese people's contemporary anxiety when confronting the era of Mao, because his designs parallel the perspective of the people, rather than the state, yet they do not evoke people's sense of feeling awkward about their own youth. Although the assertion of socialist aesthetics in the Chinese context, no matter how contrived, might be assumed at face value to be a kind of politically correct manoeuvre, the analysis reveals that the architecture designed by Liu has overcome ideological deviation and retains its integrity, instead of serving the purposes of the government, simulating a sense of involvement in the socialist regime, or serving the imagination of the West. It also demonstrates how such works have further enriched the architectural language in contemporary China. The result is the expression of genuine folk language linking new identities emerging from the everyday urban landscape and general anxieties in China.

\section{Notes}

1 Charlie Q. L. Xue, Building a Revolution: Chinese Architecture Since 1980 (Hong Kong: Hong Kong University Press, 2006).

2 See, for example, Michael Falchikov and Hilary Chung, In the Party Spirit: Socialist Realism and Literary Practice in the Soviet Union, East Germany and China (Amsterdam; Atlanta, GA: Rodopi, 1996). 
3 Catherine Cooke, "Socialist Realist Architecture: Theory and Practice," in Art of the Soviets: Painting, Sculpture, and Architecture in a One-Party State, 1917-1992, ed. Matthew Cullerne Bown (Manchester; New York: Manchester University Press, 1993), 86.

4 Xiao Hu, "Reorienting the Profession: Chinese Architectural Transformation Between 1949 and 1959” (Ph.D. Dissertation, University of Nebraska - Lincoln, 2009), 188.

5 Peter Rowe and Seng Kuan, Architectural Encounters With Essence and Form in Modern China (Cambridge, MA: The MIT Press, 2004), 100.

6 Yan Kai, "The Course and Prospect of Chinese Housing Industrialization in the Past 60 Years," Residential Technology no. 5 (2009): 3.

$7 \mathrm{Hu}$, "Reorienting the Profession: Chinese Architectural Transformation between 1949 and 1959," 188.

8 The politburo of the Chinese Communist Party decided to construct ten large-scale building projects in Beijing as monuments displaying the first ten years of great socialist achievement by the People's Republic and celebrating the tenth anniversary of the People's Republic in August, 1958. The ten building projects included: the Great Hall of People, used as the Parliament building of China; the National Museum of China; the Beijing Railway Station; the Cultural Palace of Nationalities; the Worker's Stadium; The National Agricultural Exhibition Hall; the Military Museum of China; The Minzhu Hotel; the Daoyutai State Guesthouse; and the Huaqiao Hotel. In October 1959, the construction of all ten buildings was completed. It took only one year to complete both the design and construction of ten large-scale buildings.

9 Rowe and Kuan, Architectural Encounters with Essence and Form in Modern China, 121.

10 Daniel Leese, Mao Cult: Rhetoric and Ritual in China's Cultural Revolution (Cambridge: Cambridge University Press, 2011), 31.

11 Richard Curt Kraus, The Cultural Revolution: A Very Short Introduction (Oxford; New York: Oxford University Press, 2012).

12 Sun Sheng Han and Yong Wang, "Chongqing," Cities 18, no. 2 (2001): 115.

13 Ibid.

14 Began in the 1960s, the Third Front was a massive development of industry by China in its southwestern inland, where it would be strategically secure in a war.

15 Han and Wang, "Chongqing," 115.

16 The hall was built in memory of the Prime Minister Zhuge Liang of the Shu State during the Three Kingdoms Period (220-280). It was originally built in the Northern and Southern Dynasties (420-589). In 1961, it was listed as a key historical site under state protection.

17 Kuanzhai Alley is the name of a pedestrian area that is the last remnants of the Old Shaocheng part of Chengdu that housed the Imperial officials and soldiers from the Qing Dynasty and has been transformed into shops, cafes, bars and hotels. Being the typical epitome of Chengdu, Kuan Zhai Alley is the combination of history and modern changes. The two alleys are now home to trinket stands, upscale restaurants and teahouses, a Starbucks and a few art dealers.

18 Liu Jiakun, interviewed by the author at January 9th, 2013

19 Marshall Berman, All That Is Solid Melts into Air: The Experience of Modernity (New York: Simon and Schuster, 1982).

20 Robin Porter, From Mao to Market: China Reconfigure (New York: Columbia University Press, 2011), 57.

21 Xiaoping Deng, "Hold High the Banner of Mao Zedong Thought and Adhere to the Principle of Seeking Truth from Facts," September 16, 1978.

22 Porter, From Mao to Market: China Reconfigure, 234.

23 Kraus, The Cultural Revolution: A Very Short Introduction.

24 Porter, From Mao to Market: China Reconfigure, 57. 
25 Jiakun Liu, “Wo Zai Xibu Zuo Jianzhu我在西部做建筑 [My Architectural Practice in Western China]," Shidai jianzhu no. 4 (2006): 45-47.

26 Wu Hung and Peggy Wang, eds., Contemporary Chinese Art: Primary Documents (New York: The Museum of Modern Art, 2010); Wu Hung, Transience: Chinese Experimental Art at the End of the Twentieth Century (Chicago: David and Alfred Smart Museum of Art, University of Chicago, 1999); Annamma Joy and John Sherry Jr, "Framing Considerations in the PRC: Creating Value in the Contemporary Chinese Art Market," Consumption Markets \& Culture 7, no. 4 (2004): 307-348.

27 Taru Salmenkari, "Implementing and Avoiding Control: Contemporary Art and the Chinese State," China: An International Journal 2, no. 2 (2004): 235-261.

28 Richard Kraus, "China's Artists Between Plan and Market," in Urban Spaces in Contemporary China: The Potential for Autonomy and Community in Post-Mao China, ed. Deborah S. Davis, et al. (Cambridge; New York; Melbourne: Cambridge University Press, 1995).

29 Julia F. Andrews and Minglu Gao, "The Avant-Garde's Challenge to Official Art," ibid.

30 Abigail Fitzgibbons, "Zhang Xiaogang: Biography," Zhangxiaogang Art Studio, accessed January 19, 2013, http://zhangxiaogang.org/enArtText_XQ.aspx?Tb1 CollegeClnum $=78$.

31 Ibid.

32 Ibid.

33 Joy and Sherry Jr, "Framing Considerations in the PRC: Creating Value in the Contemporary Chinese Art Market 1," 327.

34 Ibid.

35 John Clark, "Postmodernism and Expressionist Tendencies in Recent Chinese Oil Painting," Asian Studies Review 15, no. 2 (1991): 119.

36 Jiakun Liu, “Gei Zhu Jianfei De Huixin给朱剑飞的回信 [A Letter to Jianfei Zhu],” Shidai jianzhu no. 5 (2006): 67-68.

37 Salmenkari, "Implementing and Avoiding Control: Contemporary Art and the Chinese State," 256.

38 Ibid.

39 “Zhang Xiaogang Artist Biography," Wendtgallery, accessed November 3, 2013, www. wendtgallery.com/Zhang-Xiaogang-Artist-Biography.

40 Tsong-Zung Chang, Reckoning With the Past: Contemporary Chinese Painting (Edinburgh: Fruitmarket Gallery, 1996), 96.

41 Hua Tang, “Jiakun 家琨 [Jiakun],” Jian zhu shi no. 5 (2007): 161-162.

42 Liu, “Wo Zai Xibu Zuo Jianzhu我在西部做建筑 [My Architectural Practice in Western China],"

43 Andrews and Gao, "The Avant-Garde's Challenge to Official Art," 235.

$44 \mathrm{Nu}$ Peng, “Benzhi Shang Bujinjin Shi Jianzhu 本质上不仅仅是建筑 [The Essence Is Not About Architecture]," in Ci Shi Ci Di 此时此地 [Here and Now], ed. Jiakun Liu (Beijing: Zhongguo jianzhu gongye chubanshe, 2002).

45 Liu Jiakun, interviewed by the author on January 9, 2013.

46 Helen F. Siu and Zelda Stern, Mao's Harvest: Voices From China's New Generation (New York; Oxford Oxfordshire: Oxford University Press, 1983).

47 Song Cheng, Jiming Kong, and Hongtao Song, "Wenchuan 512 Earthquake and Giant Panda Habitat in Wolong, China: A Review of Strong Earthquake Effects," Frontiers of Forestry in China 4, no. 4 (2009): 388-393.

48 Bianca Bosker, Original Copies : Architectural Mimicry in Contemporary China (Honolulu: University of Hawaii Press, 2013), 96.

49 Nancy Lin, "Architecture Shenzhen," in Great Leap Forward, ed. Chuihua Judy Chung, et al. (Köln: Taschen GmbH, 2001), 165.

50 Ibid., 183.

51 Through state-business client list connections, officials can serve as power brokers, marketing their power for case payments that benefit private firms/investors. 
Power-holders in administrative positions can sell their power to private firms and businessmen in a variety of ways: expeditious approval of business proposals (typical involving land allocation); relaxation of administrative regulations; and leaking critical information concerning business opportunities.

52 Lin, "Architecture Shenzhen," 183-184.

53 Jianghe Ouyang, "Jianzhu Zuowei Bendi Shiwu De Chouxiang - Jianzhushi Liu Jiakun Fangtan 建筑作为本地事物的抽象 - 建筑师刘家琨访谈 [Architecture as a Regional Abstract - an Interview with Liu Jiakun], J Jin tian Spring Volume, no. 84 (2009).

54 Feng Yuan, “Jishao Yu Jiduo 极少与极多 [Minimum and Maximum, Interpretation of the Design of Construction Regulatory Center of Qingpu New Town, Shanghai]," Shidai jianzhu no. 1 (2007).

55 Clifford Pearson, "China: Projects \& Features-Luyeyuan Stone Sculpture Museum, Xinmin," Architectural Record 192, no. 3 (2004): 86-89.

56 Tao Zhu, “'Jiangou’ De Xunuo Yu Xushe “建构”的许诺与虚设 [Promises and Assumptions of Tectonics: On the Emerging Notions of Tectonics in Contemporary Chinese Architecture]," Shidai jianzhu no. 5 (2002): 30-33.

57 Ibid., 33.

58 Jiakun Liu, “Luyeyuan Shike Bowuguan 鹿野苑石刻博物馆 [Luyeyuan Stone Sculpture Museum]," Beijing guihua jianshe no. 6 (2004): 176-182.

$59 \mathrm{Nu}$ Peng, “Zai 'Jiangou' Zhiwai-Guanyu Luyeyuan Shike Bowuguan Yinfa De Piping 在'建构'之外 - 关于鹿野苑石刻博物馆引发的批评 [Beyond Tectonics: Discussions of Luyeyuan Stone Sculpture Museum]," Shidai jianzhu no. 5 (2003): 48-55.

60 Jiakun Architects, "Design Philosophy," PSA Publishers Ltd, accessed August 17, 2011, www.chinese-architects.com/en/Jiakun.a.

61 Luo Zhongli (1948-), born in Chongqing, is considered one of China's foremost realist painters and known for his portraits of the people of southwestern China. His work has been exhibited in cities. Luo's 1980 portrait, Father, his most highly acclaimed work, is considered one of the most recognisable works of contemporary Chinese art.

62 He Duoling (1948-), born in Chengdu, is among China's most prominent contemporary realist painters. He is best known for his images of female nudes and various minorities in the west and southwest of China's countryside.

63 Kraus, "China's Artists Between Plan and Market," 175.

64 Ibid., 185.

65 Kirk A. Denton, "Museums, Memorial Sites and Exhibitionary Culture in the People's Republic of China," The China Quarterly 183 (2005): 567.

66 Ibid., 569.

67 Edward Vickers, "Museums and Nationalism in Contemporary China," Compare 37, no. 3 (2007): 368.

68 Andrew Kipnis, Chinese Modernity and the Individual Psyche (New York: Palgrave Macmillan, 2012), 34.

69 Jiakun Liu, Ci Shi Ci Di 此时此地 [Here and Now] (Beijing: Zhongguo jianzhu gongye chubanshe, 2002), 14. The original text: 问题的核心在于学习如何驾驭功 利, 它既是建设的驱动力, 同时又是破坏力. 


\section{Renarrating the state \\ Cui Kai}

Cui Kai is the deputy president and chief architect of China Architecture Design \& Research Group (CAG). He has been honoured with the highest recognition of achievement in China's building industry. His designs have been widely published in journals, magazines and books. His work has its roots in modernism and postmodernism from Mao to early post-Mao. I have devised two terms in my analysis of Cui Kai's architecture - "delayed modernism" and "hazy postmodernism". Chinese architecture was destined to continue its way in the international modernist trend in 1950s, but this move was cut short by the Communist Revolution in 1949. With the launch of the open policies in mainland China after 1978, Chinese architecture finally re-embraced modernism, after a delay of almost thirty years. The term "delayed" is utilised to describe the modernist condition for Cui Kai and his generation of architects. While Chinese architecture was absorbing modernism in the late 1970s, this movement was interrupted by the intrusion of postmodernist theories into Chinese discourse. However, for many reasons, when postmodernist theories travelled to China, they took a different form from the postmodernist theories originating in the West. In other words, Chinese postmodernist theories were ambiguous, originating from a different family tree; that is why they can be described as hazy postmodernism. All these factors manifested in Cui Kai's architecture in a subtle way. In comparing the trajectory of modernism and postmodernism in Mainland China and Taiwan, I will address two issues: first, why it is impossible to detect the Bauhaus-influenced clean lines of modernism in Cui Kai's early designs, a trend which was given full expression in early Taiwanese modern architecture; second, why postmodernist characteristics emerged so abruptly in his designs.

Cui Kai joined CAG in 1984, and his works have been consistent with CAG's step-by-step reform from the early 1980s until the present. In the second part, the analysis of powerful sources that sparked his aspirations in architecture will be located within the trajectory of CAG. The critical review of Cui Kai's work associated with CAG was initiated by Feng Li's master's thesis $(2010)^{1}$ which gave a general overview of the history of the CAG, CAG's reform, CAG'S works and Cui Kai's works separately, following a critical analysis and explanation of the causes and effects of reform on its working mechanism. Yet Li does not directly associate Cui Kai's designs with the exploration of CAG; he lists a separate 
chronologic stylistic analysis of Cui Kai's work. In other words, Feng Li's analysis of Cui Kai's designs was limited to the domain of stylistic studies and set apart from CAG's reform amid the broad societal transformation.

\section{Delayed modernism and hazy postmodernism}

In Feng Li's analysis, the first pattern emerging in Cui Kai's earlier works in the 1990s reflected influences from both eclectic historicism and postmodernism. The style might be traced back to Hyatt Hotel E'fang Palace (Xi'an, 1991), Shenzhen Minghua Centre (Shenzhen,1992) and the office building for Foreign Language Teaching \& Research Press completed in 1998. ${ }^{2}$ The office building for Foreign Language Teaching \& Research Press (Beijing, 1997) is a milestone design in Cui Kai's career, which later became an icon for Foreign Language Teaching \& Research Press. Li described this building as "suspended bridges, stacking and falling balconies, non-orthogonal axis, complex mass cut", ${ }^{3}$ which are recognisable postmodernist characteristics. However, what is the origin of Cui Kai's vision of postmodernism? Does it really arise from postmodern theory?

Like the majority of architects in the twentieth and twenty-first centuries, Cui Kai's response to modernism and postmodernism and his own interpretations of the two trends are principal factors shaping his view on architecture and his designs. It is also useful to make a comparison between the social and political conditions that allowed modernism and postmodernism to influence architecture in mainland China and Taiwan. This comparison between mainland China and Taiwan elucidates the trajectory of modernism and postmodernism in China's architecture, giving a context to Cui Kai's early works from Maoist China to the early market transition, and revealing the underlying social conditions and educational conditions that determined the characteristics in Cui Kai's works. We are then in a position to understand the accidental combination of modernism and postmodernism in Cui Kai's works.

\section{- Delayed modernism for Cui Kai}

Prior to 1949, thirteen Christian universities in mainland China made great contributions to the nation's higher education. From the "Archives of the United Board for Christian Higher Education in Asia", documented by Yale University, at a meeting of representatives of the China Christian Educational Association, it was proposed to establish a "Board of Co-operation of the Union Institutions of Higher Education in China", which would serve to facilitate coordination in the areas of educational programme, faculty recruitment and financial promotion in May 1920. ${ }^{4}$ St. John's College (later St. John's University) was one of the first institutions to be founded as a college. ${ }^{5}$ In September 1937, following the start of the Sino-Japanese war, it was decided to move St. John's University to the International Settlement in Shanghai. ${ }^{6}$

In 1942, Huang Zuoshen set up the Department of Architecture in St. John's University in Shanghai and, in this way, formally introduced the Bauhaus 
approach to China. Huang Zuoshen had first trained at the AA School of Architecture, and he later became committed to modern architecture under the influence of Walter Gropius at Harvard University. ${ }^{7}$ The Bauhaus approach was introduced by Huang to St. John's University in the 1940s. Yet social realism imported from the Soviet Union in the early 1950s was imposed as an official style in the People's Republic of China (PRC). Therefore, abstract art and modern architecture were not promoted. Artists were required to produce realistic works that any proletarian could understand, and the architecture's mission was also to celebrate the triumph of socialism and serve the proletariat.

Since the Bauhaus approach had totally disappeared in mainland China by the early 1950s, understanding architecture in Taiwan helps us to realise the limitations of a linear investigation of mainland China. The defeat in the Civil War (1927-1950) led the Chinese Nationalist Party - also known as Kuomingtang - to retreat to the island of Taiwan, colonised by Japan fifty-one years previously. Taiwan, an offshore Chinese island, was thus raised to independent status overnight. When the political leadership in China split in 1949, it also brought cultural and architectural isolation. Furthermore, since the geographical split, the two Chinese higher education systems developed separately, led by two Chinese ruling parties. ${ }^{8}$ In mainland China, after 1949, all rival forces which the Communist Party perceived to be associated with capitalism - such as the free market and religious observances - were eliminated. Like other private institutions, all pre-1949 private colleges and universities, particularly those run by foreign associations, were nationalised in the early 1950s; their ownership and administrative powers were transferred to the state. ${ }^{9}$ After 1949, the Christian universities, including St. John's University, were forced to close, and their campuses were gradually taken over by the People's government. The era of Christian Higher Education in mainland China was terminated at that time.

However, in Taiwan, in 1950, a group of enthusiastic Chinese educators proposed to the United Board for Christian Colleges in China to foster the spirit of Chinese youth by establishing an ideal university in Taiwan that would both continue the work of Christian education in China and inherit the grand tradition of the thirteen mainland universities..$^{10}$ In this way the establishment of Tunghai University in Taiwan would continue the legacy of Christian universities in mainland China. In 1952, the board's secretary, Dr. William P. Fenn, made a trip to Taiwan to investigate the possibility and decided to establish a university. In June of 1953, the board sent Dr. Thomas W. Graham of Oberlin College, Ohio representing the organisation, together with Dr. Fenn, to set up a preparatory office and board to oversee the establishment of the school. ${ }^{11}$ In 1955 , Tunghai University was established. At this point we must examine the question of whether this continuing enthusiasm of Christian Colleges in Taiwan assisted an architectural continuance of modernism or caused a serious deviation.

Zhang Zhaokang is the key figure in the modernist shift of the Bauhaus architectural spirit by way of St. John's University in mainland China to the United States and then to Taiwan. Zhang was born in Guangzhou and graduated from the Department of Architecture in the St. John's University in 1946, the first university 
to adopt the Bauhaus architectural education in China. However, the founder of the Department of Architecture in the St. John's University, Huang Zuoshen, chose to stay in mainland China after the Communist Revolution, and he was later persecuted in the Cultural Revolution. There was thus no chance for him to spread a Bauhaus approach either in education or in practice in that period. However, Zhang Zhaokang, as the first graduate from the Department of Architecture in St. John's University, moved from mainland China to the United States. In 1949, Zhang enrolled in the Harvard Graduate School of Design (GSD) and became a disciple of Bauhaus architect Walter Gropius. The approach he absorbed was brought back to Taiwan by Zhang, who received an invitation from the founder of the Department of Architecture of Tunghai University, Chen Qikuan. With help from the United Board for Christian Colleges, Chen was the architect who established the Department of Architecture of Tunghai University in 1960, which has been a leader in defining and piloting the discipline of architecture in Taiwan. I. M. Pei and Zhang Zhaokang were invited to cooperate in the planning of Tunghai University. Concerning Chen Qikuan, I. M. Pei and Zhang Zhaokang's education backgrounds, it is not hard to trace their convergence in Harvard and their connections with Gropius, the founder of the Bauhaus School and one of the pioneering proponents of modern architecture. In 1935, although Pei had enrolled in the University of Pennsylvania's architecture school and the Massachusetts Institute of Technology successively, he later transferred to and finally graduated from the Harvard GSD. In 1951, Chen enrolled in Gropius's architectural research group and subsequently joined his design firm. His teaching at MIT was soon terminated by his new role at Tunghai University.

According to Ming-Song Shyu and Chun-Hsiung Wang's book, Rustic \& PoeticAn Emerging Generation of Architecture in Postwar Taiwan, as the economy gradually revived in the mid-1950s, three trends in architecture dominated Taiwan: one was Chinese nationalist architecture; the second trend was modernist architecture supported and promoted by the architectural academy, some intellectual architects and the economic construction department in the national government. The third trend was the so-called "Chinese modern architecture". ${ }^{12}$ Looking at Wang Dahong's Architect's Own House on Jien-Guo S. Road (Taipei, 1953), St. Christopher's Church (Taipei, 1957), Kung-Tung Technical Senior High School (Taitung, 1960) and Tsz Hechen's Third Refectory in National Cheng Kung University (Tainan, 1962), it is possible to detect in these buildings the characteristics of buildings constructed in the heyday of modernism in Europe. Some of them are unembellished white boxes featuring flat roofs and open plans that offer light, air, space, transparency and dynamism. Yet these pure modernist characteristics, reflected in the buildings mentioned above, did not emerge in Cui Kai's early works or the early works of his generation of architects in mainland China.

In other words, the Bauhaus-based modernism, which did not have enough time to rise to prominence and stabilise in mainland China, was forced from mainland China after 1949. However the opportunity offered by the United Board shifted the site of its continuance to Taiwan. Thus in post-war Taiwan, we can see a generation of architects' designs displaying rational, practical and simple 
characteristics. On the mainland, there was an absence of Bauhaus-based modernist theory in architectural education during the founding period of the PRC, and this gap delayed the absorption of Bauhaus-inspired modernism for a generation of Chinese architects.

Cui Kai, as the representative of this generation, was consigned to the countryside in the "Up to the Mountains and Down to the Countryside Movement". ${ }^{13}$ He seized the first chance to pursue his ambitions. In 1977, due to hepatitis, he was assigned to pasture cattle in the countryside, and at the same time, he started to prepare for examinations. The university examinations, which had been suspended in 1966, were held again from 1977 onwards. In acknowledgement of more than a decade of missed opportunity, candidates ranging in age from 13 to 37 were allowed to take the exam. "A pent-up reservoir of talent and ambition was released as 5.7 million people took the two-day exam in November and December 1977, in what may have been the most competitive scholastic test in modern Chinese history." ${ }^{14}$ Cui was successful and received an offer to study architecture at Tianjing University at 1977 . He continued to pursue his master's degree in the Department of Architecture, graduating in 1984.

In respect of modernism in Chinese architecture in his undergraduate study, Cui Kai wrote,

At that time, teachers basically taught modernist architecture. Due to the extreme lack of relevant reference material about modernist theory or masterpieces of modern architecture, teachers always drew modern architecture from foreign magazines by pen and converted them into printing. In that era, we felt exhilarated confronting the modern architecture that was extremely novel for us. I always drew the modern architecture by pen after class. The understanding of architecture at that time was more close to the monument, focusing on the architectural form, composition of a picture, proportion, style and so on.... The relevant material was very limited. Therefore, it was good enough for us to find some site plans in the usual information, regardless of the understanding and personal interpretation of the historical significance and humanistic significance. ${ }^{15}$

After the death of Mao in 1976 and the reforms initiated by Deng Xiaoping in 1978, the Chinese architecture curriculum began to reflect modernist theory. The resumption of uniform entrance examinations for universities across the country was prompted by the need to promote "four modernisations" under chairman Hua's policy. ${ }^{16}$ The Chinese leadership thought it to be the only way to achieve the objective of the "four modernisations", raise the standard of education and thereby the standard of living of Chinese people. ${ }^{17}$ Hence the four modernisations were first outlined in February 1978, by Chinese premier and party chairman Hua Guofeng. Hua identified the success of the campaign with the completion of 120 key industrial projects, including mines, steel mills, power plants and harbours. ${ }^{18}$ Modernist architecture was categorised into the disciplines of applied sciences and technology - including mechanical, electrical and civil engineering and 
water conservancy. Parallel with the process of reforming Institutions of Higher Learning, the restoration of scholastic examinations and the need for talented young people was the importance given to science and technology.

Therefore, modernist architecture was an integral part of the ideology of modernisation in the late 1970s and early 1980s. A dialogue between Cui Kai and the Taiwanese Wang Weijen"19 titled "Cross-Strait Questioning and Retrospecting A Dialogue between Cui Kai and Wang Weijen" ${ }^{20}$ was recorded by Time + Architecture in 2012. It suggests that Cui Kai and Wang Weijun, who took their undergraduate studies and postgraduate studies in the similar period, but studied in mainland China and Taiwan, respectively, held different ideas about modernism. Wang was taught to be critical of modernism while learning it. Therefore, in Wang's early designs, the architectural language is always far from the "puritanically moral language of orthodox modern architecture". ${ }^{21}$ In the Fumin Primary School (Taichung, 2002), which won the 2003 award for Far East Architecture Award, it is apparent that the regional motive, which serves as an inspiration, counters the influence of modernism. In the planning of Fumin Primary School (Taichung, 2002), Wang said,

As it develops from the dance with the trees, we do not employ a geometric idea that follows the sense of view and touch: thus, our design becomes vivid so even the windows seem to be dancing with the trees. ${ }^{22}$

The concept that Wang promotes could be defined simply as a local sense of space, aware of itself. The overall planning does not fall into a geometrical strictness. The façade windows and the roof shapes reject the highly-industrialised prototype.

In contrast, the Bauhaus-based modernism was inspirational for Cui Kai when he first began to study architecture. On the one hand, the dominant ideology was strongly leaning to modernism in that period. On the other hand, the modernist exile enhanced the eagerness for modernism in architecture. If his designs had continued in this way, a committed modernism would have been reflected in Cui Kai's architecture. However, after he graduated, his early projects - the Hyatt Hotel E'fang Palace (Xi'an,1991) and the Shenzhen Minghua Centre (Shenzhen,1992) (Figure 4.1), Beijing Feng Ze Yuan Hotel (Beijing, 1994) (Figure 4.2) and the office building for Foreign Language Teaching \& Research Press (Beijing, 1997) do not reflect the characteristics of high modernism in the European tradition, with its practicality and emphasis on integrity of expression.

\section{- Hazy postmodernism for Cui Kai}

In the dialogue between Cui Kai and Wang Weijen, ${ }^{23}$ "Cross-Strait Questioning and Retrospecting - A Dialogue between Cui Kai and Wang Weijen", Wang states that he directly adopted postmodernist theories when he was an undergraduate student. Wang graduated from the Department of Geography at National Taiwan University in 1981. It is evident that Wang's view on the subject of architecture in 


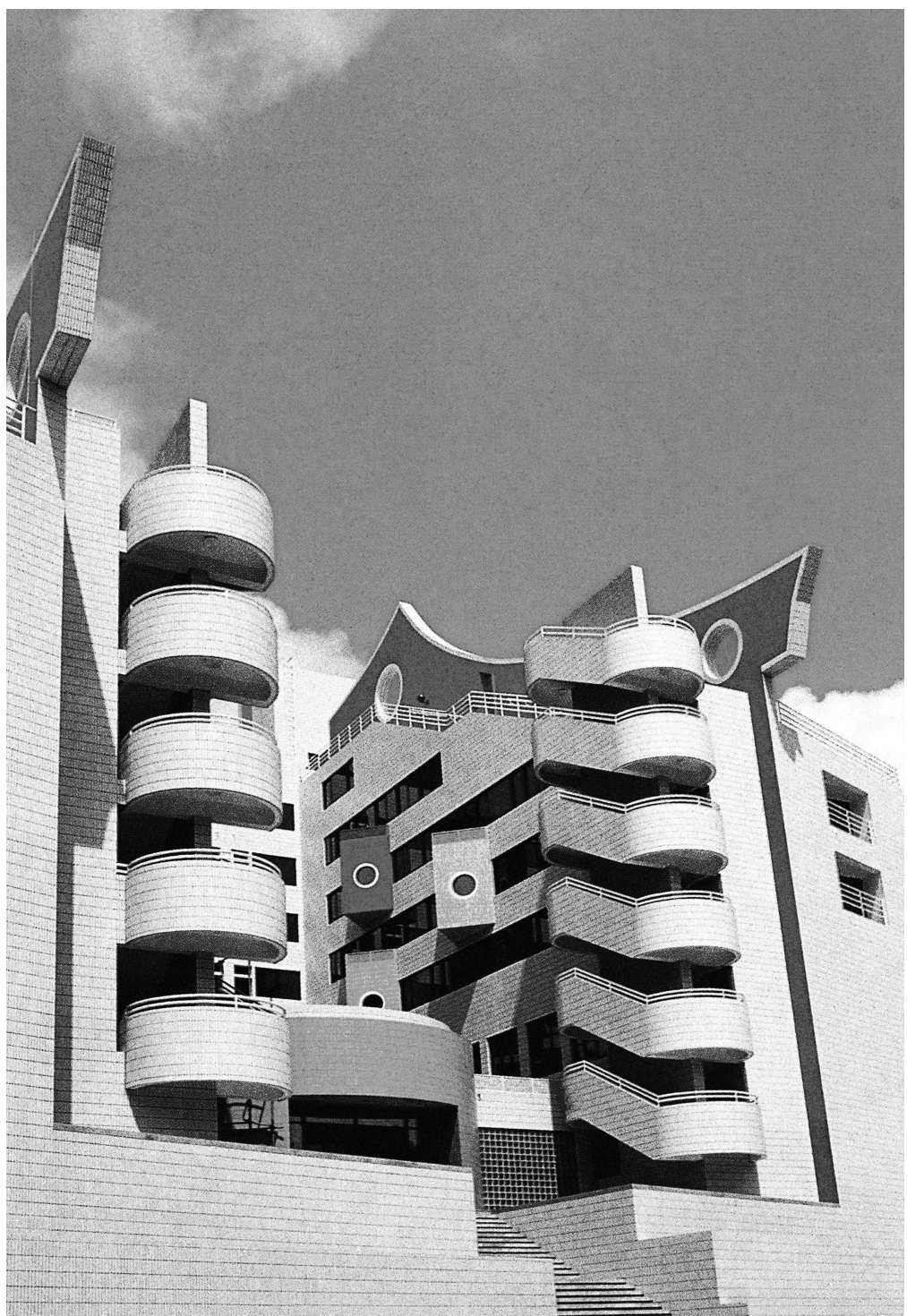

Figure 4.1 Cui Kai, Shenzhen Minghua Centre, Shenzhen, 1992

Taiwan has the limitation of his own personal experience, especially as it is possible that he did not have the opportunity to learn the entire architectural curriculum as a geography student. But it does reflect the general historical moment that postmodernism came to Taiwan. Complexity and Contradiction in Architecture, written by Robert Venturi, was published in 1966. It evolved from the emerging historicist architectural movement in the United States and travelled to Taiwan in 


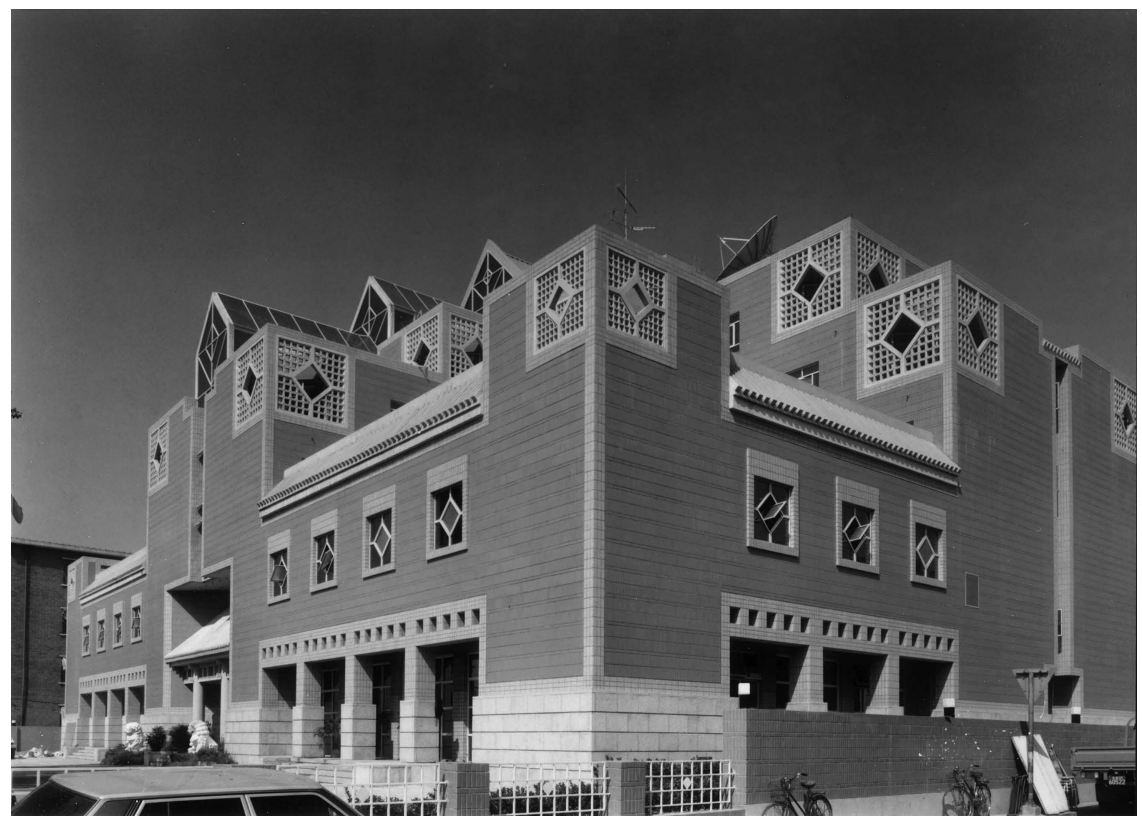

Figure 4.2 Cui Kai, Beijing Feng Ze Yuan Hotel, Beijing, 1994

1980, translated by Tingfang Ye. ${ }^{24}$ For Taiwan, after the emphasis on modernism, but before the development boom of the 1970s, there was a lull that gave a generation of Taiwanese architects an opportunity to lay a modernist foundation between the 1950s and 1970s, allowing more than twenty years of autonomous development. In the 1970s, a major turning point in Taiwan's economy and its real estate seduced Taiwan's architecture away from the seriousness of modernist ideals. In contrast, when modernism arrived in mainland China in the late 1970s, it accompanied the influx of new information, ideologies, theories and cultures which flooded into China at the beginning of the 1980s, including postmodern theory.

In the early 1980s, there were some signals reflecting the trend of antiauthoritarianism and personal liberation in China. Cui Kai was a young architect in the 1980s, when the importation of postmodernist theories took place, and loyalty to modernism was shaken. It is also clear that the decorativeness, pastiche, collage, parody and playfulness in postmodern architecture, which was easily associated with consumer culture, confused the first generation of young architects in that era. They were trained in higher education in mainland China, which was marked by "overspecialisation, the separation of the natural sciences from technology" 25 and incapable of the deep digestion of the postmodern cultural trend and its real context. Xu said, "It is true that Western writers and theorist now known as 'postmodernists' were introduced in the 1980s, but they were part of the upsurge of Western names and -isms of that decade and enjoyed no special status." ${ }^{26}$ Furthermore, Chinese architects and Chinese culture were simultaneously introduced 
to several generations of schools of thought, making them almost too overwhelming to digest. Therefore, "suspended bridges, stacking and falling balconies, nonorthogonal axis, complex mass cut" (Figure 4.3), Li Feng's description for the office building for Foreign Language Teaching \& Research Press (Beijing, 1997), are indications that the major sources for Chinese postmodernism in architecture are simultaneously "deconstruction, post-colonialism, and third-world theory". ${ }^{27}$

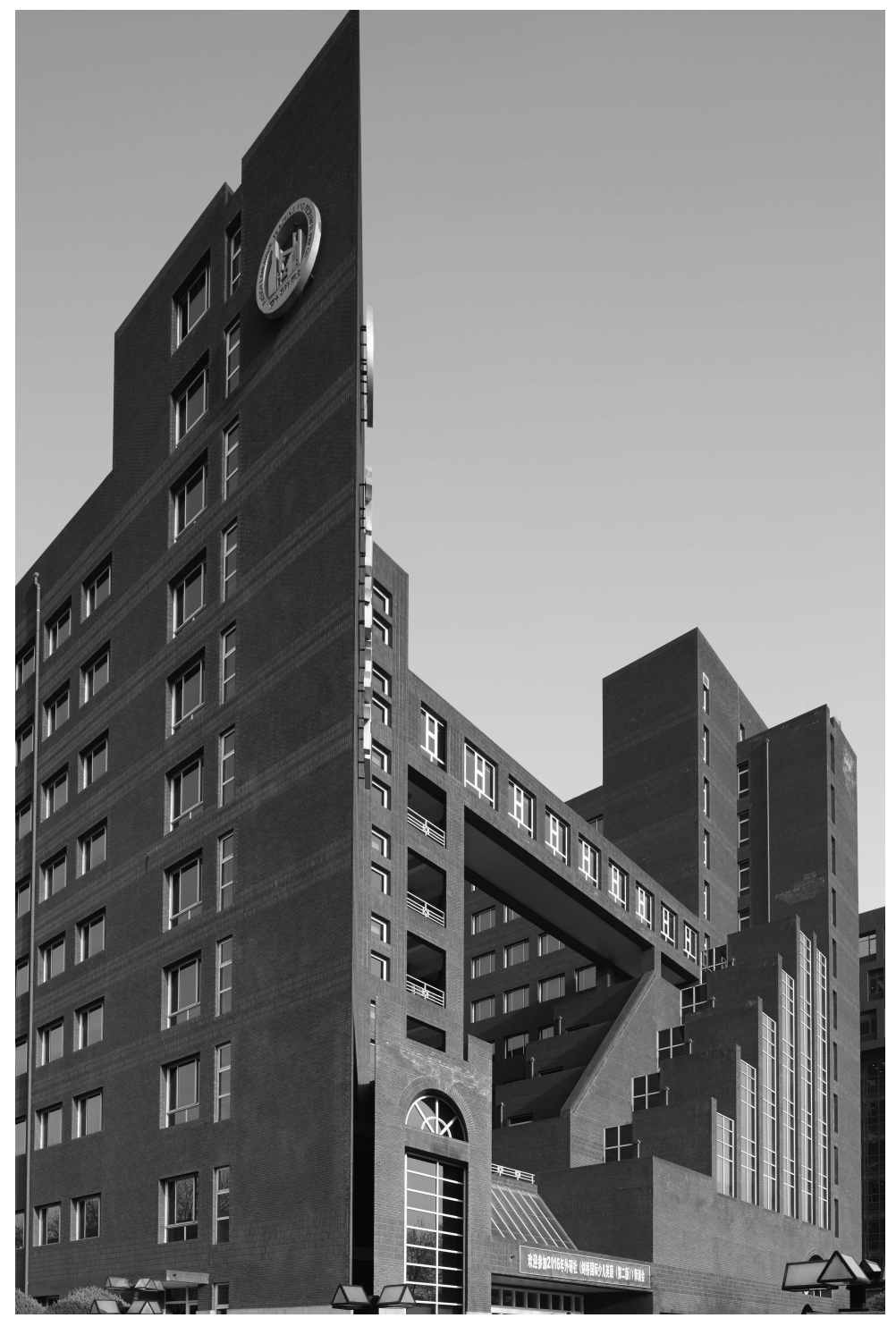

Figure 4.3 Cui Kai, office building for Foreign Language Teaching \& Research Press, Beijing, 1997 
It should be noted that although postmodernism in China emerged under the influence of Western postmodernism, in particular from the United States, Chinese postmodernism's theoretical intentions and historical contents are very different from the West's. Similarly, postmodern architecture did not evolve from the same historical trends.

Regarding Cui Kai's designs, I first argue that the postmodernism conveyed in his early works betrayed the modernist language yet still to emerge within a borrowed frame of modernity. The new episode of Chinese architectural history associated with postmodernism in the 1980s was guided and influenced by the Chinese American architect I. M. Pei, in the late 1970s. Pei's achievements in the United States and his Chinese cultural inheritance added an authoritative weight to the new fashion. Pei's ambition was to forge a new architectural language for a new China. It was to be a hybrid of old and new - a third way - for young Chinese designers to follow. ${ }^{28}$ When he was asked to design the Fragrant Hill Hotel (a low-rise hotel of 325 rooms that was a modest venture by his standards) in Beijing in 1977, Pei's search for a new style began with his own past - the gardens and courtyards in Suzhou. The eaves, moon gates, accented windows and trickling waters are the elements which he identifies with his past memory of China. He was convinced that, despite political upheaval, this vocabulary still had meaning to most Chinese. He wanted to revive those stylistic traits that still spoke to the average person - not the red pillars and golden roofs of obsolete palaces and temples but the white walls and the grey tiles of ordinary residences. ${ }^{29}$

Influenced by I. M. Pei in the projects of Hyatt Hotel E'fang Palace (Xi'an, 1991) and Beijing Feng Ze Yuan Hotel (Beijing, 1994), historical elements are evident in Cui Kai's design for their environment. $\mathrm{Xu}$ argued that there were a good number of Chinese scholars who wrote about postmodern writers, theorists and theories in the 1980s but no self-conscious Chinese postmodernists, for it was not the purpose of these scholars to construct Chinese postmodernism. ${ }^{30} \mathrm{It}$ could be argued that the postmodernist language in Cui's early design was not part of self-conscious postmodernism as well. "In the post-Mao years prior to 1989, modernization was the predominant discourse that was used by both the government and intellectuals to envision progress and development and to prevent the Cultural Revolution from happening again."31 To some extent, Cui Kai's designs emerged within a borrowed frame of modernity in architecture that was partially triggered by I. M. Pei's achievements and spiritually exhibited distinctive modern attributes. The postmodernism in his architecture was more of a mindset architecturally influenced by Pei than of any theory; it was also "more a cluster of shared preconceptions than a closely argued system of thought" 32 in this period.

Second, by incorporating elements from the classical, the vernacular and popular culture, US postmodernism appears to be more egalitarian in spirit - a distinct contrast from the imposition of the modernist designs on the masses by architectural elites. However, China's new nationalism in the late 1980s and early 1990s rationalised the traditional architectural forms to be easily co-opted into postmodernist designs. These different political conditions led to distinct differences between China's postmodernism and Western postmodernism in architecture. 
Under the motto of the revival of nationalism, postmodernism did not allow more playful light-hearted designs. In architecture, Western postmodernist architecture embraced both high and popular culture, but in China, architecture was restricted to high culture in the 1980s and the early 1990s.

Cui Kai's early designs, Hyatt Hotel E'fang Palace (Xi'an, 1991) and Beijing Feng Ze Yuan Hotel (Beijing, 1994), do not deliberately co-opt the forms typical of their locations: Xi' an and Beijing. These designs reflect his rediscovery of the historical reference and its transformation into a new Chineseness, combined with an ancient national identity through architecture. The increasingly relaxed application of vernacular and traditional architectural elements does not show "the impacts from historicism and symbolic post-modernism, which were developed in the Maoist era and the 1980s, ${ }^{, 33}$ as Li argued, but elucidate the ambiguity in Cui's avoidance of a discourse on nationalism, informing his postmodern designs. Dirlik and Zhang argued the uniqueness of Chinese postmodernity as a reaction to modernity in general and to Chinese "socialist and revolutionary modernity" in particular. ${ }^{34}$ The deliberately relaxed application of vernacular and traditional architectural elements demonstrates that though Cui Kai considered the nationalist revival, he did not want to connect this remote Western discourse - postmodernism - to any sense of "socialist and revolutionary modernity" triggered by the nationalism.

By investigating the historical ups and downs from the pre-Maoist, Maoist and early market eras, as well as by identifying the trajectories of modernism and postmodernism and how they determined the characteristics of Cui Kai's early works, this section has identified a number of contentions: Cui Kai cherished delayed modernism in his school days; postmodernist architecture in mainland China did not experience modernism (as understood in the West and in Taiwan) and, as such, coincidently overrode the modernism in Cui's designs that was ready to bloom in the 1980s. Also, although modernist language was not evident in Cui Kai's early works, his prime concern was still in the realm of modernity, especially the Western affiliation of those architectural principles, since his practical interests were still motivated by a desire to move into modernity, not out of it; the abrupt emergence of the postmodernist language in Cui's design and the demand for nationalist expression in architecture that occurred simultaneously was not a coincidence, but Cui intentionally weakened its socialist and revolutionary character. From his early works, the combination of modernism and postmodernism has been achieved in distinct ways. How modernism and postmodernism's became entangled in the later stage of Cui Kai's designs will be clarified in the following sections.

\section{A mission, not a commission}

Cui Kai has worked consistently for the CAG after his graduation from Tianjin University in 1984. He experienced every change within CAG, which reflected a society-wide transformation involving interdependent changes in state policy and regulation and the informal norms and organisational culture embedded in it. 
This interdependence of politics, economics and cultural aspects suggests that the study of Cui Kai's designs associated with CAG'S transition is better pursued as an interdisciplinary question. Therefore, it is imperative to understand the connection between Cui Kai and the development of CAG in order to determine where his characteristics originate.

\section{- The state-owned CAG, Cui Kai and their mission}

The state-owned CAG may be traced back to the Central Design Company, established in 1952. During this time, the Institute has endured many name changes: "Design Institute of Ministry of Works" in 1953, "Beijing Industrial Building Design Institute of Ministry of Works" in 1955, "Academy of Building Research of the Construction Commission" in 1971, "The Architectural Design \& Research Institute" in 1973, the "Building Design Institute Ministry of Construction" in 1988 and, finally, the "China Architecture Design \& Research Group" (CAG), which was established in 2000 with the final merger of Architecture Design Institute Ministry of Construction, the China Building Technology Development Centre, the North China Municipal Engineering Design \& Research Institute and the China Urban Construction \& Research Institute. CAG is authorised by the State Council and under the guidance and supervision of the State-Owned Assets Supervision and Administration Commission of the State Council (SASAC) that supervises and manages state-owned assets of enterprises under higher supervision of the Central Government and enhances the management of state-owned assets. Xue and Ding reviewed the history of design institutes over the past six decades and how they have served the state's strategic need for socialist construction and urbanisation. They clearly pointed out two instrumental missions the design institutes have fulfilled, one tangible and the other intangible: the construction of a socialist-built environment and the legitimation of socialist aesthetics and ideologies. ${ }^{35}$

The corporate governance system in pre-reform CAG was marked by the deprivation of enterprise autonomy in the absence of market competition and sufficient information on enterprise performance in Maoist China. CAG had a far more complex structure and far more staff than the private sector.

The Group has over 4,000 staff and boasts of 2 academicians of Chinese Academy of Engineering, 8 national design masters, 90 plus experts who enjoy the government subsidy that were approved by the State Council, 240 plus class A registered architects, over 210 class A registered structure engineers, over 40 class A registered urban planners, 30 plus class A registered quantity surveyors, over 50 class A registered consulting engineers, 50 class A registered supervision engineers, 180 class A registered mechanical engineers, 80 class A registered electrical engineers, 10 other registered engineers, around 1100 senior designers and researchers, 900 plus medium titled technical staff. ${ }^{36}$

The large-scale state-owned CAG also works differently from either small-scale private architectural firms or large-scale architectural companies. In addition, in 
state-owned or derived institutes like $\mathrm{CAG}$, people have more enduring relationships, similar to the relationships between comrades in pre-reform China.

Rather than piecemeal incremental reform, the grand theories ${ }^{37}$ proposed by Buchanan and Galbraith advised post-communist China to follow guidelines derived from textbook economics: to rapidly dismantle the economic institutions of state socialism and replace them with a full set of market initiatives. Although in theory this approach was persuasive, in practice the "big bang approach" failed to realise its objectives, at least in the short term. ${ }^{38}$ Chinese reformers emphasised piecemeal incremental change, not by design, but by trial and error, resulting in an open-ended evolutionary process of institutional change. ${ }^{39} \mathrm{CAG}$ also underwent piecemeal incremental change, without conforming to textbook economics, and the timing and sequence of reform measures were still shaped by the politics of a political elite.

For example, in June 2012, CAG finalised the takeover of a major Singaporean design firm - Singaporean CPG, a leading infrastructure and building development company in the Asia Pacific region. It was the first overseas acquisition of its kind for China's survey and design service industry. CAG bought the CPG Corporation for AUD\$147 million from the Australian heavy engineering company Downer Group in a deal brokered by the investment bank UBS. ${ }^{40}$ CPG Corporation contributed largely to the development and management of distinguished landmarks in Singapore, including the Singapore Changi Airport, the Singapore Racecourse, the National Art Gallery and the National University of Singapore. ${ }^{41}$ China's "going out" policy has led to a number of overseas acquisitions in the past decade, primarily in the natural resources and equipment sectors, as the nation draws on its stockpile of foreign reserves to obtain much-needed raw materials. ${ }^{42}$ Regarding the acquisition of the CPG corporation, the head of CAG stated, "This is not an opportunistic purchase but part of the national policy to encourage going out and improving international competitiveness." 43 As the only engineering design corporation in the 115 corporations under the guidance of the State-Owned Assets Supervision and Administration Commission of the State Council, CAG had been listed as a selected enterprise to go public. The acquisition is also a signal of accelerating the process of going public. However, the underlying driving force for this acquisition is national need; it is a relatively passive choice for CAG itself. CAG takes on the mission of upgrading the nation's design status. In other word, the changes of CAG are still shaped by the politics of a political elite in the process of marketisation.

Cui Kai joined CAG in 1984. He was quickly promoted to an important position in CAG. There is no doubt that the promotion was accelerated by his own hard work. But the specific era of societal transformation also provided this opportunity. The suspension of operations in architectural departments and schools in China during the Cultural Revolution and the political slant given to architecture during that thirty-year period led to a generation gap in the architectural profession. The resulting scarcity of professionals to meet the increasing demand for building, and the advanced age of many professionals, became increasingly apparent in the 1980s. ${ }^{44}$ By 1984, the average age of high-level design technicians 
was 58.9, and the average age of mid-level design technicians was $48.3 .{ }^{45}$ In the architectural practice, Cui Kai described,

Advanced education was abruptly paused for ten years during the Cultural Revolution, and architecture courses cancelled for a time. That led to a missing generation of architects. Look at the age composition of the technicians in design institutes. Senior colleagues from the Cultural Revolution have already retired, with only a few reemployed after retirement. Those who graduated right after the Revolution and who are in their forties and fifties are now playing the leading role. But, as some went abroad and others turned to business in the last few years, the remaining number is limited. Young people in their twenties and thirties, and sometimes student trainees are the ones who really do the job, and that is the present situation. ${ }^{46}$

The support and help from CAG brought him credit in a short time and gave him a chance to mature quickly in the profession. Until the new generation of architects from the 1980s matured, Cui Kai was offered the leading role in the state-owned design institute in his thirties, which increased his loyalty to the mission associated with the CAG. Some of the practicing architects in contemporary China gradually left the large-scale design institutes, especially those who had the opportunity to be educated overseas. It is possible that their sense of mission gradually faded and became a pure expression of their Chineseness, rather than an expression of the nation-state. But it was difficult for Cui Kai to dispense with this sense of mission.

\section{- The culture of nationalism}

CAG espoused a specific national purpose from the beginning. Although it was reforming for the market, the state was still a decisive force in determining the timing and scope of CAG's reforms, because it represents a national presence in architecture. Since neither CAG - a state-owned design institute - nor Cui Kai - a nationalist architect in the $\mathrm{CAG}$ - could dispense with the sense of mission, the direct way to uphold the mission came through incorporating nationalist forms in their architecture.

In the university years of Cui Kai, national forms were still crucial to education, "In my university years, the most popular topic in school transactions was mainly on how to inherit national tradition, combining together the national forms and modern construction." ${ }^{47}$ Yet in the late 1980 s, there was a signal indicating the architectural intention to escape the grip of the state, which is usually associated with the use of the strict axis in design. The 1986 awards for excellent architectural works are very revealing. The works taking first and second prize have an axial distribution similar to the previous single-axis preoccupation. But one can easily observe that the distribution of all the illustrations of the designs somehow departs from the axis; Li concluded that the 1986 award for architecture in China still revealed a single-axis structure, an axis of familiarity. ${ }^{48}$ But the slight 
deviation from the single-axis reflected architectural relaxation regarding political correctness. The other characteristic of Chinese national form is the "Big Roof" due to Liang Sicheng's interest in China's heritage: between 1952 and 1954, Chinese roofs were designed for most civil building projects. ${ }^{50}$

The emphasis on a national form such as the "Big Roof" was significantly eased in the 1990s, but it was still occasionally adopted in some types of building, such as university campus buildings, museums, hotels and office buildings. The utilisation of traditional vocabulary in reform-era architectural practice was reflected in Cui Kai's Er Pang Gong Hyatt Hotel (Xi'an, 1991) and the Feng Ze Yuan Hotel (Beijing, 1994); yet neither building adopted the "Big Roof" in any way. Authorities perceived the traditional form as a way of warding off foreign influence in Chinese cultural affairs in that period. Of this design, Cui Kai wrote,

In 1986, not long after the Reform and Open Policy took effect, internally people craved for a reconnaissance of the national economy, while externally people were curious about the outside world. Emerging at the time, the Er Pang Gong Hyatt Hotel (Xi'an, 1991) was required to meet both the economical demands from Hong Kong investors, as well as the image demands from the city to embody the modernization progress of the historical Xi'an. ${ }^{51}$

With regard to traditional architecture in China, some advocates of historical districts or buildings focused on the preservation of traditional buildings and structures. Cui Kai's idea concerning tradition more or less followed the outstanding Chinese scholar Liang Sicheng.

In his presentation to the Architectural Society of China in 2007 titled Following Liang Sicheng's Footprints and Toddle on the Road of Native Architecture, Cui Kai said,

Our strategy was, while pursuing contemporary geometrical appearance, we also tried to express traditions embedded in nationality and locality. . . . Later I took the Feng Ze Yuan Hotel project at Zhushikou outside Qianmen in Beijing. The location was within the historical district, and at that time the city government vowed to "Recapture the style of old Beijing", so, the design for its appearance and interior space utilized symbols from traditional Chinese housing. ${ }^{52}$

Liang himself dedicated his entire life to preserving Beijing's old site and documenting and establishing the discipline of traditional Chinese architecture. Liang's belief in adopting the traditional architectural vocabulary was an attempt to create a new socialist style of Chinese architecture, and he succeeded in meeting the Chinese Communist Party leaders' cultural demands as well.

Cui Kai, born in Beijing and educated in the Beaux-Arts design principles in Tianjing University, is technically capable of presenting historical values in the execution of elaborate new designs and possibly adheres to the old Beijing and its architecture as well. Does the nationalist form in Cui's designs differ from Liang's discourse? If so, how do we distinguish Cui from Liang? 
Dai and Zhi quoted Xu's argument in describing China's architectural development from the year 2000 onwards: there are three trends of thought that deconstruct the enlightenment from different directions - nationalism, classicism and multiple modernities, but they all have positive values in the theory. ${ }^{53}$ My concern here is that nationalism is a consistent thread running through the 1980s, the 1990s and the 2000s in China, but there were marked changes in terms of motive, meaning and manifestation in different periods. In general, nationalism has always formed a part of the official discourse of the Chinese Communist Party. Nationalist sentiment may be expressed as a feeling of anger aroused by the violation of the perceived nationalist aspiration or the feeling of satisfaction aroused by its fulfilment. ${ }^{54}$ After 2000 , education, technological development and the bureaucratic structure involved in becoming a modern state were increasingly driven by rationalist, administrative imperatives in China rather than by a sovereign manipulation. However, the modernising imperatives in contemporary China occurred simultaneously with the dissemination of national ideology, especially within CAG, a fundamental state-owned design enterprise.

With regard to nationalism in the modern context, Geller conceived of modernity as a distinctive form of social organisation and culture, and he considered nationalism to be a function of modernity. ${ }^{55}$ That is to say, CAG's underlying mission is to disseminate the satisfaction aroused by the fulfilment of nationalist principles through modernisation: nationalism is seen to be a function of modernity in China's new era. In the new era, therefore, distinct from the nationalism in Liang's discourse and designs, I propose that the culture of nationalism in Cui's designs has since the 1990s demonstrated a new relationship between modernity and nationalism. Unlike Liang, Cui Kai does not have to reflect on the new socialist style, which permitted him to think about national culture and form beyond ideological and political needs. He states that

the progress of modern technology has also played a part. New structures, new materials, and new techniques have provided enormous creative opportunities and broad possibilities. This is factually the primary foundation of modern architecture, and the primary cause for architectural forms to go global. The tidal wave of globalization is irrevocable, and any suggestion of "Recapturing the style of old Beijing" will eventually get nowhere. ${ }^{56}$

His suspicion of "recapturing the style of old Beijing" allowed him to look at the ways in which new national identities and new architectural vocabularies are enacted and produced in the new context. Geller argued that cultures, like plants, can be divided into savage and cultivated varieties. The savage kinds are produced and reproduce themselves spontaneously, as parts of the life of men, yet cultivated or garden cultures are different, though they have developed from the wild varieties. ${ }^{57}$ Cui Kai's designs that conflated the imperatives of nationalism and modernism in the new era are not the savage kinds that are produced and reproduce themselves spontaneously. Irrigated, cultivated and promoted by CAG, Cui Kai's designs become a repository of a broad aesthetic knowledge in the high cultural domain, transcending the class system. 


\section{- Organisational culture}

Although CAG has been gradually opened to the market for twenty years, the bureaucratic environment still plays a significant role in the structuring and management of the CAG in the transitional economy. In order to maintain social stability and the political influence of large state-owned enterprises within China, some government authorities still intervene in employment policy, the appointment of board directors and chief executive officers, the political careers of senior managers and reward policies. ${ }^{58}$ Many state-owned enterprises (SOEs) remain encumbered by legacy assets, such as broad social obligations like health care and worker pensions, and the Communist Party continues to exert some control over both labour and management in SOEs. ${ }^{59}$ Although CAG has adopted restructuring, the influence from "inside the system", as explicitly introduced in Chapter One, remained unchallenged. In order to maintain social stability, a large stateowned enterprise, for example CAG, continues to employ a substantial portion of the population in China. The traditional CAG system is composed of a set of interlinked institutional arrangements. Reform began by increasing autonomy and improving incentives in micro-management mechanisms that, in turn, prompted a reform of the resource allocation system. But CAG has been still plagued by a series of policy burdens left over from the previous development strategy, and the state still has to provide CAG with various kinds of open and hidden subsidies, as well as other types of policy protection.

Since early 1992, the drive to abolish the cadre system in the SOEs has gathered momentum, thanks to the party's new consensus on the market. ${ }^{60}$ However, the Personnel Ministry clearly stipulated that the contract cadres in SOEs must be incorporated into the management of cadres by the state. ${ }^{61}$ The command economy in the pre-reform era is, by nature, an administrative economy requiring an all-powerful bureaucracy to execute central planning. ${ }^{62}$ Built upon this state ownership structure is a vast economic bureaucracy. All state factories are embraced in this system and are ranked hierarchically according to criteria such as the amount of state investment they receive, the importance of their products and the number of workers they employ. ${ }^{63}$ Cui Kai, depending on his ranking, is granted an official status at the levels of a governmental support enterprise. In this hierarchy, Cui Kai is inevitably accorded a certain administrative rank, and more significantly, gains an administrative superiority. From an organisational point of view, these twenty-plus years of reforms have involved considerable effort to change the state firms' internal culture, and its relationship with the external environment, but only to a limited extent.

The National People's Congress legislated the Enterprise Law in 1993, which covered clear property rights and clarified rights and responsibilities and separation between government, enterprise and scientific management. Furthermore, the SOEs were encouraged to enhance their presences in the international markets. CAG is now following the Western or fashionable styles in architecture. Yet emphasis on the Western quality of design and open-mindedness to the globalising world trend does not rest on pure Western style management degrees or the executive business model. Research on organisational cultures in reform-era Chinese firms has found that there remains a stronger emphasis on the cultural 
values of hierarchy in SOEs than in joint ventures, wholly owned subsidiaries and private firms in China. ${ }^{64}$

Within CAG, a further project-oriented managing system has been established. It has a Design Business Managing Centre and has appointed a group of design project directors; a number of celebrities' studios and discipline research studios have been set up. Cui Kai's studio was set up in 2004. However, the hierarchical cultural component is still a desired SOE culture within CAG. O'Connor has argued that larger SOEs with greater social responsibility (e.g., managing the burden of retirement pensions, social-welfare costs and redundant workers) towards maintaining employment will have a reduced capacity to achieve profit maximisation objectives. ${ }^{65}$ Although Cui Kai appears to avoid politics and bureaucratic culture and the state control over contract managers is much weaker than state cadres, he and his studio are still within this cadre system.

\section{- Shared values of CAG and their impacts on Cui Kai}

In respect to the relationship between Cui Kai's designs and the development of CAG, Cui Kai's works possess a complexity and richness rooted in the distinctive nourishment of national institution where he has continued to work as one of the dedicated personnel. Based on the discussion of the impact of nationalism and organisational culture, it is possible to speculate that nationalism and the culture of hierarchy have significantly impacted long-term shared values and beliefs in CAG, which also imparts a certain tone in Cui Kai's designs. Furthermore, the personalised national culture in Cui Kai's designs, for example, the International Conference Centre of Foreign Language Teaching \& Research Press (Beijing, 2004) and the office building of Foreign Language Teaching \& Research Press (Beijing, 1997), reveal the development of a sophisticated array of architectural codes in new China from the 1990s onwards, which illustrate the relationship between nationalism and modernity in modern China. Hence, his designed buildings are cultivated as an elaborate code, of explicit, grammatical and regularised architectural forms, dispensing high culture and harmonising with the organisational culture in CAG.

As discussed above, the high culture carried through Cui Kai's designs became far more authoritative and normative than the old doctrines in modern society. Similar to architectural communication, verbal text comes to be more pervasive and universal in urban-based societies. The high organisational culture is reflected not only in Cui Kai's designs but also in his articles.

First, his articles always have a professional and contextual interest, and his critical analyses of the international context have persuasive power. He disputes the negative attitude regarding the entry of foreign architectural design in China, and advises his readers to take "the opportunity to learn and assimilate their experience more quickly and more systematically through cooperation." ${ }^{96}$ He wrote of this perceived invasion:

Many colleagues criticize that some projects are flashy yet without concrete substance, wasting a lot of money merely for the sake of show or novelty. But, in my opinion, what is done cannot be undone. Why not take the chance 
to learn a lesson or two from these irrational designs with a rational attitude. . . . If our architectural technology can march forward in large strides through these projects, the expenses are not paid to little avail. If our architectural creative environment can link up with the international standard with these years of opening-up, the expenses will be worthy indeed. ${ }^{67}$

He further elaborated on the specific aspects of how China should quicken its pace and catch up.

By comparison, the advantages of the foreign agencies are very obvious in age composition and team structure, in profession and accumulation of experience, let alone that they possess a huge international network of technique consultancy, enabling them to make prompt contact with top-flight experts for cooperation in case of any problems. It is perceptible that the difference in team composition has an immediate effect on the quality of design. ${ }^{68}$

Second, Cui Kai's comments on the national building code applied to all provinces.

Now buildings are no longer functioning as the street wall of the city, the structure of historical city spaces breaks down bit by bit. There are other planning requirements which must also adhere to city regulations - like fire prevention distance, fire loop road, set back, building density, green ratio etc. Even in this way, a city constructed under strict planning control is still viewed as lacking due order and the city status is losing its due character and looks helpless. ${ }^{69}$

Rather than commenting on any specific design, a reflection on the building code is filled with quotidian assumptions of a role that may rarely be challenged. Therefore, his occasional tangents on the building codes do reveal aspects of his privileged position.

Third, Cui Kai is capable of reading and criticising architecture from the perspective of a People's expert, who shoulders social responsibility and offers social services.

When buildings are assessed in line with this cultural concept, the American Congress Hall will not be copied in China however beautiful it is; the selection of architectural designs will not slip into a contest of beautiful renderings, and the assessment based on undue emphasis on formal beauty must be checked. It is the duty of experts to guide the management and the public to comprehend and evaluate constructions in terms of environment, culture and technique innovation. ${ }^{70}$

With regard to the word "public", Cui authentically refers to "people" or "the mass". In contrast, Liu Jiakun always refers to "we", and Liu Xiaodu of URBANUS always refers to the civic society and related concepts. 
Fourth, he can easily relate the abstract concept in the architectural discourse to designs in China or culture in China.

It can be seen that "beauty" is a disputed part of the guideline of present architectural design. Then what can take beauty's place? In my opinion, in the present wave of globalisation, people have come to pay increased attention to the sense of belonging, and localization. In the architectural community, especially in developing countries, regional culture has been more frequently mentioned. Therefore, I think it possible to substitute "beauty" with "culture", that function and form should be balanced, and that the congruence should be further balanced with culture, and this is a positive and meaningful solution for the display of Chinese architectural culture and tradition. ${ }^{71}$

Cui Kai rejects the fashionable concept as the only course for contemporary architecture in China. His model presumes that the present focus on beauty would, at some point in the future, have to be adjusted in favour of Chinese culture. The efficacy of his argument may depend on the level of people's cognition of CAG and the position of Cui Kai, not only in the architectural industry, but also regarding his role in the architectural discourse.

Fifth, confronting the history of China, that is, the political revolution of modern China, he has written extensively, but not critically. On the one hand, he is not like any angry young man in criticising socialist China; on the other hand, he is confident in commenting on it.

The victory of the Chinese revolution made the people dominant in the country. The socialist system which takes fair and average wealth as its character has made sunlight in every apartment the critical condition in city housing projects as a citizen's right of health, and the non-obstacle sunlight distance is one of the most important elements for planning approval. The most sensitive focus of the neighbouring construction activities for normal people is sunlight obstruction. Therefore, from north to south, almost all residential buildings are facing south and north in their tower and slab buildings. And the most important relationship between all buildings is the problem of nonobstruction of sunlight. ${ }^{72}$

His argument, informed by a macro-perspective, entrenches the socialist rituals and criticises the socialist routines at the same time. In general terms, his tone in the articles emanate from a nationalist ambition, social arrangement and hierarchy in the organisation.

\section{Cui Kai's dual role}

The marketisation of CAG, which has been evolving over the past twenty years, has had an influential impact on Cui Kai's designs. The state-centred analysis assumes that both society and the economy are subordinated to the political order, 
as largely passive entities to political power. ${ }^{73}$ Analysts referring to SEOs as symptomatic of the communist political order overwhelmingly emphasise the dominant role of the party; my research on the evolving designs of Cui Kai has sought to move beyond this approach by looking at the relationships between market and institute, market and people, society and reform and market and architecture. These appear to be direct causal links shaping his designs within the forces of a planned economy and a market economy.

\section{- CAG's market transition}

As an architect working in an institute, Cui Kai is always classified in China as a mainstream architect. Cui Kai spoke about the difference between the large-scale institute and privately operated firms:

I joined the CAG in 1984, and if we take 60 years old as the retirement time, two thirds of my professional working life has passed, and I have more or less arrived at the middle of my career. I have been working in the state-owned large-scale institute, close to the Ministry of Construction and Architectural Association, which accustomed me to the environment, and the sense and pace of "inside the system" working. In recent years, reform in the design industry has been opened up; many of my friends switched to business from the large-scale institute, or opened their own firms in China after overseas experiences. Some people have asked me, "which is more competitive, the state-owned large-scale institute or small private firms?" I find it difficult to answer this question; it should be rated according to the choice of the market and the contribution to the profession as well. Actually I am keen to find a system featuring smallness embodied in largeness and vice versa. ${ }^{74}$

Pilot reforms in CAG had been carried out as early as 1979, since CAG and other design institutes began to charge fees from the client, based on a contract. The main objective of this reform was to separate the design institutes from the governmental sectors and let the institutes assume sole responsibility for their profits or losses. ${ }^{75}$ The internal change in CAG occurred in 1992, when the chief manager, Liu Xunfan, pushed an important reform through CAG. In order to solve the problem of financial shortfalls and to increase the efficiency of production, Liu asked each studio to run design assistants on a contractual basis and linked the income of each architect to his productivity. ${ }^{76} \mathrm{He}$ also propelled macropolicy environment reform, especially the financial system and interest rate policy reforms: the top bracket enterprise income tax rate was reduced from 55 percent in the older system, to 33 percent, and a variety of surtaxes were eliminated, making the tax structure leaner and more transparent. ${ }^{77}$ In the early 1990 s, the central government decided to list some large state firms as a portion of China's state-owned enterprises and sell off small state enterprises. ${ }^{78}$ The competitive market dynamics generated by market growth and the entry of foreign competition, for example, the international architectural bid for China's National 
Centre for the Performing Arts, which was won by Paul Andreu, created pressure for $\mathrm{CAG}$, which had grown accustomed to occupying a dominant position in the Chinese market.

Although some scholars initially held negative ideas on the partial reform of China, and argued that it was not likely to result in improved economic performance, ${ }^{79}$ in a recent analysis, Ralston argued that the SOEs have substantially transformed to approximate a configuration desired by the Chinese government when it began the SOE transformation two decades ago to make them globally competitive. ${ }^{80}$ With regard to $\mathrm{CAG}$,

CAG's business scope includes project consultation, planning, design . . . etc. covering the whole process of fixed assets investment. Its main business scope covers: architecture design and consultation; urban and town planning; municipal engineering comprehensive design; urban gas and industrial gas design; sewage and garbage disposal; road and bridge design; building intelligence and systems design . . . and other above mentioned items. The Group has now set up its business structure to integrate building design, urban planning, municipal engineering, building standardization, construction information, project consultation, interior decoration, landscape and gardening and housing research/development as its chained businesses. ${ }^{81}$

This strongly suggests that CAG has been re-engineered into a viable and competitive economic entity.

The role of private clients, including developers, businessmen and any people from the private sector with money and ambition has gradually changed in the 1990s. These private clients have been relatively free from government influence with a more market-oriented attitude towards architectural projects. With national economic growth, Cui's working environment in the market has been improved. However, market reform in a nation-based design institute is far from accomplished, and the reform process is still troubled by a series of contradictions, in which Cui's architectural designs attract undeniable tensions.

\section{- Cui Kai's dual role in the market transition}

The evident tensions between the state and the private market endow Cui Kai with a dual role, and he has his own reflections about the nation-state and the market,

I think the localization of Chinese architecture satisfied both the need for protecting and for proliferating our own culture, and the roots of us, the Chinese architects. The concept of localization is different from the style theory of "national formats with socialistic contents", and it also rejects the commercialistic stance that caters to market fashions by copycatting. ${ }^{82}$

The design of SOHO New Town (Phase I) (Beijing, 1998) (Figure 4.4) is Cui Kai's first attempt to collaborate with a real estate developer. SOHO China Limited 


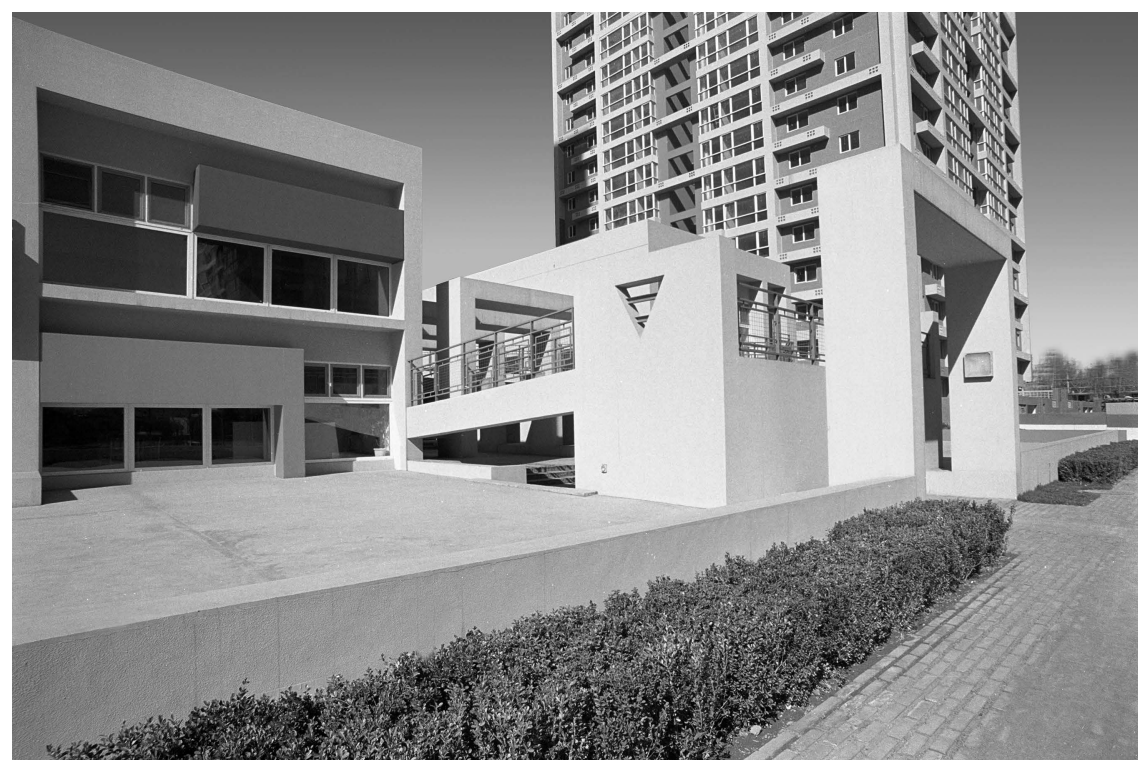

Figure 4.4 Cui Kai, SOHO New Town (Phase I), Beijing, 1998

was founded in 1995. It is the largest prime office real estate developer in China. It focuses on developing properties in the central business districts of Beijing and Shanghai. SOHO New Town is the first project of SOHO China. These New Towns are professionally designed and built to a high standard, which makes them easier to rent and allows investors to achieve rental yields earlier.

SOHO New Town (Beijing, 1998) is a mixed-use development of 471,000 square metres in gross floor area, including forty-eight shops, 283 offices, and 1,897 apartments. Designed by Cui Kai and Zhu Xiaodi, and initiated and operated by SOHO China, it was recognised as the best-selling development in Beijing in 1999 and 2000. In an article written by Cui Kai's collaborative designer Wu Xiaohong, in the Architectural Journal, he states:

The collaboration between the architect and the developer in the SOHO New Town (Beijing, 1998) should be noted. In the first phase of design, based on the developer's rich market experiences, they offered us good suggestions and requirements; for example, no large apartment types facing the north, protecting the view of the landscape even sacrificing the orientation, duplex apartments required to meet the housing standard, and so on. They constantly provide updated information from the market, which made us understand the dynamics in the market of the psychological requirement of the clients. . . . Generally speaking, in the marketization of the residential buildings, what an architect should face is not only the developer, but all the residents and the 
whole market. How to maximize the requirements from the buyers and how to produce selling points is a brand new task for every architect. ${ }^{83}$

In this process, the pursuit of profit, the participation of eventual residents and the interactive influence of fashion cultures expanded Cui Kai's vision and further pushed his designs to run in tandem with the maturity of the market.

Furthermore, in the market transition, Cui Kai's architectural styles reflect increasing diversity, which results from his dual roles in at once finding his individual style and representing a collective identity. Cui Kai's studio was set up in the CAG in 2004. Cui Kai gradually realised that the work would reflect his own identity, rather than reflect the collective unit. He began to understand that his individual world view, experiences and values created a framework informing his design decisions. With the emergence of prominent architects, most of whom are independently practicing, it is natural for Cui Kai to expect that his personal expression will allow other people to define his unique place in the discourse of architecture. Therefore, he has aimed for a more personal expression, striving for a personal identity in his architectural designs, a move which has resulted in various experiments. However, when questioned in regard to his personal achievement, he insists on the collective effort, "The accomplishment of so many works obviously is not an achievement of my own, but the fruition of the collective work of the whole China Architecture Design and Research Group, a collaborative effort by numerous participants from all fields." ${ }^{84}$ This comment indicates that Cui Kai is still very conscious about his responsibility within the collective work unit.

Moreover, Cui Kai's idiosyncratic position in a national design institute, but also within a relatively free market, gives him easy access to both national projects and private projects of various scales. His dual role has also resulted in a variety of designs. Some examples are: the Lhasa Railway Station (Lhasa, 2006) (Figure 4.5), the Liangshan Nationality Culture Art Centre and Torch Square (Liangshan, 2007) and the Beichuan Cultural Centre (Beichuan, 2011). The 1956-kilometre-long Qinghai-Tibet railway starts in Xining, Qinghai Province, and ends at Lhasa, the capital of the Tibet Autonomous Region. This is the highest and longest plateau railroad in the world. The Lhasa Railway Station is the terminal of the Qinghai-Tibet railway. The Liangshan Nationality Culture Art Centre and Torch Square, designed by Cui Kai, is also a crucial project for the Liangshang Yi Autonomous Prefecture fostering local culture.

Simultaneously, the significant technical support from CAG gives him more opportunities for architectural experimentation. In addition to the architectural institute, CAG is composed of many distinct departments, each with its own agenda. The Functional Department, the Structure Institute, the Design Business Managing Centre, the MEP Institute, the Town Planning Institute, the Environmental Art Institute, the Human Settlement Engineering Centre, the Building Energy Engineering Centre, the Assistant Department and the Research Department are all represented. The rich sources of expertise and solid collective support in the large-scale design institute in China provides an integrated platform as a basis. Therefore, Cui Kai is also able to work on experiments with new materials 


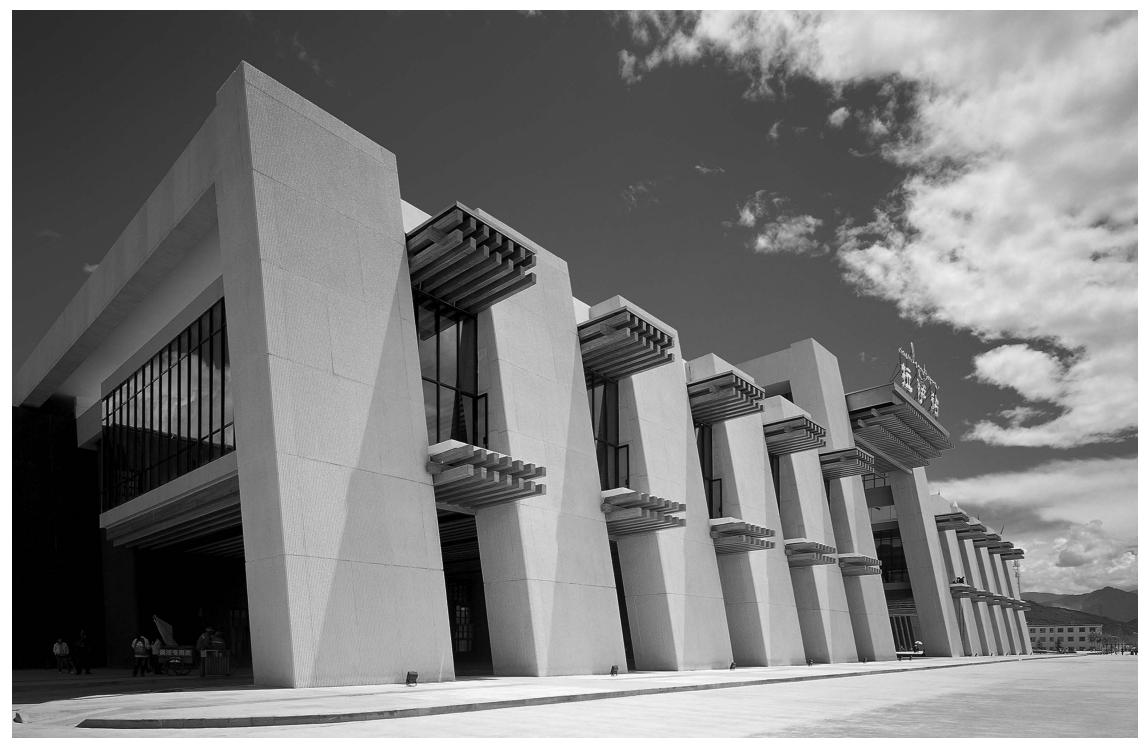

Figure 4.5 Cui Kai, Lhasa Railway Station, Lhasa, 2006

and new structure. For example, In the Multi-Function Broadcasting Tower in Olympic Green discussed above, the Exquisite Tower (Beijing, 2008) assumes a triangular shape, in which the three angles contain respectively the stairs and elevator shafts, which are also support points for the steel frames (Figure 4.6). Oblique beams are crossed, joined and connected with each other among the frame shafts, naturally forming rhombic spaces as TV broadcasting studios.

\section{- Resolving the challenge of "inside the system"}

In Cui Kai's designs and his relationship with CAG related in the previous section, Westernised architecture clearly camouflages the true nature of some stateowned design institutes; in this sense, CAG is not an autonomous corporation. The goal of every reform effort undertaken by the party regarding the CAG has been to achieve a balance between the free market and elements "inside the system", as laid out in Chapter One. However, there have been increasing public concerns about the one-party authoritarian regime and complex organisations. Similarly, the shared architectural norms influenced by one-party nationalism and the organisational culture in Cui Kai's designs could easily considered to be bureaucratic and stereotypical.

The party's strategy in the post-Mao era was proven successful for economic growth. The shift from class struggle to economic modernisation as the key task of the party, however, made the party dependent on technocrats and entrepreneurs. 


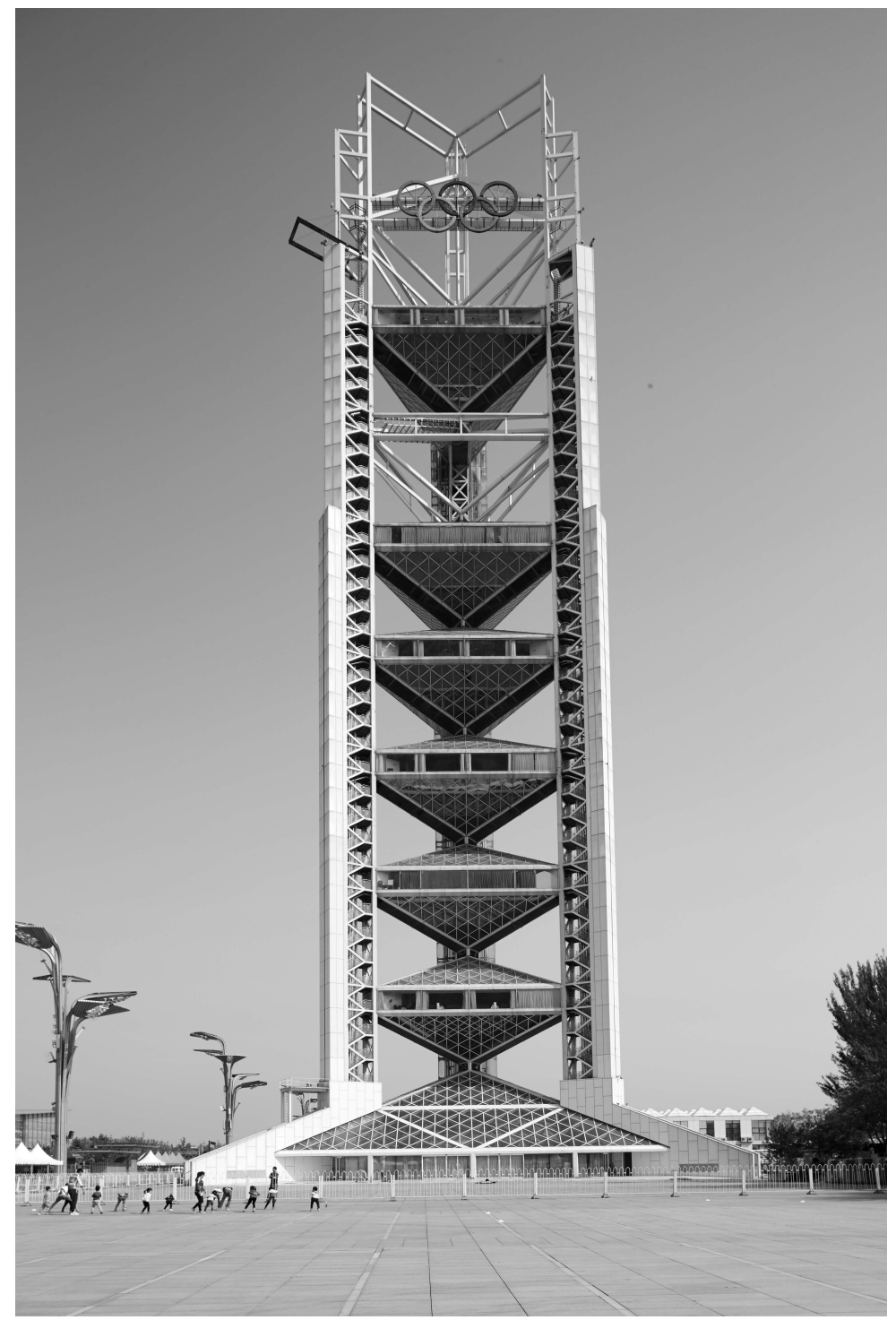

Figure 4.6 Cui Kai, Exquisite Tower, Beijing, 2008

In the contemporary context, Chinese people are not committed to party traditions but economic growth. Dickson has argued,

The party retains its monopoly over political participation and takes credit for the economic growth created by the entrepreneurs. Entrepreneurs may be 
unwilling to risk the certain benefits of the existing system, despite its many irrationalities, for the uncertainties of an alternative arrangement.

Allied with entrepreneurs, Cui Kai, as a technocrat, functioned within a noncritical realm; he was primarily concerned with promoting architecture in China and, to that end, limiting the influence of ideology in architecture. Moreover, he lacked exposure to alternative political values and institutional arrangements, since he did not receive college degrees from Western countries. Although committed to current political values and institutional arrangements, he did not want to be considered to be a bureaucratic technocrat.

Though people have increasingly challenged the one-party authoritarian regime and complex organisations of China, Cui Kai's design approach, influenced by organisational culture, has upgraded stereotypical imagery of bureaucratic, stateowned institutions. As such, it does not result in an imbalance between the quality of design and the political demands imposed on those designs. What has limited the negative effect of the authoritarian and institutional culture's impact on the designs has been the emergence of the market. For Cui Kai, his dual role of mediating the state and market finally guaranteed his design as accessible and acceptable to the Chinese people.

Negotiating the contradictions between challenges of elements "inside the system" and the requirements from "outside the system," his designs appear evolutionary, not revolutionary. An open-ended evolutionary process of institutional change has characterised China's reforms. Though CAG has already formed an entrepreneurial or competitive culture, due the burden of the hierarchy of cultural constraints, the designs are usually not provocative, but they aim to meet the aesthetic requirements of the public. Though newness and originality are key ingredients for breaking into the market, innovation is of secondary importance in Cui Kai's works, compared to other private design firms, as a result of long-term hierarchical control in the culture of CAG. Therefore, Cui Kai's designs are more stable and less innovative than those of his counterparts. Yet they have evolved along with the market's evolution and have thus been recognised and accepted by the market.

Moreover, Cui Kai's standpoint and his reflections on architecture have the tone of high culture as previously discussed, but this opinion is not restricted to state agendas. Cui Kai's designs do not focus on high culture as pure adornment, confirmation and legitimation of state government. He also gives importance to popular cultures. Achieving the balance between his sense of mission for the nation, and the demand from the market, his designs have become a shared medium or shared atmosphere that tie the diversified locality-tied popular cultures and integrate them into high culture. Consequently, what Cui Kai seeks is a mediated style reflecting modernism and nationalism, an architectural language supervised by the academy, codified for bureaucratic communication with the state, but available to Chinese residents who are eager for a new world and the growing market. In the context of globalisation, this high culture is also striving for communication with the rest of the world. 


\section{The operation of rationalism in architecture}

Cui Kai's first booklet, Projects Report, was published in 2002. The title of this design collection did not even use the term architecture or design, which reflects his modest attitude towards his achievements, although by 2002 he had already been awarded National Best Science and Technology Engineer in 1997, Expert Who Enjoys Special Subsidy from the State Council in 1998, Excellent Mid-Young Aged Expert of the Ministry of Personnel in 1999, and Candidate of "National Hundred, Thousand \& Ten Thousand Reserves Project" in 1999. Cui Kai wrote, "It was named so for fear that I should not have attained enough aptitude to brag of anything that can be termed a design concept." ${ }^{85}$ Native Design is his second design collection book published in 2008. It was the first time Cui Kai tried to adopt a conceptual term, native, in the retrospective appraisal of his own designs. It could be ascribed to his increased overseas experience and the increased popularity of a celebrity architects' cluster across China. From 2003, Cui Kai was continuously invited to international exhibitions, including La Biennale di Venezia (2003), the 8th International Architectural Exhibition in Italy (2003), Urban Rumor-Chinese Architecture Exhibition in Taipei (2004), the first Shenzhen Architectural Biennale (2005) and the Creative China Exhibition in London (2008). Meanwhile the celebrity architects' cluster, assembling pioneer architects in China and outside China, flourished within China. Cui Kai, as the representative architect in a large-scale design institute, was always invited. For example, he participated in the "Commune by the Great Wall" in 2002, a collection of contemporary architecture designed by twelve Asian architects, where he worked with Kengo Kuma, Yo Hong Chang and other architects in the group design. It was possible for him to see that most of his peers inside or outside China had already located themselves and their designs into some conceptual framework, regardless of motivations, for business promotion or for a theoretical rationale for their designs.

Furthermore, Native Design contains detailed reflections on the term native,

As far as I understand, this concept of native contains several meanings. The first is about environment, that is, the land on which we live. . . Native designs should stand out and shoulder this responsibility. The second is about culture, the culture growing and thriving on this fertile land.... Local designs should take root in it, and continue to produce new cultural leaves. The third is about space, the regionalism and localization of buildings. . . . Native designs should be the creation with such localization, helping the city to retrieve its features, and the citizens to recognize themselves. ${ }^{86}$

However, due to the word-to-word direct translation from Chinese to English and absence of an equivalent word in English, problems arose for foreigners in understanding this concept. When Cui Kai gave books with the translated expression to peers and friends from other countries, they always associated him with nativism, or something done or designed exclusively by local people. ${ }^{87}$ Therefore, he 
started to use the Chinese pronunciation of the Chinese word or the Chinese word juxtaposed with native. He made this more explicit statement, "I am a 'Ben Tu / native' architect. I said so not only because of the absence of overseas educational experience, but also because of my proposition for design in land-based terms." ${ }^{88}$ The expression native or "BenTu design" is more likely to deliver his sense of values towards society, rather than a theoretical framework for his design. In other words, native is geared towards his world view, but the approaches could be multi-faceted.

Cui Kai expanded his idea to "Land-based Rationalism" in his third design collection book titled Cui Kai, which is less poetic and less equivocal. In regard to the "Land-based Rationalism", he wrote,

In summary, Land-based Rationalism is a rational design principle, taking the natural and human environment resources as its base, and emphasizing the importance of its supporting land and surrounding backgrounds. It indicates both a stance to unremittingly explore the possibilities of new socialist buildings with Chinese characteristics, and a policy for land-based constructions with distinguished features to gain the rightful place in international architecture. Moreover, it reflects a cultural value, serving as the architectural embodiment of "harmony", which is the core cultural idea of Chinese society. ${ }^{89}$

It could be summarised that the underlying explanation of this concept is that the project might occur next to a historical site, or there is strong local culture and tradition or the existing urban environment is daunting, and what he insists on is to take root in the soil of natural and human environmental resources through rationalist design. The term rationalism has been used to refer to several different outlooks and movements of ideas. "The earliest organized form of rationalism in philosophy is stoicism, that is, the Hellenistic philosophy that sought to make the personal and political views of people as orderly as the cosmos." 90 Cui Kai's education was in the Beaux-Arts tradition, in which he was taught the art of composition and aesthetics. His own architecture, although not strictly cubical, symmetrical or composed, shows his preference in adapting the art of composition and aesthetics to the requirements of new times, new technology and a new economic reality. But Cui Kai does not use the term composition often in describing his own designs. The term composition that traditionally stands for timeless values that corresponds to static phenomena was over-emphasised in his architectural education. However, the choice of native reflects a more dynamic quality Cui Kai wants to achieve.

As previously discussed, the culture of nationalism and internal and external surveillance of the institute, shape the rationalism in his design and underscore the conventions about appropriate ways of thinking and designing. The market also prevents his designs from irrational nationalism and limits the negative effect of the institutional culture's impact on his designs. Some standards and criteria imposed by the outside forces and the architect himself make his individual identity visible, and this identity embodies a strong sense of rationalism. It is possible 
to detect two sides within the rationalism practices: on one hand, it leans towards a higher degree of complexity in composition, but still under the guidance of rational principles, evident in the Inside-Out, Artist Colony (Beijing, 2009), the Office Building of Beijing Foreign Studies University (Beijing, 2009), the Library of Nanjing Arts Institute (Nanjing, 2010) and the Agriculture \& Ecology Group of Zijingang Campus, Zhejiang University (Hangzhou, 2010). On the other hand, he aims for a higher degree of rational simplicity in another series of designs, for example, the Legation Quarter (Beijing, 2008) and the Reconstruction of CSEC Office Building (Beijing, 2011).

\section{- The rationalism of complexity}

The International Conference Centre of Foreign Language Teaching \& Research Press (Beijing, 2004) is a good example illustrating complexity within rationalism. The design of the office building of the Foreign Language Teaching \& Research Press (FLTRP) (Beijing, 1997) in 1996 was a milestone in Cui Kai's career. The office building is a single project, featuring high-standard spatial quality and innovative geometrical properties. As the FLTRP developed rapidly in the early 2000s, there was an urgent demand for a large-scale book circulation centre to distribute and transport a substantial volume of books. Concurrently a new place for publishing was also needed. It is located in the southern suburb of Beijing, $30-\mathrm{km}$ away from the inner city. This was the first chance for Cui to practice and explore the systematic meaning of architectural language in a group of buildings. The Book Circulation Centre of Phase I is designed as parallel linked units, with four stack rooms and one large paper storage room connected by the discharging platform. The architecture here firmly responds to the functional demand.

In the design of Phases II and III, the communications between buildings, and forms connecting different volumes, have also evolved into an informal system. The Educational Building Phase II in the east faces the main street of the industrial park, and the Western part of the building organically fuses with Phase III. It should be noted that there is an echo between a series of refectory, multi-function and reception rooms that are scattered in the long and narrow central courtyard in Phase II. It is possible that Cui Kai realised that the static and fully enclosed traditional courtyard space is an obstacle to modern ideas of movement in architecture. The long wing of the L shaped main building in the Conference Centre of Phase III is connected to the Swimming Pool, Entrance Lobby and Auditorium, while facing the training section. In mediating the styles, volumes and façades of a group of buildings, he enriched his own architectural language and further circulated them in a rational well-orderly system.

Compared to the International Conference Centre of FLTRP (Beijing, 2004), Cui found a further territory to work in and developed a rational, organic and organisational principle in the planning of a group of buildings in the design of the Business Office Area of Songshan Lake New Town (Dongguan, 2005). Confronting the project, Cui described it as a "beautiful environment, abundant funding, enlightened client and an attractive development." ${ }^{91}$ His designed group 


\section{0}

Renarrating the state

of buildings are located on a hilly site to the north of the Songshan lakeshore, stretching from the Administration Office Building that extends to the lake, and ending at the library in the south. The buildings are connected to one another in a symmetric layout. They together constitute the central area of the Songshan Lake High-tech Industrial Park.

The Software Engineer Apartment in the Dalian software area (Dalian, 2006) shows that Cui positively responds to the local condition and aims for a sustainable habitation condition. At the same time, he achieves elegance of detail with maximum functional demand and correctness of proportions (Figure 4.7) in one building. The site for the building of this engineer's apartment building is limiteda piece of long and narrow land fronting a road street: $160 \mathrm{~m}$ from the north to the south, and 48-m wide from east to west. Cui Kai designed the two bottom floors as shops to fuse into the nearby pedestrian areas. A small five-storey apartment building sits in the middle, with east-west orientation and with an upper middle-sized apartment section facing northward and southward in a grouped form, give the building a sense of stretched volume. It is important for living quality in Dalian, which has a continental climate with dry winters and hot summers, to achieve a north-south orientation, and so the crucial point of this 90 degree rotation is not purely about formal composition. It is also the best approach in order to realise the highest number of apartments. In the detailed design, the bay windows increase the surface of day lighting, and the opening leaf and positioning of air conditioners are also carefully considered. Cui Kai adopted grey and white as the main

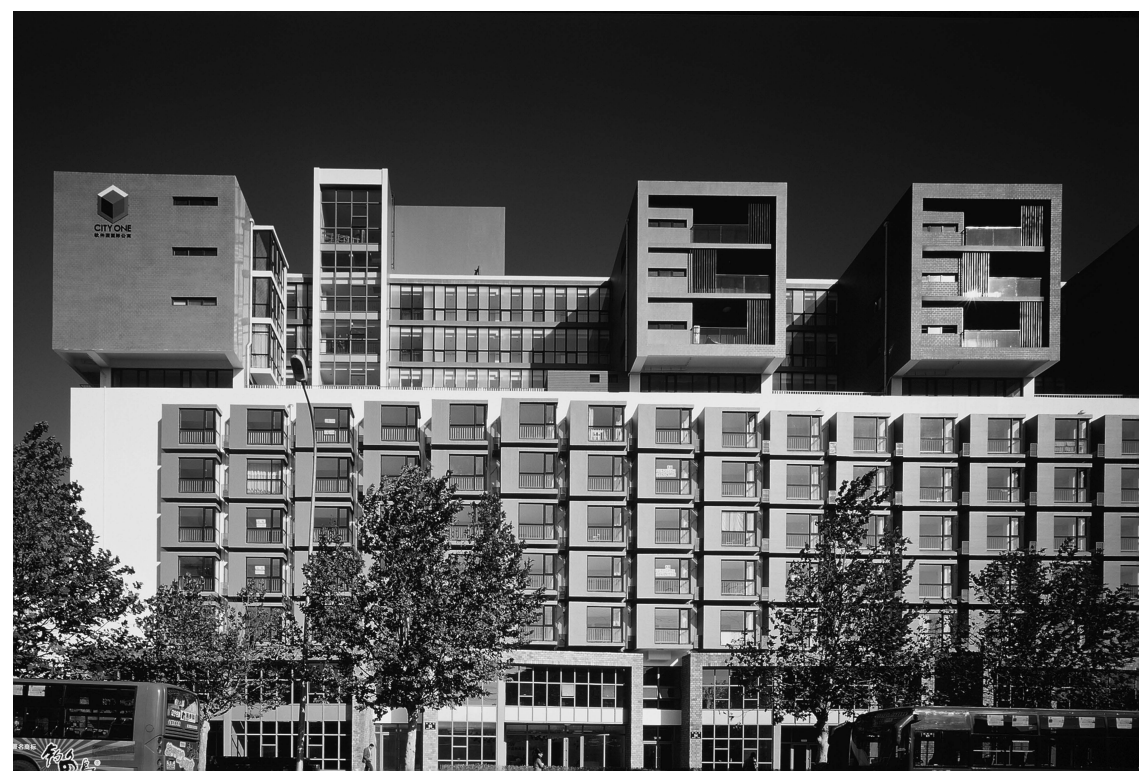

Figure 4.7 Cui Kai, Software Engineer Apartment in the Dalian software area, Dalian, 2006 
hues, and small schists and paint as supplements, which have also been applied in other projects. It seems that on occasion his designs adopt a Beaux-Arts style, and in contrast, his designs sometimes utilise a Miesian approach.

Cui Kai continued evolving and updating the complexity of the composition in the Inside-Out, Artist Colony (Beijing, 2009), but this time using a skeleton grid. In this design, Cui Kai started to throws off the constraints of an old, static order, to free up a new starting point (Figure 4.8). The block is arranged according to the relationship between working and living. The whole project consists of seventy-five suites of artist studios on a $108 \mathrm{~m} \mathrm{X} 108 \mathrm{~m}$ site, with a height limit of $18 \mathrm{~m}$. The concept - "floating container" - is employed by Cui Kai to represent the interaction of working and living in the same studio unit: for an artist, working appears like diving beneath the water surface, holding his breath to do his best, while breathing freely depicts his life in rest time. ${ }^{92}$ A cramped, material, stable equilibrium gives way to a new bolder equilibrium: the boxes are raised up or sunken down.

The Beijing Foreign Studies University Complex Gymnasium (Beijing, 2008), and the Office Building of Beijing Foreign Studies University (Beijing, 2009) also demonstrate his capacity in more complex geometrical systems, which attempt to achieve more intricate, dynamic formal expressions and relationships. Both these buildings are located on the campus of the Beijing Foreign Studies University.

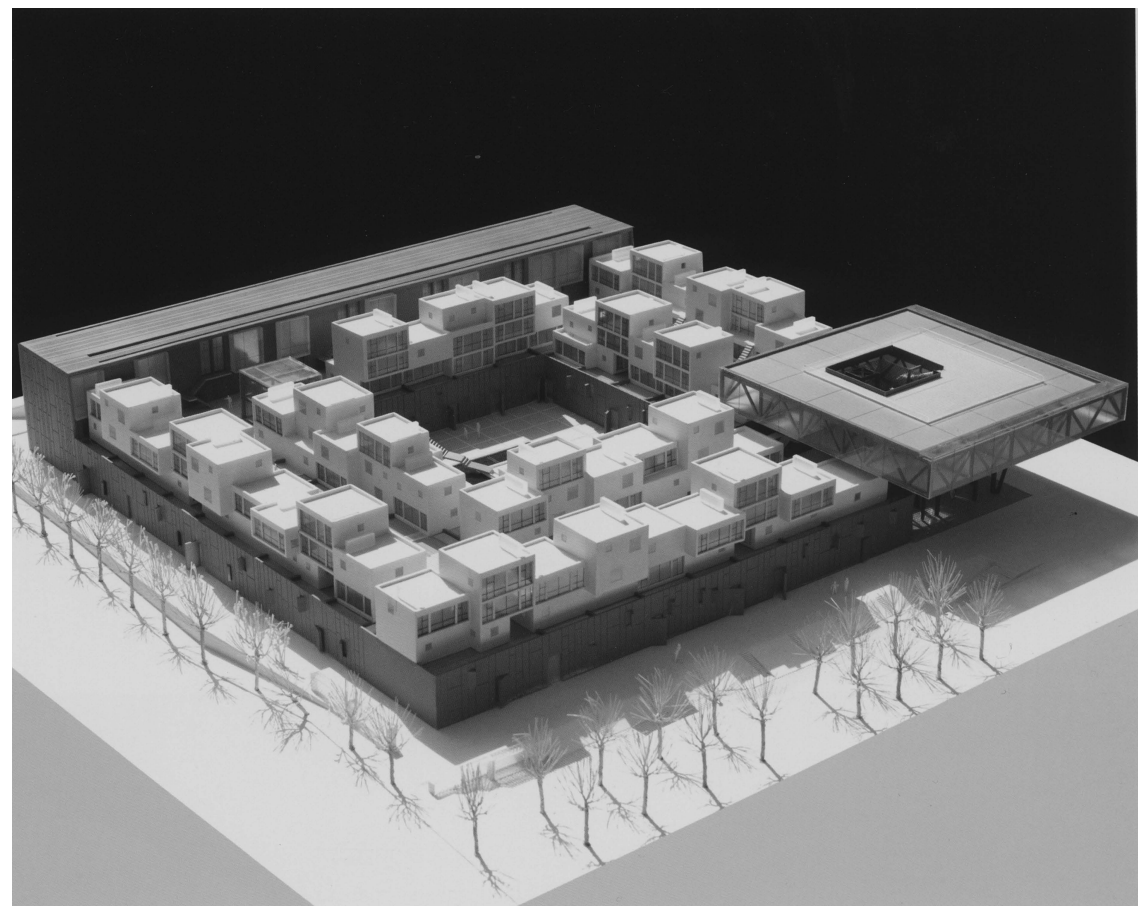

Figure 4.8 Cui Kai, Inside-Out, Artist Colony, Beijing, 2009. Model 


\section{Renarrating the state}

These two projects aim to restore a sense of wholeness to the campus's original master plan, designed in the 1950 s by Zhang Bo. ${ }^{93}$ The original forms, vocabulary and colours are maintained in the new buildings. Since the existing architectural themes are strictly cubical, the Complex Gymnasium (Beijing, 2008) shows Cui Kai's attempts to exploit the possibility of blurring the cube's boundaries without destroying the sense of whole. It has two grand arcades with a four-story height and 2.7-m width on either side, which obscure the straight edge of the huge mass. The large balcony on the east façade extends the interaction between the gym and its surroundings.

The projects discussed above have one shared feature: the cube-based strategy. Yet Cui Kai occasionally searched for rational ways of achieving irregularity and spontaneous contrasts as well, extending the limitations of the cube shape. In projects like the Beijing Digital Publication Information Centre (Beijing, 2007) (Figure 4.9) and Chengde City Planning Exhibition Hall (Chengde, 2009), Cui Kai attempted to free the organisational order from the characteristic rigidity of rationalism. This direction has been pioneered by many renowned architects, like Ma Yansong. However, it should be noted that Cui Kai did not impose the undulating surfaces on the Beijing Digital Publication Information Centre (Beijing, 2007). The site of this building is on the border of old Beijing city that results in a sharp difference of height limitations on one site. The challenge was how to harmonise the distinct sizes of a traditional inner city with the rapidly growing modern city. The client requested the building to be divided into two parts. Combined with the different height limitation given by the site, the architect - as

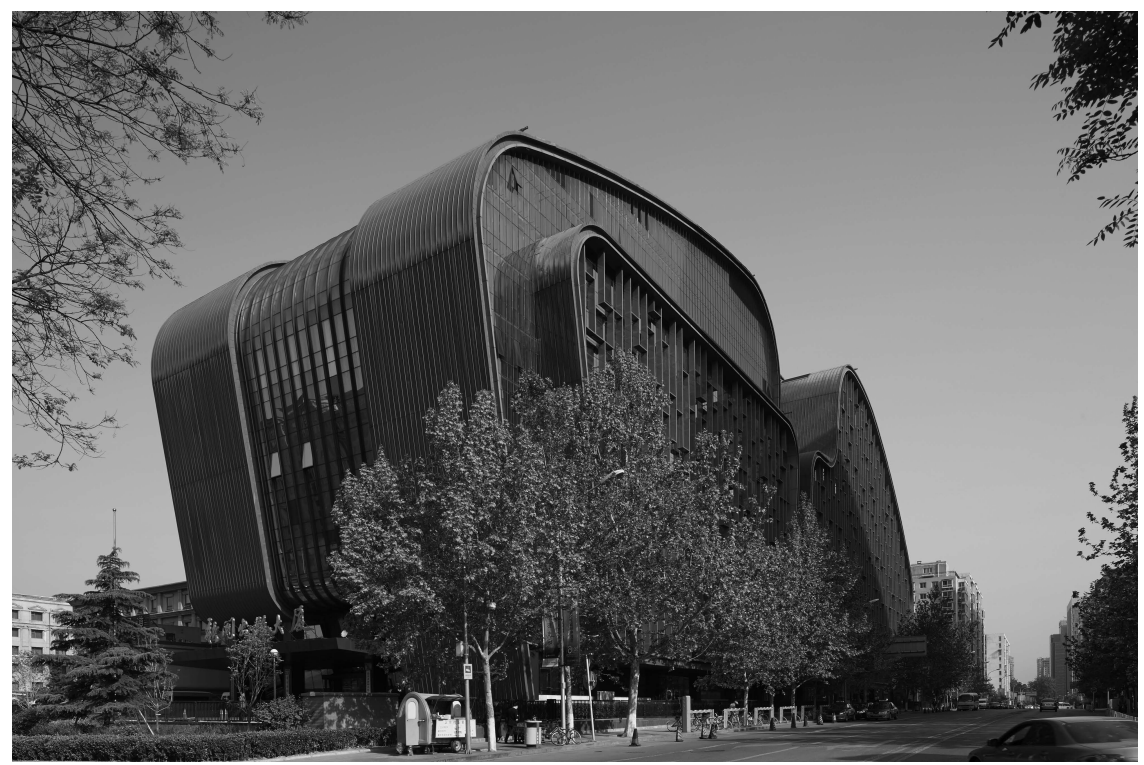

Figure 4.9 Cui Kai, Beijing Digital Publication Information Centre, Beijing, 2007 
interpreter - chose the undulating surfaces as a device to connect all the height limitation points, and simultaneously satisfy the daylight codes and maximise useful space, a rational solution portrayed as a formal invention. Cui Kai avoids being identified as a pure follower of fashion: "Telling a story behind design is not to deny the influence of current fashionable trends, but to present a reasonable design process." 94 For many contemporary architects, fashion trends and consumer culture are part of practice. But Cui Kai is constantly alert to the corrupting nature of fashion. In these projects, Cui Kai was striving to find a rational way of working with the free forms and loose structure current in contemporary architecture.

\section{- Rationalism of simplicity}

The buildings discussed above represent Cui Kai's path to maturity in a complex architectural vocabulary based on rationalism. In his mature work, Cui Kai's initiatives are increasingly reflected in a series of designs, for example, the No.9 Building of Dalian Software Park (Dalian, 2004), the No.10 Building of Dalian Software Park (Dalian, 2006), the Legation Quarter (Beijing, 2008) and the Yin Ruins Museum (Anyang, 2006), all of which show order and discipline tending towards simplicity, in an attempt to combine his worldviews, goals, strategies and cultures into a single theme. Yet the simplicity in Cui Kai's works does not necessarily rest on a singular geometry. For instance, the fusion between formal dignity, functionality and modern technology is revealed in the No.9 and No.10 buildings (Dalian, 2006) (Figure 4.10, 4.11) of Dalian Software Park. Compositionally, No.9 building is an advance for him in the easy combination of volume and ornament. He emphasises horizontal lines in the tension between the five upper floors and the five floors below. Cui Kai suggested prefabricated reinforced concrete panel to the client: "compared to stone, it has a larger size; compared to aluminium sheet, it does not look as light; compared to other composite materials, it is durable, solid and has a high working precision." 95 The prefabricated reinforced concrete panel has great mass compared to other materials and plays an important role in demonstrating the sophistication in the rationalist approach. It achieves the aesthetic composition of boxes from the basic elements of accelerated horizontal movement. The choice of small slate wall tiles in the lower floors makes the buildings look as though they are a component of the street, since this material was used to clad as the adjacent school building of the Information College.

The design of the Legation Quarter (Beijing, 2008) is a more extreme case. Initially built as the American Legation in the beginning of twentieth century, No.23 Qianmen East Street housed many institutions before the renovation, while its original layout, five independent buildings and a quadrangle, was corrupted after several additions. The renovation focused on restoring the quadrangle and making it a centre for high culture in the centre of Beijing city, providing restaurants, galleries, theatres and entertainment services. The enclosing and nonstructural volumes achieved a high degree of integration of the modern and the traditional in strict orderliness, but with lyrical qualities. By using a series of steel and glass structural elements, the Legation Quarter (Beijing, 2008) achieves a 


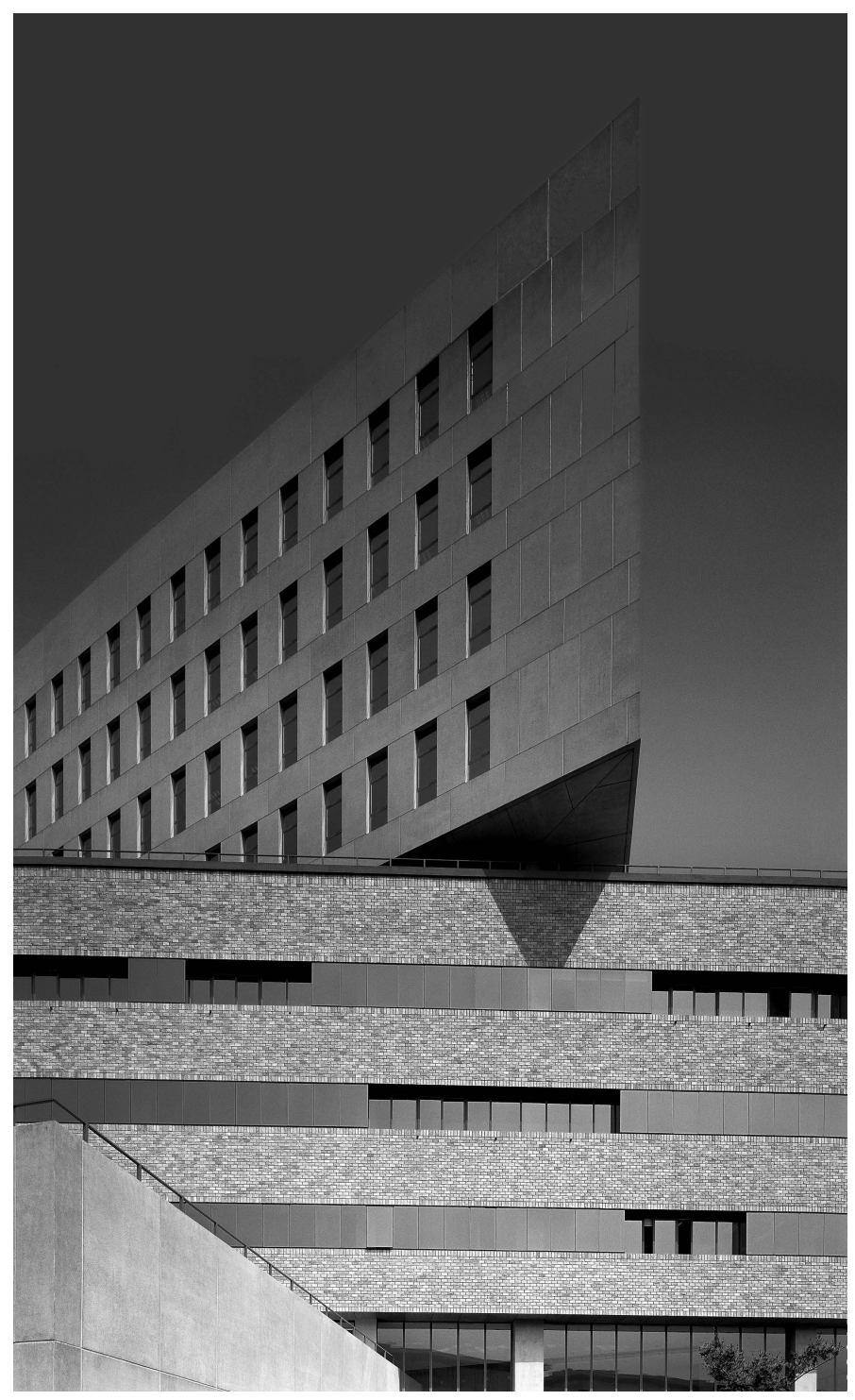

Figure 4.10 Cui Kai, No.9 Building of Dalian Software Park, Dalian, 2004

simple, unobstructed connection to the surrounding environment and the history of the buildings themselves.

In Yin Ruins Museum (Anyang, 2006), on the basis of achieving a balanced combination of structural and material soundness and functional comfort, Cui employs the ideals of simplicity and regularity. The history of Yin Ruins is rich and provided the architect with numerous ideas. The main part of the building lies fully 


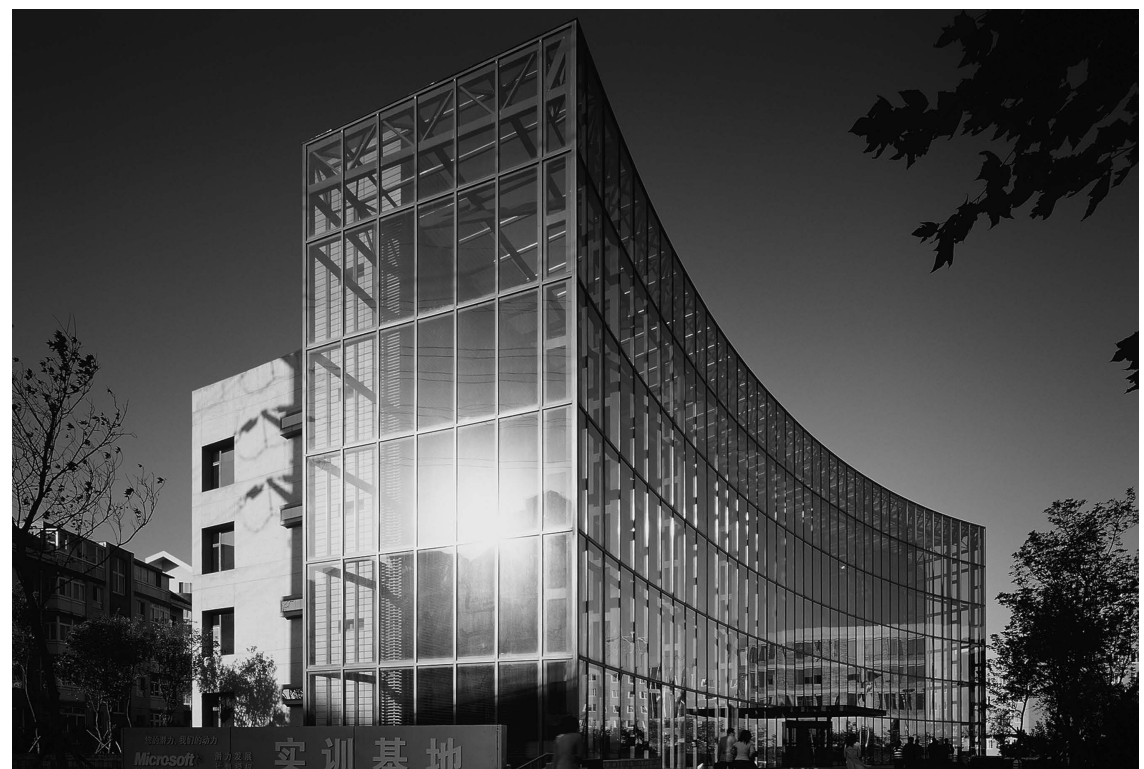

Figure 4.11 Cui Kai, No.10 Building of Dalian Software Park, Dalian, 2006

underground, covered with green vegetation. Only the bronze walls around the yard are slightly above the ground, indicating the presence of a mysterious concealed space. Thus the building integrates into the surrounding environment, preserving the natural original form of Yin Ruins to the utmost. Cui mainly used one material:

There is only one basic material in the appearance of the museum-pisolite plaster. It is the same as that used for the few outer walls and side walls of the downward ramp. This round local-produced pisolite, being quite cheap and simple in construction, is also the main material for the paving in the museum park; even the workers were wondering why the museum was being built again in such an old fashion that had been given up for twenty years. ${ }^{96}$

When walking along the narrow lane, the simple wall on both sides is calming; with the gently moving treetop in the sky above, it conveys to the visitors that they are comprehensively removed from the uproar of urbanity. Therefore, simplicity and serenity here is a matter of functional logic, site logic and locally produced materials, to achieve the aesthetics of simplicity.

\section{- The fluctuation between modernism and postmodernism within rationalism}

In Cui Kai's design, simplicity does not display a wholly simple, or unacceptable and sterile scientific rigour, but an acceptable and humanistic rigour. The 


\section{Renarrating the state}

simplicity manifest in his designs does not narrowly focus on one element at the expense of others. He suppresses the picturesque and stresses constructional and compositional elements. Ideas of simplicity are also given a complex twist, with the introduction of a syntax that explicitly describes many elements. In contrast, the complexity he employs does not incorporate too many traditional or popular elements. That is to say, the rationalism of simplicity and the rationalism of complexity are that far from each other in their selection and rationalisation of devices. It could be argued that Cui Kai's designs are contained within a specific area which has been marked out by his belief in, and tactics of, rationalism.

In this specified area of possibilities described by rationalism, the trajectory of his designs can be traced back to how his design evolved in the broader historical context, including pre-reform China and pre-PRC China and their relation to the dominant styles of modernism and postmodernism, two movements exerting influence over his designs. However, in addressing the role of modernism and postmodernism in his early works, there has remained one question unanswered from section one: how did modernism and postmodernism engage with each other in his design from the early 1990s onwards?

Cui Kai experienced a delayed exposure to modernism via the architectural curriculum in mainland China, in which the new and modernisation are roughly synonymous in the late 1970s and early 1980s. Cui Kai was initially educated as a modernist disciple, but he soon experienced a significant societal change: the "delayed modernism" bloods strongly dominant after the termination of the Mao era was then caught up in the theories of "hazy postmodernism" in the postMao era. Chronologically analysing his works from the angles of complexity and simplicity, it seems evident that modernist architectural language is never absent in Cui Kai's designs, and his designs that can be categorised as postmodern have never incorporated popular elements. In other words, the two characteristics of complexity in composition, and a high degree of rational simplicity, have been the manifestation of the conflict between the modernism and postmodernism.

The consciousness of serving private clients contrasted with the consciousness of serving the nation in a state-owned design institute provided Cui Kai with a norm in architecture and a rational mindset. The role of rationalism is to delimit the potential and define the boundaries for his designs. Yet the fluctuation between modernism and postmodernism determines the trajectory of his designs, which are insulated from kitsch culture and overt political practice by rationalism as a practice. In the different stages of China's transition, there have been different factors that maintain this unique fluctuation in his designs.

It is also important to define kitsch culture in the context of contemporary China. In his essay "The Cultural Logic of Late Capitalism," Jameson lays out the differences in culture between the modern and postmodern periods. The author argued that postmodernism is not a style, but it is a dominant cultural form indicative of late capitalism.

What has happened is that aesthetic production today has become integrated into commodity production generally; the frantic economic urgency 
of producing fresh waves of ever more novel-seeming goods (from clothing to air-planes), at ever greater rates of turnover, now assigns an increasingly essential structural function and position to aesthetic innovation and experimentation. ... Of all the arts, architecture is the closest consecutively to the economic, with which, in the form of commissions and land values, it has a virtually unmediated relationship. It will therefore not be surprising to find the extraordinary flowering of the new postmodern architecture grounded in the patronage of multinational business, whose expansion and development is strictly contemporaneous with it. ${ }^{97}$

The later stages of market transition are different from the combination of the frantic economic urgency producing fresh waves of postmodern architecture in the West or in 1970s Taiwan, and the maturing market in the late 1990s has been quickly combined with glass-concrete-steel modernism or international style in China. Modern architecture combined with a capital boom does not display a wholly naïve idealism, but rather a belief in money. Therefore, modernism to some extent becomes kitsch in the speedy development of real estate in China. In China's social transitioning, modernism - here possibly defined as "low modernism" or "popular modernism" - as a kitsch culture has been a negative aesthetic phenomenon in the lost cultural realm. When neither traditional Chinese architecture nor Maoist style can meet the aesthetic challenges of the contemporary landscape in massive urban construction, China-in-transition only seeks temporary relief from the glass boxes with colourful curtain wall panels or white boxes in a speedy design and construction. Cui Kai is an architect determined not to bow to kitsch culture. At the same time, he does not want his architecture to become the source of illusions, like the thoughtless glass boxes or white boxes in a speedy design and construction.

By contrast to low modernist kitsch, Cui Kai still holds onto naïve idealism in modernism as he was taught in his early years. After the early designs featuring postmodern surfaces, postmodernism gradually weakens in his designs but never disappears. In his later designs - for example, the design for the Legation Quarter (Beijing, 2008) and the Yin Ruins Museum (Anyang, 2006) - achieved after several years of practice, the unembellished boxes feature a flat roof and open plan that offer light, air, space, and manifest themselves in a high-modernist way. The hazy postmodernism, with its uncertain nature from the very beginning in the Chinese context, has come to rival the low modernist kitsch in the later stage of his designs. Cui Kai does not see architecture as decoration, but he views postmodernism as a way to resist the over-commercialised and to claim the values of complexity and diversity of styles confronting kitsch culture. It is also a way to express his lasting interest in the recovery of historical reference. However, this kind of interest remains recessive in his design, partially because of his avoidance of being directly connected to unsuspecting nationalist advocacy or bureaucrat technocrat. Therefore, it could be argued that the grand narrative in modernist and postmodernist expression has been combined in his design principles in his own way, yet within the area fenced off by rationalism. 


\section{Renarrating the state}

\section{Modernism and postmodernism as historical developments}

The characteristics of Cui Kai's designs begin to make sense if we understand what modernism and postmodernism mean to him as historical developments. The historical process in China cannot be defined as postmodernism challenging the basic assumptions of modernism, but rather, that the specific ideologies in the Mao era and post-Mao era are challenging the tenets of modernism and postmodernism. This special circumstance manifests as unique fluctuations between modernism and postmodernism in Cui Kai's designs. This fluctuation does not achieve extreme innovation but continues to vacillate in a circular orbit around rationalism.

While the rationalism running through the fluctuation between modernism and postmodernism has been influenced by Cui Kai's personal preferences, it still maintains a solid connection to his life experiences from pre-reform China through to the most recent decades of Chinese modern history. His role and career has fluctuated with CAG and the associated tension between state and market. Therefore, his designs vacillate between being representative of nationalism and being an expression of his individuality. From the planned economy to the market economy, the changes in Cui Kai's works are primarily focused on developing a more acceptable lever mediating between social responsibilities and the private sector, which finally manifests as the rational. Furthermore, from the late 1990s, the unravelling of the traditional planned system and reforms of CAG gave the opportunity of diversified client sources for Cui Kai.

As a rising power, China is still searching for a balance between its market power and governmental power. Political power and the governmental mode are still being questioned and tested in the market transition. It should be noted that the full range of expression, including negative and positive comments about the state and its policies, has not been allowed in China. Under these circumstances, Cui Kai's aesthetic contains a sense of the state-owned enterprise's mission inherited from the collectivist-transmitted culture, yet it is neither transmitted by politics nor folk. The contested high culture in his design is not only acceptable to the state but also acceptable to the majority of Chinese people, the market and the rest of the world. The increasing importance of the market mechanism does not allow his designs to be emblematic of stoic rationalism. For Cui Kai, his individual design is still subordinate to the masses, to the collective good of the Chinese people. Fundamentally, his designs are the manifestations of his individual excellence raised to a high state of social responsibility and rationalism. The architectural rationalism promoted by Cui Kai strengthens affective and cognitive links that consolidate a sense of shared aesthetics in the new China.

\section{Notes}

1 Feng Li, "Critical Practice in State-Owned Design Institutes in Post-Mao China (19762000s) : A Case Study of CAG (China Architecture Design and Research Group)" (Master Research Thesis, The University of Melbourne, 2010).

2 Ibid., 63.

3 Ibid., 64. 
4 Martha Lund Smalley and Karen Jordan, "Archives of the United Board for Christian Higher Education in Asia, Record Group No. 11, Special Collections" (New Haven: Yale Divinity School Library, 1982).

5 Jessie Gregory Lutz, China and the Christian Colleges, 1850-1950 (Itahaca; London: Cornell University Press, 1971), 32.

6 Dongqiang Er and Martha Lund Smalley, Hallowed Halls: Protestant Colleges in Old China (Shanghai: Old China Hand Press, 1998).

7 Xiaodong Li and Keng Hua Chong, "Implications of Chinese Architectural Education in Contemporary Chinese Architecture," The Journal of Architecture 8, no. 3 (2003): 306.

8 Wing-Wah Law, "The Role of the State in Higher Education Reform: Mainland China and Taiwan," Comparative Education Review 39, no. 3 (1995): 322-355.

9 Ibid., 324.

10 "History (Tunghai University)," Tunghai University, accessed June 26, 2013, http:// wwwo.thu.edu.tw/english/01_05_01_history.htm.

11 Ibid.

12 Ming-Song Shyu and Chun-Hsiung Wang, Cukuang Yu Shiyi Taiwan Zhanhou Diyidai Jianzhu 粗獷與詩意: 台灣戰後第一代建築 [Rustic \& Poetic an Emerging Generation of Architecture in Postwar Taiwan] (Taipei: Muma wenhua, 2008), 12.

13 The Down to the Countryside Movement was a policy instituted in the PRC by Mao in the 1960s and 1970s. Although it's known as "Down to the Countryside" in English, the exact translation from the original Chinese term is "up to the mountains and down to the villages." Young people from the city were sent to work in villages in order to remove any bourgeois or privileged sentiments and reduce the urban population. From December 1968 onward, millions of educated urban youth, consisting of secondary school graduates and students, were mobilized and sent to rural villages and to frontier settlements.

14 David Lague, "1977 Exam Opened Escape Route into China's Elite," The New York Times, January 6, 2008.

15 Kai Cui and Weijen Wang, “Liangan Zhuiwen Huisu Cui Kai/Wang Weijen 两岸・追 问・回溯 崔恺/王维仁对谈 [Cross-Strait Questioning and Retrospecting-A Dialogue Between Cui Kai and Wang Wenjen]," Shidai jianzhu no. 4 (2012): 51.

16 Nalini Mathur, Educational Reform in Post Mao China (New Delhi: A.P.H. Publishing Corporation, 2007), 152.

17 Ibid., 153.

18 Richard Baum, "Science and Culture in Contemporary China: The Roots of Retarded Modernization," Asian Survey 22, no. 12 (1982): 1169.

19 Wang Weijen is the Head of Department and Professor in the Department of Architecture at the University of Hong Kong. He is a graduate of UC-Berkeley and Taiwan University.

20 Cui and Wang, “Liangan Zhuiwen Huisu Cui Kai/Wang Weijen 两岸・追问・回溯崔恺/ 王维仁对谈 [Cross-Strait Questioning and Retrospecting-A Dialogue Between Cui Kai and Wang Wenjen],"

21 Robert Venturi, Complexity and Contradiction in Architecture (London: Architectural Press, 1977).

22 Weijen Wang, "Fumin Primary School 2003 Far East Architecture Award," Wang Weijen Architecture, accessed June 27, 2013, www.arch.hku.hk/ wang/INDEX2.html.

23 Wang Weijen is the Professor in the Department of Architecture at the University of Hong Kong. He is a graduate of UC-Berkeley and Taiwan University.

24 Robert Venturi, Jianzhu Zhongde Fuza Yu Maodun 建築中的複雜與矛盾[Complexity and Contradiction in Architecture], trans. Tingfang Ye (Taipei: Shanglin chubanshe, 1980).

25 Law, "The Role of the State in Higher Education Reform: Mainland China and Taiwan," 324. 
26 Ben Xu, "The Cultural Revolution and Modernity: The Contradictory Political Implications of Postmodernism in China," Journal of Contemporary China 8, no. 21 (1999): 249.

27 Hui Wang and Rebecca E. Karl, "Contemporary Chinese Thought and the Question of Modernity," Social Text 16, no. 2, Summer (1998): 27.

28 Xiaodong Li, "The Celebration of Superficiality: Chinese Architecture Since 1979," The Journal of Architecture 5, no. 4 (2000): 394.

29 Ibid., 395.

$30 \mathrm{Xu}$, "The Cultural Revolution and Modernity: The Contradictory Political Implications of Postmodernism in China," 249.

31 Ibid., 241.

32 Ibid., 250.

33 Li, "Critical Practice in State-Owned Design Institutes in Post-Mao China (19762000s): A Case Study of CAG (China Architecture Design and Research Group),".

34 Arif Dirlik and Xudong Zhang, "Introduction: Postmodernism and China," Boundary 2 24, no. 3 (1997): 8.

35 Charlie Xue and Guanghui Ding, A History of Design Institutes in China: From Mao to Market (London; New York: Routledge, 2018).

36 Long Xiu, "China Architecture Design \& Research Group," China Architecture Design \& Research Group, accessed June 20, 2013, http://en.cadreg.com/introduce/ introduce.shtml.

37 James M. Buchanan, "Economics in the Post-Socialist Century," Economic Journal 101, no. 404 (1991): 15-21; John Kenneth Galbraith, "Economics in the Century Ahead," ibid.,41-46.

38 David Stark, "Recombinant Property in East European Capitalism," American Journal of Sociology 101, no. 4 (January 1996): 993-1027.

39 Cyril Zhiren Lin, "Open-Ended Economic Reform in China," in Remaking the Economic Institutions of Socialism: China and Eastern Europe, ed. Victor Nee and David Stark (Stanford: Stanford University Press, 1989), 95.

40 Lucy Hornby, "China Enters New Era of Services Expansion with Singapore CPG Buy," Reuters, accessed June 19, 2013, www.reuters.com/article/2012/05/27/ china-cpg-idUSL4E8GR0CI20120527.

41 CPG, "Our Profile,” CPG Corporation, accessed June 20, 2013, www.cpgcorp.com.sg/ index.php/about-us/our-profile.

42 Xu Rui, "Chinese Architecture Group Buys out Singaporean CPG," China News Service (CNS), accessed June 19, 2013, www.ecns.cn/cns-wire/2012/05-28/15991.shtml.

43 Hornby, "China Enters New Era of Services Expansion With Singapore CPG Buy,".

44 Bing Wang, "Structuring of the Architectural Profession in Modern China" (Ph.D. Dissertation, Harvard University, 2004), 148.

45 Ibid., 149.

46 Kai Cui, “Ganxing Haishi Lixing 感性还是理性 [The Perceptual and the Rational]," in Mingshi Zishu 名师自述 [Master's Narration], ed. Yongsheng Yang and Huili Wang (Beijing: Zhongguo jianzhu gongye chubanshe, 2008), 252.

47 Cui, Kai, “Minzu Xingshi Haishi Bentu Wenhua 民族形式还是本土文化 [National Forms vs. Native Culture]," in Mingshi Zishu 名师自述 [Master's Narration], ed. Yongsheng Yang and Huili Wang (Beijing: Zhongguo jianzhu gongye chubanshe, 2008), 254.

48 Daxia Li, "Current Chinese Architecture: Deviating From the Single Axis Structure," Habitat International 15, no. 3 (1991).

49 Liang's intention was to pass on the essence of Chinese architecture. This specific "essence" was considered to be the "Big roof", the temple-style concave curved roofs and overhanging eaves to denote their Chinese origin.

50 Xiao Hu, "Reorienting the Profession: Chinese Architectural Transformation Between 1949 and 1959" (Ph.D. Dissertation, University of Nebraska - Lincoln, 2009), 166. 
51 Cui, “Meiguan Haishi Wenhua 美观还是文化 [Beauty vs. Culture],” 269.

52 Ibid.

53 Chun Dai and Wenjun Zhi, "Jianzhushi Qunti Yanjiu De Shijiao Yu Fangfa Yi 50 Niandai Sheng Zhongguo Jianzhushi Weili建筑师群体研究的视角与方法 以50年代生中 国建筑师为例 [The Perspectives and Approaches of Research on Architect GroupsChinese Architects Born in the 1950s in Focus]," Shidai jianzhu no. 4 (2012): 10-15.

54 Ernest Gellner, Nations and Nationalism, Second Edition (Malden, MA: Blackwell Publishing, 2006).

55 Ibid.

56 Cui, “Ganxing Haishi Lixing 感性还是理性 [The Perceptual and the Rational],"

57 Gellner, Nations and Nationalism, 48.

58 Neale G. O'Connor, F. Johnny Deng, and Jingsong Tan, “The Impact of Political Constraints and Formal Incentive Systems on the Performance of Chinese State-Owned Enterprises," Pacific Accounting Review 23, no. 1 (2011): 6.

59 Jonathan R. Woetzel, "Reassessing China's State-Owned Enterprises," McKinsey Quarterly 3 (2008): 59.

60 You Ji, China's Enterprise Reform: Changing State (London: Routledge, 1998), 73.

61 Ibid., 76.

62 Ibid.

63 Ibid.

64 Rohit Deshpande and John U. Farley, "Market-Focused Organizational Transformation in China," Journal of Global Marketing 14, no. 1-2 (2000): 7-35.

65 O'Connor, Deng, and Tan, "The Impact of Political Constraints and Formal Incentive Systems on the Performance of Chinese State-Owned Enterprises,".

66 Cui, “Minzu Xingshi Haishi Bentu Wenhua 民族形式还是本土文化 [National Forms vs. Native Culture],".

67 Ibid., 253.

68 Ibid., 252.

69 Cui, “Meiguan Haishi Wenhua 美观还是文化 [Beauty vs. Culture]," 260.

70 Cui, Kai, Bentu Sheji 本土设计 [Native Design], trans. Xiaoqing Li, et al. (Beijing: Tsinghua daxue chubanshe, 2008).

71 Ibid., 249.

72 Cui, “Meiguan Haishi Wenhua 美观还是文化 [Beauty vs. Culture]," 260.

73 Victor Nee and Rebecca Matthews, "Market Transition and Societal Transformation in Reforming State Socialism," Annual Review of Sociology 22, (1996): 402.

74 Kai Cui, “Zai Zhongjian - Yizhong Zhuangtai He Yizhong Juese在中间 - 一种状态 和一种角色 [In Between-One Status and One Role], ” Jianzhu xuebao no. 3 (2007): 4-5.

75 Li, "Critical Practice in State-Owned Design Institutes in Post-Mao China (19762000s): A Case Study of CAG (China Architecture Design and Research Group)," 34.

76 Ibid., 36.

77 KPMG, "China Looking Ahead," International Tax Review, www.kpmg.de/docs/ China-Looking-Ahead-ITR-201105-2.pdf.

78 Justin Yifu Lin, Fang Cai, and Zhou Li, State-Owned Enterprise Reform in China (Hong Kong: Chinese University Press, 2001).

79 Janos Kornai, The Road to a Free Economy: Shifting from a Socialist System: The Example of Hungary (New York: Norton, 1990).

80 David A. Ralston et al., "Today's State-Owned Enterprises of China: Are They Dying Dinosaurs or Dynamic Dynamos?” Strategic Management Journal 27, no. 9 (2006): $825-843$.

81 Xiu, "China Architecture Design \& Research Group,".

82 Cui, “Meiguan Haishi Wenhua 美观还是文化 [Beauty vs. Culture],”. 


\section{Renarrating the state}

83 Xiaohong Wu, “Miandui Zhuzhai Shichanghua面对住宅市场化[Confronting the Marketization of Residential Building]," Jianzhu xuebao no. 2 (1999): 20-21.

84 Cui, “Ganxing Haishi Lixing 感性还是理性 [The Perceptual and the Rational],” 251.

85 Cui Kai 崔恺 [Cui Kai], Dangdai Jianzhushi Xilie 当代建筑师系列 [Contemporary Architecture Series] (Beijing: Zhongguo jianzhu gongye chubanshe, 2012), 10.

86 Cui, “Meiguan Haishi Wenhua 美观还是文化 [Beauty vs. Culture]," 11.

87 Cui Kai 崔恺 [Cui Kai], 10.

88 Ibid.

89 Ibid., 11.

90 Michael Mack, "Modernity as an Unfinished Project: Benjamin and Political Romanticism," in Walter Benjamin and the Architecture of Modernity, ed. Andrew Benjamin and Rice Charles (Melbourne: Re-Press, 2009), 19.

91 Kai Cui, “Zhongdian Zai Jianzhu Zhijian 重点在建筑之间[Emphases in Spaces between Architecture]," Shidai jianzhu no. 1 (2006): 72-75.

92 Cui Kai 崔恺 [Cui Kai].

93 Bo Zhang's well-known works include the Great Hall, Beijing Hotel, Friendship Hotel and Diaoyutai State Guesthouse.

94 Cui, "Meiguan Haishi Wenhua 美观还是文化 [Beauty vs. Culture],”.

95 Cui, “Zai Zhongjian - Yizhong Zhuangtai He Yizhong Juese在中间 _ 一种状态和一 种角色 [In Between-One Status and One Role],”.

96 Nan Zhang and Kai Cui, “Yinxu Bowuguan殷墟博物馆[Yinxu Museum]," Jianzhu xuebao no. 1 (2007): 35.

97 Fredric Jameson, "The Cultural Logic of Late Capitalism," in Rethinking Architecture: A Reader in Cultural Theory, ed. Neil Leach (London: Routledge, 1997), 240. 


\section{Casting a civic shadow in the city URBANUS}

This chapter analyses three architects in the firm URBANUS, the architectural designs of URBANUS and the social, economic, cultural transformation in the Pearl River Delta. These three architects shared a common background from the Maoist era to the 1990s: their education in China and in the United States until late 1980s gave them an unusual individual nature in the 1990s, and the urbanisation in the Pearl River Delta during the 1990s gave them opportunities for experimentation in architectural design. The three architects and their firm URBANUS in the Pearl River Delta region were then able to make a smooth transition to the peak of the market.

Generally, studies regarding the construction boom in the Pearl River Delta are inclined to ascribe it simply to the sober pursuit of money in the region. The urban strategies initiated by URBANUS are not an isolated professional experiment but an attempt to reconcile the ideological anxiety between private and public sectors. This conflict is an inevitable effect of the social transition in China, and it is particularly well illustrated in the Pearl River Delta.

\section{The "Haigui" Chinese architects}

In an ad hoc expression in newspapers, TV and other Chinese media, three architects in the firm URBANUS were titled "Haigui" architects. Since the mid1990s, large numbers of Chinese overseas residents have returned to mainland China. These three architects, Liu Xiaodu, Meng Yan and Wang Hui, returned in 1999 and established URBANUS in Shenzhen. At present this architectural firm is recognised as one of the leading forces among China's design firms. It was featured as one of the ten global "Design Vanguards" by Architectural Record in December, 2005, and has been awarded many prestigious architecture prizes. ${ }^{2}$ The partners Liu Xiaodu, Meng Yan and Wang Hui all graduated from Tsinghua University in China in the 1980s and received their master of architecture degrees from Miami University in the United States in the 1990s. Prior to establishing URBANUS, they had worked in different US design firms as project architects. Liu Xiaodu worked in Design Group Inc. and Stang and Newdow Architects from 1993 to 1998. Meng Yan worked in the New York office of KPF and MELTZER/ MANDL from 1996 to 2000. Wang Hui worked in Gensler New York and Gary 
Edward Handel from 1997 to 2001. It was during this period in the United States that the three architects met and befriended a group of avant-garde architects in China. Yet Liu, Meng and Wang seldom mention what exactly has been the influence of their first degree from the top university in China and second degree from Miami.

\section{- From the East to the West}

The architects' background and education in China and the United States enables us to sketch out the East-West contours of power from two perspectives: the value exchange and linguistic capacity. First I will consider what they have gained in the clash of values between the West and the East: on one hand, they want to bring Western values such as democracy, civil liberties and individualism into their booming motherland, whose underlying values were and are being shaken dramatically; on the other hand, despite the differences between West and East experienced during their overseas education, they are still inspired to retain Chinese values such as collectivism in the new projects.

Liu Xiaodu, Meng Yan and Wang Hui grew up during the Cultural Revolution and became the first generation to have the opportunity to study at university after the revolution. "The education of our generation has a strong idealist hue and sense of social responsibility", ${ }^{3}$ Meng noted. The complex factors informing their collective and idealistic view cannot be explained in a single observation, but a major influence comes from the age into which they were born. Ideologically, their teenage years in the idealistic Mao era were associated with a collective identity. Many idealistic decisions by Mao ended in failure or even in disaster and atrocity. However, this is a contemporary assessment within China. As discussed in Chapter Two, for many Chinese of that generation, the historical turbulences in Maoist China were not disastrous childish experiences. People's communes were clearly an idealist communist reference for a physical entity as well. This opinion echoes many of the ideas championed by Chinese who were born in the 1950s and 1960s.

Soon after their school days in Tsinghua University, the URBANUS founders went to the United States and were exposed to Western democracy, individualism and consumerism. They read Western theory in books, but gained an understanding in the United States. Liu summarised his generation's trajectory in my interview with him:

They were born in the 1960s in China, and received undergraduate degrees in the 1980s in China. The 1980s is a special period in China, one that has been dominated by idealist ideas. China's intellectuals were active, and there were many pioneer voices in both the intellectual and cultural spheres in China. When they left China and arrived in America in the 1990s, they found that American was a country with a similar atmosphere to China of the 1980s. The intelligentsia had a serious sense of mission, especially in the universities. 
The strong sense of social responsibility occupied a leading position in the social sphere. ${ }^{4}$

He used a term to describe this life experience from 1980s China to 1990s America: "seamless graft". ${ }^{5}$ The considerable impact of study and work in America remains one of the pivotal points of their architectural narrative and discourse of democracy and civic liberties. When asked about the resistance they encountered when they wanted to express the concept of civic society or other similar attitudes in their designs, Liu stated that many people in China, throughout the whole social structure, from top to bottom, do not have such a consciousness regarding forming a democratic society at the moment. Liu referred to the big civic square as an example: why is there no large-scale square designed without any installation in the current time? He speculated,

On the one hand, the government appreciates this grand view; but on the other hand, they do not want people to use it. The large scale square in the contemporary Chinese history indicates a place facilitating a pledge to those in power, not for a gathering of the people. ${ }^{6}$

In addition, the nostalgia originating from being "the other" in their overseas experience increased their desire to re-make and explain China. The period in which the three architects studied and worked in the United States was characterised by poor communications between China and the United States, and images and impressions related to China were usually demonised. Therefore, a long tradition of false images of China in Western culture further strengthened their ambition to explain China. According to Ouroussoff, that range of experience is doubtless what enables them to see the world through multiple lenses, a trait invaluable to architects, whose most onerous task is balancing what may seem like irreconcilable values. ${ }^{8}$

Second, the trans-national studies not only made them bilingual but also made them bilingual in architecture. Three architects with Chinese faces can talk about their designs in fluent English, and URBANUS has been invited to exhibitions worldwide and presented in prestigious newspapers and magazines, including The New York Times,${ }^{9}$ Time + Architecture, ${ }^{10}$ World + Architecture, ${ }^{11}$ Architecture Record (USA), ${ }^{12}$ BLUEPRINT (Britain). ${ }^{13}$ Being educated in Tsinghua and Miami Universities, URBANUS represents a typical bilingual architects' group in China. The diagrams they draw are always accompanied by text both in Chinese and English (Figure 5.1). Jianfei Zhu argues that Chinese bilingual scholars often read in both Chinese and foreign languages. Some worked and published in two languages, such as Chinese and English. He concluded that this pattern of bilingual work was revived after the 1980 s among younger scholars. ${ }^{14}$ Furthermore, due to Chinese efforts to modernise, and the pressure to learn from the West, all modern Chinese intellectuals since 1990 have been fundamentally bicultural if not technically bilingual. ${ }^{15}$ 


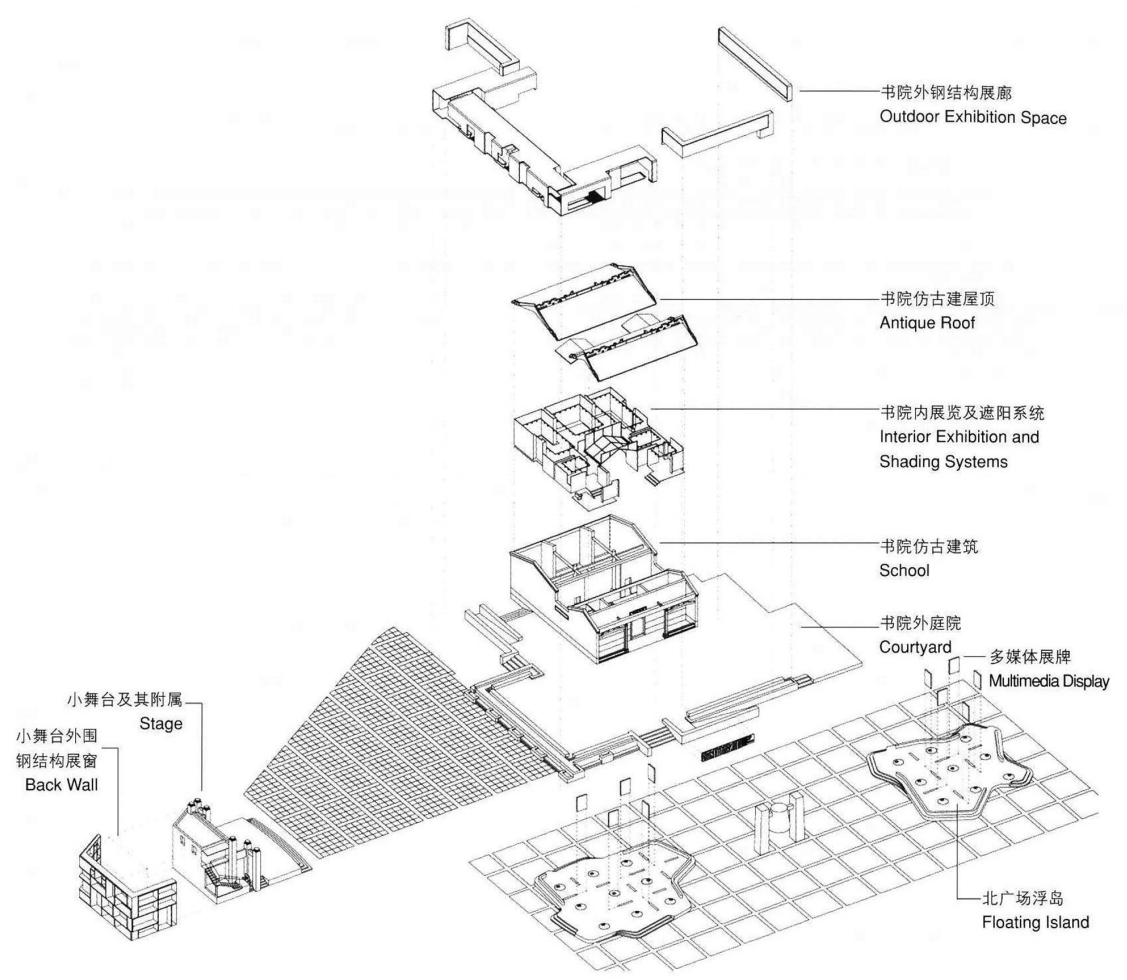

Figure 5.1 URBANUS, Dongmen Photography Plaza, Shenzhen, 2009. Diagram

The three architects began their architectural studies in Tsinghua University, one of the most famous universities in China. The School of Architecture of Tsinghua was initially established by Liang Sicheng, one of the founders of China's modern architectural education: most importantly, he contributed to the implementation of the Ecole des Beaux-Arts curriculum in China's architectural education, as described in Chapter Two. Emphasis was placed on drawing in the Ecole des Beaux-Arts. Hence virtuosity in drawing was inherited by successive generations of architects. It suggests that Liu, Meng and Wang had to go through a rigorous progression of advancement in the basic skills of architecture. In addition, Liang was a pioneer in the research of traditional Chinese architecture. By creating the discipline of architectural history in China, Liang initiated a new set of historical, research and aesthetic values based on careful documentation of the physical fabric and form of traditional buildings in China and their historical development. Regarding understanding of traditional Chinese culture and acquiring basic skills in drawing, the three members of URBANUS owe a debt to Tsinghua University's strict training.

In addition, although both the generation of Liang Sicheng and the generation of Liu Xiaodu had the opportunity to understand Western society and 
intellectual trends, and have brought their observations into their works in China, the URBANUS architects are independently thinking individuals compared to earlier generations. For example, Yang Tingbao's architectural works, as well as his teaching, show a unique interplay between universal virtues and localities. Yang was never obliged to express regionalism or individual identity, ${ }^{16}$ but the URBANUS architects are more at liberty to express their individuality in architectural drawings.

It is equally important to remember that postgraduate education at the University of Miami extended their skills in expressing their ideas in a manner more acceptable to the West. URBANUS is the foremost exponent of the collage approach in architectural visualisation, in lieu of the mass production typical of China's particular architectural rendering drawings (Figure 5.2). Marling noted,

In the West, we usually do not expect very much of Chinese drawing offices. Therefore, it is surprising to see several innovative and aesthetically beautiful projects carried out by the architects Liu Xiaodu, Meng Yan and Wang Hui, proprietors of the URBANUS drawing office which has branches in Beijing and Shenzhen. ${ }^{17}$

It could be argued that the linguistic capacity makes them more sensitive to global trends, and they understand the importance of being part of it. Liu Xiaodu remarked, "If you admit globalization is one trend and you are happy with this trend, you should learn English. Regarding architecture, you should learn modernist language."

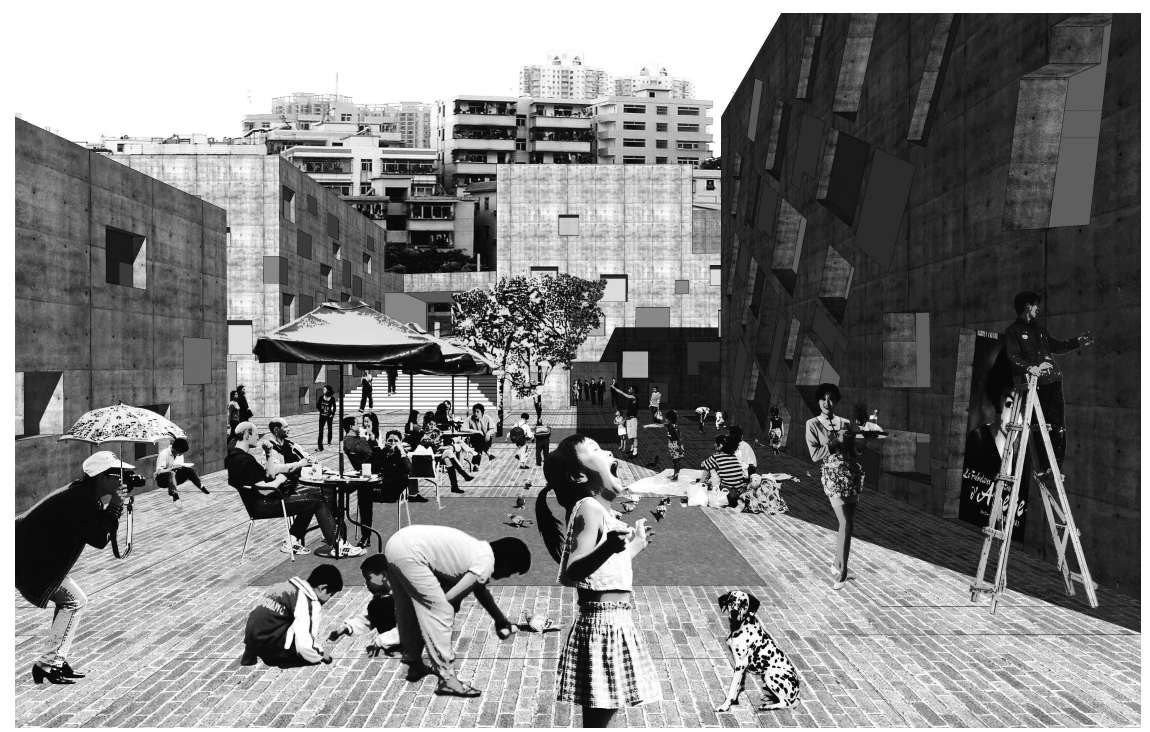

Figure 5.2 URBANUS, Dafen Art Museum, Shenzhen, 2007. Rendering drawing 


\section{- Back to the Pearl River Delta: a new context to work in}

However, the trans-national dialogue between the East and the West was not powerful enough to push their designs to the forefront. What finally gave their architectural practice an experimental flavour was the unusual high-speed urbanisation in the Pearl River Delta. Urban development in China since 1949 has been subject to close monitoring and careful planning as part of the strategy for national economic development. ${ }^{18}$ The introduction of economic reform measures in 1978 placed China at the dawn of rapid urbanisation, which is conventionally associated with socio-economic development and industrialisation. The Pearl River Delta, one of the most vigorous economic regions in China, covers nine prefectures of the province of Guangdong, namely Guangzhou, Shenzhen, Zhuhai, Dongguan, Zhongshan, Foshan, Huizhou, Jiangmen and Zhaoqing. The Pearl River Delta has become the major manufacturing base for goods such as electronic products, toys, garments and textiles, plastic products and a range of other goods that China exports to the world. Much of this output is tied to investments by foreign enterprises and is geared to the foreign market. The Chinese government expected that manufacturing in Guangzhou would utilise its proximity to abundant capital resources. This has resulted in the massive migration of large numbers of the rural population towards cities. People in rural areas all over China swarmed into the Pearl River Delta during the development of industrial cities; generally they were paid only minimum wages.

The 2010/2011 State of the World Cities report, published by the United Nations Human Settlements Program, estimates the population of the Pearl River Delta region at 120 million people. ${ }^{19}$ However, as conservative estimates show, at the end of the 1990s, the volume of the "floating population" in the Greater Delta alone reached 10 million, with the most dynamic areas attracting the greatest number of predominantly young female migrant workers. ${ }^{20}$ In many cities in the Delta, those in the floating population frequently outnumber the permanent population. In 1999, the municipality of Shenzhen had a floating population of $2,850,000$ people, compared to a permanent population of $1,250,000$, while in 1980, 90 percent of the fewer than 100,000 residents of Shenzhen were holders of a permanent household registration. ${ }^{21}$

The rate of urbanisation in the Pearl River Delta, being the greatest in China, is taking place at an unprecedented pace and will continue over the next decades. Furthermore, "floating" in a temporary situation affects a surprising portion of the population. The huge population and the immense pressure for urbanisation also made it difficult to sustain economic development in a stable manner. The level of urbanisation in China has risen from 18 percent in 1978 to 30 percent in 1995 and to 39 percent in $2002 .{ }^{22}$ But more significantly, considerable numbers of new immigrants, including industry workers, construction labourers, and graduates from the universities, have all had the intention to pursue the integration of local long-term living in the city with the accelerating process of urbanisation. Increased industrial activities have created a need to accommodate them, which places tremendous pressure on housing supply and urban construction, including urban infrastructure and public buildings. 
In the Pearl River Delta, affordable housing became increasingly problematic in the new century. Since housing construction was limited under the centrally planned economy, housing demand remains, although large-scale real estate development has been carried out. Because marketisation and commoditisation have transformed the primary housing provider from the government to the market (developer), the city government now makes little effort to provide low-rent housing. Moreover, since low-rent urban housing can only produce small margins, it is less attractive to real estate developers and relies heavily on government subsidies. ${ }^{23}$ Although the policy of affordable housing was launched several years ago, the city government has a lack of enthusiasm for implementing low margin housing construction. ${ }^{24}$

One distinctive conflict of the Pearl River Delta associated with the radial expansion of urban built-up areas lies in the new type of urban neighbourhood, namely the "urban village" (Chengzhongcun). ${ }^{25}$ These villages used to be located on the outskirts of the city, but with the expansion of the city, farmlands formerly cultivated by the villagers are compulsorily purchased and turned into urban land by the government; however, the villages themselves have been preserved. The urban village is a special urban form emerging in China's political and economic transition. Although the notion of the "urban village" has been well explored to encourage social interaction in a balanced community in the West, an urban village in China is a unique phenomenon and social form that is part of current urbanisation efforts. By the early 2000s these villages housed 60 percent of the "floating", illegal workers attracted to the factories. ${ }^{26}$ There are an estimated 139 urban villages in Guangzhou and 241 in Shenzhen. ${ }^{27}$ As a semi-urbanised community, the urban village usually functions as the springboard for migrants to be gradually integrated into urban society. In fact, the urban village shares the city government's responsibility to provide migrants with housing and has made it possible for the city to take advantage of cheap and flexible labour without bearing the extra costs associated with labour relocation and so avoiding social instability. ${ }^{28}$ Consequently, these new emerging problems and new conditions of urbanisation in the Pearl River Delta gave URBANUS a new context to work in.

\section{The market founded by Deng}

The relationships between URBANUS and the social transition to market in the Pearl River Delta is epitomised by Shenzhen. The most relevant paper, From Opposition to Alienation, written by Yan Wang, attempts to embed the 1960s-born architects' practice within the urbanisation process of Shenzhen and its changing social condition by using Shenzhen as an extreme example. ${ }^{29}$ The paper was partially based on the literature documenting the social process of Shenzhen's thirty years of urbanisation historically and partially based on the interview with Meng Yan, a principle architect of URBANUS, and Rao Xiaojun, recording this changing context. ${ }^{30}$ The interview clearly points out the changing supply and demand relation in the development of URBANUS and the macro environment, however, the historical and social narrative is not rich enough to complement the relations assessed, which this part intends to address. 
In illustrating the changing supply and demand relations, Wang divided the practice of URBANUS in his paper into two periods: 1999-2005 and 2005 onwards. In Wu's paper "Critical Urban Practice in China (Learning from Shenzhen)", he divided URBANUS's development into three phases: "Development Phase One: Genesis in Shenzhen (1999-2003)", "Project Phase Two: Shifting cities culture design experimentation (2003-2007)" and "Projection Phase Three: Addressing issues larger than architecture (2006-2009)". ${ }^{31}$ In summary, firstly, both studies lack a critical exploration of URBANUS's initial collaborative model with the government. Secondly, Wang's research took the establishment of the URBANUS Beijing branch into account, which changes the direction of the analysis. The research in this part focuses specifically on Shenzhen. Therefore, my analysis will begin with a review of the period before the 1999 and propose the years around 2005 as the crucial turning point.

\section{- Before 1999}

After 1990, the pace of reforms in all aspects of Chinese society was faster than even the highest point of reformation in the 1980s. In January 1992, Deng Xiaoping paid an inspection tour to south China, where he delivered a series of speeches that aimed at clarifying the idea of whether the establishment of special economic zones are capitalist or socialist in nature. Shenzhen was established as China's first special economic zone (SEZ) in 1980 and, to date, has been one of the most successful. Deng's southern tour played a significant role in the formation of the radical attitude towards modernisation in Southern China, especially in the Pearl River Delta. Since economic liberalisation was implemented there, the Delta has become a major leading economic region attracting large sums of foreign capital.

Because the Pearl River Delta is far removed from the political centre of China, the ideology there appears less politics-dominated and characterised more by pure pragmatism. In the first ten years of China's economic reform, industrial growth in Dongguan, a Pearl River Delta city between Guangzhou and Shenzhen SEZ, grew at more than 40 percent per year. "If you can make one dollar in Hong Kong you can make two dollars in Dongguan," one official remarked. ${ }^{32}$ The fever of pragmatic expectations underlies an obsession with the modern image and a refusal to think about national identity. In the Pearl River Delta, identity is perceived as an illusion, and greater importance is placed on getting rich. The issue could be summarised as not who I am, but whether I can play golf. However, from another perspective, the Pearl River Delta strictly follows the Red ideology. Wu commented: "Shenzhen Special Economic Zone was Deng Xiaoping's brainchild in 1978, representing the Chinese Miracle since it was a city created from zero by both Chinese political ideology and international market mechanisms." ${ }^{33}$ The political shift initiated by Deng during that period was also intended to secure the "planned commodity economy" in the modernisation of cities.

Shenzhen was once a sleepy border town, but in the first draft of the Master Layout Plan of Shenzhen created in August 1980, it was planned to "to develop Shenzhen into an industry-led modernized Special Economic Zone (SEZ) at the 
border, based on the integration of agricultural and industrial development." ${ }^{34}$ Because there were not many historical streets, or architecture of conservation importance, the architects had considerable freedom in the 1980s and early 1990s. Indeed, the rapid modernisation of architecture has provided a new order which blurs stylistic distinctions. The absence of prevailing archetypes in the area renders the Pearl River Delta totally modern and obviates the need to compensate for a lack of historical reference. It is a city without any particular identity, apart from its incredible growth rate, and its apparent restructuring and transformation in twenty-year cycles. Rem Koolhaas notes that communists' fascination with the future has translated, during the twentieth century, into attempts to merge utopian visions with the realities of modern industrial cities. The image of the industrial city was adopted as a symbol of the class struggle: the socialist city was seen as an inverted twin of the capitalist metropolis. ${ }^{35}$ In twenty years, the industrial areas of Shenzhen have been transformed for new purposes.

The cities in the Pearl River Delta are remarkable for their "copy and paste" architecture in initial capital accumulation. Despite this, the quality of the design was not inferior to Beijing or Shanghai in the 1980s and 1990s. Since the late 1990s, numerous architects from various national institutions of design in Beijing and Shanghai were sent to Shenzhen, and many of them were assigned to the Shenzhen Office for Shenzhen's development. For example, Cui Kai worked in Huasen Architectural \& Engineering Design Consultants from 1985 to 1989, which was a constituent company of China Architecture Design \& Research Group. Some architects individually went to Shenzhen seeking greater opportunities. Shenzhen in the 1980s and early 1990s offered ideal opportunities to pioneer architects, although the heavy workload outweighed the good pay and comfortable work conditions. However, the local national design institute, based on the old system, could not digest so many new projects, and so the introduction of liberal policies in Shenzhen, together with the growth in the urban infrastructure and the mechanism to cooperate with the government, all provided fertile ground for the development of private design firms. For example, the founder of Zhubo was active in the mid-1990s, and Zhubo Design Co., Ltd. was officially founded in 1996. Currently, Zhubo Design Co. Ltd. is made up of more than 1,600 professional, technical and management employees, 25 percent of whom hold advanced degrees or PhDs. ${ }^{36}$ In 2012, it was officially incorporated into a joint stock company.

In an interview with Huang Weiwen, who worked in the Shenzhen City Planning Department, he observed:

In the mid-1990s Shenzhen lacked influential works or top works of foreign masters. . . Over a period of time, Shenzhen was a leader in the nation's house design. For example, it learned from Singapore and built the East China Sea Garden in 1990s, and was experimental with modern Chinese-style Sakata Garden the 5th in the 21 st century. The office buildings here are behind Beijing and Shanghai in terms of individual size and level, but their relations in the urban space are relatively sophisticated. In addition, without too many 
limits, Shenzhen's buildings have more possibilities, and at a higher level overall and therefore, more relaxed. ${ }^{37}$

China's economic reforms introduced market forces to the domain of urban construction. Architects in Shenzhen were pragmatic in their approach to the emerging market: "cross a river by feeling the stones", to use a phrase from Deng. ${ }^{38}$ A market evolved in Shenzhen in the 1990s that suggested that urban development in China appears to resemble capitalist economies. The URBANUS founder architects were all working in the United States, with Meng Yan and Wang Hui licensed in New York State. They decided to return and form a private firm based in Shenzhen and could be seen as pioneers in detecting the possibilities in this market. Instead of focusing on a self-contained and mature US market, or serving the nation's political requirement, Liu, Meng and Wang have a wider, international perspective, as well as local domestic awareness in China, where the domestic market and social conditions were constantly changing. In 1999, the private architect's practice began to occupy its own position in the market, which was no longer dominated by huge state-owned or municipal design institutes. Their rich experiences as commercial architects in the United States laid the foundation for their careers in Shenzhen, where China's progressive architecture programme was still under development.

\section{- 1999-2005}

Because of their well-known works, most of which are public buildings and urban designs, it may seem that Liu Xiaodu, Meng Yan and Wang Hui have always been able to work in a refined manner, able to refuse the repetitive housing designs that might not give full scope to their potential in design. However, in Wang's interview with Meng, he stated,

In the early stage of URBANUS, they did not shun housing design, they knew that housing design in demand could bring a good income, and at the same time their professional intervention could possibly provide a slight change to the fast and rough residential construction. However, there was no big developer who commissioned any design services from them in that period. Only several brave businessmen who were significant in other professions, who sought to dabble in real estate came to them and commissioned them for some small business projects. ${ }^{39}$

URBANUS designed over 170 projects in its first 7 years, of varying scales and complexity. ${ }^{40}$ Yet most of them were commissioned by the government. Since they were the first "Haigui" generation after the economic reform, large developers did not have a clear of idea of what URBANUS could do, and to what extent they could handle the complexities of a large-scale project as a "Haigui architect". The state-owned large design institute still held the advantage in their early years. The fast-expanding local private design enterprises also commanded a large proportion of market share. Although in reality the market was a harsh environment 
for them, they knew that urbanisation in the Pearl River Delta was the beginning of a new chapter in a traditionally rural city. Despite the slow nature of the transformation which allowed many old institutions to remain effective, in time the architects of URBANUS transformed themselves into a model of cooperation with the local government. In URBANUS' large-scale urban renovation plan for the city of Shenzhen in 1999, Diwang Urban Park (Shenzhen, 1999) was the only project executed. ${ }^{41}$

Jieming Zhu wrote in 2000: "Decision making is decentralized during the reform process to two entities: state-owned enterprises (SOEs) and local governments." 42 However, in Shenzhen, a brand new city, the state-owned enterprises did not have a long history or solid foundation in terms of scale and number compared to other big cities. Jieming Zhu commented that "The economic reforms gave rise to the decentralisation of property rights over state assets to local governments in making investment decisions for local growth." ${ }^{\prime 3}$ URBANUS collaborated positively with the Shenzhen local government, which was empowered to carry out local development with a realignment of revenue distribution between the central government and localities in transformation. Reports at the time stated:

In the 1980s and 1990s, governments of many booming coastal cities nurtured the local property market under local government-enterprise coalitions; these coalitions, whether in the name of local state corporatism or local state entrepreneurialism, have helped facilitate the process from central planning to market orientation. ${ }^{44}$

In 1999, coincidentally, Shenzhen won the Sir Abercrombie Award at the Twentieth UIA Congress in Beijing in 1999, which was the first time in forty years that this award was given to an Asian city. Driven by this award, Shenzhen local government made the decision to raise their urban design to a new level.

The high demand for design quality in urban spaces from the Shenzhen local government precipitated a coalition with URBANUS, who, at that time, did not have a foot in the Shenzhen real estate market. This coalition has helped facilitate the process from central planning to market orientation in Shenzhen. Ironically, the Diwang Urban Park I project was demolished just two years after it was completed and replaced by a large-scale business centre project that it planned to link with. ${ }^{45}$ The demolition reflects the quick process from central planning to market orientation. This measure also paved the way for further development in the firm of URBANUS. In addition, in 2003, the URBANUS Beijing Brand was founded after the 2008 Olympics were announced, which conveyed a new market signal. This indicates that they had achieved success in the primitive accumulation of capital and experience in the Chinese market, and their commissions gradually flourished.

\section{- 2005 onwards}

In Wang's interview with Meng, he said, “In 2005, some developers began to see the completed buildings designed by URBANUS. The completion of the new Shenzhen Planning Bureau Headquarters in 2005 was a turning point for 
URBANUS's prestige in the market." ${ }^{" 46}$ At that time, most of the mega-developers had accumulated working capital and moved into the stage of shaping and promoting their brand image. The new demand from developers gave the URBANUS team more opportunities. Therefore, Meng defined the period from 2005 to 2007 as URBANUS's heyday. In 2006, they published their first design collection book documenting their works of 1999-2006. At this time, the Shenzhen Planning Building (Shenzhen, 2005), completed in 2005, still remained a symbol of planning power and a place of architectural discourse in Shenzhen.

In recent years, the Shenzhen government declared that their goal was to build a modern international city. Shenzhen local government does not only strive for recognition of authority from the central government but also desires to promote its image abroad. In Beijing, the Birds' Nest by Swiss team Herzog \& de Meuron, the National Grand Theatre by Paul Andreu from France, the CCTV by Dutch architect Rem Koolhaas and the Beijing Capital International Airport by Britain's Norman Foster are not only architectural achievements themselves but part of Beijing's strategy to be a city of global importance. Apart from Beijing, cities of different sizes have launched a number of international architectural bids for a similar international image construction. Shenzhen is not an exception. At the same time, foreign architects also gradually realised that China was a place of opportunities for architectural design. With a new orientation for Shenzhen, URBANUS is confronting new problems in holding a market share. In Yan Wang's interview with Meng, he noted,

In the recent Shenzhen-initiated local architectural bidding project, there was almost no local design institute involved. URBANUS has always been the last one to get invited. The competition is very international; URBANUS has to face many international figures in architectural design, including figures like Thom Mayne. ${ }^{47}$

It is difficult at this stage to say that the goal of becoming a global city is an ideological barrier to the systemic transformation, economic restructuring and social realignments of Shenzhen. URBANUS is still consolidating its position in the myriad changes in the relationship between the market and the state in China.

\section{- Anti-market behaviour}

Substantial investments have been made in buildings and infrastructure in Shenzhen since 1980.

The rapidly growing number of developers in cities of rapid marketization have been driven by the potential in the emerging property market and the existence of a great amount of pent-up demand accumulated over many years of central planning suppression. ${ }^{48}$

The rapidly growing number of developers demands great speed in completing designs. For most architectural firms, profit maximisation is a key factor 
attributable to the genesis of this market-oriented industry. Incentives for profit maximisation are clearly present in marketplaces where architectural design services, and developers' demands, guarantee changeable prices. As previously discussed, URBANUS architects are not aloof from the market, but their prestige does not come from pursuing profit. In such a market-oriented industry, surpassing even the capitalist market economy, I would argue that the uniqueness of URBANUS comes from specific anti-market projects and research. Urban Tulou (Guangzhou, 2008) (9 $^{9}$ is the best known example of their "anti-market behaviour" in architecture. From the marketing strategy side, Feng defined it as an "anti-real estate" real estate project. ${ }^{50}$

URBANUS received the commission of Urban Tulou from the Vanke Real Estate firm, which was aiming to undertake a project of low-income housing. Wang Shi, CEO of Vanke Real Estate, took a tour of an intact Fujian Tulou at the end of 2005 and saw an opportunity to build a more humanitarian architecture in this traditional residential type, proposing that the architectural form of the Tulou is close to the modern dormitory. Wang Shi asked URBANUS whether they could do some research on traditional housing and design a prototype for small-sized housing units. ${ }^{51}$ The partners in URBANUS strongly agreed with Wang Shi on the architectural value of Fujian Tulou and confirmed the feasibility of the project.

In order to have a better understanding of the current living conditions of the target customers, the main designer, Liu Xiaodu, visited the house of a cleaner who worked in the offices of URBANUS. It was a $30 \mathrm{~m}^{2}$, two-room apartment, without kitchen space, shared by four couples. They were all migrant workers and had no hope of staying in the city permanently. The majority of the migrant workers were accommodated in the urban villages. The average rent of tenure housing in urban villages is usually cheaper (around 10RMB per square metre per month) than that of the central urban districts (around 15RMB per square metre per month). ${ }^{52}$ "It is not unusual to see a family of three sharing a single rental room with no facilities and using a corner to set up a small cooking area with either a kerosene burner or propane stove. ${ }^{\circ 3}$ In "Vanke Four Seasons Flowery City" a large, gated residential district near Urban Tulou, there are 5,000 households. The service staff, most of whom are migrant workers, number 1,000 to 2,000 people; they were the target inhabitants of the Urban Tulou envisaged by the architects. They work hard but are underpaid, and they have no hope of ever affording urban housing in Guangzhou or Foshan.

The remarkable and controversial aspect of this project was precisely that the target users are the low-income population, or the migrant workers in the city. As Weiping $\mathrm{Wu}$ points out, the general disadvantage experienced by migrants in the city is caused by the institutional restrictions of the Hukou system that outweigh the combined effects of socio-economic factors. ${ }^{54}$ Implemented since the mid1950s, the Hukou system requires each citizen to register in one, and only one, place of regular residence. It entails two related parts: place of registration and type of registration (urban versus rural). ${ }^{55}$ Due to the restriction of Hukou to local urban residents and permanent migrants, urban amenities are either priced low or 
provided free. On the other hand, migrants without local Hukou have very limited or no access to local schools, citywide welfare programmes, state sector jobs, or the housing distribution system. ${ }^{56}$

From the point of view of providing an equitable share of items of personal and collective consumption, this would seem to be a regression from the ideals and fundamental beliefs of the socialist housing system. Under the traditional planned economy, all housing production was the responsibility of the State in China. Since 1949, China as a socialist country has adopted a welfare housing system where the production, allocation and maintenance of housing have been the responsibility of the relevant work unit (Danwei). ${ }^{57}$ Yet housing reform has been a crucial component of the overall economic reforms in urban China from the mid-1980s. In 1988, the government issued a major reform document, the Ten Year Reform Strategy. Its main objectives were to encourage urban residents to buy their houses, to formulate new housing finance arrangements and to restructure rents in the public sector. Since then, various central and local legislation and regulations for the privatisation of urban housing have been issued. ${ }^{58}$

To some extent Urban Tulou has been forced on the public by civic necessity. An analysis made by Weiping Wu shows that migrants are largely excluded from the mainstream housing distribution system, and recent reforms in urban housing provisions seem to overlook the needs of this population..$^{59}$ In spite of housing reforms in China, a socially responsible government is required to play a dominant role in protecting the vulnerable, low-income population, or "floating population", within the evolving political and financial systems. Because these migrant workers are largely employed in the manufacturing and construction industries, they provide the powerhouse of human force behind the urbanisation process. In this situation their needs have been ignored and exploited. The housing market has played a key role in the rapid growth of China in recent years. McKinsey Global Institute estimates that over the past decade land sales have contributed to more than 60 percent of the annual income of some Chinese cities. ${ }^{60}$ With the introduction of capitalist labour relations into China certain attitudes, competencies and values associated with global capitalism seem to be increasingly valued. ${ }^{61}$ The developments for industry have been overwhelming, but migrant workers have no understanding of how they might safeguard their rights and interests.

Crucial to implementing affordable housing was the investment costs, operating systems and methodology. When the project began operation, there was still a long struggle to make it a reality. The Vanke mass housing development was mostly based on the mature operation of a commercial residential building. Vanke owns its own property management division offering professional services, unlike most real estate corporations in China. Urban Tulou is no exception, and every resident has to comply with the commune rules laid out in the initial contract. All residents must undertake the cleaning together in the neighbourhood, so that they are exempt from Vanke's property management fee. Urban Tulou started managing itself in 2008. The occupancy rate has stabilised around 92 percent. From my observation, the only vacant rooms in the Urban Tulou are the collective dormitories each accommodating four people, not suitable for the nuclear 
household pattern. In the administration room, there are piles of application forms for living in Urban Tulou on the desk. There are some criteria for the applicants: the annual income should be under 30,000RMB, and the applicants should have neither house property nor own a car in Guangzhou and Foshan.

From the latest financial data provided by Vanke, the land cost of Urban Tulou is $12,810,000 \mathrm{RMB}$, the development and construction cost is $32,400,000 \mathrm{RMB}$, and the overall investment is $46,250,000 \mathrm{RMB}$. The building cost per square metre is $3822 \mathrm{RMB}$. Officially issued by a Board of Directors, the 15,000,000RMB enterprise citizenship fund was first allocated by Vanke Corporation. The rest of the prime investment had to be supplemented by the Guangzhou Vanke Corporation. Currently, Vanke has set the rent of Tulou as 450RMB to 500RMB per suite, similar to peasants' houses in the urban village in the centre of the city, and a little higher than the rent of peasants' houses nearby. Vanke forecast that the investment would be covered in fifty-seven years. From the residents' reluctance to move and satisfaction of living conditions, we can safely say that Urban Tulou is operating comfortably under the supervision of Vanke, but it is a provocation from the perspective of commercial interests.

From this project, it should be noted that the initiator, executor and maintainer was neither local government nor state government, but a private company, and the technical supporter was a private design firm, URBANUS. Vanke as a private developer and URBANUS as a private design firm attempted to share the responsibility of the public housing project with the central and local governments, by developing a private project for public welfare. URBANUS and Vanke were both acting in their private capacities, and it is a pragmatic association. They had first put forwards a proposal to the relevant government, which suggested that the government should assist with Urban Tulou as a part of subsidies to extreme low-income people in the urban area. But being subject to several strong and often conflicting currents of social problems and public policies, the proposal was rejected. To what degree the three architects in URBANUS and the associates of Vanke Real Estate represent the interests of the tenants in this project is difficult to ascertain. But it was certainly developed with considerable effort. It is possible that their enthusiasm could be diverted towards constructing a new nexus between developers and government in the future. In this instance, the three architects in the URBANUS practice did not engage in the pursuit of profit, but they instead focused their creative and business energies on behalf of the groups most vulnerable in the social transition.

In general they are supported by two aptitudes in their "anti-market behaviour": their capacity for critical thinking - they not only challenge social and urban conditions but also challenge the existing Western model in urban design theory. In Weidong Ma's interview with the three architects, Meng said,

Our popularity has increased; there is no great survival problem at the moment. So, we may have more opportunities to make choices: developing knowledge, maintaining consistency in concept design, or converting experience into design strength and quality through an objective process rather than continued reproduction of existing ideas. ${ }^{62}$ 
Liu continued:

I feel our success also lies in our own self-criticism. Some designer will follow only his or her own aspirations while turning a blind eye to critical problems and peer critiques. ... Internally we three have a review system which formed spontaneously. ${ }^{63}$

The other capacity is their enthusiasm for research into emerging urban problems, such as the Urban Village phenomenon in Shenzhen, which later resulted in a commission to build the Dafen Art Museum (Shenzhen, 2007). ${ }^{64}$

\section{The circular path: travelling architects and the wandering imagination of China}

The influence of market and personal experiences in the work of URBANUS is clearly seen in the development of Urban Tulou (Nanhai, 2008) (Figure 5.3). The outcome of other projects by URBANUS can be unfolded from these perspectives as well, but multiple forces cannot usually be reconciled in one project. In all URBANUS's works, the circular plan of Urban Tulou (Nanhai, 2008) is their most incisive architectural expression conciliating multiple forces and influences - including the domestic market, the global market and many indicators from their life experiences and educational background.

Designed by the up-and-coming Chinese firm URBANUS, the Tulou is a centuries-old housing prototype, reworked for the hard realities of the global capitalist city. It reminds us that bold architecture can serve a good cause, acknowledging the dignity of people who are often treated as invisible. ${ }^{65}$

This impression of Urban Tulou (Nanhai, 2008), offered by The New York Times, also presented images of a nightmare labyrinth of residential buildings in China. In 2008, a row of Tulou study models was displayed in a glass case in the CooperHewitt National Design Museum (New York). The prototype of Urban Tulou (Nanhai, 2008) is the Fujian Tulou, defined as: "A large multi storey building in southeast Fujian mountainous region for large community living and defence, built with weight bearing rammed earth wall and wood frame structure." ${ }^{66}$ Liu Xiaodu, Meng Yan and Wang Hui talk about Urban Tulou in English whenever it is exhibited on the international stage. While many reports and studies have been published on the subject of innovation of the traditional Chinese form, the consideration of traditional form is generally related to a region with a long history and many stories, for example, Beijing, Xi'an and Nanjing. But the renovation of traditional form in this particular project does not convey its location's actual regional culture, "Lingnanism". ${ }^{67}$ So how and why did this architecture, which could be mistakenly categorised as pure regionalism, come from this particular group of young architects in the Pearl River Delta, at this particular historical moment? Feng argued that Urban Tulou (Nanhai, 2008) is an example of the 


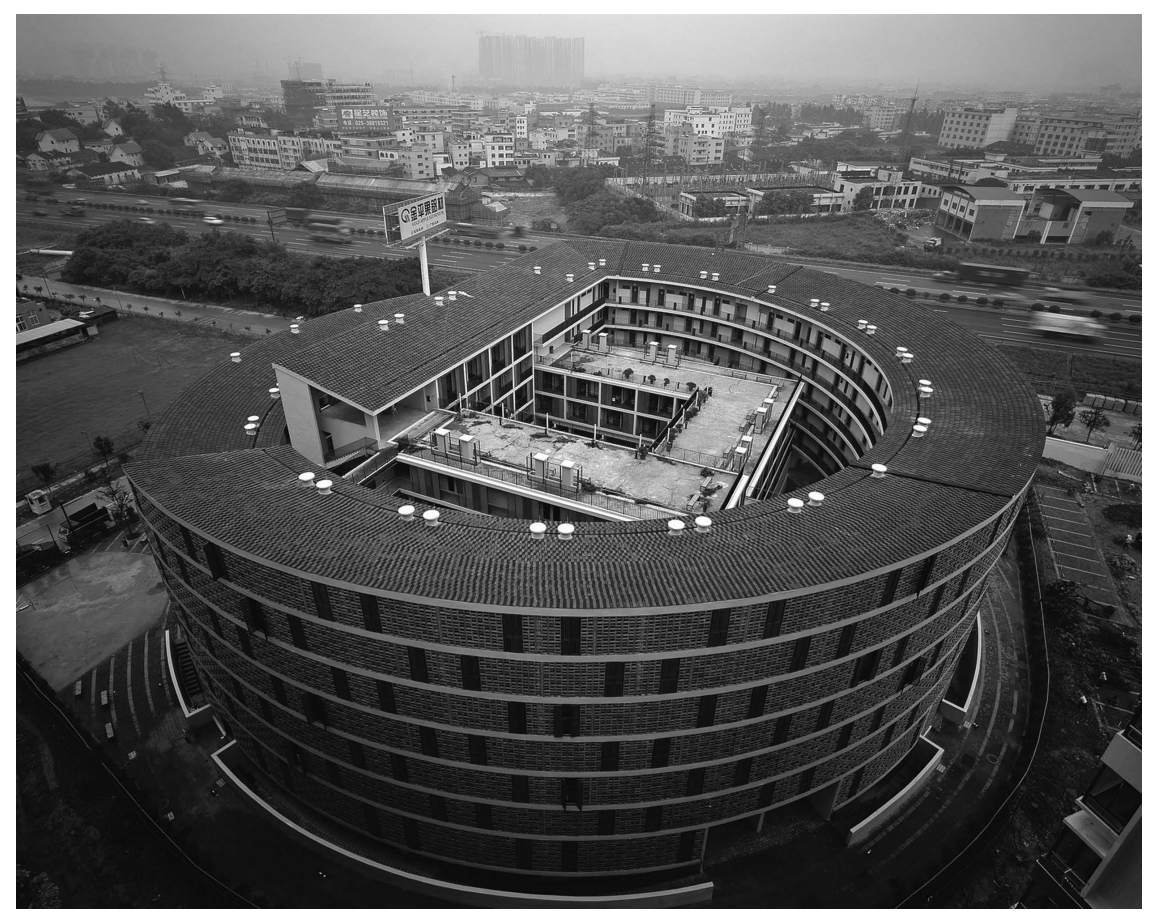

Figure 5.3 URBANUS, Urban Tulou, Nanhai, 2008

neo-regionalism of Guangdong province: "It is an exercise to elevate Lingnanism to an international level, thereby providing a non-Guangdong stage for the regionalism-restricted Guangdong. $" 68$

In Fujian Tulou, the rectangular Tulou is an earlier design, whereas the circular ones are more recent. The rectangular Tulou is direction-oriented and has different lighting and ventilation characteristics, often resulting in damp and dark corners. Hence, these were slowly replaced by the circular design. Both designs are built around a central courtyard that allows light and ventilation and is designed to house livestock (some of the circular Tulous also have an inner circular single level building, within the compound). Mixed among square, rectangular, and elliptical shapes, circular Tulous appear in plain view as dramatic forms. Similar to its prototype, the most remarkable and internationally recognised aspect of Urban Tulou is its nearly circular plan, instead of featuring a richly textured façade or having a social significant for the social transition. Regarding their choice of a circular plan, the URBANUS team have explicitly stated their attitude:

1. We do not deny the fact that we take Fujian Tulou as the prototype. 2 . We believe that the radial units have very influential value of reference for a modern living model. 3. Traditional units in Urban Tulou are evenly laid 
out along its perimeter, like modern slab-style dormitory buildings, but with greater opportunities for social interaction. 4. The sense of social cohesion and a sense of belonging are now gaining more attention in it. 5 . The circular plan can result in better lighting and a larger usable floor area for each unit. 6 . Tulou is not the only a circular dwelling pattern; it will also serve as the start of a series of research regarding low-income housing. 7. We hope that the circular design will help Tulou to become iconic architecture. ${ }^{69}$

Except for their own justification of the circular design in its functional and cultural aspects, the reasons why the circular design was intuitively chosen and how it is further translated by the architects into its new context and accepted in international exhibitions have not been deeply investigated. The ethos of Urban Tulou's (Nanhai, 2008) construction is part of the larger picture - the overseas education of the architects and the imagination underpinning China's reconstruction in a globalised world. In considering which ends are served by translating the circular design, the perspectives of both the translator and the reader are necessary to explain how the circular represents an identity of the travelling nature of these architects, seen in a global context. Edward Said proposed the travelling theory and argued that cultural and intellectual life are usually nourished and often sustained by this circulation of ideas, and

whether it takes the form of acknowledged or unconscious influence, creative borrowing, or wholesale appropriation, the movement of ideas and theories from one place to another is both a fact of life and a usefully enabling condition of intellectual activity. ${ }^{70}$

He stated that when ideas and theories move from one culture to another, it necessarily involves processes of representation and institutionalisation in the new place, different from those at the point of origin. This complicates any account of the translation, transference, circulation and commerce of theories and ideas. ${ }^{71}$ The three architects of URBANUS were nourished through travelling: as discussed earlier in this chapter, the circular plan takes the form of acknowledged or unconscious influence and creative borrowing along with the movement. The circular plan also involves the process of representation and institutionalisation different from those at the point of origin, which in fact was the large, defensive, circular building built between the thirteenth and twentieth centuries in Fujian.

\section{- Weaving multiple values into a circular path}

In order to identify the acknowledged or unconscious influences and creative borrowing in the choice of this circular design, the remainder of this section looks at two summarised points that indicate the contours of power the group of architects proposed: first, they wished to bring Western values to China, but to simultaneously maintain Chinese values, and in this design, to better explain the old and new China. Second, they have the capacity to bilingually absorb and express the 
architecture within an understandable language. In other words, a circular design is the clear physical manifestation of their socio-logical philosophy.

How then do the architects weave the values they are promoting into this circular design? From the beginning of the project, the notion of the circular design was associated with utopian visions, some social, some political, some purely spatial and architectural. The sense of social cohesion and communal spirit revival in concentric housing functions as micro-utopias that arise easily in a socialist country. For example, if we pay close attention to the architectural drawings by URBANUS, as they compress the information and provide hints on the drawing in visual forms, we can identify the values they are promoting. The architectural drawing produced by URBANUS in the twenty-first century and the poster produced in pre-reform China share many aesthetic characteristics. The performance of the dragon's dance and red banner on the entrance of the Urban Tulou in the architectural drawing are subtle evidence of their affective memories of their first youthful commitment to the ideals of collectivism (Figure 5.4). In contrast to the typical bland architectural drawings produced by professional rendering companies, an understanding of China in drawings of Urban Tulou is captured by incorporating the vision of a lived experience from the early and mid-1970s. The figures wearing uniforms in the poster try to impress on the population how the working class sustained the speed of China's recovery and further development, which is ideologically based on proletarian solidarity. The anciently hued picture, full of pleasure, corresponds to the architectural message of, and collective unity proposed by, URBANUS.

In Vanke Zhoukan, the case of Huang Yu, who lived in the Urban Tulou, gives a fairly vivid illustration of the communal life:

Huang Yu has rented one bedroom at level 3 in Zone C. The circular-shaped new Tulou is divided into several zones; each of them is isolated from others by partitions ... The room has basic furniture, such as a bed and a wardrobe. Huang does not spend money on a washing machine. It is convenient to use the public laundry facility. He does not own a TV set because a computer is better entertainment. Public bathrooms can also be seen in the building. Though Huang is a tenant of Vanke Property, he rarely sees staff from Vanke in his routine life. The build is administrated by an elected commission. There are nearly 300 apartments. However, only a few months later, Huang knew his neighbours from the same floor, and evolved close relationships with them.

This description by a resident reveals that the sense of communal cohesion and a sense of belonging are now revived in this circular plan, which transcends the traditional clan, and re-establishes modern families into a single community. Traditional Tulou residential complexes provide structural and architectural confirmation of the importance of patrilineal clan organisation within singlesurname communities. ${ }^{72}$ All rooms in a traditional Tulou are of the same size. Each household has one room on each floor. The room on the first floor serves 


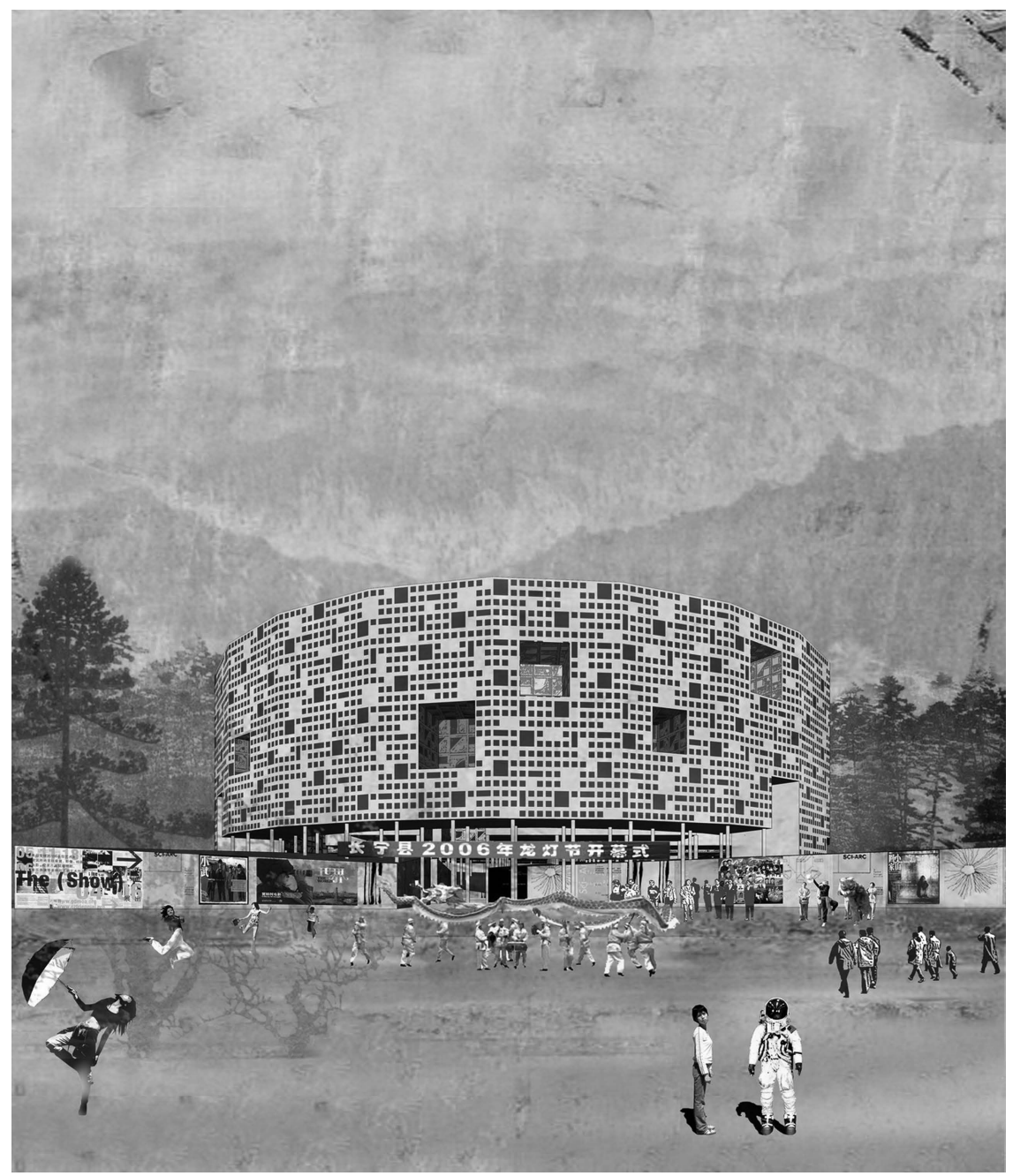

Figure 5.4 URBANUS, Urban Tulou, Nanhai, 2008. Rendering drawing

as kitchen-cum-dining room, the one on the second floor as storeroom, and all the others above as bedrooms. ${ }^{73}$ Urban Tulou (Nanhai, 2008) is by no means a traditional patriarchal community but a modern community based on contractual arrangements. The architects employed the idealised Tulou composition: the circular design was divided into blocks or units of space according to their purpose and then dynamically linked with corridors and bridges. The Urban Tulou (Nanhai, 2008) is by no means a collective proletariat housing design proposal. Yet the new Tulou complex provides architectural confirmation of the communal spirit from the socialist era of China, with different surnames living in one community. 
It emphasises the spatial quality of traditional Tulou as much as its communal role, along with the new architectural elements of modern construction. The open staircase, natural lighting in the yard induced from above and the refined but concrete sensibility of the roof garden with planting covering the equipment - all contribute to the development of the circular spatial prototype.

\section{- Weaving bilingual capacity into a circular path}

Certain questions now arise: how do the architects utilise their bilingual capacity between English and Chinese, and modernity and tradition within architecture itself, in demonstrating and improving this circular design in the new global context? The properly assembled abstract vocabulary from the traditional Tulou façade, its security mesh, Chinese lattice window and clothes lines, reinforces the circular identity (Figure 5.5). Traditional Tulou draws on local resources including cedar, sliced bamboo, tree branches, glutinous rice ${ }^{74}$ and so on, which results in the one-metre thickness of the exterior wall. The windowless feature is wrought on the first two-story exterior wall; the rest of the wall is punctured by small windows. Walls are typically battered and have only a limited number of openings. Most Tulou have only a single entrance, although some have subsidiary gates

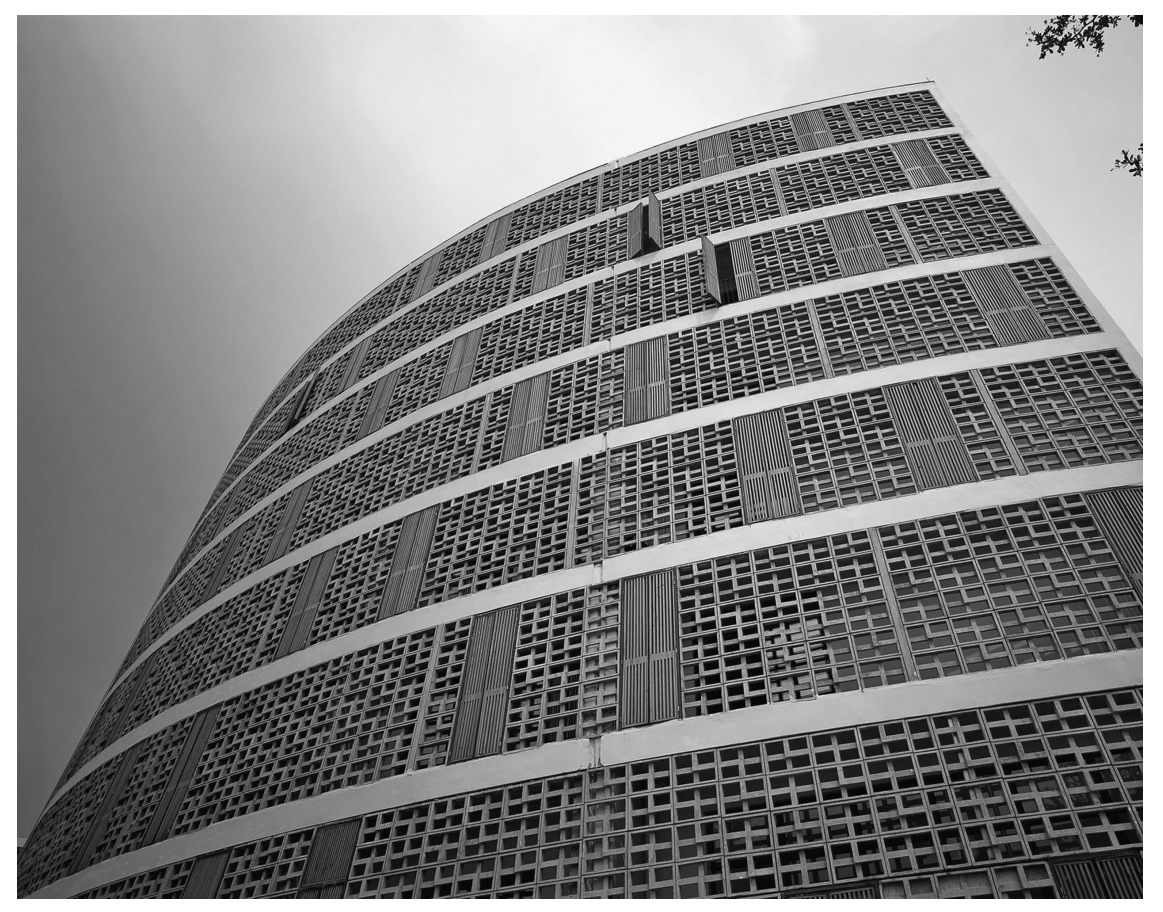

Figure 5.5 URBANUS, Urban Tulou, Nanhai, 2008. Reinforcement for the circular identity 
approximately ninety degrees from the main gate. ${ }^{75}$ Hence the striking exterior wall is endowed with an effect of massiveness and integrity.

However, due to the requirement of privacy for modern family life, natural lighting in the kitchen and improvement in the sanitary conditions, many elements of a circular design are no longer suitable for modern life. The first step in their strategy is based on the deconstruction and realignment of traditional patterns, and reconstructing a different façade. It is necessary to note that cage-like security meshes are widely adopted in the southern part of China. The final exterior face thus functionally echoes this element, at the same time giving enough light through the prefabricated concrete, which covers the balconies outside. The operable shutters for each unit using denser fabric seem to frame a Chinese motif of an abstraction of timber grids, reminiscent of a lattice window. The initial random arrangements of different sized windows, a typical idiom in modern and contemporary architecture, were abandoned in the final scheme. Hence, the identity of the building is primarily constructed through a thoroughly modernist device of integrating abstract forms and modern materials, which achieves a balance between a traditional sense of solidity and modern life's requirement for privacy, light and ventilation. The abstract elements recall the image of the traditional Tulou and emphasise the circular form.

\section{- The imagination of China as a circular path}

In addressing the acknowledged or unconscious influence on the architects who translated the circular in the new context, it is necessary to address the acknowledged or unconscious influence on the audience who respond to the circular design and recognise its significance. Urban Tulou (Nanhai, 2008) achieved striking international success and gained overwhelming international attention, which has been reported by many international magazines and professional journals. ${ }^{76}$ Urban Tulou (Nanhai, 2008) reflects upon a traditional type and a modern translation of it; it is a prototype related to a mountainous region in Fujian province but relocated to the edge of Guangzhou. Therefore, Urban Tulou and the location of Urban Tulou (Nanhai, 2008) lack a historical identity and a form. However, for the international audience, URBANUS provided an intriguing Chinese circular symbol. They expect to see exotica, "Chineseness", both novelty and the modern world at the same time, all of which are demonstrated by this circular design. The unusual and even playful gestures of integrating a circular design into an alien environment bolster the consensus that the building ultimately represents both Chinese culture and a brand of avant-garde aesthetic, free of pomp. The main reason it captured the attention of international audiences is that it accommodates all identities as a generic signifier of both China and modernity.

The URBANUS architects are cautious when talking about Chineseness, or the Chinese identity. They quickly move to the contemporary quality of the building as one of the most important issues in the evolution of modern architecture in China. They refer to it as "Contemporaneity", a term which can be traced through several of their essays. ${ }^{77}$ They emphasise the contemporary power of China - its 
ability to represent an underlying series of new ideas or new movement in the field of architecture. Yan Meng commented,

We did not intentionally impose Chinese elements into our projects. I would call it the social condition of contemporary Chinese people, the special conditions of a city which are manifested in architecture, even if it is imperfect, but it makes the contemporary Chinese moments stand out. It is difficult to describe this condition; however, we always believe that doing further research about it is more beneficial than simply doing a value judgment of the history. ${ }^{78}$

This appears, on one hand, to narrow down an extremely complex word China to a simpler question of contemporary urban condition, but on the other hand, they also provide no room for direct reference.

However, when URBANUS architects stand on the international stage, it is possible that Liu Xiaodu, Meng Yan and Wang Hui benefit from their Chinese ethnicity because there are some specific kinds of expectations and projections of China by the world audience. When talking about Zhang Yimou, Liu Xiaodu pointed out that the upsurge of international interest in his movies in the 1990s coincided with a re-imagining of the past. But the inaccuracy of the re-imagining allowed emphasis to be placed on a more abstract and more specific movie language, which situates it in an indeterminate phase of history. Liu argued that

Zhang's films are not situated in the framework of regionalism. For example, in his film Ju Dou, the dyehouse looks like the "JiangNan (regions south of the Yangtze River)", but many scenes in it make it look like northern China, which creates a mix of references. However, I think these discussions about its locality are not important; his films are definitely very Chinese. ${ }^{79}$

From this point of view, URBANUS's expression of China is analogous to Zhang Yimou. For the international audience, the circular design of Tulou is both more abstract and more real than the heritage. In the project of Urban Tulou, from the very beginning the architects were concerned with cultural re-evaluation and social reality in the new social context rather than international appeal, but consequently Urban Tulou achieved striking international success and approval.

How the emerging process of high-speed urbanisation in the Pearl River Delta gave URBANUS new space to work is also reflected in this case. As with other URBANUS projects, they identified the circular site plan as the most adaptable to the residual land left over by rapid urbanisation. In other words, the circular design is part of a new vision using the residual land from rapid urbanisation and scattered urban planning. In discussing their own project, URBANUS wrote,

Our experiments explored ways to stitch the Tulou within the existing urban fabric of the city-green areas, overpasses, expressways, and residual and left over spaces produced by urbanization. The cost of residual sites is quite low 
due to incentives by the government, and this is an important factor in developing low-income housing. ${ }^{80}$

This strategy can also sharply reduce the budget of land for the private developer.

In addition, URBANUS's choice of this idealist circular design coincides with their maturing role in the market. As previously noted, around 2005 URBANUS reached its high point in the market. Many developers or governmental officers were intrigued with URBANUS's designs and commissioned them. Vanke Real Estate came to URBANUS at that time. Vanke, as a private firm, is currently the largest professional housing developer in China. In 2011, Vanke sold floor space totalling 10.75 million square metres, and sales reached RMB 121.5 billion, the largest in the global real estate industry. ${ }^{81}$ It could be said the largest player in the global real estate industry strikes a note of self-mockery in this "anti-real estate" project.

Therefore, similar to the circular design in Urban Tulou (Nanhai, 2008), URBANUS's architectural expressions manifested the architects' own travels and international projections of China and created an in-between identity, formed by juxtapositions of many regions and times, experiments in nostalgia for a grand landscape of experiences and heavily influenced by realignments, or new market orientation, to facilitate the Pearl River Delta's transformations into a vast conurbation.

\section{Urbanised intervention and private/public anxiety}

\section{- Moving the public space ahead}

In their first published design collection book, the architects of URBANUS categorised their designs into four groups, "Urban Intervention, Renovation \& Regeneration, Urban Landmark, Urban Design \& Research". ${ }^{22}$ Urban intervention is implemented in the projects Public Art Plaza (Shenzhen, 2000), ${ }^{83}$ Sales Centre for Grand Constellation Development (Beijing, 2003) and Vanke Experience Centre (Shenzhen, 2006). The strategy of renovation and regeneration with urban concern can be found in Dafen Art Museum (Shenzhen, 2007) (Figure 5.6), Tangshan Museum Park (Tangshan, 2008) ${ }^{84}$ (Figure 5.7) and OCT Loft North Area Renovation (Shenzhen, 2011) ${ }^{85}$ (Figure 5.8). Urban landmark is represented by Shenzhen Planning Building (Shenzhen, 2005), ${ }^{86}$ Digital Beijing (Beijing, 2007) ${ }^{87}$ and Longgang Education Bureau Office Building (Shenzhen, 2005). ${ }^{88}$ Urban Tulou (Nanhai, 2008), the study on the Fuxin Village and the study on the Gangxia Village represent Urban Design \& Research. Laurence Wu summarised the 170 projects done in the first seven years of URBANUS into several urban categories: "Urban Intervention, Urban Edge, Urban Retention, Urban Anchors, Urban Landmark, Urban Public Space and Urban R\&D”, ${ }^{89}$ part of which overlaps with URBANUS's own classification. However, these classifications and summaries are all based on architects' solutions, rather than on investigating the problems that occur in the situation of urbanisation. To avoid a superficial analysis 


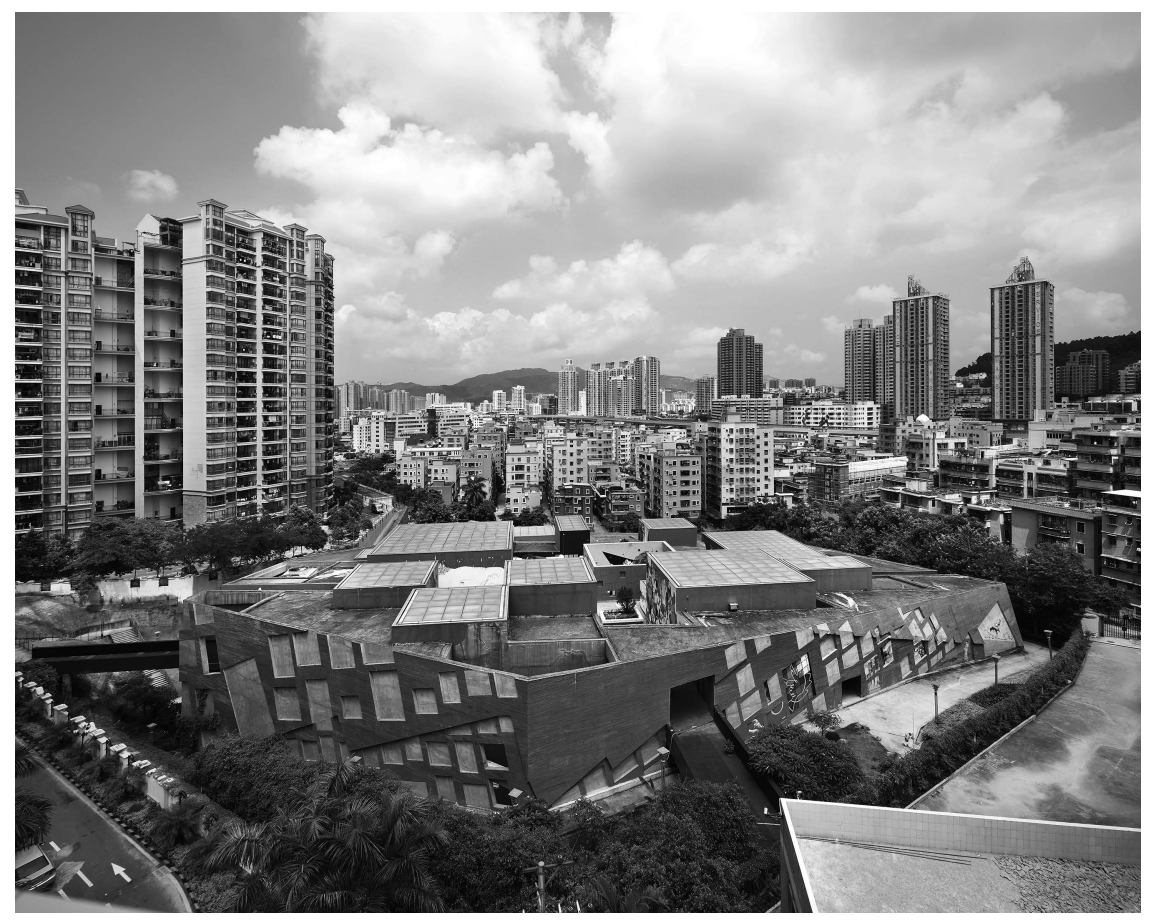

Figure 5.6 URBANUS, Dafen Art Museum, Shenzhen, 2007

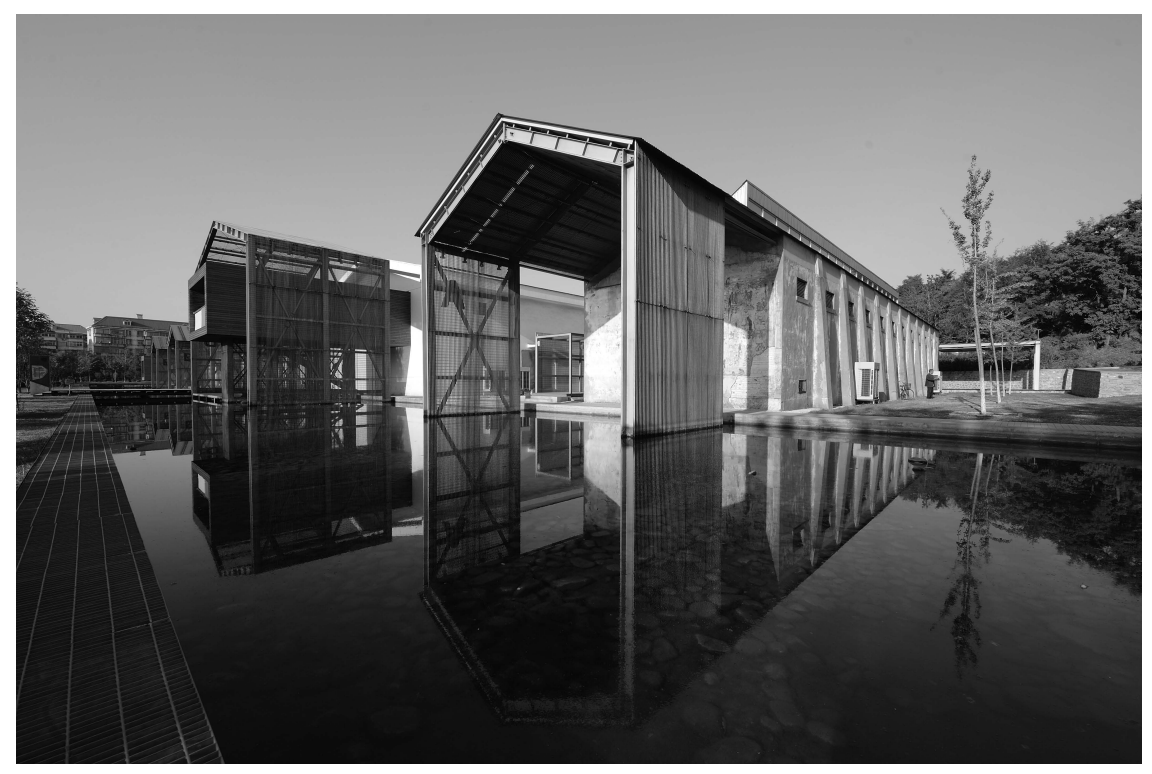

Figure 5.7 URBANUS, Tangshan Museum Park, Tangshan, 2007 


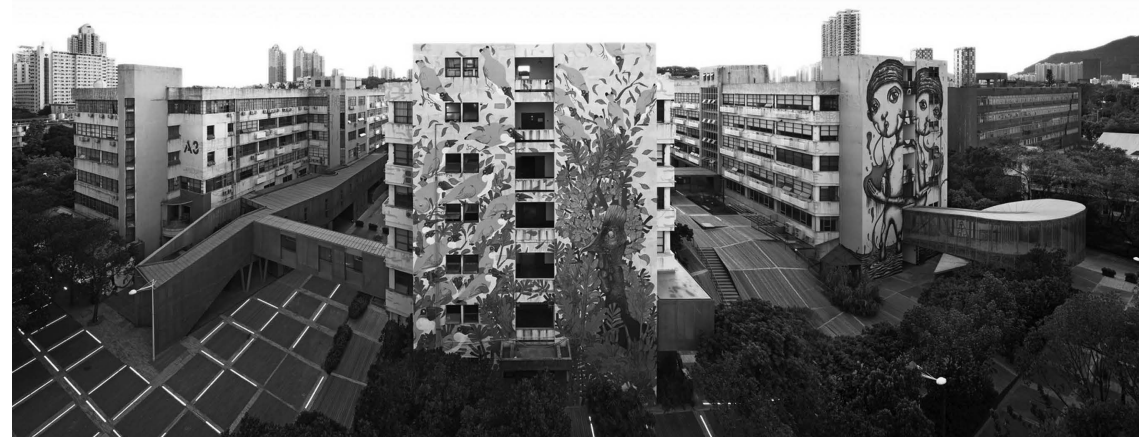

Figure 5.8 URBANUS, OCT Loft North Area Renovation, Shenzhen, 2011

and in trying to expose the problems as they arose dealing with, I will analyse URBANUS in the context of contemporary China's socio-political constructs and ideological struggles, resting on the distinction between private and public.

From the name of URBANUS, which derives from the Latin word of urban, it is possible to get the sense of their design approach: reading architectural programme from the viewpoint of the urban environment in general.

When the founders tried to find a proper name for the new office, most thought that it should incorporate the concept of "city" in some way. One day Meng Yan, who was then working in New York, came across a word in his office dictionary, "urbanus". In a country like China where the economic foundation is weak and the society is developing in a fast track manner . . . the city may bring endless joy, but it is also a source of pain and evil. ${ }^{90}$

The phrase "urban public space" has the highest frequency of occurrence in introductory design literature published by URBANUS. In one of their early designs, Public Art Plaza (Shenzhen, 2000), which is located in one of the most densely populated areas of downtown Shenzhen, URBANUS converted a shabby parking lot into a semi-underground parking garage integrated with arts programmes, such as an outdoor display area, a gallery, a bookshop, a café, artist studios and a lecture hall. In URBANUS's maturing stage, Tangshan Exhibition Park (Tangshan, 2007) addresses the public urban identity within a typical second-tier city in China, in an expiring post-industrial and banal setting. The park helps to reinforce an urban confidence in exploring public spaces in this second-tier industrial city near Tianjing. The single building is no exception in taking the urban public space as the primary concern. In the Futian Library Complex (Shenzhen, 2001), URBANUS emphasised that the library becomes an impressive civic icon with a generous front plaza, and the sectional-visible architectural façade integrates the interior activities into the urban spaces outside. The urban public space has 
been also reflected in the Tangshan Museum Expansion (Tangshan, 2011) ${ }^{91}$ (Figure 5.9), OCT Loft North Area Renovation (Shenzhen, 2011) (Figure 5.10), Dongmen Photography Plaza (Shenzhen, 2009) ${ }^{92}$ (Figure 5.10), Jade Bamboo Cultural Plaza (Shenzhen, 2009), ${ }^{93}$ Wenjin Garden Plaza (Shenzhen, 2011) ${ }^{94}$ and Nanshan Marriage Registration Centre (Shenzhen, 2011) ${ }^{95}$ (Figure 5.11).

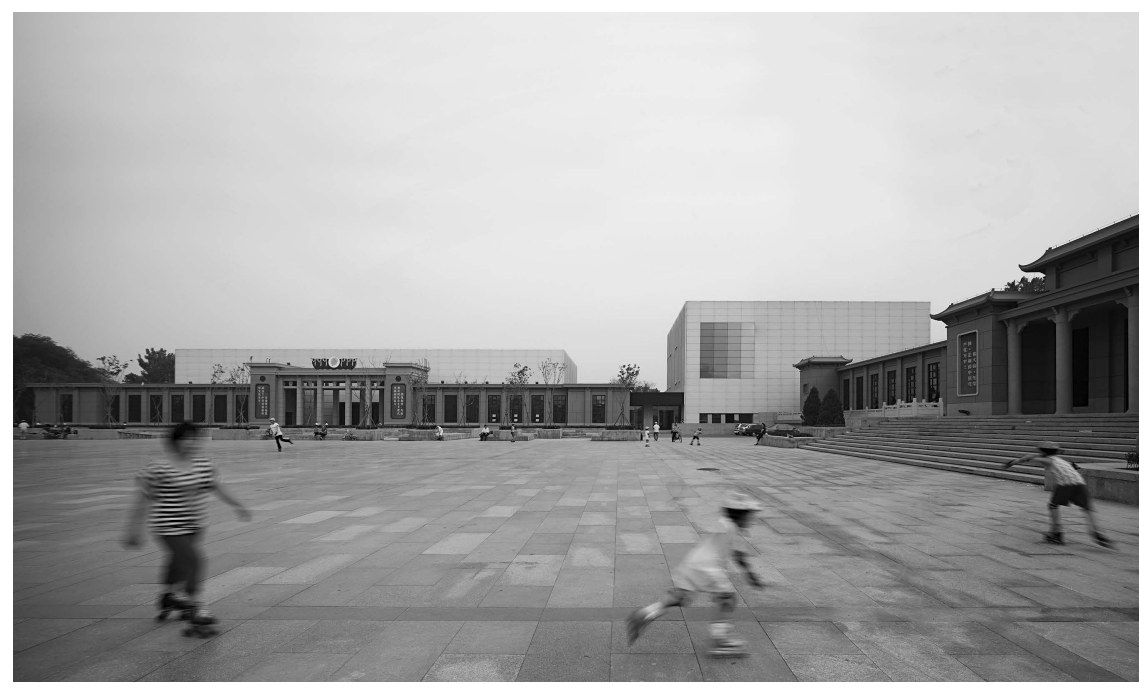

Figure 5.9 URBANUS, Tangshan Museum Expansion, Tangshan, 2011. Public space

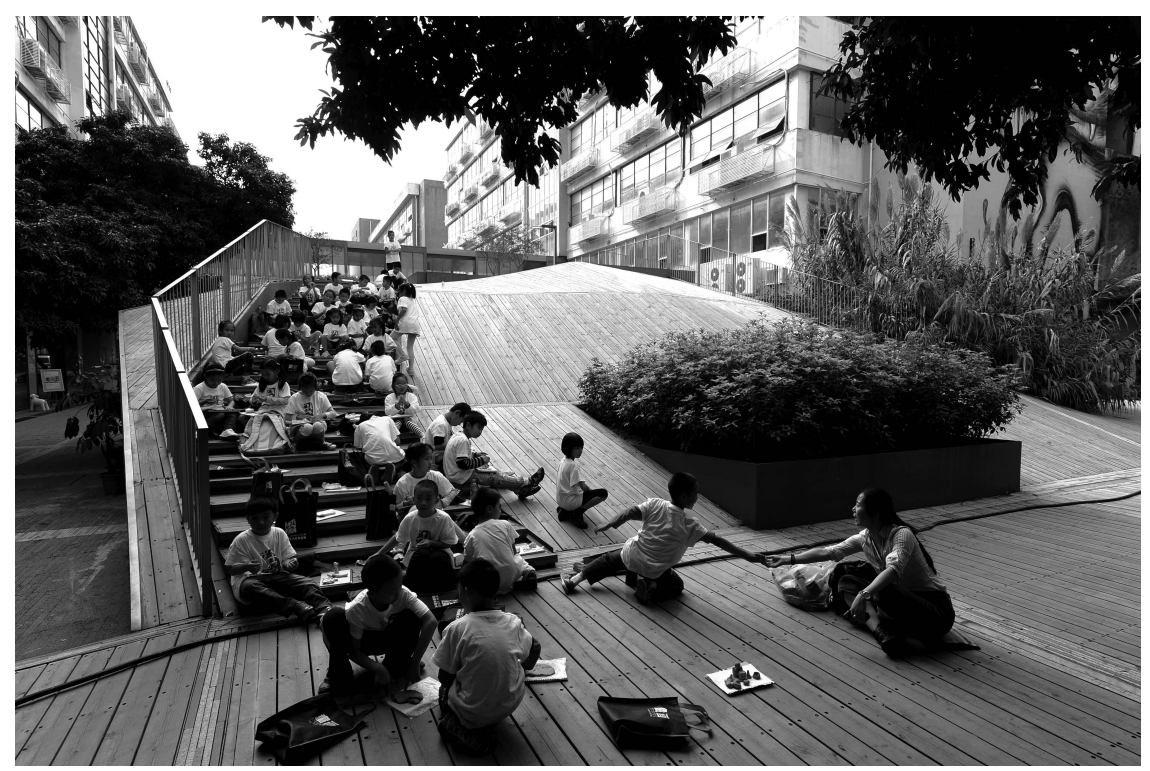

Figure 5.10 URBANUS, OCT Loft North Area Renovation, Shenzhen, 2011. Public space 


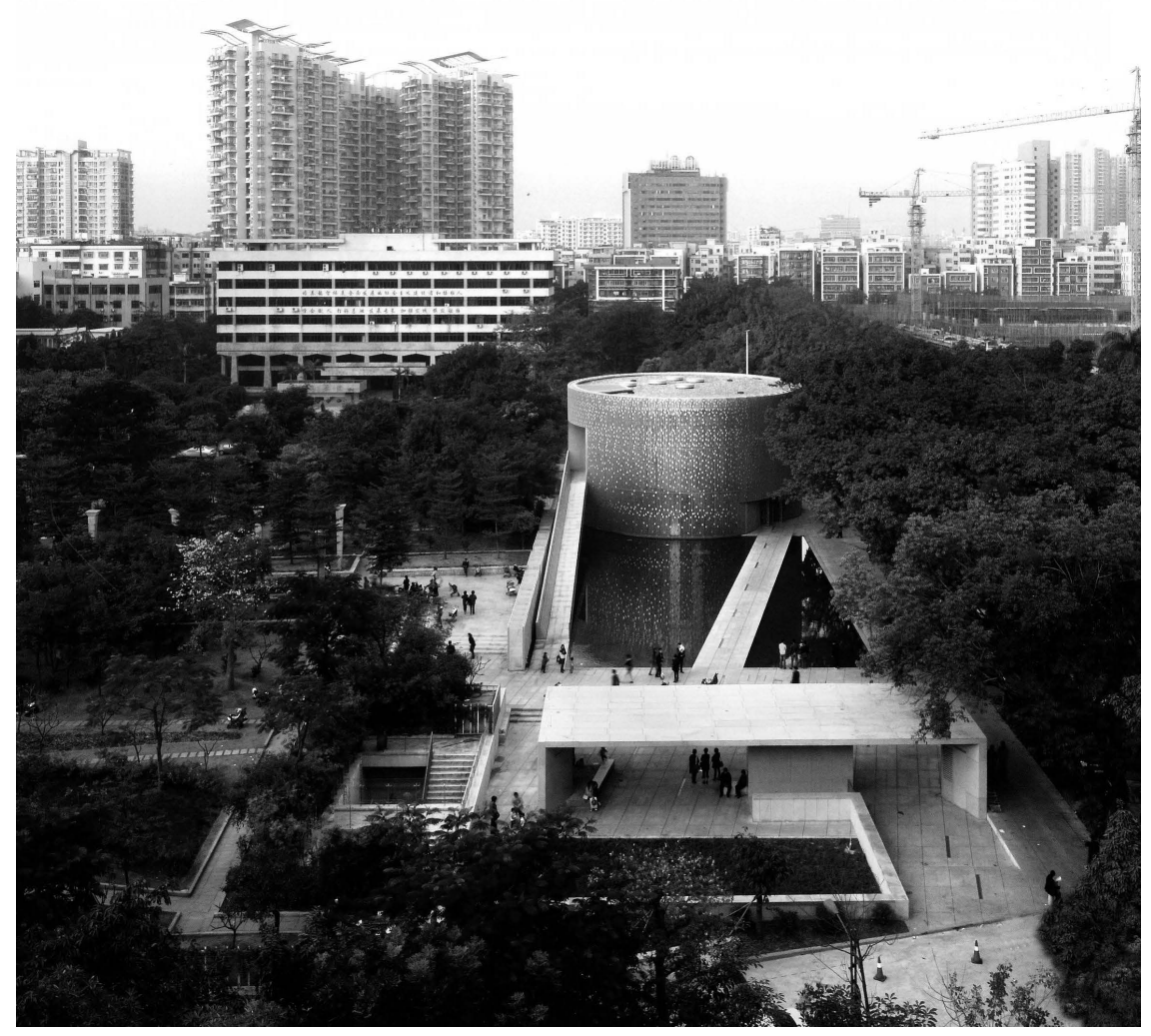

Figure 5.11 URBANUS, Nanshan Marriage Registration Centre, Shenzhen, 2011, Public space

Furthermore, regarding urban public space, the URBANUS architects undertook intensive research into the urban village and proposed several design solutions. In the urban village, without planning and development control, and stimulated by rental income, every villager tries to build a house as high and as big as possible. High-density construction in urban villages is technically illegal, but government administration in the urban village is less effective. ${ }^{96}$ Accommodating a large number of migrants and characterised by unplanned construction, the urban village actually becomes a public space and activity desert. Dafen Village is a typical urban village in the Pearl River Delta, which to a large degree is occupied by a floating population. Best known for its replica oil painting workshops and manufacturers, its exports to Asia, Europe and America bring billions of RMB each year to the area. Before the reform in 1978, villagers in Dafen lived on farming and the annual income per person was less than 200 RMB. Except for a few old houses and ancestral temples in Dafen Village, there were no public spaces. 
High-density buildings, narrow, engulfed streets and poor infrastructure are common features.

Dafen Art Musuem (Shenzhen, 2007), designed by URBANUS, emerges as a potential organisational catalyst for the chaos in the urban village. The architects created a hybridised mix of different activities, like art museums, oil painting galleries and shops, commercial spaces, rental workshops and studios under one roof. Dafen Village has some special features: high and low roofs, tall but narrow streets and diversification in colours. By carefully investigating the site and collecting first-hand information in Dafen Village, the architects considered that the village layout was analogous to gridiron plans in some American cities, for example, New York. Single buildings compose independent street blocks; however, there is little distinction between single buildings in high-density use and street blocks. The Barbican and the ancestral halls are still in the centre of the old village. Drawing on the village texture, the architects introduced an inversion of Dafen Village's texture into the architecture of Dafen Art Musuem (Shenzhen, 2007).

The variation that Dafen Art Museum (Shenzhen, 2007) has brought to the urban village is the public space integrated into urban life. The first floor in the Dafen Art Museum (Shenzhen, 2007), which is open to an adjacent plaza, seeks to provide areas for local artists to sell their paintings, and also an auditorium for public events. This strategy aims to allow the plaza and part of the first floor to have the same commercial morphology as Dafen Village, and thus the museum is able to become a natural part of daily life in the village. An article titled "The Achievement of Good Urban Public Space" can be found in the official blog of URBANUS:

In 28th January 2010, an extraordinary event named "One Thousand Artists Painting" happened in the open plaza of Dafen Art Museum. This activity was held in cooperation with the exhibition in Shenzhen Pavilion in Shanghai World Expo. Every painter produces two oil paintings of small size, the paintings which will be displayed in Shenzhen Pavilion in some special way. The spectacular scene lasted for more than six hours: painters were working hard; some veteran painters dealt with the supervision seriously; volunteers in red waistcoats were busy with keeping order and offering services; many curious villagers gathered around; the children were rushing about among the painters. In the memories of villagers, Dafen has never had this kind of folk activities. ${ }^{97}$

The event demonstrates that the urban public space created by URBANUS began to play a significant role in improving urban life for the residents in the village. In the open plaza and outdoor public spaces on the third floor of the Dafen Art Museum, villagers can come together for various activities, such as commodity exchanges, celebrations of festivals and social events, which are fundamental elements of urban life. However, what the URBANUS architects are striving for is more public space for vulnerable groups in society. However, with cities 
expanding so fast, urban space is becoming privatised at an unprecedented speed in contemporary China.

\section{- Private/public anxiety in contemporary China}

Urban public space, the most frequent phrase in URBANUS's discourse, to some extent implies its opposite, private space and the uncertain relationship between them.

The division of urban space into the public and private is a physical manifestation of the relationship between private and public spheres in society. In turn, these spheres are one reflection of the deeper relationship between the individual and society, between the self and the other. ${ }^{98}$

Individual citizens and their requirements, and their expectations regarding either private space or public space, have new manifestations in the changing urban conditions in China. I would argue that the barrier to success of "Urban Intervention, Urban Edge, Urban Retention, Urban Anchors, Urban Landmark, Urban Public Space and Urban R\&D"99 is the clash between individual and shared expectations of private/public space in the social transition.

The relationship between the private and public sectors can be usefully traced back to ideological development. The emergence of the market as a central legitimising institution brought the public/private distinction into the core of legal discourse during the nineteenth century. ${ }^{100}$ However, China's trajectory, which began from the pre-reform socialist regime of production and accumulation dominated by, and designed solely for, the state's extensive socialist industrialisation programme, then moved to a more market-based and uniquely hybridised system of production marked by quasi-public, quasi-private forms of ownership, production and accumulation. ${ }^{101}$ The private and public sectors have become combined and entangled together in complex ways, the complexity of which cannot be conceptualised or explained by conventional socialist or market theories. The liberal perspective on the emergence and development of the modern state and modern capitalism is grounded in the distinction between the public and private sectors. ${ }^{102}$ The assumption of the dominant neo-liberal ideology is that post-communist market transitions will lead to and require a sharpening of the boundaries, both legal and practical, between the state and the expanding private sectors. However, the post-communist economic transitions belie these assumptions. ${ }^{103}$

Private society and its actors flourish, but they do not stand across a clearly delineated divide from the public. For example, in 1949, China, as a socialist country, adopted a welfare housing system where the production, allocation and maintenance of housing became the responsibility of the relevant work unit (Danwei). ${ }^{104}$ In 1988, the government issued a major reform document, the Ten Year Reform Strategy. Its main objectives were to encourage urban residents to buy their houses, to formulate new housing finance arrangements and to restructure rents in the public sector. Since then, various central and local legislation and 
regulations for the privatisation of urban housing have been issued. ${ }^{105}$ In other words, the residential space, which had been de-commodified to a public welfare benefit in the communist victory, has been nominally re-privatised, but urban residents still only hold the right to use privately and sell privately for a limited number of years, rather than being freehold private property owners. That is to say, residents are still in public urban housing stock, with leasehold titles.

The active, intensive, unorthodox and opaque interaction between the public and the private sectors puzzles and entangles Chinese citizens. The transformation has affected all kinds of state entities - local and municipal governments, national ministries, the army, national and local public security bureaus, party organisations, universities and scientific research institutes - many of which have become profit-seeking players in the market who run their own extensive business empires. ${ }^{106}$ An ever-growing proportion of people feel anxious about the opaque cooperation between state agencies and private associations. According to Laurance Ma's analysis, the pursuit of entrepreneurial activities by state officials and newly emerging individuals has proven to be politically acceptable and economically rewarding; the most critical aspect pointed out by $\mathrm{Ma}$ is that this pursuit is socially admired. ${ }^{107}$

Therefore, the sense of ownership and the sense of place do not fall easily into the private-public dichotomy. This social anxiety has emerged among different social groups throughout Chinese society. Farmers feel anxious that their distributed and so-called privatised farmlands, formerly cultivated by themselves, can be compulsorily purchased and turned into urban land by the government at any time. Migrant workers have no chance to access urban housing in terms of eligibility and affordability, because the emerging political and economic structure is not capable of providing public and urban welfare to a growing labour force from rural areas not covered by the traditional welfare system. The new middle class in the cities is not clear about which class of private-owned assets would be nationalised or de-commoditised within emerging policies. ${ }^{108}$

In contemporary China, people find that it is difficult to discern whether the state agencies are still involved in collective housekeeping, a situation that prevailed for forty years before the 1990s, or are going to exploit them - in the manner of a commercial enterprise. Since the emergence of a relatively autonomous private demand is irresistible, increasing numbers of people in China are urged to live in gated communities in seemingly secure privatised property and space. As urban sprawl rapidly increases, urban public space is being swallowed up by privatisation, and the urban form resulting from privatisation in the contemporary city is subject to gating. Gating is the manifestation of a psychological anxiety in confronting current ideological struggles, more specifically, a new expression of the growing enthusiasm for privatisation: increasingly a loss of confidence in collective house-keeping drives people to entrench privatised living in gated communities in China.

The physical division between private and public spaces, and the enclosed form of the gated community, embody the sense that nobody wants to be disadvantaged again in the changing urban property regime. Therefore the gated form in China 
seems to be the easiest urban strategy to address psychological discomfort. "Gates are reassuring in the face of anxiety levels heightened by economic, demographic, and social change. They shield us from a world we feel vulnerable." ${ }^{109}$ Hence how the urban enclave addresses the anxiety, on one hand, is through this physical division and enclosed form which enhances the sense of ownership and privatisation, and on the other hand, the housing buyer in a Chinese gated community is not only the owner of his or her apartment but also the joint owner of the open space and community buildings. In this manner the eagerness for privatisation proliferates gated communities in the Chinese context, as people become more demanding in the sharp spatial division between private and public sectors, in order to ensure the stability of their personal space and assets. Furthermore, it also allows architects and urbanities to indulge in an easy solution: gated communities.

As a result, gated communities have now become the most prevalent and acceptable urban housing settlements in China as a solution to maintaining boundaries between public and private spaces. Miao stated that almost all the added housing stock in China took the form of gated communities from around 2000, and gates have become the standard feature of master-planned new communities in suburban areas, but they are also found in the central city. While national statistics are not available, there is no denying that gated residential districts or communities as the dominant pattern in the housing market has influencing both urban form and people's lives in contemporary China. ${ }^{110}$ Bray observes that the appearance of huge numbers of gated residential communities has become the key feature of China's urban transformation. The reason for the boom in gated communities in urban China can be attributed to a scarcity of land and population pressure, which has influenced planning authorities to promote high-rise and high-density development. ${ }^{111}$ The tolerance towards sharing space in such a neighbourhood is particularly low, and it is uncommon for domestic activities to encroach into the public space in a gated community. As a result, people usually do not know each other in one residential development, but they prefer to be zealously guarded and protected under property management control.

\section{- Urban Tulou in the private/public whirlpool}

Interestingly, Urban Tulou, targeting low-income groups, is a gated residence in URBANUS's final proposal, which integrates living, storage, shopping, spirituality and public entertainment into one single building entity. In a broader perspective, Urban Tulou is an epitome of China's gated residential district: Urban Tulou is enclosed by an outer circular block with a rectangular box within; both the circular and rectangular blocks contain small apartment units; the lower floors contain convenience shops, restaurants, a barber shop near the entrance and other community facilities including a reading room, sports room and entertainment room in a box form. Urban Tulou bears a resemblance to typical residential districts in China, caused by general concerns for security and management. However, the target market for Urban Tulou is the migrant workers living in the city, who are still very much dependent on the control exercised by neighbourhood 
institutions. Most migrant workers undertake jobs undesirable to the urban population, and it is difficult for them to integrate into the urban life in the city, because they are generally excluded by the urban population. They constitute a class in themselves.

In a series of essays, URBANUS admitted that they had devised two plans at the very beginning:

We had two directions at first. The first one is that rounded Tulou rests on the meshed grouped buildings, which is influenced by the urban village. We were expecting this residential district would not be gated, but extremely active in the regional commercial development. It will be easy to merge into the urban context, achieving good urban features. The bottom of the building, street space, can ascend in the centre of Tulou, similar to the form of residential form in the Urban Village. As a result, this community will be ready to become a self-built, self-serviced and energetic place with good flexibility, adaptability, ductility and the ability to self-repair. Furthermore, it can build an information platform for job seekers or the employed. The second direction drops the idea of first floor business, directly concentrating on the traditional composition. This method proved to be easily managed, sizecontrollable and close to circular. After a number of comparisons, we chose the second one. ${ }^{112}$

As a result, Urban Tulou (Nanhai, 2008) is now an enclosed and gated structure, placed exactly in the void created by high-speed urbanisation. Although there is no clear explanation for the final choice of direction or strategy, the first option was abandoned.

A city's streets, parks, squares and other shared spaces have been seen as symbols of collective well-being and possibility, expressions of achievement and aspiration by urban leaders and visionaries, sites of public encounter and formation of civic culture, and significant spaces of political deliberation and agonistic struggle. ${ }^{113}$

Based on this, the question can be asked: Would it be possible that rural migrants would be capable of enjoying more urban amenities and sharing more information if the URBANUS architects had chosen the first plan they worked on? Would it be possible for Urban Tulou to become an actual active entity assisting the new consciousness towards personal involvement with public affairs? In this scenario they would influence the public participation and sense of urban identity, as in the design of Dafen Art Museum (Shenzhen, 2007).

These kinds of constraints were highlighted in the process of locating this building. Regarding land use, it was not easy to find a suitable location for such an affordable housing project. The developer, Vanke Real Estate, originally locked in land beside a high-class residential neighbourhood "The Fifth Garden" in Shenzhen; however, the proposed affordable housing project was very strongly opposed 
by the owners from the neighbourhood. They argued that the project would affect their life quality and depreciate their housing. Vanke had to cancel the plan and move the pilot project to its current location. The face of class struggle has taken on a new form. Regardless of any concern about the price of land, one issue could be detected: people have become increasingly concerned with their own property, although their private housing is different from private housing in most other market economies.

Both Urban Tulou (Nanhai, 2008) and Urban Village serve as fundamental organisational units for a migrant rural population in an awkward position. Ironically, Urban Tulou (Nanhai, 2008) creates friction with urban dwellers in the wider context. The struggles in the project of Urban Tulou and the awkward location of the Urban Village all reflect the steady erosion of public space for the underclass and social inequality, when cities in China are struggling with the redistributive framework of centralised welfare. Confronting the new relationship between the private and public sectors, between the private space and public spaces, it is apparent that URBANUS architects have tried but failed to control the chaos in the urban struggles in this societal transformation.

The implications of gating in the Urban Tulou again confirm the anxiety in the elapsing of the sense of collectivism and dynamic relationships between the private and public in current ideological struggles. Evidently, the visions had outstripped the aspirations of architects and developers of settling the rural migrants into the city. Urban Tulou, as inserted into the city, could be innovative from the perspective of architecture, but they still lack flexibility to accommodate conflicting urban contexts and the conflicts arising through the increasing separation of the private and public. However, I argue that the balance between enclosure and openness in the Urban Tulou can be read as an analogy for the relationship between the rural migrants and society at large. In the final chosen configuration, the cut of the circular form in the composition does more than suggest openness and accessibility; it suggests mutual dependence in a wait-and-see attitude between the individual and society.

\section{Civil justice and the commercialisation of space}

The liberalisation policies from 1978 gave these three architects opportunities to be educated overseas and to experience the nostalgia originating from being situated elsewhere and assuming the identity of "the other". The liberalisation policies from 1978 also spurred remarkable rates of economic development and urbanisation in the Pearl River Delta which attracted the "Haigui architects" back to China and simultaneously gave architects massive opportunities in architecture. They had come to understand the market in a capitalist country. However, the fluctuating and unclear relationships between the market and the state in the early stage of market transition in China often placed the "Haigui architects" in an uneasy position. They initially aligned with the Shenzhen local government and personally experienced the process from central planning to market orientation in Shenzhen. The growing market also brought negative effects to the lives of the 
residents, for example, the widening gulf between the extremes of high-income and low-income groups, born of pragmatism and unprincipled expediency. Yet in the maturing stage of the market transition, URBANUS's efforts in anti-market projects show their unique role in working for civil justice, while confronting the commercialisation of space.

By examining the translations of traditional circular designs into the new urban context, three architects demonstrate the paradoxical nature of maintaining identity during trends of migration and globalisation in the contemporary world. For these three architects, the circular design was translated through a complex of amalgamation and contradiction: the amalgamation of the architects' intercultural study and practice, as well as the contradictions implicit in how they locate themselves geopolitically and architecturally. From the perspective of the translator of this circular design, it expresses a combination of old China and new China, tolerating numerous identities, and readers' imaginations regarding China. The creation of an ideal circular design in the market also confirms the architects' idealism in establishing a position between the state and market with integrity.

Architectural designs in response to urban issues during the transition emerged with private/public anxiety, which gives the architecture an unexpected quality: gating. My analysis shows that the ideological transformation between private and public sectors creates a psychological shift towards a growing enthusiasm for privatisation, which quickly edged out collectivism in the urban spread, prompting people to secure their private property and space in a move associated with the loss of confidence in the collective mindset, and finally dragging the cities into an unhealthy social condition. URBANUS's massive efforts in urban public space are erected between areas of privatisation and the traditional collective or civil society; although, by examining the case of Urban Tulou (Nanhai, 2008), we can see that the architects themselves cannot fully resolve these conflicts through architecture. However, the urban space they created can be seen as a unique celebration of the "expanding area between the absolute state and the classical civil society". ${ }^{114}$ Regardless of innovation in design, this "anti-market" behaviour and their attempts in the urban public space all indicate a potential position in the third realm between the state and the market.

\section{Notes}

1 In Chinese, hai means "sea" or "overseas," and gui is "to return." Literally, the term haigui (海归) refers to those who have returned from overseas.

2 Architectural Record, "Design Vanguard 2005," Architectural Record 194, no. 12 (2005).

3 Lan Ai, “Women Shizhong Guanzhu Xianshi 我们始终关注现实 [We Always Pay Attention to Realtiy (an Interview with Yan Meng)]," She ji jia no. 10 (2007): 32-39.

4 Liu Xiaodu, interviewed by the author April 19, 2012.

5 Ibid.

6 Ibid.

7 Bill Ashcroft, Gareth Griffiths, and Helen Tiffin, Post-Colonial Studies the Key Concepts, Routledge Key Guides (London: Routledge, 2000). In general terms, the "other" is anyone who is separate from one's self. The term is used extensively in 
existential philosophy to define the relations between Self and Other in creating selfawareness and ideas of identity, and the definition of the term as used in current postcolonial theory is rooted in the Freudian and post-Freudian analysis of the formation of subjectivity.

8 Nicolai Ouroussoff, "In Modern China, 'Little Kingdoms' for the People," The New York Times, October 12, 2008.

9 Ibid.

10 URBANUS, “Dushi Shijian—_Zhizao Zhongguo'Yu 'Zhongguo Zhizao'都市实践 - ‘ 制造中国, 与“中国制造[URBANUS: 'Making China' \& 'Made in China'], ' Shidai jianzhu no. 4 (2004): 80-85.

11 URBANUS, “Tulou Gongshe, Nanhai, Guangdong, Zhongguo土楼公社, 南海, 广东, 中国 [Tulou Collective Housing, Nanhai, Guangdong, China]," Shijie jianzhu no. 5 (2011): 84-85.

12 Record, "Design Vanguard 2005,".

13 Peter Kelly, "Dafen Art Museum," Blueprint no. 265 (2008): 38-48.

14 Zhu, Architecture of Modern China: A Historical Critique.

15 Ibid.

16 Xing Ruan, “Accidental Affinities: American Beaux-Arts in Twentieth-Century Chinese Architectural Education and Practice," The Journal of the Society of Architectural Historians 61, no. 1 (2002): 43.

17 Gitte Marling, "The Experience City and Challenges for Architects and Urban Designers," Nordisk Arkitekturforskning 20, no. 1 (2008): 6.

18 Roger C. K. Chan and Yao Shimou, "Urbanization and Sustainable Metropolitan Development in China: Patterns, Problems and Prospects," GeoJournal 49, no. 3 (1999): 269.

19 John Vidal, "Un Report: World's Biggest Cities Merging into 'Mega-Regions'," The Guardian, 2010.

20 Gregory Eliyu Guldin, What's a Peasant to Do? Village Becoming Town in Southern China (Boulder, CO: Westview Press, 2001), 17.

21 Eric Florence, "Migrant Workers in the Pearl River Delta: Discourse and Narratives About Work as Sites of Struggle," Critical Asian Studies 39, no. 1 (2007): 121-150.

22 Yan Song, Chengr Ding, and Lincoln Institute of Land Policy, Urbanization in China: Critical Issues in an Era of Rapid Growth (Cambridge, MA: Lincoln Institute of Land Policy, 2007).

23 Lihua Wei and Xiaopei Yan, "Sustainable Urban-Rural Relation in Rapid Urbanization Areas," Chinese Geographical Science 15, no. 3 (2005): 137.

24 Ibid.

25 The villages used to be located on the outskirts of the city, but with the expansion of the city, farmlands formerly cultivated by the villages were compulsorily purchased and turned into urban land by the government, whereas the villages themselves were reserved due to the high social and economic costs.

26 David Grahame Shane, "Transcending Type: Designing for Urban Complexity," Architectural Design 81, no. 1 (2011): 130.

27 Him Chung, "Building an Image of Villages-in-the-City: A Clarification of China's Distinct Urban Spaces," International Journal of Urban and Regional Research 34, no. 2 (2010): 423.

28 Wei and Yan, "Sustainable Urban-Rural Relation in Rapid Urbanization Areas," 138.

29 Yan Wang, “Cong 'Yiduan' Dao 'Yihua' 从“异端'到‘异化'[From 'Opposition' to 'Alienation']," Shidai jianzhu no. 1 (2013): 46-51.

30 Ibid.

31 Laurence Liauw Wie Wu, "Critical Urban Practice in China (Learning From Shenzhen)," A+U Architecture and Urbanism Chinese Edition 6, no. 27 (2009): 142-179.

32 Chuihua Judy Chung et al., eds., Great Leap Forward (Köln: Taschen GmbH, 2001).

33 Wu, "Critical Urban Practice in China (Learning From Shenzhen)," 144. 
34 Mee Kam Ng, Wing-Shing Tang, and Jiang $\mathrm{Xu}$, "Building a Modern Socialist City in an Age of Globalization: The Case of Shenzhen Special Economic Zone, People's Republic of China, ।" (paper presented at the Globalization, Urban Transition, and Governance in Asia, New York, 2001), 122.

35 Chung et al., Great Leap Forward.

36 Zhubo, “About Zhubo," Zhubo Design, accessed December 12, 2013, www.zhubo. com/intro.

$37 \mathrm{a}+\mathrm{u}$, "Rule X Planning (Interview; Weiwen Huang)," A+U Architecture and Urbanism Chinese Edition 6, no. 27 (2009): 138.

38 "Cross a river by feeling the stones" originally refers to the pragmatic policy of Deng Xiaoping.

39 Wang, “Cong 'Yiduan' Dao 'Yihua' 从“异端'到‘异化'[From 'Opposition' to 'Alienation'],".

$40 \mathrm{Wu}$, "Critical Urban Practice in China (Learning From Shenzhen)," 144.

41 URBANUS, Du Shi Shi Jian 都市实践[URBANUS] (Shenzhen: Baitong jituan jianzhu gongye chubanshe, 2007), 224.

42 Jieming Zhu, "Urban Physical Development in Transition to Market the Case of China as a Transitional Economy," Urban Affairs Review 36, no. 2 (2000): 181.

43 Ibid.

44 Jieming Zhu, "Local Developmental State and Order in China's Urban Development During Transition," International Journal of Urban and Regional Research 28, no. 2 (2004): 440.

45 URBANUS, Du Shi Shi Jian 都市实践[URBANUS], 224.

46 Wang, “Cong 'Yiduan' Dao 'Yihua' 从‘异端'到‘异化'[From 'Opposition' to 'Alienation'],".

47 Ibid.

48 Zhu, "Urban Physical Development in Transition to Market the Case of China as a Transitional Economy," 189.

49 The Principal Architects are Liu Xiaodu and Meng Yan.

50 Yuan Feng, "Southernism of Differences-Spatial History in Guangdong and Architectural Construction in Pearl River Delta," A+U Architecture and Urbanism Chinese Edition 6, no. 27 (2009): 131.

51 Xiaodu Liu, Meng Yan, and Hui Wang, “ 'Chengshi Tiankong': Yixiang Gei 'Chengshi Kongxu' Chongzhu Huoli De Jihua “城市填空”: 一项给”城市空虚”重注活力的计划 [Urban Infill as a Strategy to Rejuvenate Urban Voids]," Shijie jianzhu no. 8 (2007): 25.

52 Roger Chan, Y. M. Yao, and Simon Xiaobin Zhao, "Self-Help Housing Strategy for Temporary Population in Guangzhou, China," Habitat International 27, no. 1 (2003): 26.

53 Weiping Wu, "Migrant Housing in Urban China," Urban Affairs Review 38, no. 1 (2002): 105.

54 Weiping Wu, "Sources of Migrant Housing Disadvantage in Urban China," Environment and Planning A 36, no. 7 (2004): 1285.

55 Ibid., 1287.

56 Ibid.

57 Stanley Chi-Wai Yeung and Rodney Howes, "The Role of the Housing Provident Fund in Financing Affordable Housing Development in China," Habitat International 30, no. 2 (2006): 344.

58 Ya Ping Wang and Alan Murie, "Social and Spatial Implications of Housing Reform in China," International Journal of Urban and Regional Research 24, no. 2 (2000): 397.

$59 \mathrm{Wu}$, "Sources of Migrant Housing Disadvantage in Urban China,".

60 Laurence Liauw, "Emerging Chinese Architectural Practice under Development: Mada Spam, URBANUS Architecture \& Design, Atelier Zhanglei, Standardarchitecture, Mad," Architectural Design 78, no. 5 (2008): 9. 
61 Florence, "Migrant Workers in the Pearl River Delta: Discourse and Narratives About Work as Sites of Struggle," 121.

62 Weidong Ma, "Building for Cities (Interview: URBANUS)," $A+U$ Architecture and Urbanism Chinese Edition 6, no. 27 (2009): 175.

63 Ibid.

64 The Principal Architect is Meng Yan.

65 Ouroussoff, "In Modern China, 'Little Kingdoms' for the People,".

66 Hanming Huang, Fujian Tulou (Beijing: SDX Joint Publishing Company, 2009).

67 Lingnan is a geographic area referring to lands in the south of China's "Five Ranges" which are Tayu, Qitian, Dupang, Mengzhu, Yuecheng. The region covers the modern Chinese provinces of Guangdong, Guangxi, Hunan, Jiangxi and Hainan.

68 Feng, "Southernism of Differences-Spatial History in Guangdong and Architectural Construction in Pearl River Delta," 131.

69 Liu, Yan, and Wang, “'Chengshi Tiankong': Yixiang Gei 'Chengshi Kongxu' Chongzhu Huoli De Jihua ‘城市填空': 一项给”城市空虚”重注活力的计划 [Urban Infill as a Strategy to Rejuvenate Urban Voids]," 27.

70 Edward Said, "Traveling Theory," The World, the Text, and the Critic 226 (1983): 157.

71 Ibid.

72 Ronald G. Knapp, China's Old Dwellings (Honolulu: University of Hawaii Press, 2000), 259.

73 Liguan Wu, Local-Style Dwelling Houses in China (Beijing: China International Press, 2007), 20.

74 The juice of glutinous rice and some lime is mixed into the earth for strength.

75 Knapp, China's Old Dwellings, 266.

76 See, for example, Laurence Liauw, "Urban Dwelling Guangzhou," Domus no. 923 (2009): 64-69; Laurence Liauw, "Urban Dwelling, Guangzhou-the Tulou, Traditional Dwelling of the Hakka People, Becomes a New Type of Collective Residence-Design URBANUS," Domus (2010): 64; Ouroussoff, "In Modern China, 'Little Kingdoms' for the People,"; Andrew Yang, "The Underdog Archetype: The Building Boom in China," Cooper-Hewitt National Design Journal (2008): 6-9; Fuad Mallick, "Tulou Collective Housing (2010 on Site Review Report)" (2010).

77 URBANUS, “Dushi Shijian—_Zhizao Zhongguo'Yu 'Zhongguo Zhizao'都市实践 - ' 制造中国, 与'中国制造'[URBANUS: 'Making China' \& 'Made in China'],'; Xiaodu Liu, Yan Meng, and Hui Wang, "Yong 'Dangdaixing' Lai Sikao He Zhizao 'Zhongguoshi'用 当代性“来思考和制造’中国式 [Using 'Contemporaneity' to Contemplate and Create 'Chinese Style']," ibid., no. 3 (2006).

78 Ai, “Women Shizhong Guanzhu Xianshi 我们始终关注现实 [We Always Pay Attention to Realtiy (an Interview with Yan Meng)]," 39.

79 Liu Xiaodu, interviewed by the author at April 19th, 2012.

80 URBANUS, “Tulou Gongshe, Nanhai, Guangdong, Zhongguo土楼公社, 南海,广东, 中国 [Tulou Collective Housing, Nanhai, Guangdong, China],".

81 Vanke, "Company Overview," China Vanke Co Ltd, accessed June 15, 2013, www. vanke.com/en/newstext.aspx?id=97\&u=AboutVankeNav.

82 URBANUS, Du Shi Shi Jian 都市实践[URBANUS].

83 The Principal Architect is Meng Yan.

84 The Principal Architect is Wang Hui.

85 The Principal Architects are Liu Xiaodu and Meng Yan.

86 The Principal Architects are Zhu Pei, Wang Hui and Liu Xiaodu.

87 The Principal Architects are Zhu Pei and Wang Hui

88 The Principal Architects are Meng Yan and Liu Xiaodu.

89 Wu, "Critical Urban Practice in China (Learning From Shenzhen)," 144.

90 URBANUS, Du Shi Shi Jian 都市实践[URBANUS], 14.

91 The Principal Architect is Wang Hui. 
92 The Principal Architect is Meng Yan.

93 Ibid.

94 Ibid.

95 Ibid.

96 Yuting Liu, Shenjing He, FulongWu, Chris Webster, "Urban Villages Under China's Rapid Urbanization: Unregulated Assets and Transitional Neighbourhoods," Habitat International 34, no. 2 (2010): 135-144.

97 URBANUS, "URBANUS Blog," In The Achievement of Good Urban Public Space, 2010, www.urbanus.com.cn/blog/article.asp?id=137.

98 Ali Madanipour, Public and Private Spaces of the City (New York: Routledge, 2003), 5.

99 Wu, "Critical Urban Practice in China (Learning From Shenzhen)," 144.

100 Karl Polanyi, The Great Transformation (New York: Rinehart, 1944).

101 Francis, "Quasi-Public, Quasi-Private Trends in Emerging Market Economies: The Case of China," 276.

102 Ibid.

103 Ibid.

104 Yeung and Howes, "The Role of the Housing Provident Fund in Financing Affordable Housing Development in China," 344.

105 Wang and Murie, "Social and Spatial Implications of Housing Reform in China," 397.

106 Francis, "Quasi-Public, Quasi-Private Trends in Emerging Market Economies: The Case of China," 285.

107 Ma, "From China's Urban Social Space to Social and Environmental Justice," 558.

108 In China, a land user obtains only the land use right, not the land or any resources in or below the land; Ownership of residential properties is limited to a term of 70 years.

109 Edward James Blakely and Mary Gail Snyder, Fortress America: Gated Communities in the United States (Washington, DC: Brookings Institution Press, 1997).

$110 \mathrm{Pu}$ Miao, "Deserted Streets in a Jammed Town: The Gated Community in Chinese Cities and Its Solution," Journal of Urban Design 8, no. 1 (2003): 45-66.

111 David Bray, "Garden Estates and Social Harmony: A Study into the Relationship Between Residential Planning and Urban Governance in Contemporary China" (paper presented at the China Planning Network 3rd Annual Conference, Beijing, 2006), 176.

112 Liu, Meng, and Wang, "Yong 'Dangdaixing' Lai Sikao He Zhizao 'Zhongguoshi'用' 当代性'来思考和制造' 中国式 [Using 'Contemporaneity' to Contemplate and Create 'Chinese Style']," 26.

113 Ash Amin, "Collective Culture and Urban Public Space," City 12, no. 1 (2008): 5.

114 Xudong Zhang, Postsocialism and Cultural Politics: China in the Last Decade of the Twentieth Century (Durham, NC: Duke University Press, 2008), 103. 


\section{A delicate balance}

This book examines the conflicting ideologies of China's market transition and their impact on architects and architectural design. The micro-analysis of specific architects and architectural designs complements the macro-perspective of existing urban research on cities. It demonstrates that architecture itself is an important and accurate reflection of the societal transformation of China from Mao to market. People who define Chinese ideologies from the perspective of East vs West or socialist vs capitalist antipathies are limiting themselves. Contemporary Chinese architects have drawn inspiration from both the East and West, but they are creating an identity that moves beyond this binary. Contemporary architecture in China does not fit easily into recent terminologies: modernism, postmodernism, avant-garde, post-avant-garde, structuralism or deconstruction. Nor does it reject all traditional forms.

I have designated different architectural designs as "untamed", "rational" and something epitomised by the "circular form" - terms which may sound like an intuitive assessment, but which arise from a close scrutiny of the combined influence of the architect's subjectivity and the new social conditions. The concept of being "untamed" reflects Liu Jiakun's choice of continual dialogue in architecture, between self-expression and commercial interest in exploiting rapid marketisation. In contrast, Cui Kai prefers to adapt the art of composition and aesthetics to the new requirements of nationalism, sometimes achieving a higher degree of complexity in his designs, other times achieving a higher degree of rational simplicity in his designs. By intuitively tapping into the circular design from the perspectives of both the translator and reader of Urban Tulou, the URBANUS architects' travelling life experiences, travel-enhanced professional capacities and wandering imagining of China, a maturing third realm between state and society converge into something epitomised by the "circular" design. They confront the socio-political challenges and the socio-economic problems of the transitional period. They not only break with the conventional imagining of modernity, but they also enrich the architectural discourse on the convergence of this imagined modernity and the actual socio-political environment.

The significance of these three stories should be reviewed within the context of the three common, deep-seated misconceptions highlighted at the beginning: "Is Money the Only Language?"; "Has China Forgotten Mao?"; and "Do People Just 
Want to Be the Individuated Self?" The value of each case study is situated in the context of the real socio-political conditions in contemporary China and unsolved conflicts in the societal transformation. Each case study primarily addresses one misconception, with supplementary references to combined issues that cannot be detangled, allowing us to reconsider the alternative manifestations of modernity in China.

First, China is an economic miracle. China's hyper-rapid growth has already lasted three times longer than a typical transformative episode in in other countries in world history. Chinese people who enjoy the fruits of this economic miracle desire China to join the group of the countries in the West that benefit from a developed market economy. Yet money is not the only language in contemporary China, despite what may be commonly imagined. The fundamental conflicts at an ideological level began with the people's challenge of the tradition "inside the system", that continued to enjoy unchallenged power in the twenty-first century. Chinese people identified unambiguously the lack of open institutions, transparent government and a just legal system that they could observe operating in Western countries.

The discussion of Cui Kai and his works in the context of "Is Money the Only Language?" reveals that the culture of hierarchy, and long-term shared values and beliefs in the state-owned enterprise, impart a certain tone to the marketoriented designs. Cui Kai unconsciously dispenses high culture in his works. Yet his dual role does not allow him to focus on high culture as a confirmation and legitimation of state government. The market also encourages Cui Kai to give importance to popular cultures. To balance his sense of mission for the nation, and the demand from the market, his designs have become a shared medium or shared atmosphere that tie the diversified, locality-tied, popular cultures accepted by the market, and integrate them into high culture. An architectural language for bureaucratic communication satisfying the state, and communication with Chinese residents in Cui Kai's designs, provided an appropriate way of mediating this conflict around "inside the system". Cui Kai's architecture is an interesting example of its own kind of modernity in terms of China's state governance. I am not suggesting it would be a new paradigm, but it is an architectural outcome evolving from the functioning of the state into an increasingly market-oriented economy while maintaining its stability and dynamism. I cannot give an answer to how far the socio-political reform in China can go, but it shows the alternative implementation of national policies and the alternative reception and assimilation of the national willingness.

Second, I would argue that China has not forgotten Mao, but the relationship has grown psychologically complex. In the Mao era, people wore Mao's badge, and Mao's ideology was felt everywhere - in the workplace, on the streets, in the classroom, in the media and in every aspect of the nation's cultural life. But the current opinions of the people about the pre-reform era, and even to the grimy architecture dominant in the Mao era, is less straightforward and remains a sensitive issue. Apart from the documents of the People's Congress, and nostalgia for the Maoist era portrayed by certain artists, for example, in the 798 Art District, 
Mao's image is absent from contemporary Chinese cities. Discussion of Mao is absent from conversations, especially between people who experienced the era. There is a pervading ignorance of the architecture of the Mao era, especially in the first-tier and second-tier cities.

"The Necessity of Being Real" discussed how Liu Jiakun as an architect avoids evoking the awkward side of his generation's youth, but legitimises the psychological acceptance of the new dynamics in the architecture, which are based on the reinterpretation of a collective memory of Mao, even the collectively traumatic memories. Liu Jiakun's architecture confirms that socialism under the planned economy was a significant, though often forgotten, part of Chinese history and the people's collective memory. This section argues that architecture designed by Liu Jiakun is a vehicle provoking Chinese people to confront their memories and is a strong indicator of China's struggles over the tensions between communist and capitalist versions of modernity. Although Liu Jiakun is not intended to be associated with the socialist rhetoric, his concern about the collective memory, manifested in his design, gives a clear demonstration of how the Chinese psyche is processing the socialist rhetoric and socialist production of the built environment in a post-Mao China.

Third, the misconception, "Do People Just Want to Be the Individuated Self?" reflects the conflict between individual ambitions and public service. From 1949 until 1978, the Communist Party required that personal sacrifices be made by its members and by the population in the campaign for a socialist construction. However, in the shift from Mao to market, a process that encourages individualism, private goals run counter to a socialist policy. "Urban Intervention and the Private/ Public Anxiety", shows that the ideological conflict between private and public attitudes created a psychological shift towards a growing enthusiasm for privatisation, which quickly edged out collectivism. The opening provided by urban expansion accompanied by the loss of confidence in the collective viewpoint, pushed people to secure their private property and space, a process that instilled a negative trend in new cities.

URBANUS worked positively on the public space, not only from the perspective of a designer, but also from the perspective of a social worker. My research opens new lines of enquiry on URBANUS's urban strategies by highlighting the ideological shifts between the private and public sectors. The architecture of both Liu Jiakun and URBANUS reveal that modernity, in its struggle between socialist and capitalist beliefs, between public service and the individuated self, is attempting to connect with the inner life of Chinese people. This has proved challenging, because Chinese society changed dramatically in such a short time, and many people are unable to experience a separate identity in the movement towards modernisation. For example, Chinese people are aware that socialist the movement betrayed its founding principle in 1989, but they do not want to debate whether this failure implies a deeper betrayal of the individual. After the sudden loss of confidence in the collective viewpoint, the idea of individualism is complicated by a negative interpretation of "selfishness". In this unique situation, it is evident that "individualism" needs to be clearly defined for the people, specifically in 
relation to Chinese modernity, and in this context, such a definition has manifested in contemporary Chinese architecture.

In general, from this book, Chinese contemporary architecture has manifested the proliferation of modernity in its multiplicity and increasingly defined itself following its own social, historical and political logic. Chinese contemporary architecture moves beyond existing scholarship's interpretation of modernity. The audience of China's contemporary architecture is not confined to China but has expanded to the global stage. The image of architecture can easily go viral on the Internet in a global professional circular, and the architecture itself will be glazed, experienced or even occupied by people from diverse backgrounds, with diverse perspectives. However, whether the original Western viewpoint continues to serve as the global reference point is a doubt. There is no intention to justify a "Chinese way" of dealing with everything, yet it is imperative to map the different historical trajectories in the unfolding of modernity in China, from a largely Europeanoriented perspective to an inclusive global perspective.

Furthermore, this study argues that the changing interactions between the market and the state are in fact the source of architectural innovations. Liu Jiakun's innovations derive from his insight into the between individual designs and the expectations of an immature market. Cui Kai's innovations emerge from his compromise between individual efforts to follow the market mechanism, while retaining a high level of social responsibility subordinate to the emergent society and to popular taste. URBANUS's innovations come from the tension between impulses towards the market and critical thinking about the market. The mix of "Mao" and "market" has created a modern Chinese vernacular that has been true both in the sense of complying with the demands of the state and also deeply rooted in the nature of the capitalist market. The tense dialogue between neo-liberal logic and socialist sovereignty is reconfiguring contemporary China, and furthermore reconfiguring China's contemporary architecture, all of which contributes to the idea that the innovation and uniqueness of contemporary architectural design is not driven solely by the state, nor by the market, but rests with the struggle between the state and the market.

Each of these architects has evolved a mediated codified language. Cui Kai's designs provide an acceptable way of mediating people's disquiet with the status quo by operating within the official institutes. Architecture designed by Liu Jiakun becomes an architectural medium to reconcile the differences in the perception of Mao and his era between those who support pre-reform China and those who share enthusiasm for China's market-driven capitalism. URBANUS's urban strategies attempt to resolve the conflict evident in a planned vs a market economy in the city, by assuming a halfway position that includes elements of private goals and of public service.

These architects also share a common vision, which enables them to see backwards and forwards at the same time in dealing with issues of modernity, so that the pursuit of progress has manifested through resourceful and ingenious architectural developments. In the foreword to the 2012 edition of Liquid Modernity Revisited, Zygmunt Bauman wrote, "It was the formlessness of the oozing, leaking 
and flowing liquid that prompted the efforts at cooling, damping and moulding."1 Challenged by dramatic economic growth, how far could the socio-political system be reformed in China? In the face of capitalism and rapid change, how much longer could the socialist version of modernity persist in China? In the light of claims about the abuse of human rights, how far would an individual advance in China? This research cannot give satisfying answers to these big questions. But it prompts us to reflect how to effectively take over the oppressive functions of state powers and how to escape the pursuit of a consumerist lifestyle, by understanding the example set by the multiple outcomes of Chinese architecture. As well as the necessity of charting the many different faces of modernisation, it is important to recognise the evolving convergence and divergence between China and the world, in both economic and architectural forms.

For architects, in general, the emerging market is a new site for the latent commercialisation that gradually provided alternative resources for an individual architect, like Liu Jiakun and the three architects in URBANUS. Cui Kai's idiosyncratic position in a national design institute, and also in a burgeoning market, provided even more chances to include national projects and private projects of various scales. Gone are the days when only one or two Chinese architects were visible on the international stage. China's engagement with the international economy and a burgeoning market has created a requirement for architects with a broader education and new skills. There is now a sustained interest overseas in news of contemporary architecture in China. International exhibitions and the development of the market create architect celebrities. International exhibitions in Europe, the United States and in China, devoted to Chinese architects, expand their professional networks with their peers and in the overseas media. This situation complicates personal goals that might have been considered risky in the Mao era and early post-Mao. However, some of the risks that might be associated with the architects' projects, like URBANUS's personal fight for the vulnerable group of migrant workers, or Liu Jiakun's works in engaging with ordinary people after Wenchuan earthquake, have been mitigated by their connection with their peer overseas, and with attention in overseas media, assisting the architects to expand their personal architectural discourse. But this approach is more or less limited to the individual architects who operate outside the government system.

However, it is difficult for architects to find a systematic and coordinated path between the ideological conflicts emerging from the transition from central planning to the market economy. The process from Mao to market can be simply read as the reordering of power relations in the whole society. The old locus of power is suspect, and the old value judgement system has also lost efficacy. The architecture by itself is not powerful enough to improve social adjustment to the uncertain nature of the transition. However, architects already started to affect civil justice and to spread the idea of civil liberties through their professional activities. They reflect a third voice emerging between the state and the market in contemporary Chinese society. Currently, when an individual architect confronts authority, resorting to contacts "inside the system" is still the most effective route to a resolution. However, if the Chinese government stays on 
its course of reform, the third voice will have more room to move in the future, and architect's professional approach might assist in coordinating some of the ideological conflicts emerging from the societal transition. If the party continues to succeed in bringing prosperity to the population, and to remain in power as a consequence, they must at least be seen to tolerate the pursuit of professional and personal objectives by those architects who are instrumental in achieving this prosperity. With the development of the architectural discipline, architecture is no longer categorised as only engineering, and architects increasingly appear to be profiled profile as independently minded intellectuals. Therefore, any attempt by the party to coerce these architects into mirroring its policies would prove a tough undertaking.

The Communist Party certainly recognises this dilemma, and could make a genuine attempt to make political life more transparent. It could also reinforce the independence of the courts. In this case, would Chinese architecture undergo a metamorphosis of its own? The historical epoch of communist ideology, shifting government policies and changing land policies have dominated Chinese thinking for a long time. Hence it is hard to foresee what kind of ideological evolution will emerge in China. However, it should be noted that the Party has been able to counter any criticism of its position as guardian of political ideologies by reference to the impressive development of recent times. Similarly, contemporary Chinese architecture has been able to counter any criticism of its position as the most exciting location for global architects. But will this position be sustained if the wave of prosperity ends?

The atmosphere in the architectural industry is volatile. Many architects have been spoiled by the high demand for production in recent years. In less than two decades, several important industries have changed from dormant to active, and several have changed from active to dormant in China. The new conditions have cast a sober atmosphere on the architectural industry. How the dynamics of architecture will continue to play out in the uneasy interactions between the state and the market must be left to a future study. I think the focus will be placed on the developments of architectural practices. For example, whether the rise of an independent professional practice in China can be associated with integral control of the design process, and whether the rise of an independent professional practice would enable technological pathways of relevance for the building environment in China will be studied in the future.

One of my architect colleagues, facing the uncertain future of the architectural industry in China, ironically quoted the communist manifesto, "Proletarians of the world, Unite". It is difficult to see how a union of "proletarians" might bolster the architectural industry at this time, after it has enjoyed international success.

\section{Note}

1 Zygmunt Bauman, Liquid Modernity (Cambridge: Polity Press, 2012), ix. 


\section{Glossary}

$\begin{array}{ll}\text { Chengzhongcun } & \text { 城中村 } \\ \text { Dangdai } & \text { 当代 } \\ \text { Danwei } & \text { 单位 } \\ \text { Haigui } & \text { 海归 } \\ \text { Hukou } & \text { 户口 } \\ \text { JiangNan } & \text { 江南 } \\ \text { Jindai } & \text { 近代 } \\ \text { Tulou } & \text { 土楼 } \\ \text { Wansuiguan } & \text { 万岁馆 }\end{array}$




\section{Illustration credits and sources}

The author would like to thank all those who granted permission to use illustrations.

\section{Chapter three}

Fig. 3.1, 3.9, 3.10, 3.13 @Jiakun Architects, Photographer: Bi Kejian

Fig.3.2@Jiakun Architects, Photographer: Lv Hengzhong

Fig. 3.3, 3.5, 3.7, 3.8, 3.12@Jiakun Architects

Fig.3.4@Jiakun Architects, Photographer: ARCHEXIST

Fig.3.6@ ZhangXiaogang Studio

Fig.3.11@Jiakun Architects, Photographer: Yao Li

\section{Chapter four}

Fig. 4.1, 4.2, 4.4, 4.5, 4.7, 4.8, 4.10, 4.11 @ Land-based Rationalism D.R.C, Photographer: Zhang Guangyuan

Fig. 4.3, 4.6, 4.9 @, Photographer: Si Chengyi

\section{Chapter five}

Fig. 5.1, 5.2,5.4@URBANUS

Fig. 5.3, 5.5, 5.7@URBANUS, Photographer: Yang Chaoying

Fig. 5.6, 5.8, 5.11@URBANUS, Photographer: Wu Qiwei

Fig. 5.9, 5.10@URBANUS, Photographer: Meng Yan 


\section{Bibliography}

$\mathrm{a}+\mathrm{u}$. "Rule X Planning (Interview; Weiwen Huang)." $A+U$ Architecture and Urbanism Chinese Edition 6, no. 27 (2009).

Ai, Lan. “Women Shizhong Guanzhu Xianshi 我们始终关注现实 [We Always Pay Attention to Reality (An Interview With Yan Meng)]." She ji jia no. 10 (2007): 32-39.

Amin, Ash. "Collective Culture and Urban Public Space." City 12, no. 1 (2008): 5-24.

Andrews, Julia, F., and Minglu Gao. "The Avant-Garde's Challenge to Official Art." In Urban Spaces in Contemporary China: The Potential for Autonomy and Community in Post-Mao China, edited by Deborah S. Davis, Richard Kraus, Barry Naughton, and Elizabeth J. Perry. Cambridge; New York; Melbourne: Cambridge University Press, 1995.

Architects, Jiakun. "Design Philosophy." PSA Publishers Ltd, accessed August 17, 2011, www.chinese-architects.com/en/Jiakun.a.

Arendt, Hannah. The Human Condition. Chicago: University of Chicago Press, 1998.

Ashcroft, Bill, Gareth Griffiths, and Helen Tiffin. Post-Colonial Studies the Key Concepts. Routledge Key Guides. London: Routledge, 2000.

Baum, Richard. "Science and Culture in Contemporary China: The Roots of Retarded Modernization." Asian Survey 22, no. 12 (1982): 1166-1186.

Bauman, Zygmunt. Liquid Modernity. Cambridge: Polity Press, 2000.

Liquid Modernity. Cambridge: Polity Press, 2012.

Berman, Marshall. All That Is Solid Melts into Air: The Experience of Modernity. New York: Simon and Schuster, 1982.

Blakely, Edward James, and Mary Gail Snyder. Fortress America: Gated Communities in the United States. Washington, DC: Brookings Institution Press, 1997.

Bosker, Bianca. Original Copies: Architectural Mimicry in Contemporary China. Honolulu: University of Hawaii Press, 2013.

Bray, David. "Garden Estates and Social Harmony: A Study into the Relationship between Residential Planning and Urban Governance in Contemporary China." Paper presented at the China Planning Network 3rd Annual Conference, Beijing, 2006.

Broudehoux, Anne. The Making and Selling of Post-Mao Beijing. New York; London: Routledge, 2004.

Buchanan, James, M. "Economics in the Post-Socialist Century." Economic Journal 101, no. 404 (1991): 15-21.

Cardoso, Eliana, and Shahid Yusuf. "Red Capitalism: Growth and Inflation in China." Challenge 37, no. 3 (1994): 49-56.

Chan, Roger, Y. M. Yao, and Simon XiaobinZhao. "Self-Help Housing Strategy for Temporary Population in Guangzhou, China." Habitat International 27, no. 1 (2003): 19-35. 
Chan, Roger, C. K., and Yao Shimou. "Urbanization and Sustainable Metropolitan Development in China: Patterns, Problems and Prospects." GeoJournal 49, no. 3 (1999): 269-277.

Chang, Tsong-Zung. Reckoning With the Past: Contemporary Chinese Painting. Edinburgh: Fruitmarket Gallery, 1996.

Cheng, Song, Jiming Kong, and Hongtao Song. "Wenchuan 512 Earthquake and Giant Panda Habitat in Wolong, China: A Review of Strong Earthquake Effects." Frontiers of Forestry in China 4, no. 4 (2009): 388-393.

Chung, Chuihua Judy, Jeffrey Inaba, Rem Koolhaas, and Sze Tsung Leong, eds. Great Leap Forward. Köln: Taschen GmbH, 2001.

Chung, H. "Building an Image of Villages-in-the-City: A Clarification of China's Distinct Urban Spaces.” International Journal of Urban and Regional Research 34, no. 2 (2010): 421-437.

Clark, John. "Postmodernism and Expressionist Tendencies in Recent Chinese Oil Painting." Asian Studies Review 15, no. 2 (1991): 104-129.

Cooke, Catherine. "Socialist Realist Architecture: Theory and Practice." In Art of the Soviets: Painting, Sculpture, and Architecture in a One-Party State, 1917-1992, edited by Matthew Cullerne Bown. Manchester; New York: Manchester University Press, 1993.

CPG. "Our Profile.” CPG Corporation, accessed June 20, 2013, www.cpgcorp.com.sg/ index.php/about-us/our-profile.

Cui, Kai. Bentu Sheji 本土设计 [Native Design]. Translated by Xiaoqing Li, Lingbo Sun, Jun Wang, Gang Wang and Hao Ren. Beijing: Tsinghua daxue chubanshe, 2008.

ed. Cui Kai 崔恺 [Cui Kai]. Edited by Dan Liu and Ran Xu, Dangdai Jianzhushi Xilie 当代建筑师系列 [Contemporary Architecture Series]. Beijing: Zhongguo jianzhu gongye chubanshe, 2012.

—. "Ganxing Haishi Lixing 感性还是理性 [The Perceptual and the Rational]." In Mingshi Zishu 名师自述 [Master's Narration], edited by Yongsheng Yang and Huili Wang. Beijing: Zhongguo jianzhu gongye chubanshe, 2008.

“Meiguan Haishi Wenhua 美观还是文化 [Beauty vs. Culture].” In Mingshi Zishu 名师自述 [Master's Narration], edited by Yongsheng Yang and Huili Wang. Beijing: Zhongguo jianzhu gongye chubanshe, 2008.

. "Minzu Xingshi Haishi Bentu Wenhua 民族形式还是本土文化 [National Forms vs. Native Culture].” In Mingshi Zishu 名师自述 [Master's Narration], edited by Yongsheng Yang and Huili Wang. Beijing: Zhongguo jianzhu gongye chubanshe, 2008. . "Youli Youli Dongruan Dalian Ruanjianyuan Jiuhaolou Sheji 有礼, 有理 - 东软大 连软件园9号楼设计 [Politeness and Justification - on Design of the No. 9 Building in Neusoft Dalian Software Park]." Shidai jianzhu no. 6 (2007): 46-53.

. “Zai Zhongjian - Yizhong Zhuangtai He Yizhong Juese 在中间 _ 一种状态和一 种角色 [In Between - One Status and One Role].” Jianzhu xuebao no. 3 (2007): 4-5.

—. “Zhongdian Zai Jianzhu Zhijian 重点在建筑之间 [Emphases in Spaces Between Architecture]." Shidai jianzhu no. 1 (2006): 72-75.

Cui, Kai, and Weijen Wang. "Liangan Zhuiwen Huisu Cui Kai/Wang Weijen 两岸・追 问・回溯 崔恺/王维仁对谈 [Cross-Strait Questioning and Retrospecting - a Dialogue Between Cui Kai and Wang Wenjen]." Shidai jianzhu no. 4 (2012): 50-55.

Currier, Carrie Liu. "The Gendered Effects of Market Reforms." In China in an Era of Transition: Understanding Contemporary State and Society Actors, edited by Reza Hasmath and Jennifer Hsu. New York: Palgrave Macmillan, 2009. 


\section{Bibliography}

Dai, Chun, and Wenjun Zhi. "Jianzhushi Qunti Yanjiu De Shijiao Yu Fangfa Yi 50 Niandai Sheng Zhongguo Jianzhushi Weili 建筑师群体研究的视角与方法 以50年代生中国建 筑师为例 [The Perspectives and Approaches of Research on Architect Groups - Chinese Architects Born in the 1950s in Focus]." Shidai jianzhu no. 4 (2012): 10-15.

Davis, Deborah, S., Richard Kraus, Barry Naughton, and Elizabeth J. Perry, eds. Urban Spaces in Contemporary China: The Potential for Autonomy and Community in PostMao China. Cambridge; New York; Melbourne: Cambridge University Press, 1995.

Deng, Xiaoping. "Hold High the Banner of Mao Zedong Thought and Adhere to the Principle of Seeking Truth From Facts." September 16, 1978.

Denton, Kirk, A. "Museums, Memorial Sites and Exhibitionary Culture in the People's Republic of China." The China Quarterly 183 (2005): 22.

Deshpande, Rohit, and John U. Farley. "Market-Focused Organizational Transformation in China." Journal of Global Marketing 14, no. 1-2 (2000): 7-35.

Dimou, Augusta. Entangled Paths Towards Modernity: Contextualizing Socialism and Nationalism in the Balkans. New York: Central European University Press, 2009.

Dirlik, Arif. "Modernity as History: Post-Revolutionary China, Globalization and the Question of Modernity." Social History 27, no. 1 (2002): 16-39.

Dirlik, Arif, and Xudong Zhang. "Introduction: Postmodernism and China." Boundary 2 24, no. 3 (1997): 1-18.

Dubrau, Christian. Sinotecture: New Architecture in China $=$ Neue Architektur in China. Berlin: DOM Publishers, 2008.

Eastman, Lloyd, E. The Nationalist Era in China, 1927-1949. Cambridge; New York: Cambridge University Press, 1991.

Edward, Denison, and Guang Yu Ren. Modernism in China: Architectural Visions and Revolutions. Chichester, England; Hoboken, NJ: John Wiley, 2008.

Efimova, Alla. "To Touch on the Raw: The Aesthetic Affections of Socialist Realism." Art Journal 56, no. 1 (1997): 72-80.

Eisenstadt, Shmuel. "Multiple Modernities." Daedalus 129, no. 1 (2000): 1-29.

Er, Dongqiang, and Martha Lund Smalley. Hallowed Halls: Protestant Colleges in Old China. Shanghai: Old China Hand Press, 1998.

Evans, Harriet, and Stephanie Donald. Picturing Power in the People's Republic of China: Posters of the Cultural Revolution. Lanham, MD: Rowman \& Littlefield Pub, 1999.

Falchikov, Michael, and Hilary Chung. In the Party Spirit: Socialist Realism and Literary Practice in the Soviet Union, East Germany and China. Amsterdam; Atlanta, GA: Rodopi, 1996.

Feng, Yuan. "Southernism of Differences - Spatial History in Guangdong and Architectural Construction in Pearl River Delta." A+U Architecture and Urbanism Chinese Edition 6, no. 27 (2009).

Fitzgibbons, Abigail. "Zhang Xiaogang: Biography." Zhangxiaogang Art Studio, accessed January 19, 2013, http://zhangxiaogang.org/enArtText_XQ.aspx?TblCollegeClnum=78.

Florence, Eric. "Migrant Workers in the Pearl River Delta: Discourse and Narratives About Work as Sites of Struggle." Critical Asian Studies 39, no. 1 (2007): 121-150.

Francis, Corinna-Barbara. "Quasi-Public, Quasi-Private Trends in Emerging Market Economies: The Case of China." Comparative Politics 33, no. 3 (2001): 275-294.

Fung, Stanislaus, and Kai Wang. "Zhongguo Jianzhuxuezhong Kuawenhua Duihuade Qianjing Zouyi 中国建筑学中跨文化对话的前景刍议 [Notes on the Prospects of Cross-Cultural Dialogue in Chinese Architecture].” Shidai jianzhu no. 5 (2006): 24-29.

Galbraith, John Kenneth. "Economics in the Century Ahead." Economic Journal 101, no. 404 (1991): 41-46. 
Galikowski, Maria. Art and Politics in China, 1949-1984. Hong Kong: The Chinese University Press, 1998.

Gay, Peter. Freud for Historians. New York: Oxford University Press, 1985.

Gellner, Ernest. Nations and Nationalism. Second Edition. Malden, MA: Blackwell Publishing, 2006.

Gittings, John. The Changing Face of China: From Mao to Market. New York: Oxford University Press, 2005.

Guldin, Gregory Eliyu. What's a Peasant to Do? Village Becoming Town in Southern China. Boulder, CO: Westview Press, 2001.

Han, Jiawen, and Harry Margalit. "Imagining Modernity Through Architecture in Contemporary China." The International Journal of Design in Society 7, no. 1 (2013): 29-39.

Han, Sun Sheng, and Yong Wang. "Chongqing." Cities 18, no. 2 (2001): 115-125.

Harvey, David. The Condition of Postmodernity: An Enquiry into the Origins of Cultural Change. Oxford; Cambridge, MA: Blackwell, 1990.

Hewitt, Duncan. Getting Rich First: Life in a Changing China. London: Chatto \& Windus, 2007.

“History (Tunghai University).” Tunghai University, accessed June 26, 2013, http://wwwo. thu.edu.tw/english/01_05_01_history.htm.

Hornby, Lucy. "China Enters New Era of Services Expansion With Singapore Cpg Buy." Reuters, accessed June 19, 2013, www.reuters.com/article/2012/05/27/china-cpg-idUSL 4E8GR0CI20120527.

$\mathrm{Hu}$, Xiao. "Reorienting the Profession: Chinese Architectural Transformation Between 1949 and 1959.” Ph.D. Dissertation, University of Nebraska - Lincoln, 2009.

Huang, Hanming. Fujian Tulou. Beijing: SDX Joint Publishing Company, 2009.

Huang, Yuan-Shao. “Zhongguo Dangdai Siyouhua Jianzhu Zhiye De Xingqi Yu Yanbian 中 国当代私有化建筑执业的兴起与演变 [Development and Evolution of Contemporary Chinese Private Architectural Offices].” Chengshi huanjing sheji no. 2 (2010): 16-26.

Hung, Wu. Transience: Chinese Experimental Art at the End of the Twentieth Century. Chicago: David and Alfred Smart Museum of Art, University of Chicago, 1999.

Hung, Wu, and Peggy Wang, eds. Contemporary Chinese Art: Primary Documents. New York: The Museum of Modern Art, 2010.

Jameson, Fredric. "The Cultural Logic of Late Capitalism." In Rethinking Architecture: A Reader in Cultural Theory, edited by Neil Leach, 238-247. London: Routledge, 1997.

Ji, Guohua. "Building Under the Planned Economy - A History of China's Architecture and Construction 1949-1965." Ph.D. Dissertation, ETH, 2007.

Ji, You. China's Enterprise Reform: Changing State. London: Routledge, 1998.

Joy, Annamma, and John Sherry Jr. "Framing Considerations in the PRC: Creating Value in the Contemporary Chinese Art Market 1." Consumption Markets \& Culture 7, no. 4 (2004): 307-348.

Kai, Yan. "The Course and Prospect of Chinese Housing Industrialization in the Past 60 Years." Residential Technology no. 5 (2009): 1-5.

Kelly, Peter. "Dafen Art Museum.” Blueprint no. 265 (2008): 38-43.

Kipnis, Andrew. Chinese Modernity and the Individual Psyche. New York: Palgrave Macmillan, 2012.

Knapp, Ronald, G. China's Old Dwellings. Honolulu: University of Hawaii Press, 2000.

Kornai, Janos. The Road to a Free Economy: Shifting from a Socialist System: The Example of Hungary. New York: Norton, 1990.

KPMG. "China Looking Ahead." International Tax Review, www.kpmg.de/docs/ChinaLooking-Ahead-ITR-201105-2.pdf. 


\section{Bibliography}

Kraus, Richard. "China's Artists Between Plan and Market." In Urban Spaces in Contemporary China: The Potential for Autonomy and Community in Post-Mao China, edited by Deborah S. Davis, Richard Kraus, Barry Naughton and Elizabeth J. Perry. Cambridge; New York; Melbourne: Cambridge University Press, 1995.

Kraus, Richard Curt. The Cultural Revolution: A Very Short Introduction. Oxford, New York: Oxford University Press, 2012.

Lague, David. "1977 Exam Opened Escape Route into China's Elite." The New York Times, January 6, 2008.

Law, Wing-Wah. "The Role of the State in Higher Education Reform: Mainland China and Taiwan." Comparative Education Review 39, no. 3 (1995): 322-355.

Lee, Leo Ou-fan. Shanghai Modern: The Flowering of a New Urban Culture in China, 1930-1945. Cambridge, MA: Harvard University Press, 1999.

Leese, Daniel. Mao Cult: Rhetoric and Ritual in China's Cultural Revolution. Cambridge: Cambridge University Press, 2011.

Lemos, Gerard. The End of the Chinese Dream. New Haven: Yale University Press, 2012.

Li, Daxia. "Current Chinese Architecture: Deviating from the Single Axis Structure." Habitat International 15, no. 3 (1991): 43-50.

Li, Feng. "Critical Practice in State-Owned Design Institutes in Post-Mao China (19762000s): A Case Study of CAG (China Architecture Design and Research Group).” Master Research Thesis, The University of Melbourne, 2010.

Li, Shiqiao. "Reconstituting Chinese Building Tradition: The Yingzao Fashi in the Early Twentieth Century." The Journal of the Society of Architectural Historians 62, no. 4 (2003): 470-489.

- Understanding the Chinese City. Theory, Culture \& Society. Los Angeles: Sage, 2014.

Li, Wuying. “Guoyou Daxing Jianzhu Sheji Qiye De Liuanhuaming 国有大型建筑设计 企业的柳暗花明 [State-Owned Large-Scale Architectural Design Enterprises Facing a Bright Future Despite Difficulties]." Shidai jianzhu no. 1 (2004) 37-39.

Li, Xiangning. " 'Make-the-Most-of-It' Architecture." City: Analysis of Urban Trends, Culture, Theory, Policy, Action 12, no. 2 (2008): 226-236.

Li, Xiaodong. "The Celebration of Superficiality: Chinese Architecture Since 1979." The Journal of Architecture 5, no. 4 (2000): 391-409.

Li, Xiaodong, and Keng Hua Chong. "Implications of Chinese Architectural Education in Contemporary Chinese Architecture." The Journal of Architecture 8, no. 3 (2003): 303-320.

Liang, Samuel, Y. Mapping Modernity in Shanghai: Space, Gender, and Visual Culture in the Sojourners' City, 1853-98. Asia's Transformations. Oxon England; New York: Routledge, 2010.

Liauw, Laurence. "Emerging Chinese Architectural Practice Under Development: Mada Spam, Urbanus Architecture \& Design, Atelier Zhanglei, Standard architecture, Mad.” Architectural Design 78, no. 5 (2008): 82-93.

."Urban Dwelling Guangzhou." Domus no. 923 (2009): 64-69.

"Urban Dwelling, Guangzhou-the Tulou, Traditional Dwelling of the Hakka People, Becomes a New Type of Collective Residence-Design Urbanus." Domus no. 923 (2010): 64 .

Lin, Cyril Zhiren. "Open-Ended Economic Reform in China.” Chap. 3 In Remaking the Economic Institutions of Socialism: China and Eastern Europe, edited by Victor Nee and David Stark. Stanford: Stanford University Press, 1989. 
Lin, George, C. S. Red Capitalism in South China: Growth and Development of the Pearl River Delta. Vancouver: UBC press, 1997.

Lin, Justin Yifu. Demystifying the Chinese Economy. New York: Cambridge University Press, 2012.

Lin, Justin Yifu, Fang Cai, and Zhou Li. State-Owned Enterprise Reform in China. Hong Kong: Chinese University Press, 2001.

Lin, Nancy. "Architecture Shenzhen." In Great Leap Forward, edited by Chuihua Judy Chung, Jeffrey Inaba, Rem Koolhaas, and Sze Tsung Leong. Köln: Taschen GmbH, 2001.

Liu, Jiakun. Ci Shi Ci Di 此时此地 [Here and Now]. Beijing: Zhongguo jianzhu gongye chubanshe, 2002.

—. “Gei Zhu Jianfei De Huixin给朱剑飞的回信 [A Letter to Jianfei Zhu]." Shidai jianzhu no. 5 (2006): 67-68.

- “Luyeyuan Shike Bowuguan 鹿野苑石刻博物馆 [Luyeyuan Stone Sculpture Museum]." Beijing guihua jianshe no. 6 (2004): 176-182.

—. "Wo Zai Xibu Zuo Jianzhu 我在西部做建筑 [My Architectural Practice in Western China]." Shidai jianzhu no. 4 (2006): 45-47.

Liu, Kang. "Is There an Alternative to (Capitalist) Globalization? The Debate About Modernity in China." Boundary 2: An International Journal of Literature and Culture 23, no. 3 (1996): 193-218.

Liu, Xiaodu, Yan Meng, and Hui Wang. 'Yong ‘Dangdaixing' Lai Sikao He Zhizao 'Zhongguoshi'用 ‘当代性”来思考和制造'中国式 ['Using 'Contemporaneity' to Contemplate and Create 'Chinese Style'].” Shidai jianzhu no. 3 (2006): 22-27.

Liu, Xiaodu, Meng Yan, and Hui Wang. “'Chengshi Tiankong': Yixiang Gei 'Chengshi Kongxu' Chongzhu Huoli De Jihua ‘城市填空': 一项给”城市空虚”重注活力的计划 [Urban Infill as a Strategy to Rejuvenate Urban Voids].” Shijie jianzhu no. 8 (2007): 22-27.

Liu, Yuting, Shenjing He, Fulong Wu, and Chris Webster. "Urban Villages Under China's Rapid Urbanization: Unregulated Assets and Transitional Neighbourhoods." Habitat International 34, no. 2 (2010): 135-144.

Lu, Duanfang. "Building the Chinese Work Unit: Modernity, Scarcity, and Space, 19492000." Ph.D. Dissertation, University of California, 2003.

- Remaking Chinese Urban Form: Modernity, Scarcity and Space, 1949-2005. London; New York: Routledge, 2006.

Lutz, Jessie Gregory. China and the Christian Colleges, 1850-1950. Itahaca; London: Cornell University Press, 1971.

Ma, Laurence, J. C. "From China's Urban Social Space to Social and Environmental Justice." Eurasian Geography and Economics 48, no. 5 (2007): 555-566.

Ma, Laurence, J. C., and Fulong Wu, eds. Restructuring the Chinese City: Changing Society, Economy and Space. New York: Routledge, 2005.

Ma, Weidong. "Building for Cities (Interview: Urbanus)." $A+U$ Architecture and Urbanism Chinese Edition 6, no. 27 (2009): 174-179.

MacFarquhar, Roderick, Eugene Wu and Timothy Cheek, eds. The Secret Speeches of Chairman Mao: From the Hundred Flowers to the Great Leap Forward, Harvard Contemporary China Series. Cambridge, MA: Council on East Asian Studies/Harvard University, 1989.

Mack, Michael. "Modernity as an Unfinished Project: Benjamin and Political Romanticism." In Walter Benjamin and the Architecture of Modernity, edited by Andrew Benjamin and Rice Charles. Melbourne: Re-Press, 2009. 


\section{6}

Mackerras, Colin. China in Transformation, 1900-1949. Harlow, England; New York: Pearson/Longman, 2008.

Madanipour, Ali. Public and Private Spaces of the City. New York: Routledge, 2003.

Mallick, Fuad. "Tulou Collective Housing (2010 on Site Review Report)." 2010.

Margalit, Harry. "The State of Contemporary Architecture in Australia." Architectural Theory Review 11, no. 1 (2006): 7-16.

Marling, Gitte. "The Experience City and Challenges for Architects and Urban Designers." Nordisk Arkitekturforskning 20, no. 1 (2008): 5-11.

Mathur, Nalini. Educational Reform in Post Mao China. New Delhi: A.P.H. Publishing Corporation, 2007.

Miao, Pu. "Deserted Streets in a Jammed Town: The Gated Community in Chinese Cities and Its Solution." Journal of Urban Design 8, no. 1 (2003): 45-66.

Nee, Victor, and Rebecca Matthews. "Market Transition and Societal Transformation in Reforming State Socialism." Annual Review of Sociology 22 (1996): 401-435.

$\mathrm{Ng}$, Mee Kam, Wing-Shing Tang, and Jiang Xu. "Building a Modern Socialist City in an Age of Globalization: The Case of Shenzhen Special Economic Zone, People's Republic of China." Paper presented at the Globalization, Urban Transition, and Governance in Asia, New York, 2001.

O’Connor, Neale, G., F. Johnny Deng, and Jingsong Tan. "The Impact of Political Constraints and Formal Incentive Systems on the Performance of Chinese State-Owned Enterprises." Pacific Accounting Review 23, no. 1 (2011): 6-33.

Ouroussoff, Nicolai. 'In Modern China, 'Little Kingdoms' for the People." The New York Times, October 12, 2008.

Ouyang, Jianghe. “Jianzhu Zuowei Bendi Shiwu De Chouxiang - Jianzhushi Liu Jiakun Fangtan 建筑作为本地事物的抽象 - 建筑师刘家琨访谈 [Architecture as a Regional Abstract - An Interview with Liu Jiakun].” Jin tian Spring Volume, no. 84 (2009).

Pearson, Clifford. "China: Projects \& Features-Luyeyuan Stone Sculpture Museum, Xinmin." Architectural Record 192, no. 3 (2004): 86-89.

Peng, Nu. “Benzhi Shang Bujinjin Shi Jianzhu 本质上不仅仅是建筑 [The Essence Is Not About Architecture]." In Ci Shi Ci Di 此时此地 [Here and Now], edited by Jiakun Liu. Beijing: Zhongguo jianzhu gongye chubanshe, 2002.

_. 'Zai 'Jiangou' Zhiwai - Guanyu Luyeyuan Shike Bowuguan Yinfa De Piping 在' 建构”之外 - 关于鹿野苑石刻博物馆引发的批评 [Beyond Tectonics: Discussions of Luyeyuan Stone Sculpture Museum].” Shidai jianzhu no. 5 (2003): 48-55.

Polanyi, Karl. The Great Transformation. New York: Rinehart, 1944.

Porter, Robin. From Mao to Market: China Reconfigure. New York: Columbia University Press, 2011.

Pow, Choon-Piew. "Constructing a New Private Order: Gated Communities and the Privatization of Urban Life in Post-Reform Shanghai." Social \& Cultural Geography 8, no. 6 (2007): 813-833.

Ralston, David A., Jane Terpstra-Tong, Robert H. Terpstra, Xueli Wang, and Carolyn Egri. "Today's State-Owned Enterprises of China: Are They Dying Dinosaurs or Dynamic Dynamos?" Strategic Management Journal 27, no. 9 (2006): 825-843.

Record, Architectural. "Design Vanguard 2005.” Architectural Record 194, no. 12 (2005). Rowe, Peter, and Seng Kuan. Architectural Encounters With Essence and Form in Modern China. Cambridge, MA: MIT Press, 2004.

Ruan, Xing. "Accidental Affinities: American Beaux-Arts in Twentieth-Century Chinese Architectural Education and Practice." The Journal of the Society of Architectural Historians 61, no. 1 (2002): 30-47. 
Ruan, Xing, and Patrick Bingham-Hall. New China Architecture. Singapore: Periplus; Enfield: Publishers Group Worldwide distributor, 2006.

Rui, Xu. "Chinese Architecture Group Buys out Singaporean Cpg." China News Service (CNS), accessed June 19, 2013, www.ecns.cn/cns-wire/2012/05-28/15991.shtml.

Said, Edward. "Traveling Theory." The World, the Text, and the Critic 226 (1983).

Salmenkari, Taru. "Implementing and Avoiding Control: Contemporary Art and the Chinese State." China: An International Journal 2, no. 2 (2004): 235-261.

Scriver, Peter. "Placing in-Between: Thinking through Architecture in the Construction of Colonial-Modern Identities.” National Identities 8, no. 3 (2006): 207-223.

Shane, David Grahame. "Transcending Type: Designing for Urban Complexity." Architectural Design 81, no. 1 (2011): 128-134.

Shyu, Ming-Song, and Chun-Hsiung Wang. Cukuang Yu Shiyi Taiwan Zhanhou Diyidai Jianzhu 粗獷與詩意: 台灣戰後第一代建築 [Rustic \& Poetic an Emerging Generation of Architecture in Postwar Taiwan]. Taipei: Muma wenhua, 2008.

Siu, Helen, F., and Zelda Stern. Mao's Harvest: Voices from China's New Generation. New York; Oxford Oxfordshire: Oxford University Press, 1983.

Smalley, Martha Lund, and Karen Jordan. "Archives of the United Board for Christian Higher Education in Asia, Record Group No. 11, Special Collections.” New Haven: Yale Divinity School Library, 1982.

Song, Yan, Chengr Ding, and Lincoln Institute of Land Policy. Urbanization in China: Critical Issues in an Era of Rapid Growth. Cambridge, MA: Lincoln Institute of Land Policy, 2007.

Stark, David. "Recombinant Property in East European Capitalism." American Journal of Sociology 101, no. 4 (January 1996): 993-1027.

Tafuri, Manfredo. The Sphere and the Labyrinth. Cambridge, MA: MIT Press, 1987.

Tang, Hua. “Jiakun 家琨 [Jiakun].” Jian zhu shi no. 5 (2007): 161-162.

URBANUS. Du Shi Shi Jian 都市实践 [Urbanus]. Shenzhen: Baitong jituan jianzhu gongye chubanshe, 2007.

‥ “Dushi Shijian - 'Zhizao Zhongguo' Yu 'Zhongguo Zhizao'都市实践 - “制造中 国, 与“中国制造 [Urbanus: 'Making China' \& 'Made in China'].” Shidai jianzhu no. 4 (2004): 80-85.

. “Tulou Gongshe, Nanhai, Guangdong, Zhongguo 土楼公社, 南海, 广东, 中国 [Tulou Collective Housing, Nanhai, Guangdong, China]". Shijie jianzhu no. 5 (2011): $84-85$.

. "Urbanus Blog." In The Achievement of Good Urban Public Space. Shenzhen: URBANUS, 2010.

Vanke. "Company Overview." China Vanke Co Ltd, accessed June 15, 2013, www.vanke. $\mathrm{com} / \mathrm{en} /$ newstext.aspx $? \mathrm{id}=97 \& \mathrm{u}=$ AboutVankeNav.

Venturi, Robert. Complexity and Contradiction in Architecture. London: Architectural Press, 1977.

- Jianzhu Zhongde Fuza Yu Maodun 建築中的複雜與矛盾 [Complexity and Contradiction in Architecture]. Translated by Tingfang Ye. Taipei: Shanglin chubanshe, 1980.

Vickers, Edward. "Museums and Nationalism in Contemporary China." Compare 37, no. 3 (2007): 365-382.

Vidal, John. "UN Report: World's Biggest Cities Merging into 'Mega-Regions'." The Guardian, 2010.

Walter, Carl, and Fraser Howie. Red Capitalism: The Fragile Financial Foundation of China's Extraordinary Rise. Singapore: John Wiley \& Sons (Asia) Pte. Ltd., 2011. 


\section{Bibliography}

Wang, Bing. The Architectural Profession of Modern China - Emerging From the Past. First Edition. Beijing: China Foreign Language Press, 2011.

"Structuring of the Architectural Profession in Modern China." Ph.D. Dissertation, Harvard University, 2004.

Wang, Hui. "Contemporary Chinese Thought and the Question of Modernity." Social Text 16, no. 2 (Summer 1998): 9-44.

Wang, Hui, and Rebecca E. Karl. "Contemporary Chinese Thought and the Question of Modernity.” Social Text 16, no. 2 (Summer 1998): 9-44.

Wang, Min-Ying. "The Historicization of Chinese Architecture: The Making of Architectural Historiography in China, From the Late Nineteenth Century to 1953." Ph.D. Dissertation, Columbia University, 2010.

Wang, Weijen. "Fumin Primary School 2003 Far East Architecture Award." Wang Weijen Architecture, accessed June 27, 2013, www.arch.hku.hk/ wang/INDEX2.html.

Wang, Yan. “Cong 'Yiduan' Dao 'Yihua'从“异端'到'异化' [From 'Opposition' to 'Alienation']." Shidai jianzhu no. 1 (2013): 46-51.

Wang, Ya Ping, and Alan Murie. "Social and Spatial Implications of Housing Reform in China." International Journal of Urban and Regional Research 24, no. 2 (2000): 397-417.

Weatherley, Robert. Politics in China Since 1949: Legitimizing Authoritarian Rule. New York: Routledge, 2007.

Wei, Lihua, and Xiaopei Yan. "Sustainable Urban-Rural Relation in Rapid Urbanization Areas." Chinese Geographical Science 15, no. 3 (2005): 212-218.

Woetzel, Jonathan R. "Reassessing China's State-Owned Enterprises.” McKinsey Quarterly 3 (2008): 59.

Wong, John, and Yongnian Zheng, eds. The Nanxun Legacy and China's Development in the Post-Deng Era. Singapore: Singapore University Press and World Scientific Publishing Co. Pte. Ltd., 2001.

Wu, Laurence Liauw Wie. "Critical Urban Practice in China (Learning From Shenzhen)." $A+U$ Architecture and Urbanism Chinese Edition 6, no. 27 (2009): 142-179.

Wu, Liguan. Local-Style Dwelling Houses in China. Beijing: China International Press, 2007.

Wu, Weiping. "Migrant Housing in Urban China.” Urban Affairs Review 38, no. 1 (2002): 90-119.

. "Sources of Migrant Housing Disadvantage in Urban China." Environment and Planning A 36, no. 7 (2004): 1285-1304.

Wu, Xiaohong. “Miandui Zhuzhai Shichanghua面对住宅市场化 [Confronting the Marketization of Residential Building]." Jianzhu xuebao no. 2 (1999): 20-21.

Xiu, Long. "China Architecture Design \& Research Group." China Architecture Design \& Research Group, accessed June 20, 2013, http://en.cadreg.com/introduce/introduce. shtml.

$\mathrm{Xu}$, Ben. "The Cultural Revolution and Modernity: The Contradictory Political Implications of Postmodernism in China." Journal of Contemporary China 8, no. 21 (1999): 241-261.

Xue, Charlie, and Guanghui Ding. A History of Design Institutes in China: From Mao to Market. London; New York: Routledge, 2018.

Xue, Charlie, Q. L. Building a Revolution: Chinese Architecture Since 1980. Hong Kong: Hong Kong University Press, 2006.

Yang, Andrew. "The Underdog Archetype: The Building Boom in China." Cooper-Hewitt National Design Journal (March 2008): 6-9. 
Yang, Jing. "Red Capitalist: The Rising Chinese Private Entrepreneurs." In China in an Era of Transition: Understanding Contemporary State and Society Actors, edited by Reza Hasmath and Jennifer Hsu, 165-189. New York: Palgrave Macmillan, 2009.

Yeung, Stanley Chi-Wai, and Rodney Howes. "The Role of the Housing Provident Fund in Financing Affordable Housing Development in China." Habitat International 30, no. 2 (2006): 343-356.

Yuan, Feng. “Jishao Yu Jiduo 极少与极多 [Minimum and Maximum, Interpretation of the Design of Construction Regulatory Center of Qingpu New Town, Shanghai]." Shidai jianzhu no. 1 (2007).

Zhang, Nan, and Kai Cui. “Yinxu Bowuguan 殷墟博物馆 [Yinxu Museum].” Jianzhu xuebao no. 1 (2007): 6.

"Zhang Xiaogang Artist Biography." Wendtgallery, accessed November 3, 2013, www. wendtgallery.com/Zhang-Xiaogang-Artist-Biography.

Zhang, Xudong. Postsocialism and Cultural Politics: China in the Last Decade of the Twentieth Century. Durham, NC: Duke University Press, 2008.

Zhenning, Fang, Christophe Pourtois, and Marcelle Rabinowicz. Heart-Made: The Cutting Edge of Chinese Contemporary Architecture. Brussels: MercatorFonds, 2010.

Zhou, Enlai. "Zhengfu Gongzuo Baogao (Report on the Work of the Government)." People's Daily, September 24, 1954.

Zhu, Jianfei. Architecture of Modern China: A Historical Critique. London: Routledge, 2009.

. "Studies of Social Space in Chinese Architecture: Reflections on Their Rise, Methods and Conceptual Bases." Fabrications: The Journal of the Society of Architectural Historians, Australia and New Zealand 19, no. 2 (2010): 106.

Zhu, Jieming. "Local Developmental State and Order in China's Urban Development During Transition." International Journal of Urban and Regional Research 28, no. 2 (2004): 424-447.

"Urban Physical Development in Transition to Market the Case of China as a Transitional Economy." Urban Affairs Review 36, no. 2 (2000): 178-196.

Zhu, Tao. "Cross the River by Touching the Stones: Chinese Architecture and Political Economy in the Reform Era: 1978-2008." Architectural Design 79, no. 1 (2009): 88-93. . “'Jiangou' De Xunuo Yu Xushe “建构”的许诺与虚设 [Promises and Assumptions of Tectonics: On the Emerging Notions of Tectonics in Contemporary Chinese Architecture]." Shidai jianzhu no. 5 (2002): 30-33.

Zhubo. "About Zhubo.” Zhubo Design, accessed December 12, 2013, www.zhubo.com/ intro.

Zou, Denong. Zhongguo Xiandai Jianzhushi 中国现代建筑史 [A History of Modern Chinese Architecture]. Tianjin: Tianjin kexue jishu chubanshe, 2003.

Zou, Denong, Mingxian Wang, and Xiangwei Zhang. Zhongguo Jianzhu 60nian 19492009 中国建筑60年 (1949-2009) 历史纵览 [Sixty Years of Chinese Architecture 19492006]. Beijing: Zhongguo jianzhu gongye chubanshe, 2009. 


\section{Index}

Page numbers in italic indicate a figure on the corresponding page.

Andreu, Paul 50, 101, 134

Anti-Rightist Movement 30

architects, Chinese 1-2; common vision of 165-166; confronting the psychological burden of Mao 51-53; decoding implicit historical references 43-47; erosion of collectivism and diminishing state control effects on 5-6, 36-37; high demand for 167 ; new wave $37-39$; overseas education of $25,35,123$, 124-125; see also Cui, Kai; Liu, Jiakun Architectural Journal 32, 102 Architectural Record 123 Architectural Revolution 32 architecture, Chinese: Art Deco in 26-27; Bauhaus approach in 81-84, 85; Beaux-Arts tradition in 28, 32-33, 94; beginning of modern 25; circular path of 140-146; concept of tamed in 64-65; everyday urban $48-51$; influences 10 , 33 ; interest in 1-3; lack of Western discourse on 6; Mao's influence on, 1949-1976 28-33; mapping modernity in 7-12; new forms of fragmentation in 2; new wave 37-39; operation of rationalism in 107-117; outside investors in 4-5; postmodernism in 80-90; scholarship on 6-7, 18-19, 23-24; see also modernism; postmodernism

"Archives of the United Board for Christian Higher Education in Asia" 81 Art Deco design 26-27

artistic freedom in China 53-54 avant-garde architecture 2, 29

Bauhaus approach 81-84, 85

Bauman, Zygmunt 9-10, 165-166

Beaux-Arts tradition 28, 33, 94
Bechuan Culture Centre 63, 103

Beijing 42; Bird's Nest 50, 134; Capital International Airport of 134; Exquisite Tower 104, 105; Feng Ze Yuan Hotel 85, 87, 89-90, 94; Institute of Architectural Design of 34

Beyond Vision Style 36

Bird's Nest 50, 134

"Bloodline: The Big Family" 55, 56, 58

BLUEPRINT (Britain) 125

Bolshevik Party, Russian 25

Building a Revolution: Chinese Architecture Since 198042

Building Under the Planned Economy: A History of China's Architecture and Construction 1949-1965 7

Chang, Eileen 26

Chang, Yung Ho 35, 38, 75

Chen, Qikuan 83

Chen, Zhanxiang 30

Chengdu Architectural Design Academy 54, 56, 61

China! New Art \& Artists 56

China see People's Republic of China

China Architecture \& Design Group (CAG) 19, 90-91; Cui Kai's dual role at 99-106; culture of nationalism and 93-95; market transition 100-101; mission of 91-93; organisational culture 96-97; resolving the challenge of "inside the system" 104-106; shared values of 97-99

China Architecture Design \& Research Group (CAG) 80

China Christian Educational Association 81

Chinese Communist Party 5, 25, 28, 82; establishment of the People's Republic of 
China, 1949 27; First National Congress, 1921 25; see also Mao Zedong

Chinese Communist Revolution of 19499

Chinese People's Revolutionary Military Museum 31

Chongqing 49, 66-67; Institute of Architecture and Engineering of 60 circular path of architecture 140-146 civil justice and commercialisation of space $156-157$

Civil War 27, 28

Class-One National Treasures 75

Clock Museum of Culture Revolution 47

collectivism: erosion of, in Chinese architecture 5-6; family in context of $59-60$

commercialisation of space 156-157

Complexity and Contradiction in Architecture 86

Cooke, Catherine 29, 43

Cui, Kai 3, 37, 38, 39, 80-81, 162, 163, 165,166 ; culture of nationalism and 93-95; delayed modernism and hazy postmodernism 81-90; dual role at CAG 99-106; education of 84; mission of 91-93; modernism and postmodernism as historical developments and 118; organisational culture of CAG and 96-97; resolving the challenge of "inside the system" 104-106; shared values of CAG and their impacts on 97-99

Cultural Palace of Nationalities 31

Cultural Revolution, the 31-32, 34, 43, 46; Cui Kai on 92-93; stated goal of 47; surrealism in art and 58

Dafen Art Museum 127, 138, 146, 147, 151,155

Dafen Village 150-151

Deng, Xiaoping 16, 34, 50-51, 84; URBANUS and the market founded by 129-138

"Development and Evolution of Contemporary Chinese Private Architectural Offices" 34

Diaoyutai State Guesthouse 31

Dirlik, Arif 2, 90

Dongmen Photography Plaza 126, 149

Dubrau, Christian 35-36

Eastman, Lloyd 25

Ecole Remi 26

Enterprise Law, 199396

Er Pang Gong Hyatt Hotel 94

Eurocentrism 10, 33
European Modern Style 36

Exquisite Tower 104, 105

Feng Ze Yuan Hotel 85, 87, 89-90, 94

First Congress of Soviet Writers 29

First World War 25

Five-anti-Campaign 29

"Five Points for New Chinese Architecture" 37

Foreign Language Teaching \& Research Press 81, 85, 88, 97

Foster, Norman 134

From Mao to Market 15

From Opposition to Alienation 129

Fujian Tulou 139-140

Fumin Primary School 85

Futian Library Complex 148

Gallery of Horyuji Treasures 65-66

Gay, Peter 11-12

globalisation 11

Great Hall of the People 31, 45-46

Great Leap Forward 31, 43; housing and 44

Great Leap Forward 65

Great Proletarian Cultural Revolution 32

Guangzhou 42; Design Institute in 34; Opera House of 50

Hadid, Zaha 50

"Haigui" architects 123-129

Handel, Edward 124

Harvard Graduate School of Design (GSD) 83

Harvey, David 9

He, Duoling 72-73

Here and Now 71

Hero 61

Herzog \& de Meuron 50, 134

Highland 61-62

housing: Pearl River Delta 123, 128-129; post-war 43-44; Urban Tulou 135-146, 155-156, 162; welfare system 136

Howie, Fraser 14

$\mathrm{Hu}$, Huishan 46

Hu Huishan Memorial 46, 57, 62-64, 65

Hukou system 135-136

Hundred Days' Reform 24

Hundred Flowers Campaign 30

Hyatt Hotel E'fang Palace 81, 85, 89-90

Imperial Eclectic Style 36

individual, modernity and the $11-12$, $16-18,164$

International Olympic Committee 36

investors in Chinese architecture 4-5 
Jade Bamboo Cultural Plaza 149

Jiangsu Provincial Architectural Design Institute 34

Jichuan Museum Cluster 75

Johnston, Tess 27

Kang, Youwei 24

Kipnis, Andrew 12

Koolhaas, Rem 134

Kraus, Richard Curt 47, 53

Kuangzhai Alley 49

Lhasa Railway Station 103, 104

Li, Jie 26

Liang, Qichao 24

Liangshan Nationality Culture Art Centre and Torch Square 103

Lin, Yifu 16, 28, 37, 65

Liquid Modernity Revisited 165-166

Little Prince 75

Liu, Jiakun 3, 29, 37, 38, 39, 42, 162, 166; concept of tamed in architecture of 65; confronting the psychological burden of Mao 51-53; decoding implicit historical references 43-47; design philosophy of 72; education of 60-61; establishment in the new commercialised power 55-57; everyday urban landscape of China and 48-51; as individual architect in the emerging market 75-76; life trajectory, 1950s-1990s 54-55; necessity of being real and 42-53, 164; as tamed architect 72-75; untamed threat in works of $65-71$; Zhang Xiaogang and 53-60

Liu, Xiaodu 98, 123-127, 132, 135, 138,145

Loos, Adolf 26

Lu, Duanfang 7, 33

Luo, Zhongli 72, 74

Luyeyuan Museum 66-67, 69-71, 73-74

Ma, Laurence J. C. 13, 153

Mao Zedong 5, 7, 9, 13, 24, 124, 163-164, 166 ; call for modernity $32-33$; confronting the psychological burden of 51-53; cult 47; disillusionment with 15-16; in the everyday urban landscape of China 48-51; Great Leap Forward initiated by 31 ; influence on architecture, 1949-1976 28-33; latent role in the Chinese persona 19; see also Chinese Communist Party

Marcus, Herbert 12

May 4 Movement, 1919 24-25
Meng, Yan 123, 124, 132, 137, 145

Ming, Zhong 73

Minutti \& Co. Civil Engineers and Architects 26

modernism 10; Bauhaus 81-84, 85; Cui Kai and delayed 81-90; as historical development 118; neo-liberal understanding of 10; Western architecture becoming Chinese 35-36

modernity 1-3; Chinese modernity, Chinese architecture, and 9-11, 165; clearing the path for the architectural research 18-19; common vision for 165-166; disillusionment with Mao and 15-16; Eurocentric notions of 10, 33; and the individual 11-12, 16-18; Mao's call for 32-33; mapping, in Chinese architecture 7-12

money and Chinese reforms 13-15, 163

Nanshan Marriage Registration Centre 149,150

National Agricultural Exhibition Hall 31

National Centre for the Performing Arts $50,100-101$

National Grand Theatre 134

nationalism, culture of 93-95

National Museum of China 31

New Culture Movement 25

New York Times 125

OCT Loft North Area Renovation 146, 148,149

Opium War, 1839-1842 23, 24

Paris Peace Conference 25

Pearl River Delta 123, 128-129, 156; as special economic zone (SEZ) 130

Pei, I. M. 83, 89

People's Republic of China: artistic freedom in 53-54; art market in 55-57; concept of family in context of communist 59-60; establishment of 27; everyday urban landscape of 48-51; influence of Mao on architecture in 28-33; modern founding in 1949 23; post-war housing 43-44; private/public anxiety in contemporary $152-154$; special economic zones (SEZ) 130; transition era of $1-2,4,12-19,162$; unforgotten history, 1840-1949 24-28

Porter, Robin 15, 51

postmodernism 80; Cui Kai and hazy 81-90; as historical development 118 
private/public anxiety in contemporary China 152-154

Promises and Assumptions of Tectonics 70-71

Psalm of Life, A 60, 61

psychological burden of Mao 51-53

Qin Dynasty 48-49

Qing Dynasty 24

Qinghai-Tibet railway 103

Ralston, David A. 101

Red Capitalism: The Fragile Financial Foundation of China's Extraordinary Rise 14

Remaking Chinese Urban Form: Modernity, Scarcity and Space 33

Revolution Continues: New Art From China, The 56

Richter, Gerhard 55

Ruan, Xing 6

Rustic \& Poetic-An Emerging Generation of Architecture in Postwar Taiwan 83

Said, Edward 140

Salmenkari, Taru 53

Second World War 27, 28; Chongqing during 49

self, individuated 16-18

Shanghai 42; Civil Construction Design Institute of 34; Industrial Building Design Institute of 34; Qingpu District Exhibition Centre 69, 70; urban landscapes 49-50

Shenzhen 134; "Fifth Garden" 155-156; Minghua Centre of $81,85,86$; as special economic zone (SEZ) $130-132$

Sicheng, Liang 25, 26, 28, 94, 126

Sichuan Fine Arts Institute 44, 54, 56, 68; New Campus 44, 45, 49, 52-53

"Socialism with Chinese Characteristics" 9,13

socialist architecture $49-50$

social realism $29,43,82$

Society of Chinese Architects 25, 26

SOHO New Town 101-102

Soviet Union, the 25, 29, 43, 52; architectural theory influences on China 50 ; social realism from 82

special economic zones (SEZ) 130

St. John's University 81-83

state-owned enterprises (SOEs) see China

Architecture \& Design Group (CAG) surrealism 57-58
Tafuri, Manfredo 3

Taiwan 82-87

tamed (concept of) 64-65

Tangshan Museum Park 146, 147, 149

Ten Great Buildings 31, 46, 47

Ten Year Reform Strategy 152

Three-anti-Campaign 29

Tiananmen Square 34, 46

Time + Architecture 85, 125

Tingbao, Yang 28

Tong, Jun 28

transition era, Chinese 1-2, 4, 162; misconceptions regarding $12-19$; money and $13-15$

travelling theory 140

Treaty of Nanjing 24

Tsinghua University 124-126

United Board for Christian Colleges 82

"Up to the Mountains and Down to the Countryside Movement" 84

urban landscape of China, everyday 48-51; Pearl River Delta 128-129

urban public space 148

Urban Tulou 135-140, 162; circular path of architecture and 140-146; in the private/public whirlpool 154-156

URBANUS 3, 38, 39, 98, 162, 164, 165; addressing urbanised intervention and private/public anxiety 146-156; anti-market behaviour and 134-138; architects' background and education 124-127; civil justice and the commercialisation of space and 156-157; as "Haigui" Chinese architects 123-129, 132-133, 156-157; and imagination of China as a circular path 144-146; market founded by Deng and 129-138; Pearl River Delta and 123, 128-129; travelling architects of, and wandering imagination of China 138-146; weaving bilingual capacity into a circular path 143-144; weaving multiple values into a circular path $140-143$

Vanke Real Estate Firm 135-137, 146, 155

Vanke Zhoukan 141

Venturi, Robert 86

Wang, Dahong 83

Wang, Hui 9, 123-124, 132, 138, 145

Wang, Mingxian 55

Wang, Shi 135

Wang, Weijen 85 


\section{Index}

Weber, Max 9

Wenchuan Earthquake Memorial 45-46, 63-64

Wenjin Garden Plaza 149

World + Architecture 125

World Trade Organization (WTO) 36

Xue, Charlie Q. L. 36, 38, 42

Yale University 81

Yingzao fashi 26

Young Writer 61

Zhang, Jun 25
Zhang, Xiaogang 53-60, 76; establishment in the new commercialised power 55-57; life trajectory, 1950s-1990s 54-55; Zhang Xiaogang Art Gallery 60,67

Zhang, Yimou 145

Zhang, Zhaokang 82-83

Zhou, Enlai 30

Zhu, Jianfei6, 23, 32, 35, 125

Zhu, Qiqian 26

Zhu, Tao6, 70, 71

Zhu, Xiaodi 102

Zou, Denong34 